University of Louisville

ThinkIR: The University of Louisville's Institutional Repository

Electronic Theses and Dissertations

$12-2020$

\title{
Hydration, shrinkage, cracking, and mechanical properties of cementitious materials with lignocellulosic biomass wastes.
}

Aofei Guo

University of Louisville

Follow this and additional works at: https://ir.library.louisville.edu/etd

Part of the Civil Engineering Commons

\section{Recommended Citation}

Guo, Aofei, "Hydration, shrinkage, cracking, and mechanical properties of cementitious materials with lignocellulosic biomass wastes." (2020). Electronic Theses and Dissertations. Paper 3562.

https://doi.org/10.18297/etd/3562

This Doctoral Dissertation is brought to you for free and open access by ThinkIR: The University of Louisville's Institutional Repository. It has been accepted for inclusion in Electronic Theses and Dissertations by an authorized administrator of ThinkIR: The University of Louisville's Institutional Repository. This title appears here courtesy of the author, who has retained all other copyrights. For more information, please contact thinkir@louisville.edu. 
HYDRATION, SHRINKAGE, CRACKING, AND MECHANICAL PROPERTIES OF CEMENTITIOUS MATERIALS WITH LIGNOCELLULOSIC BIOMASS WASTES

By

Aofei Guo

B.S., Henan University of Technology, China, 2013

M.S., Hunan University, China, 2016

\begin{abstract}
A Dissertation
Submitted to the Faculty of the

J.B. Speed School of Engineering of the University of Louisville

in Partial Fulfillment of the Requirements

for the Degree of

Doctor of Philosophy

in Civil Engineering

Department of Civil and Environmental Engineering

University of Louisville

Louisville, Kentucky
\end{abstract}

December, 2020 


\section{Copyright 2020 by Aofei Guo}

All rights reserved 

HYDRATION, SHRINKAGE, CRACKING, AND MECHANICAL PROPERTIES OF CEMENTITIOUS MATERIALS WITH LIGNOCELLULOSIC BIOMASS WASTES

\author{
By \\ Aofei Guo \\ B.S., Henan University of Technology, China, 2013 \\ M.S., Hunan University, China, 2016
}

A Dissertation Approved on

October 30, 2020

By the following Dissertation Committee

Dr. Zhihui Sun (Dissertation Director)

Dr. Jagannadh Satyavolu (Co-Director)

Dr. William Mark McGinley

Dr. Young Hoon Kim

Dr. Noppadon Sathitsuksanoh 


\title{
DEDICATION
}

This dissertation is dedicated to my parents

\author{
Mr. Huiling Guo \\ and
}

Mrs. Huazi Zhang

For their love, support, and encouragement 


\section{ACKNOWLEDGEMENTS}

Above all, I would like to express my deepest gratitude to my advisor, Professor Zhihui Sun, the chair of the Civil and Environmental Engineering Department at the University of Louisville, who gave me an opportunity to work on this project. Throughout my Ph.D. study, with great enthusiasm, excellent insights, and profound academic knowledge, Dr.Sun provided tremendous help to me in many aspects such as academic writing and presentation, and research implementation. Under her supervision, the project went smoothly, and I made much progress in research beyond my expectation. It is hard to find any word to express my appreciation to my advisor.

Then I would like to thank my co-advisor, Dr.Jagannadh Satyavolu, a theme leader in the Conn Center for Renewable Energy Research at the University of Louisville. Not only he provided financial aids to me for three years but also provided me an opportunity to access many advanced material characterization instruments and gave me much guidance on research, especially in the aspect of lignocellulosic biomass modification. There is no question that any academic achievement I have made during my Ph.D. study should be partly attributed to him.

I would like to thank my committee members, Dr. Noppadon Sathitsuksanoh, Dr. Young Hoon Kim, and Dr. McGinley William Mark. During my Ph.D. study, they put forwarded many conducive suggestions to my research and also assisted me a lot in implementing experiments. 
I would like to acknowledge Dr. Chengqing Qi, the technical center director in the Ash Grove Cement Company, who helped complete some tests.

I would like to thank Dr. J. P. Mohsen, the former chair of the Civil and Environmental Engineering Department and the current associate dean of J.B. Speed School of Engineering for his kindness and help.

I appreciate the staffs in the department, Mr. Bernie Miles (our great technician) who helped me solve many problems I encountered with my experiments during the past several years and Ms. Gail Graves who kept everything going orderly and created a great environment for my working.

I also would like to thank my teammates and friends, Dr. Hong Shang, Dr. Bashir Hasanzadeh, Dr. Osama Bu Aamiri, Dr. Chamila Rajeeva Thilakaratne, Dr. Jogi Ganesh Dattatreya Tadimeti, Ms. Uyen Thi Duong, Mr. Song Wang, Mr. Li Liu, Mr. Jice Zeng, Mr. Muting Ma, Dr. Mahyar Ramezani, Dr. Xiaoming Fan, and Mr. Danming Wei, for their friendship and help at the University of Louisville.

More importantly, I would heartily like to thank my family who have been supporting me all the time.

This work has been supported by the Civil and Environmental Engineering Department and Conn Center for Renewable Energy Research at the University of Louisville. They are much appreciated. 


\begin{abstract}
HYDRATION, SHRINKAGE, CRACKING, AND MECHANICAL PROPERTIES OF CEMENTITIOUS MATERIALS WITH LIGNOCELLULOSIC BIOMASS WASTES

Aofei Guo
\end{abstract}

October 30, 2020

The disposal of lignocellulosic biomass wastes imposes a huge economic and environmental burden on this society. Recycling lignocellulosic biomass wastes and applying them to cementitious materials provides a sustainable and value-added way for both agriculture and concrete industries. To comprehensively identify the effect of lignocellulosic biomass wastes at different scales on cementitious materials, the hydration, shrinkage, cracking, and mechanical properties of cementitious materials with lignocellulosic biomass wastes were studied. Given the three different forms (powders, chips, and fibers) of lignocellulosic biomass wastes in this study, the research was implemented in three stages.

In the first stage, hemp powders were collected through grinding the residual of hemp products and then chemically treated using saturated lime water to partially remove hemicellulose, lignin, and impurities. The effect of untreated and treated hemp powders on the hydration of cement paste was studied. It was found that partially replacing cement with untreated and treated hemp powders can delay cement hydration. Compared with untreated hemp powders, treated (washed or nonwashed) hemp powders showed a lower delay effect on cement hydration, distilled-water-washed treated hemp powders delayed 
less than nonwashed treated hemp powders, and coarse hemp powders exerted a lower delay effect on cement hydration than fine hemp powders.

In the second stage, ground wood chips were lightly or highly torrefied and then used to partially replace sand in mortar. The effect of non-torrefied and torrefied ground wood chips on the mechanical properties of mortar was studied. Compared to the mortar containing non-torrefied ground wood chips, those containing highly or lightly torrefied ground wood chips were found to have higher flexural strength and compressive strength due to the enhanced bonding between the wood chips and paste matrix. Although all the tested mortars with ground wood chips have lower strength than the mortar without any wood chips, their toughness was found to be comparable or higher, indicating better energy absorption capacity.

In the third stage, kenaf fibers were chemically treated using different inorganic chemicals. The characteristics of raw and chemically treated kenaf fibers were investigated through a series of tests. It was found that chemically treated kenaf fibers have lower hemicellulose and extractives, lower moisture sorption capacity, and higher tensile strength and crystallinity index. And then, alkaline treated and alkaline-hydrogen peroxide treated kenaf fibers, together with raw kenaf fibers, were selected to be used as reinforcements in cementitious materials. The effect of these three types of kenaf fibers on the autogenous shrinkage, drying shrinkage cracking, and flexural behavior of cementitious materials was studied. It was found that compared to raw kenaf fibers, these two treated kenaf fibers can lead to reduced shrinkage and cracking and also improved flexural strength and toughness.

This research provides some guidance for the future application of lignocellulosic biomass at different scales to non-structural concrete elements (such as pavement and roof). 
Hemp powders can be used to partially replace cement, with a dosage limit of $10 \%$ by weight of cement. Wood chips can be used to partially replace sand, with a recommended replacement level of $10 \%$ by weight of sand for OW and HTW, and a recommended replacement level of $5 \%$ for LTW. Kenaf fibers can be used as reinforcement, with a recommended dosage of $0.5 \%$ by weight of cement (or $0.12-0.24 \%$ by volume of the composites). 


\section{TABLE OF CONTENTS}

ACKNOWLEDGEMENTS ........................................................................... iv





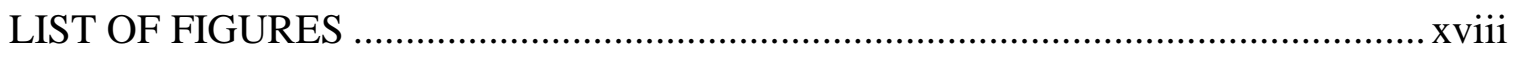



1.1 Lignocellulosic Biomass ...................................................................... 1

1.2 Application of Lignocellulosic Biomass Wastes to Cementitious Materials ....... 4

1.3 Modification on Lignocellulosic Biomass Wastes in Cementitious Materials .... 7

1.3.1 Ordinary Heating Treatment .......................................................... 7



1.3.3 Boiling Treatment .............................................................................. 8

1.3.4 Surface Coating or Impregnation Treatment ...................................... 9

1.3.5 Hornification Treatment................................................................... 10

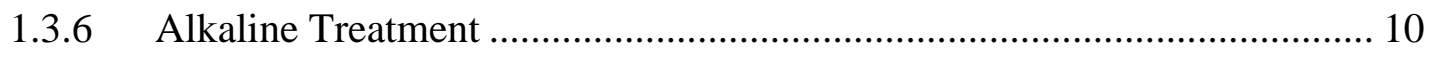



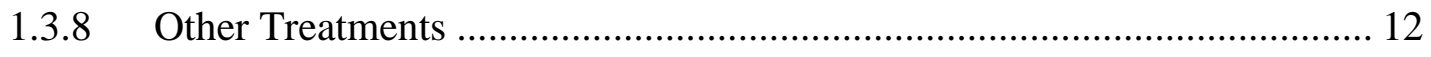

1.4 Research Significance and Objectives ............................................... 13 
1.5 Structure of the Dissertation

\section{CHAPTER 2 HYDRATION OF PORTLAND CEMENT PASTES CONTAINING UNTREATED And TREATED HEMP POWDERS …............................................ 16}



2.2 Materials and Experiments .................................................................. 17

2.2.1 Hemp Powder Preparation ............................................................... 17

2.2.2 Chemical Treatment ......................................................................... 18

2.2.3 Cement paste preparation............................................................... 19

2.2.4 Isothermal Calorimetry Test ...................................................... 20



2.2.6 Fourier Transform Infrared Spectroscopy Analysis .............................. 22

2.2.7 Scanning Electron Microscopy Analysis ........................................... 22



2.3.1 Thermogravimetric Analysis on Hemp Powders .................................... 23

2.3.2 Isothermal Calorimetry and Thermogravimetric Analysis on Cement Pastes 25

2.3.3 The Effect of Replacement Content on Cement Hydration ...................... 28

2.3.4 The Effect of Treatment Method on Cement Hydration............................ 29

2.3.5 The Effect of Hemp Powder Size on Cement Hydration ............................ 30

2.3.6 FTIR Analysis on Cement Pastes .................................................... 31 
2.3.7 Microstructure 35

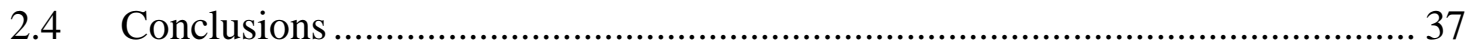

\section{CHAPTER 3 IMPACT OF THERMALLY MODIFIED WOOD ON MECHANICAL}

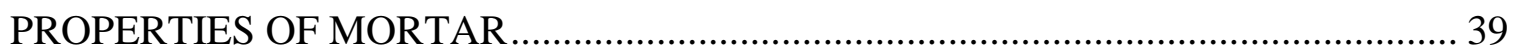



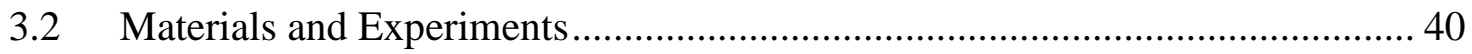

3.2.1 Ground Wood Preparation .................................................................. 40

3.2.2 Mortar Sample Preparation ..................................................................... 44

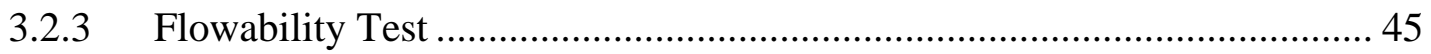

3.2.4 Mechanical Tests ................................................................................. 45

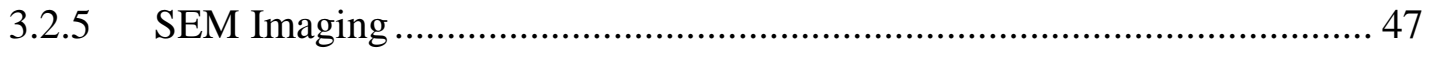



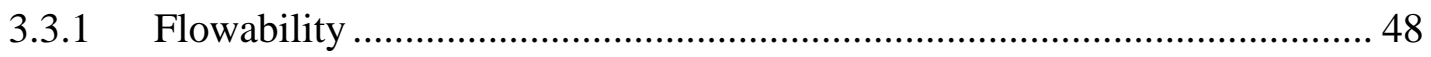

3.3.2 Compressive and Flexural Strength .......................................................... 49

3.3.3 Static and Dynamic Modulus of Elasticity ………..................................... 51

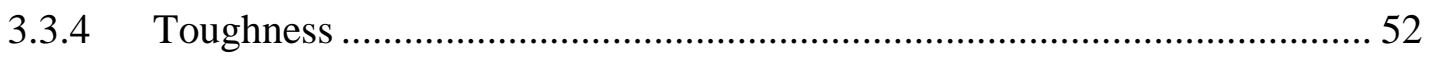

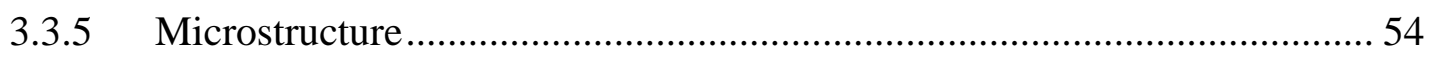

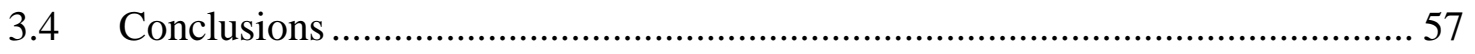

CHAPTER 4 IMPACT OF CHEMICAL TREATMENT ON THE

PHYSICOCHEMICAL AND MECHANICAL PROPERTIES OF KENAF FIBERS.... 59 
4.1 Introduction



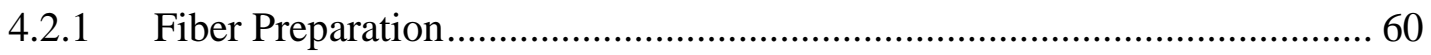



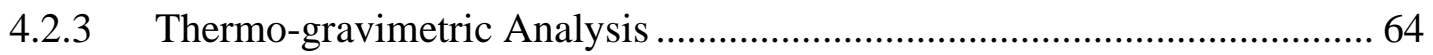

4.2.4 Fourier Transform Infrared Spectroscopy Analysis ............................... 64

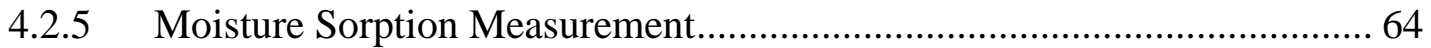

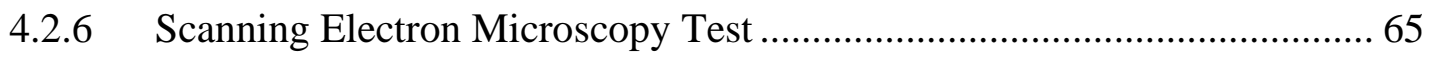

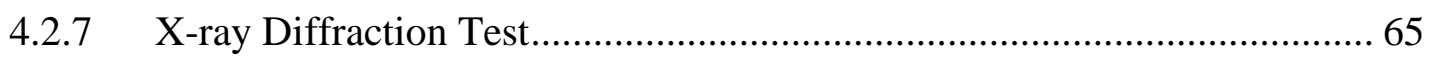





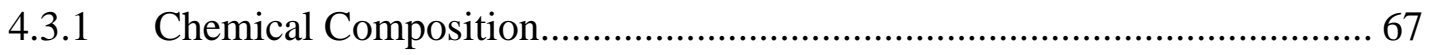

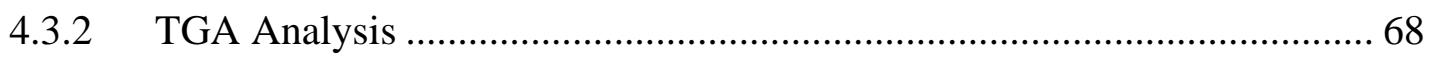

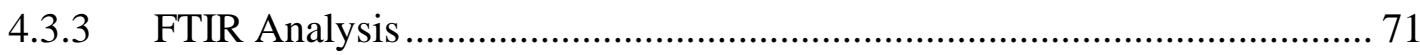

4.3.4 Moisture Sorption Analysis ............................................................... 75

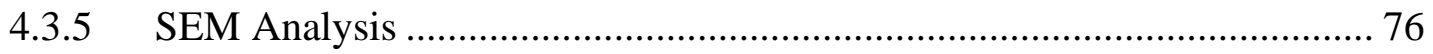

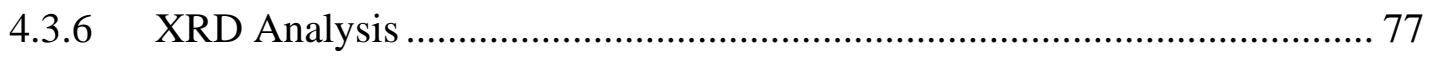

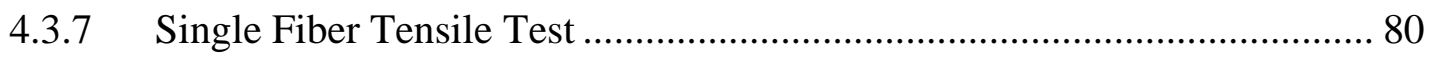

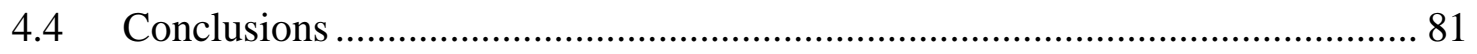




\section{CHAPTER 5 IMPACT OF MODIFIED KENAF FIBERS ON SHRINKAGE AND}

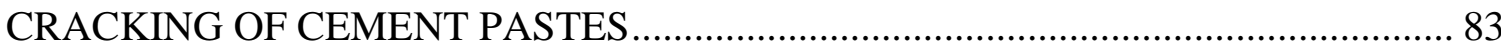

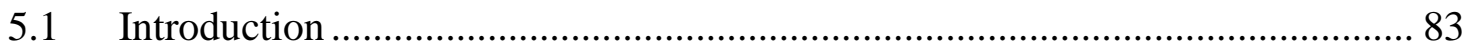

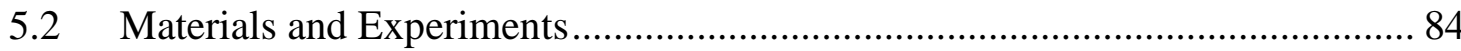

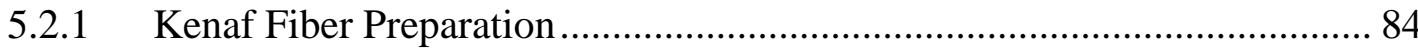

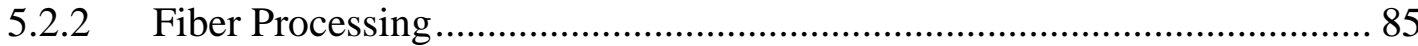

5.2.3 Physicochemical and Mechanical Properties of Kenaf Fibers.................... 86

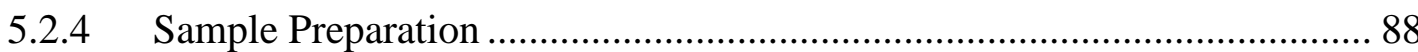

5.2.5 Setting Test on Cement Pastes ..................................................................... 89

5.2.6 Autogenous Shrinkage Test on Cement Pastes........................................... 89

5.2.7 Drying Shrinkage Cracking Test on Cement Pastes .................................... 91

5.2.8 Scanning Electron Microscopy Analysis ................................................... 93

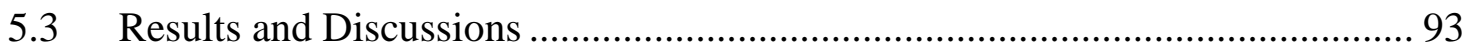

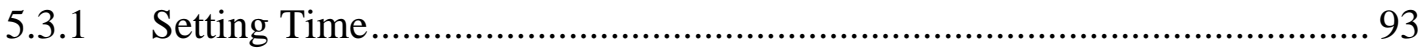

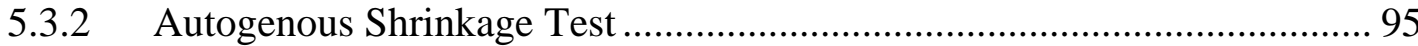

5.3.3 Drying Shrinkage Cracking Test ......................................................... 102

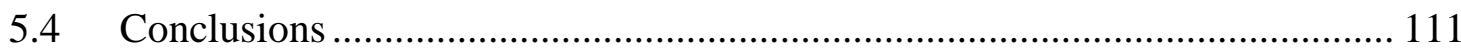

CHAPTER 6 EXPERIMENTAL AND FINITE ELEMENT ANALYSIS ON

FLEXURAL BEHAVIOR OF MORTAR BEAMS WITH CHEMICALLY MODIFIED

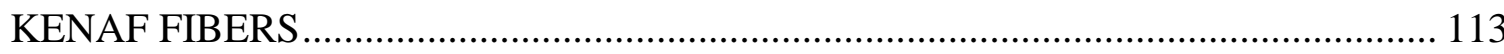


6.1 Introduction

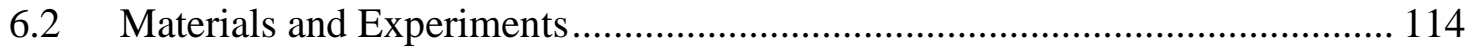

6.2.1 Kenaf Fiber Preparation and Processing ............................................. 114

6.2.2 Specimen Preparation ...................................................................... 114

6.2.3 Compressive Test........................................................................ 117

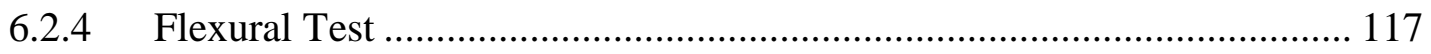

6.2.5 Scanning Electron Microscopy Analysis .......................................... 119

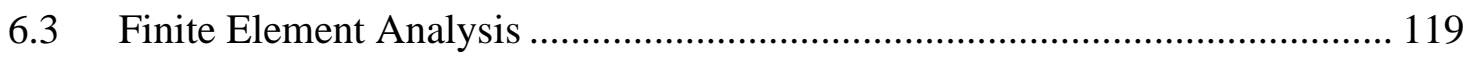

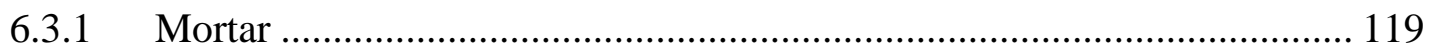

6.3.2 Kenaf Fibers .................................................................................. 123

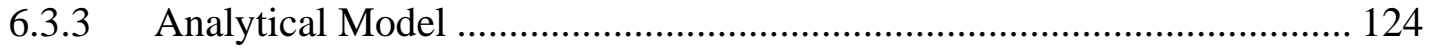

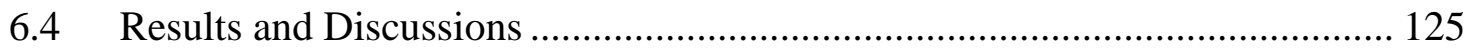

6.4.1 Crack Pattern at Failure .................................................................. 125

6.4.2 Compressive Strength and Flexural Strength ..................................... 127

6.4.3 Modulus of Elasticity and Flexural Toughness ................................... 129

6.4.4 Effect of the Addition of Superplasticizer ........................................... 131

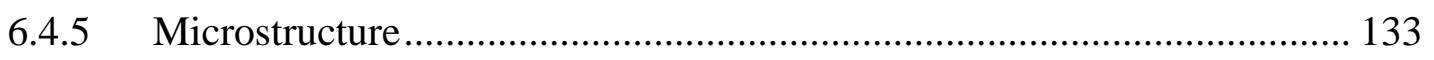

6.4.6 Finite Element Analysis ........................................................... 135

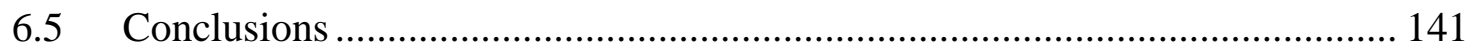

CHAPTER 7 CONCLUSIONS AND FUTURE WORK ..................................... 144 


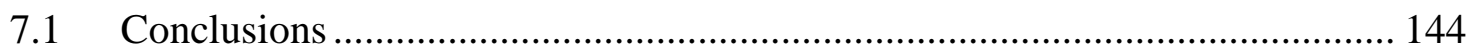

7.1.1 Effect of Hemp Powders on Cement Hydration ..................................... 144

7.1.2 Effect of Wood Chips on Mechanical Properties of Mortar ..................... 145

7.1.3 Effect of Chemical Treatment on Kenaf Fibers .................................... 145

7.1.4 Effect of Kenaf Fibers on Shrinkage and Cracking of Cement Paste....... 146

7.1.5 Effect of Kenaf Fibers on Flexural Behavior of Mortar ......................... 146

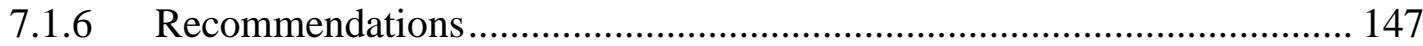

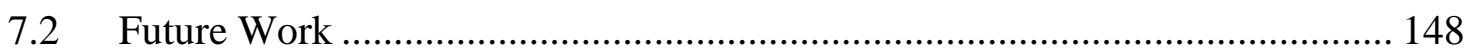

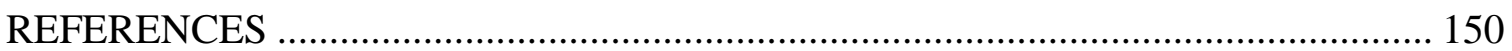

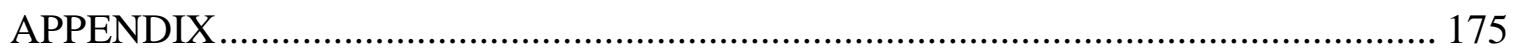

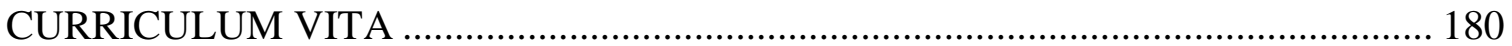




\section{LIST OF TABLES}

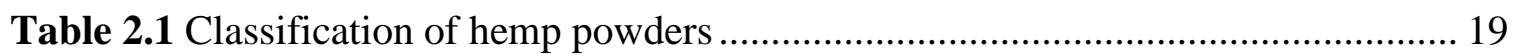

Table 2.2 Chemical composition of Type I/II low alkaline (LA) portland cement ......... 19

Table 2.3 Major compounds of Type I/II LA portland cement...................................... 19

Table 2.4 Mix proportions of cement paste..................................................................... 20

Table 2.5 Weight loss $\left(W_{L}\right)$ of all types of hemp powders........................................... 25

Table 2.6 Hydration time corresponding to peaks of heat evolution rate curves............. 28

Table 2.7 FTIR spectral data for original portland cement and hydrated cement pastes. 34

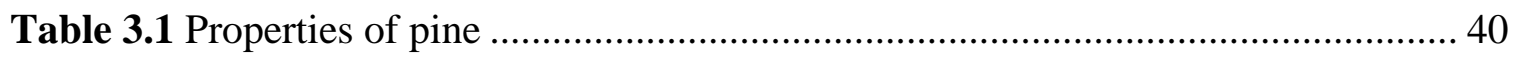

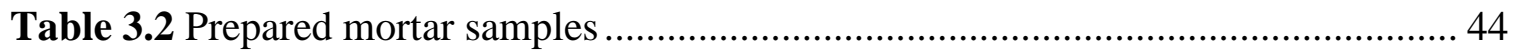

Table 3.3 Basic parameters of mortar samples ............................................................. 45

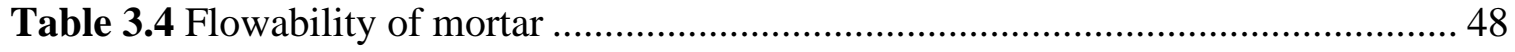

Table 4.1 Chemical composition of raw and chemically treated kenaf fibers ................. 68

Table 4.2 Weight loss $\left(W_{L}\right)$ of raw and chemically treated kenaf fibers.......................... 71

Table 4.3 FTIR spectral data for raw and chemically treated kenaf fibers ..................... 74

Table 4.4 Crystallinity index of raw and chemically treated kenaf fibers ...................... 80

Table 4.5 Tensile strength of raw and chemically treated single kenaf fibers ................. 81

Table 5.1 Physicochemical and mechanical properties of kenaf fibers .......................... 87

Table 5.2 Mix proportion of cement pastes................................................................ 88

Table 5.3 Comparison of initial setting time ( $\left.\mathrm{t}_{\mathrm{is}}\right)$ and final setting time $\left(\mathrm{t}_{\mathrm{fs}}\right)$ of all samples 
Table 5.4 The $t_{1}, t_{2}, t_{3}$, and $t_{4}$ of all samples

Table 5.5 The maximum autogenous strain $\left(\varepsilon_{\max }\right)$ and shrinkage percentage (SP) of all

samples......... 100

Table 5.6 The $T_{i c}$ and $N_{c}, L_{c}, A_{c}, W_{m c}$, and $D_{m c}$ at $72 \mathrm{~h}$ of all samples 104

Table 6.1. Mix proportion (by weight) of mortars 116

Table 6.2 Density of all specimens 116

Table 6.3 Comparison of experiment with finite element analysis for the control 136 


\section{LIST OF FIGURES}

Fig. 1.1. Structure of cellulose (Gurunathan et al. 2015) ............................................... 2

Fig. 1.2. Main and side chains of hemicellulose (Gurunathan et al. 2015) ....................... 3

Fig. 1.3. Precursors of lignin (Gurunathan et al. 2015) .................................................. 4

Fig. 2.1. (a) hemp leaves; (b) fine hemp powders; and (c) coarse hemp powders. .......... 18

Fig. 2.2. TGA and DTGA curves of (a) fine; and (b) coarse hemp ............................. 25

Fig. 2.3. (a) Heat evolution; and (b) heat evolution rate during hydration of Portland cement paste without and with hemp powders. ................................................. 28

Fig. 2.4. Degree of hydration of 7 -day cement paste samples.................................... 28

Fig. 2.5. (a) Heat evolution; and (b) heat evolution rate during hydration of RTN-

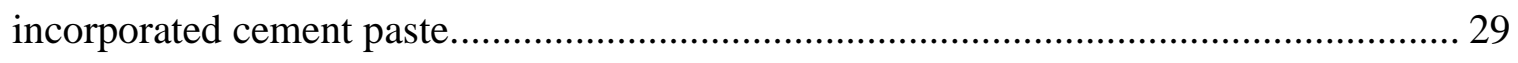

Fig. 2.6. (a) Heat evolution; and (b) heat evolution rate during hydration of portland

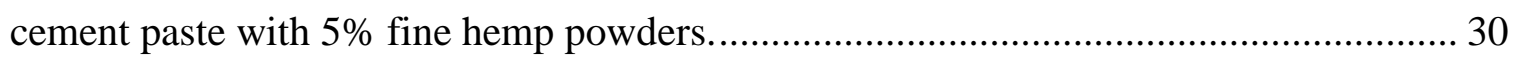

Fig. 2.7. (a) Heat evolution; and (b) heat evolution rate during hydration of portland cement paste with $10 \%$ washed treated hemp powders........................................... 31

Fig. 2.8. FTIR spectra of (a) OPC; (b) control; (c) PU5; (d) PTN5; (e) PTW5; (f) RTN5;

(g) RTW5; (h) PU10; (i) PTN10; (j) PTW10; (k) RTN10; and (l) RTW10.................... 34

Fig. 2.9. Microstructure of (a) unhydrated cement powder; (b) control; (c) PU10; (d)

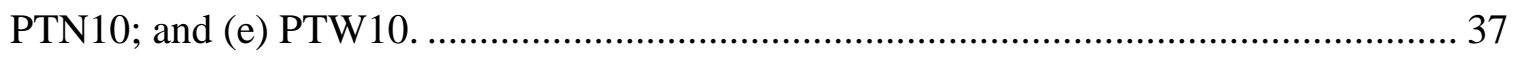

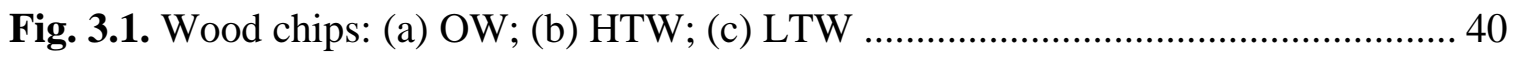

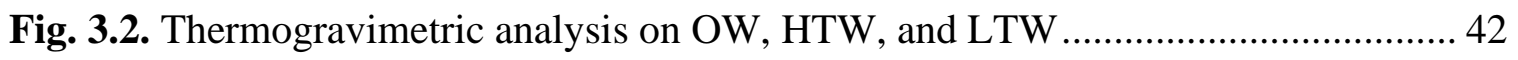


Fig. 3.3. FTIR chart of OW, HTW, and LTW. 43

Fig. 3.4. Testing configuration (a) and typical load-deflection curve (b) of flexural test 46 Fig. 3.5. Compressive strength of mortar samples (error bar is from standard deviation,

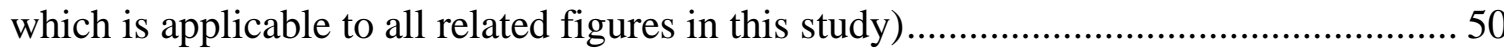

Fig. 3.6. Flexural strength of mortar samples* .................................................. 51

Fig. 3.7. Static modulus of elasticity of mortar samples .......................................... 52

Fig. 3.8. Dynamic modulus of elasticity of mortar samples ..................................... 52

Fig. 3.9. Flexural toughness of mortar samples ..................................................... 53

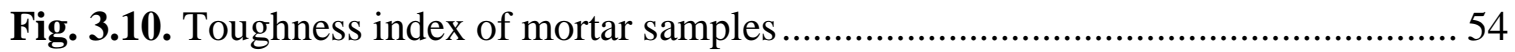

Fig. 3.11. Surface texture of (a) OW; (b) HTW; (c) LTW ......................................... 54

Fig. 3.12. (a) SEM image of mortar with OW; (b) Interface between matrix and OW



Fig. 3.13. (a) SEM image of mortar with HTW; (b) Interface between matrix and HTW

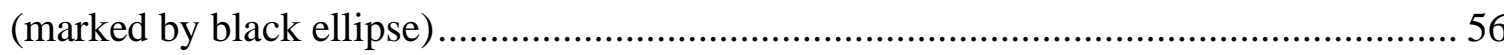

Fig. 3.14. (a) SEM image of mortar with LTW; (b) Interface between matrix and LTW

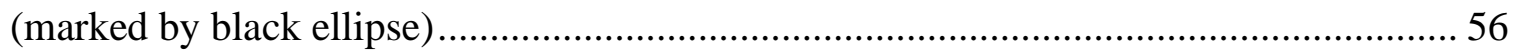

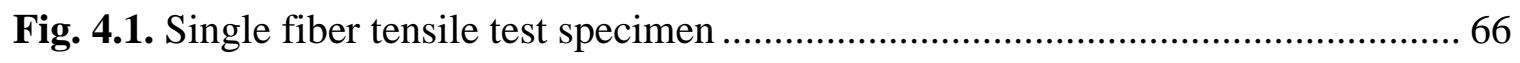

Fig. 4.2. (a) TGA and (b) DTGA curves of raw and chemically treated kenaf fibers ..... 71

Fig. 4.3. FTIR spectra of raw and chemically treated fibers .................................. 73

Fig. 4.4. Moisture sorption kinetics of raw and chemically treated kenaf fibers ............ 76

Fig. 4.5. Surface morphology of (a) RKF; (b) AKF; (c) APPKF; (d) APDKF; (e)



Fig. 4.6. XRD curves of raw and chemically treated kenaf fibers.............................. 79 


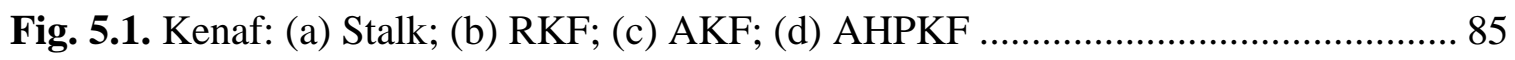

Fig. 5.2. Kenaf fibers before and after processing: (a) RKF; (b) AKF; (c) AHPKF....... 85

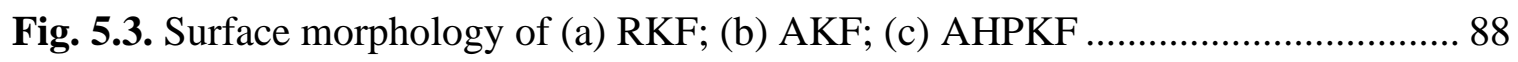

Fig. 5.4. Dilatometer with corrugated mould for linear autogenous strain measurement 90

Fig. 5.5. Autogenous strain curve for RKF0.25 ( $t_{\mathrm{fs}}$ : the final setting time; $\mathrm{t}_{\max }$ : the time

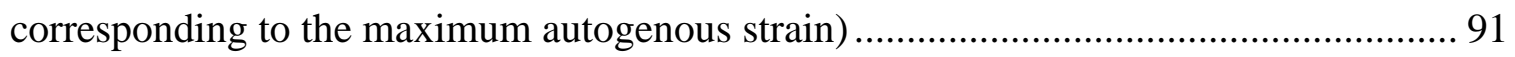







Fig. 5.9. Cracking pattern of (a) Control; (b) RKF0.25; (c) RKF0.5; (d) AKF0.25; (e)



Fig. 5.10. Comparison of (a) $N_{\mathrm{c}}$, (b) $L_{\mathrm{c}}$, (c) $A_{\mathrm{c}}$, (d) $W_{\mathrm{mc}}$ and (e) $D_{\mathrm{mc}}$ for the control, RKF0.25, and RKF0.5 (error bar is from standard deviation, which is applicable to all



Fig. 5.11. The cracking section of (a) the control, (b) RKF0.25, and (c) RKF0.5 ........ 107

Fig. 5.12. Microstructure of the (a) control, (b) RKF0.25, and (c) RKF0.5 (Cracks are



Fig. 5.13. Comparison of (a) $N_{\mathrm{c}}$, (b) $L_{\mathrm{c}}$, (c) $A_{\mathrm{c}}$, (d) $W_{\mathrm{mc}}$ and (e) $D_{\mathrm{mc}}$ for cement pastes with $0.5 \%$ kenaf fibers 109

Fig. 5.14. Comparison of (a) $N_{\mathrm{c}}$, (b) $L_{\mathrm{c}}$, (c) $A_{\mathrm{c}}$, (d) $W_{\mathrm{mc}}$ and (e) $D_{\mathrm{mc}}$ for cement pastes with $0.25 \%$ kenaf fibers 110

Fig. 6.1. Universal testing machine for compressive test .................................... 117

Fig. 6.2. Universal testing machine for flexural test.......................................... 118 
Fig. 6.3. Stress-strain relationship of mortar under (a) compression and (b) tension..... 121

Fig. 6.4. Simply supported beam model ............................................................... 124

Fig. 6.5. Schematic of reinforcement in mortar................................................... 125

Fig. 6.6. Crack pattern of mortar cubes for (a) Control, (b) AKF0.25, (c) AKF0.5, and (d)

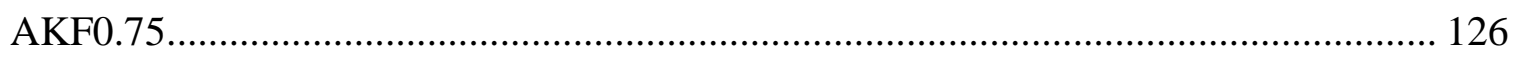

Fig. 6.7. Crack pattern of mortar beams for (a) Control, (b) AKF0.25, (c) AKF0.5, and

(d) AKF0.75

Fig. 6.8. Effect of fiber dosage and fiber type on (a) compressive strength and (b) flexural strength (error bar is from standard deviation, which is applicable to all related figures in

this study).

Fig. 6.9. Effect of fiber dosage and fiber type on (a) modulus of elasticity and (b) flexural toughness

Fig. 6.10. Effect of superplasticizer on (a) compressive strength, (b) flexural strength, (c) modulus of elasticity, and (d) flexural toughness of $0.75 \%$ kenaf fibers reinforced mortars

Fig. 6.11. SEM images of the fracture surfaces of (a) RKF0.5, (b) AKF0.5, and (c) AHPKF0.5 (Note: For each case, the right image is the enlarged rectangular section marked on the left image) 135

Fig. 6.12. Comparison of load-deflection curves of the control from FEA and experiment 136 Fig. 6.13. Comparison of load-deflection curves of mortars with $0.75 \%$ AKF from finite element analysis and experiment 137

Fig. 6.14. Stress contour band of (a) the control and (b) AKF0.75........ 139 
Fig. 6.15. Cracking strain contour band of (a) the control and (b) AKF0.75 ...

Fig. 6.16. (a) Load-deflection curves and (b) cracking strain-deflection curves of mortar beams with varying AKF dosages ...... 140 


\section{CHAPTER 1 INTRODUCTION}

\subsection{Lignocellulosic Biomass}

Biomass has been defined as "substance wholly comprised of living or recently living (non-fossil) material" by ASTM (2015). Sometimes it is referred to as renewable organic material, and includes whole or parts of plants, trees, aquatic organisms, animals, algae, and microorganisms, etc. In general, it can be categorized as lignocellulosic biomass and non-lignocellulosic biomass ( $\mathrm{Li}$ and Jiang 2017). Lignocellulosic biomass is mainly comprised of cellulose, hemicellulose, lignin, and extractives. The chains of cellulose form microfibrils, which are held together by hemicellulose and lignin to form fibrils, and then these fibrils are assembled in various layers to form the fiber structure (Correia et al. 2016). The properties of lignocellulosic biomass depend on the properties of cellulose, hemicellulose, and lignin to a large extent.

Cellulose is a semi-crystalline polysaccharide $\left(\mathrm{C}_{6} \mathrm{H}_{12} \mathrm{O}_{5}\right) \mathrm{n}$ consisting of Dglucopyranose units joined by $\beta$-(1-4)-glycosidic linkages, as shown in Fig. 1.1, and the degree of polymerization can be around 10000 (Gurunathan et al. 2015; John and Thomas 2008; Li et al. 2007). It includes not only tightly packed slender rod-like crystalline microfibrils but also amorphous regions that have a lower packing density (Gurunathan et al. 2015; John and Thomas 2008). Because most of the cellulose is crystalline that is not 
easily broken down, cellulose is harder to be decomposed than hemicellulose and lignin (Kabir et al. 2013). It was reported that cellulose is resistant to strong alkali and oxidizing agents but is easily hydrolyzed by acid to water-soluble sugars (John and Anandjiwala 2008). The decomposition of cellulose can produce a kind of monosaccharide called glucose $\left(\mathrm{C}_{6} \mathrm{H}_{12} \mathrm{O}_{6}\right)$, and each glucose unit includes three hydroxyl groups, with two of them forming intramolecular hydrogen bonds and one of them forming intermolecular hydrogen bonds (Kabir et al. 2012).

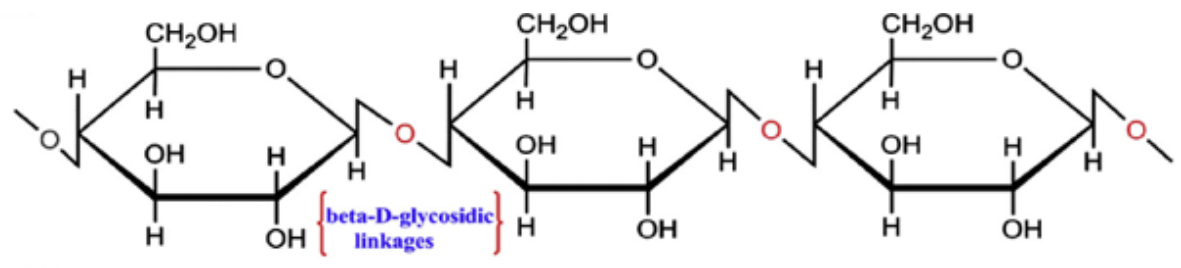

Fig. 1.1. Structure of cellulose (Gurunathan et al. 2015)

The structure of hemicellulose is more complex than cellulose, and the differences are reflected in three aspects (John and Thomas 2008). Firstly, hemicellulose is a group of homo- and heteropolymers consisting mainly of anhydro-b-(1-4)-D-xylopyranose, glucopyranose, mannopyranose, and galactopyranose main chains with several substituents (Fig. 1.2) (Gurunathan et al. 2015). Compared to cellulose containing only $1,4-\beta-D-$ glucopyranose units, hemicellulose contains different sugar units. Secondly, hemicellulose has a considerable degree of chain branching giving rise to its non-crystalline nature, while cellulose is a linear polymer. Thirdly, the degree of polymerization of native cellulose is 10-100 times higher than that of hemicellulose (around 50-300). Therefore, hemicellulose exhibits a different behavior from cellulose. Normally, hemicellulose decomposes at a lower temperature than cellulose and lignin (Kabir et al. 2013). It is soluble in alkali and easily hydrolyzed by acid (John and Anandjiwala 2008). Also, it was suggested that the 
hydrophilic nature of lignocellulosic biomass is mainly attributed to the presence of hemicellulose (Correia et al. 2016).


Fig. 1.2. Main and side chains of hemicellulose (Gurunathan et al. 2015)

Lignin is considered as a complex, three-dimensional copolymer of aliphatic and aromatic constituents with a very high molecular weight (John and Anandjiwala 2008). Because no method has been established to isolate lignin in its native state from the lignocellulosic biomass, the exact chemical nature of lignin is not identified. But hydroxyl, methoxyl and carbonyl groups associated with lignin have been identified (John and Thomas 2008). Lignin is formed from three primary precursors: trans-coniferyl, transsinapyl, and trans-p-coumaryl, as shown in Fig. 1.3 (Gurunathan et al. 2015; Mohanty et al. 2002). The only difference between the precursors is the number of methoxyl groups ($\mathrm{OCH}_{3}$ ) present on the aromatic ring. Lignin is amorphous and hydrophobic, and it has less water absorption capacity compared to cellulose and hemicellulose ( $\mathrm{Li}$ et al. 2007). It is not hydrolyzed by acids but soluble in hot alkali, readily oxidized, and easily condensable with phenol (John and Thomas 2008). The thermal decomposition of lignin occurs over a wider temperature range than cellulose and hemicellulose because various oxygen 
functional groups in lignin decompose at different temperatures (Correia et al. 2016; Kabir et al. 2013).

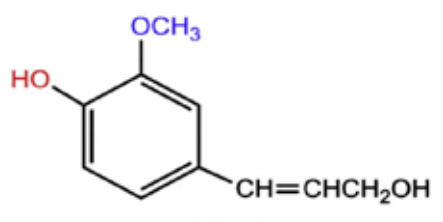

Trans-conifetyl



Trans-sinapyl

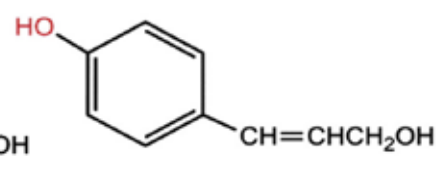

Trans-p-coumaryl

Fig. 1.3. Precursors of lignin (Gurunathan et al. 2015)

\subsection{Application of Lignocellulosic Biomass Wastes to Cementitious Materials}

In recent years, environmental issues such as global warming and energy savings are becoming more and more evident. The awareness of the importance of environmental sustainability has been increased. Lignocellulosic biomass is considered as a renewable and $\mathrm{CO}_{2}$ neutral energy resource (Rajamma et al. 2009). It has been used worldwide for food, fodder, and processing (sugar, starch, and vegetable oils, etc.) and also in energy production industry (Medina et al. 2017). Many countries or organizations have established a series of development strategies to expand the application of lignocellulosic biomass. So far, lignocellulosic biomass has attracted much attention from the concrete industry based on some advantages in addition to its environment-friendly nature. Firstly, lignocellulosic biomass is relatively cheap and plentifully supplied worldwide. It can be obtained from woody crops, vegetable plants, and agricultural by-products, etc. Secondly, the disposal of lignocellulosic biomass wastes is a major societal problem, which costs much money and labor. However, the recycling of these wastes as raw materials for concrete provides a sustainable way to deal with these wastes for the agriculture industry. Thirdly and most importantly, the application of lignocellulosic biomass to concrete can bring many benefits to the concrete industry by reducing the use of raw materials for concrete. Concrete is the 
most commonly used building material, with an annual production of over 14 billion tons, and the concrete industry accounts for $7 \%$ of global $\mathrm{CO}_{2}$ emissions (Cuthbertson et al. 2019). Also, the concrete industry not only consumes large amounts of raw materials, considerably reducing limestone and clay resources, but also is highly energy-intensive (Medina et al. 2017). The concrete industry is challenged by environmental concerns and the consumption of raw materials and energy (Teixeira et al. 2016). The incorporation of lignocellulosic biomass wastes into concrete is a sustainable way to the concrete industry.

The use of lignocellulosic biomass wastes in cementitious materials can be accomplished in two ways, one is in the form of ash derived from burning lignocellulosic biomass wastes and the other is the direct use of lignocellulosic biomass wastes. Many kinds of lignocellulosic biomass ashes, such as rice husk ash and corn cob ash, have been used as pozzolanic materials to partially replace cement because they contain a large amount of silica in the amorphous form (Rajamma et al. 2009). The chemical characteristics of the lignocellulosic biomass ash can be affected by the operating conditions (combustion temperature and technology used) and also biomass source (herbaceous, wood, or bark) (Demis et al. 2014). However, it should be noted that the application of non-coal derived biomass ashes in concrete is still prohibited by many agencies such as the American Society of Testing Material (ASTM), American Concrete Institute (ACI), EN-450, and EN197-1 (A 2016; Barbosa et al. 2013). Regarding the direct use of lignocellulosic biomass wastes, they can be applied in the form of powders, chips, shavings, and fibers depending on their sizes. Normally, powders, chips, and shavings are used in large amounts to reduce the use of fine or coarse materials in concrete, and fibers are used as reinforcements in concrete. Research on such applications is enormous, and 
some conclusions can be summarized as follows (Becchio et al. 2009; Bederina et al. 2007; Benmansour et al. 2014; Chen et al. 2017; Mohammed et al. 2014). Firstly, the weight of concrete can be reduced due to the lower specific gravity of lignocellulosic biomass, which indicates that the lightweight concrete can be developed if a sufficient amount of lignocellulosic biomass wastes is used. Secondly, the thermal and acoustic insulation capacities can be improved, which can result in huge energy savings. Thirdly, the toughness of concrete is found to be improved, which is indicative of a higher energy absorption capacity. Lastly, there are, however, some variations about the strength of concrete, and the improvement or reduction in the strength is closely dependent on the synergistic effect of lignocellulosic biomass wastes and cementitious materials.

So far, some concerns about directly using lignocellulosic biomass wastes in cementitious materials have been proposed. Firstly, hemicellulose, lignin, and impurities in lignocellulosic biomass can delay cement hydration by forming a protective layer around the partially hydrated cement grains or forming a chelate complex with the cations present in the hydrated cement (Jo and Chakraborty 2015). Besides, these organic components (hemicellulose, lignin, and impurities) can be degraded in the alkaline environment of cementitious materials, and the degree of polymerization can be reduced (Ballesteros et al. 2015; John and Anandjiwala 2008; John and Thomas 2008). The decomposition products are mainly saccharides (such as glucose and xylose), which can further delay cement hydration and affect the formation of calcium silicate hydrate that contributes the most to the strength of cementitious materials (Boix et al. 2020; Chakraborty et al. 2013; Vo and Navard 2016). Secondly, lignocellulosic biomass has high water absorption capacity, which indicates that it has poor dimensional stability, and the compatibility between 
lignocellulosic biomass and the cementitious matrix will be not good. This may lead to a bad interfacial adhesion with the matrix and thus is not beneficial to the mechanical properties of cementitious materials. Thirdly, the impurities, such as pectin and wax, cover the surface of lignocellulosic biomass and hinder interlocking with cementitious matrix. In order to mitigate these negative effects of the lignocellulosic biomass and improve its application in cementitious materials, an alternative way is to modify lignocellulosic biomass.

\subsection{Modification on Lignocellulosic Biomass Wastes in Cementitious Materials}

So far, many different treatment methods have been proposed to modify lignocellulosic biomass in cementitious materials. They are mainly focused on changing the structure or removing amorphous components (hemicellulose, lignin, and impurities) of lignocellulose biomass, or preventing the lignocellulosic biomass from contacting with cementitious materials. The commonly used treatment methods in cementitious materials include ordinary heating treatment, torrefaction treatment, boiling treatment, surface coating or impregnation treatment, hornification treatment, alkaline treatment, bleaching treatment, and other treatments, which are introduced as follows.

\subsubsection{Ordinary Heating Treatment}

Ordinary heating treatment is conducted by heating the lignocellulosic biomass at a temperature, usually less than $200{ }^{\circ} \mathrm{C}$, in an air-circulating environment. In such a temperature range, the main components of lignocellulosic biomass cannot be degraded, but the crystallinity of cellulose can be improved. Rong et al. heated sisal fibers at $150{ }^{\circ} \mathrm{C}$ in an air-circulating oven for $4 \mathrm{~h}$, and the heat-treated sisal showed superior tensile properties due to the increased crystallinity of cellulose (Rong et al. 2001). Following the 
same treatment temperature $\left(150^{\circ} \mathrm{C}\right)$, Wei et al. heated sisal for $4 \mathrm{~h}, 8 \mathrm{~h}$, and $16 \mathrm{~h}$, respectively, and the sisal fiber's crystallinity was improved from $20.27 \%$ to $22.67 \%$, $26.42 \%$, and 23.86\%, respectively (Wei and Meyer 2014). And due to the improved crystallinity of cellulose, the mechanical properties of sisal fiber were improved, which leads to an improvement in the strength and durability of sisal fiber reinforced concrete.

\subsubsection{Torrefaction Treatment}

Torrefaction (mild pyrolysis) treatment is conducted at a temperature between 200 and $300{ }^{\circ} \mathrm{C}$ under atmospheric pressure, with the oxygen absent (Chen et al. 2015). It has been reported that at $200-250{ }^{\circ} \mathrm{C}$, hemicellulose starts to decompose and can be totally degraded when torrefied at $300{ }^{\circ} \mathrm{C}$ for $2 \mathrm{~h}$, while cellulose and lignin begin to decompose at about $270-300{ }^{\circ} \mathrm{C}$ (Shang et al. 2012). Therefore, it can be concluded that after torrefaction, the hemicellulose component of lignocellulosic biomass can be mostly removed. Govin et al. applied three kinds of wood shavings (natural, torrefied at $240{ }^{\circ} \mathrm{C}$, and torrefied at $260^{\circ} \mathrm{C}$ ) to cement paste and showed that the hydration of the silicate phases can be delayed by wood shavings, while the torrefied wood shavings can promote gypsum dissolution or consumption and ettringite formation (Govin et al. 2006). Similarly, Bilba et al. indicated that the torrefied bagasse at $200^{\circ} \mathrm{C}$ and $250^{\circ} \mathrm{C}$ could improve the setting of cementitious materials compared to raw bagasse (Bilba et al. 2003). Besides, Onésippe et al. indicated that torrefied bagasse fibers could reduce the thermal conductivity of cement composites significantly (Onésippe et al. 2010).

\subsubsection{Boiling Treatment}

Boiling treatment is conducted by immersing lignocellulosic biomass into boiling water. It can reduce the amount of water-soluble substances responsible for setting delay 
and incompatibility problem with cement paste. It was found that boiling in water for $2 \mathrm{~h}$ was sufficient to reduce water-soluble substances (Asasutjarit et al. 2007). Normally, the boiling treatment is accompanied by washing process, which can further reduce the watersoluble substances, especially sugars. Sellami et al. indicated that the water-soluble sugars could be decreased from $30.78 \%$ for untreated Diss to $1.95 \%$ for boiled-but-not-washed Diss and, eventually, to $0.72 \%$ for boiled-and-washed Diss (Sellami et al. 2013). Moreover, the boiling treatment and consequent washing process have been found to improve the fiber tensile strength, fiber toughness, and fiber-concrete bonding strength (Ali and Chouw 2013; Ali et al. 2013). And the higher compressive and flexural strengths of cementitious materials were also be observed (Asasutjarit et al. 2007; Sellami et al. 2013).

\subsubsection{Surface Coating or Impregnation Treatment}

Surface coating or impregnation on lignocellulosic biomass is normally conducted by using polymer coverings on its surface. The polymer can form a film to protect the lignocellulosic biomass from contacting with the cementitious materials, so the fiber degradation can be avoided. It has been widely reported that the coating with styrenebutadiene polymer could improve the bonding with matrix and also increased the tensile strength, flexural strength, and even stiffness of cementitious materials (Ferreira et al. 2015; Fidelis et al. 2016). Additionally, Ahmad and Fan compared four types of resins (epoxy, polyurethane, vinylester, and polyester) for coating sisal fibers and showed that all coatings resulted in significant improvement in interfacial bonding and mechanical properties of cementitious composites, with polyurethane coated fibers being the best (Ahmad and Fan 2018). 


\subsubsection{Hornification Treatment}

Hornification treatment is conducted through alternatively drying and wetting of the lignocellulosic biomass. It does not change the chemical structure of lignocellulosic biomass, but the polysaccharide chains of cellulose are grouped closely together after drying, which can reduce the lumen and water absorption capacity of lignocellulosic biomass (Ballesteros et al. 2015; Lima et al. 2014). Ferreira et al. indicated that the hornification treatment could not only reduce water absorption capacity but also increased the tensile strength and stiffness of sisal fiber, leading to an improvement in the fibermatrix interface (Ferreira et al. 2015). Ballesteros et al. applied the hornification treatment to unbleached pulp and bleached pulp and showed that the treatment did not deteriorate the properties of viscosity and crystallinity index while reducing the water retention capacity for both pulps (Ballesteros et al. 2015). This resulted in a loss of the swelling capacity and thus greater dimensional stability of pulps and consequently, an improvement in the fibermatrix adhesion and the modulus of rupture and specific energy of composites.

\subsubsection{Alkaline Treatment}

Alkaline treatment, also called mercerization, is the most commonly used chemical treatment method to modify lignocellulosic biomass through the reaction of hydroxyl groups of lignocellulosic biomass with alkaline substances (John and Anandjiwala 2008).

It has been reported to remove hemicellulose and some impurities of lignocellulosic biomass, and increase the crystallinity index of cellulose (Stevulova et al. 2014). The alkaline treated lignocellulosic biomass can not only reduce the negative effect on cement hydration but also roughen its surface and increase the interfacial adhesion with matrix, leading to improved mechanical properties of cementitious materials, especially flexural 
strength and toughness (Andiç-Çakir et al. 2014; Arsyad et al. 2015; Boix et al. 2020; Yan et al. 2016). Sawsen et al. reported that cement composites with alkaline treated flax fibers have reduced setting time, higher stiffness and strength, and more pronounced ductility than those with untreated fibers (Sawsen et al. 2014). Snoeck et al. indicated that chemically treated flax and hemp fibers using $2 \%(\mathrm{~m} / \mathrm{m}) \mathrm{NaOH}$ can improve the multicracking property and reduce crack widths, which allows the autogenous healing when exposed to wet/dry cycles (Snoeck et al. 2015). In addition, de Klerk et al. indicated that at low concentrations of $2 \%, 6 \%$, and $10 \% \mathrm{NaOH}$, the fiber strength, fiber-matrix bonding, and post-peak strength of cement-based composites are improved; however, higher concentrations of $20 \%$ and $30 \% \mathrm{NaOH}$ cause the opposite result (de Klerk et al. 2020).

\subsubsection{Bleaching Treatment}

Bleaching treatment is a common practice to increase the whiteness of pulp for paper production. Given that the coloration mainly comes from lignin rather than hemicellulose and cellulose, the bleaching treatment targets at the removal of lignin, which has been adopted to modify lignocellulose biomass in cementitious materials. One commonly used bleaching agent is sodium chlorite $\left(\mathrm{NaClO}_{2}\right)$. The decomposition of sodium chlorite produces one of the strongest oxidizing gases, which is known as chlorine dioxide $\left(\mathrm{ClO}_{2}\right)$ (Abdel-Halim 2014). $\mathrm{ClO}_{2}$ reacts with lignin constituents, and then the lignin can be removed (Kabir et al. 2012). Carvalho et al. indicated that after $\mathrm{NaClO}_{2}$ treatment, lignocellulosic fibers can be disintegrated due to the extraction of lignin that holds the fibrils together, and the crystallinity index can be improved due to the increased exposure of cellulose (Carvalho et al. 2010). Another commonly used bleaching agent is hydrogen peroxide $\left(\mathrm{H}_{2} \mathrm{O}_{2}\right)$. Ghali et al. indicated that a strong $\mathrm{NaOH}$ condition could not 
affect the lignin amount significantly; however, the $\mathrm{H}_{2} \mathrm{O}_{2}$ bleaching could lead to a considerable decrease in the lignin content particularly when the concentration of $\mathrm{H}_{2} \mathrm{O}_{2}$ is increased (Amel El et al. 2012). Xie et al. reported that the $\mathrm{H}_{2} \mathrm{O}_{2}$ bleaching treatment could decrease amorphous components, especially lignin, and increase the crystallinity of rice straw, which mitigates the negative effect of rice straw on cement hydration (Xie et al. 2016). At present, $\mathrm{H}_{2} \mathrm{O}_{2}$ bleaching is gradually replacing $\mathrm{NaClO}_{2}$ bleaching due to its environmental friendliness, although $\mathrm{NaClO}_{2}$ bleaching can reduce lignin with minimal amounts of cellulose degradation at a reasonable cost (Ahmad et al. 2019).

\subsubsection{Other Treatments}

In addition to the above-mentioned treatments, some other treatments are also applied to lignocellulosic biomass in cementitious materials. Bulut et al. indicated that the oxidative modification on jute fibers with potassium dichromate and potassium permanganate reduced alcohol groups and increased $\mathrm{O}=\mathrm{C}$ groups, and thus led to a more hydrophobic surface, which is accompanied by the increased surface roughness (Bulut and Aksit 2013). Amiandamhen et al. treated kenaf fibers with hot water, $\mathrm{CaCl}_{2}$, and a combination of hot water and $\mathrm{CaCl}_{2}$, and concluded that cement boards produced from hot water and $\mathrm{CaCl}_{2}$ treated fibers had the best mechanical and physical properties (Amiandamhen et al. 2016). On the contrary, Ali et al. showed that the treated fibers with $0.25 \%$ sodium alginate $\left(\mathrm{NaC}_{6} \mathrm{H}_{7} \mathrm{O}_{6}\right)$ and $1 \%$ calcium chloride $\left(\mathrm{CaCl}_{2}\right)$ solution caused a decrease in tensile strength and strain of fibers and fiber-concrete bonding strength (Ali et al. 2013). 


\subsection{Research Significance and Objectives}

Lignocellulosic biomass is a renewable resource, and each year large amounts of lignocellulosic biomass wastes are produced across the world. However, the collection, treatment, and disposal of lignocellulosic biomass wastes can impose economic and environmental costs on this society. Recycling lignocellulosic biomass wastes to develop value-added products is becoming more and more important for agriculture industry. Meanwhile, given that concrete is the most commonly used building material, and the whole concrete industry consumes plenty of nonrenewable mineral materials and emits significant amounts of polluting gases, there is an urgent need to reduce the usage of these materials. Therefore, the application of renewable lignocellulosic biomass wastes to concrete provides a sustainable way for both agriculture and concrete industries. More importantly, the incorporation of lignocellulosic biomass wastes into concrete can bring many benefits, such as developing lightweight concrete, improving acoustic and thermal insulation performance of concrete, improving tensile strength, flexural strength, and toughness, and controlling shrinkage and cracking, etc.

The goal of this research is to explore the hydration, shrinkage, cracking, and mechanical properties of cementitious composites with lignocellulosic biomass wastes at different scales. There are three sources of lignocellulosic biomass wastes, namely hemp powders, kenaf fibers, and wood chips, in this study. Based on their unique sizes, these wastes are utilized in different ways. Meanwhile, different treatment methods are used on these wastes to achieve the desired benefits. Firstly, since the size of hemp powders is close to that of cement particles, hemp powders are preferred to partially replace cement to develop powder-type agents that can adjust the hydration rate of cement. Hemp powders 
are modified by saturated lime $\left(\mathrm{Ca}(\mathrm{OH})_{2}\right)$ solution. The hydration of cement pastes with untreated and treated hemp powders needs to be studied. Secondly, since the size of wood chips is close to that of standard silica sand, wood chips are preferred to partially replace sand to develop lightweight cementitious materials. Wood chips are torrefied at low (220 $\left.{ }^{\circ} \mathrm{C}\right)$ and high $\left(260^{\circ} \mathrm{C}\right)$ temperatures, respectively. The mechanical properties (compressive strength, flexural strength, and toughness, etc) of mortar with non-torrefied and torrefied wood chips need to be examined. Thirdly, since kenaf fibers have a relatively large length/diameter ratio, kenaf fibers are preferred to serve as reinforcement in cementitious composites. Kenaf fibers are treated using different chemical agents such as $\mathrm{NaOH}$ and $\mathrm{H}_{2} \mathrm{O}_{2}$. The effects of untreated and treated kenaf fibers on the shrinkage, cracking, and flexural properties of cementitious composites need to be studied.

\subsection{Structure of the Dissertation}

The dissertation is comprised of five parts. Part one provides a general introduction to lignocellulosic biomass, some treatment methods on lignocellulosic biomass, and their application in cementitious materials (Chapter 1).

Part two is related to the application of hemp powders to cementitious composites, which is introduced in Chapter 2. Hemp powders are chemically treated with saturated calcium hydroxide solution and then used to partially replace some cement in cement pastes. The hydration of cement pastes with untreated and treated hemp powders is studied.

Part three is related to the application of wood chips to cementitious composites, which is introduced in Chapter 3. Wood chips are torrefied with low and high temperature and then added to mortar to partially replace some sand. The impact of lightly and highly torrefied wood chips on the mechanical properties of mortar is introduced. 
Part four is related to the application of kenaf fibers to cementitious composites, which is introduced in Chapter 4, Chapter 5, and Chapter 6. Chapter 4 focuses on the chemical modification on kenaf fibers, and the physiochemical and mechanical properties of modified kenaf fibers are evaluated through a series of tests. On top of Chapter 4, three types of kenaf fibers (raw kenaf fibers, alkaline treated kenaf fibers, alkaline-hydrogen peroxide treated kenaf fibers) are selected to be used in cementitious composites. The impact of these three types of kenaf fibers on autogenous shrinkage and drying shrinkage cracking of cement pastes is introduced in Chapter 5. Afterward, the flexural behavior of mortar with these three types of kenaf fibers is elaborated through experimental and finite element analysis in Chapter 6.

Part five is the conclusions and future work, which is introduced in Chapter 7. Conclusions from this work are summarized in this part. Also, some meaningful work that can be done in the future is introduced. 


\section{CHAPTER 2 HYDRATION OF PORTLAND CEMENT PASTES CONTAINING UNTREATED And TREATED HEMP POWDERS}

\subsection{Introduction}

As the first study of the dissertation, this chapter addresses the direct application of lignocellulosic powders to cementitious materials. The existing studies on such a topic are very limited. The main challenge towards their good application is the delaying effect on cement hydration. Karim et al. studied the palm oil shell powder blended cement and concluded the partial replacement of cement with palm oil shell powders can increase the setting time of concrete (Karim et al. 2017). In order to mitigate the delaying effect of lignocellulosic powders on cement hydration, it's necessary to conduct treatment prior to their application.

Alkaline treatment has been reported to be the most commonly used method on lignocellulosic biomass wastes to mitigate the delaying effect. It was reported that alkaline treatment can remove the hemicellulose, lignin, pectin, and wax of lignocellulosic biomass (Lu and Oza 2011; Sawpan et al. 2011). Jo and Chakraborty reported that the mild alkali treatment on jute was demonstrated to reduce the set delaying effect on cement hydration compared to untreated jute (Jo and Chakraborty 2015). Quiroga et al. compared three different treatment methods including water extraction, alkaline hydrolysis, and retention of inhibitory substances on wood and concluded that alkaline hydrolysis was the most 
effective method for minimizing the set delaying effect on cement hydration (Quiroga et al. 2016). Although there are very limited reports on the application of treated lignocellulosic powders in cementitious materials, alkaline treatment is expected to be a practical method due to the alkalinity of the cementitious materials.

In this study, the residuals of hemp products were ground into powders and then treated by a saturated lime (calcium hydroxide) solution to partially remove hemicellulose, lignin, and impurities. Untreated and alkaline treated hemp powders were used to partially replace cement, respectively. The isothermal calorimetry test, thermogravimetric analysis, fourier transform infrared spectroscopy analysis, scanning electron microscopy analysis were conducted on cement pastes. While calculating the degree of hydration of cement based on the thermogravimetric analysis, the traditional procedure was modified. The purpose of this study is not only to identify the effect of untreated and alkaline treated hemp powders on the hydration of cement paste, but also to find out the effect of replacement rate, treatment method, and hemp powder size on cement hydration. Moreover, the microstructure of cement paste without and with hemp powders was also examined.

\subsection{Materials and Experiments}

\subsubsection{Hemp Powder Preparation}

Hemp powders were prepared from flowering materials (flowers and leaves) and used to partially replace cement in this study. These flowering materials were provided by Green Remedy, Inc. (Louisville, KY, USA). Cannabidiol (CBD) was extracted from them prior to hemp powder preparation. To prepare the hemp powders, oven dried flowering materials (shown in Fig. 2.1(a)) were firstly chopped and blended into powders by using a high-speed blender and then sieved through a No. 200 sieve. The powders passing through 
the sieve were called fine hemp powders, as shown in Fig. 2.1(b), and those retained on the sieve were called coarse hemp powders, as shown in Fig. 2.1(c).

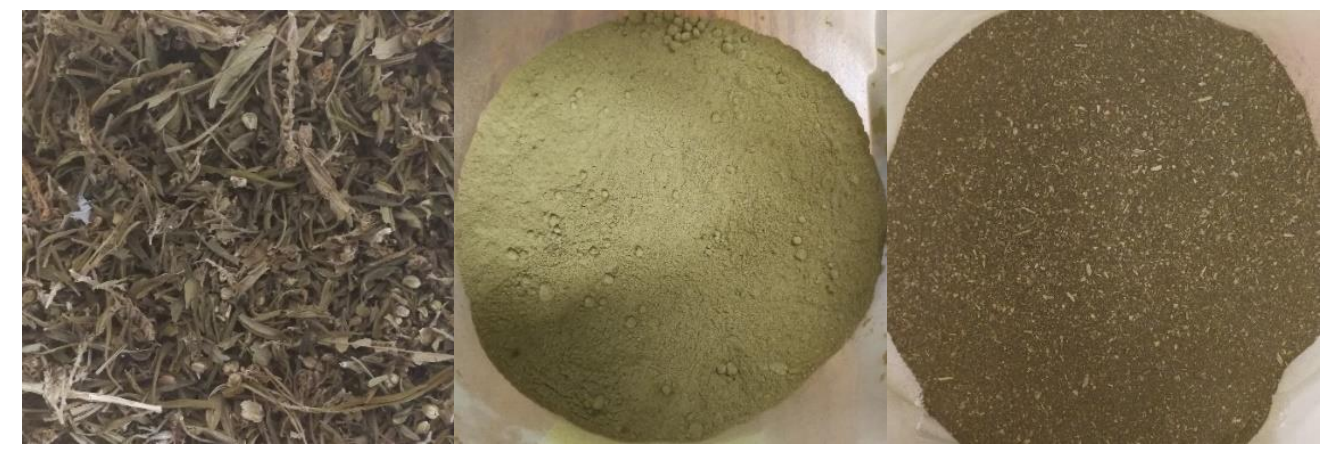

(a)

(b)

(c)

Fig. 2.1. (a) hemp leaves; (b) fine hemp powders; and (c) coarse hemp powders.

\subsubsection{Chemical Treatment}

The fine and coarse hemp powders were chemically treated by using the same procedure as introduced below. Saturated calcium hydroxide solution (saturated lime water) with a concentration of $0.155 \%$ was prepared in a beaker at room temperature. Hemp powders were introduced to the prepared solution (hemp-to -solution mass ratio $=0.1$ ) and stirred by using an AREX-6 Digital PRO (a kind of hot plate stirrer) (Velp Scientifica, Usmate, Italy) to assure good dispersion. The beaker was then covered to avoid water evaporation. After $24 \mathrm{~h}$, a centrifuge was used to filter out hemp powders from the calcium hydroxide solution. A part of treated hemp powders was collected without washing. The remaining part of the treated hemp powders was further washed by distilled water several times until the $\mathrm{pH}$ was close to neutral. The collected wet hemp powders (both washed and non-washed) were dried in an oven for $24 \mathrm{~h}$ at $40{ }^{\circ} \mathrm{C}$. And finally, the dried hemp powders were ground by using a mortar and pestle to eliminate the clumping. Based on the hemp 
powder size and treatment method, six types of hemp powders were obtained, as listed in Table 2.1.

Table 2.1 Classification of hemp powders

\begin{tabular}{lc}
\hline Sample & Specification \\
\hline RU & Untreated hemp powders retained on No. 200 sieve \\
PU & Untreated hemp powders passing through No. 200 sieve \\
RTN & Nonwashed treated hemp powders retained on No. 200 sieve \\
PTN & Nonwashed treated hemp powders passing through No. 200 sieve \\
RTW & Distilled-water-washed treated hemp powders retained on No. 200 sieve \\
PTW & Distilled-water-washed treated hemp powders passing through No. 200 sieve \\
\hline Note $: \mathrm{P}=$ passing $\cdot \mathrm{R}=$ retained $\cdot \mathrm{U}=$ untreated $\cdot \mathrm{T}=$ treated $\cdot \mathrm{N}=$ nonwashed and $\mathrm{W}=$ washed
\end{tabular}

\subsubsection{Cement paste preparation}

The chemical compositions and the mineral clinker compounds of the Type I/II cement used are shown in Table 2.2 and

Table 2.3 (Shang and Sun 2019). The water/binder ratio was kept at 0.50, and hemp powders were used to replace $5.0 \%$ and $10.0 \%$ of cement by weight. The corresponding mix proportion is shown in Table 2.4. The samples are named after the hemp powder type and dosage. For example, RTW10 denotes the paste with $10 \%$ of cement replaced by distilled water washed treated hemp powders that were retained on the No. 200 sieve.

Table 2.2 Chemical composition of Type I/II low alkaline (LA) portland cement

\begin{tabular}{lc}
\hline Chemical compound & Weight $(\%)$ \\
\hline $\mathrm{CaO}$ & 63.30 \\
$\mathrm{SiO}_{2}$ & 19.70 \\
$\mathrm{Al}_{2} \mathrm{O}_{3}$ & 5.00 \\
$\mathrm{Fe}_{2} \mathrm{O}_{3}$ & 3.47 \\
$\mathrm{MgO} \mathrm{O} \mathrm{S}_{3}$ & 3.59 \\
$\mathrm{Na}_{2} \mathrm{O}$ & 2.50 \\
$\mathrm{~K}_{2} \mathrm{O}$ & 1.55 \\
Loss on Ignition & 0.45 \\
\hline
\end{tabular}

Table 2.3 Major compounds of Type I/II LA portland cement 


\begin{tabular}{lc}
\hline Clinker phase & Weight $(\%)$ \\
\hline $\mathrm{C}_{3} \mathrm{~S}$ & 59.32 \\
$\mathrm{C}_{2} \mathrm{~S}$ & 11.81 \\
$\mathrm{C}_{3} \mathrm{~A}$ & 7.39 \\
$\mathrm{C}_{4} \mathrm{AF}$ & 10.55 \\
\hline
\end{tabular}

Table 2.4 Mix proportions of cement paste

\begin{tabular}{lcccc}
\hline Sample & Water & $\begin{array}{c}\text { Cement } \\
\text { (Type I/II) }\end{array}$ & $\begin{array}{c}\text { Hemp } \\
\text { powder }\end{array}$ & Specification \\
\hline Control & 0.5 & 1 & 0 & Cement paste with no hemp powders \\
PU5 & 0.5 & 0.95 & 0.05 & Cement paste with 5\% PU \\
RTN5 & 0.5 & 0.95 & 0.05 & Cement paste with 5\% RTN \\
PTN5 & 0.5 & 0.95 & 0.05 & Cement paste with 5\% PTN \\
RTW5 & 0.5 & 0.95 & 0.05 & Cement paste with 5\% RTW \\
PTW5 & 0.5 & 0.95 & 0.05 & Cement paste with 5\% PTW \\
PU10 & 0.5 & 0.90 & 0.10 & Cement paste with 10\% PU \\
RTN10 & 0.5 & 0.90 & 0.10 & Cement paste with 10\% RTN \\
PTN10 & 0.5 & 0.90 & 0.10 & Cement paste with 10\% PTN \\
RTW10 & 0.5 & 0.90 & 0.10 & Cement paste with 10\% RTW \\
PTW10 & 0.5 & 0.90 & 0.10 & Cement paste with 10\% PTW \\
\hline
\end{tabular}

Note: $\mathrm{P}=$ passing; $\mathrm{R}=$ retained; $\mathrm{U}=$ untreated; $\mathrm{T}=$ treated; $\mathrm{N}=$ nonwashed; $\mathrm{W}=$ washed; $5=5 \%$; and $10=10 \%$.

\subsubsection{Isothermal Calorimetry Test}

In order to evaluate the hydration of cement, Isothermal Calorimetry (IC) test was conducted on cement paste according to ASTM C1702 (ASTM. 2009). TAM Air (TA Instruments, New Castle, Delaware), a commercial calorimeter, was adopted in this study (Sun et al. 2017). It is an eight-channel isothermal heat conduction calorimeter with an operating temperature range of $5-60^{\circ} \mathrm{C}$. Before the testing, the equipment was carefully calibrated based on the calibration procedures specified by the manufacturer's manual. The energy change during hydration was collected and registered by an automated dataacquisition program. The energy value was calculated based on the unit weight of cementitious materials' mass. 


\subsubsection{Thermogravimetric Analysis}

Thermogravimetric analysis (TGA) was conducted on each type of hemp powders under nitrogen atmosphere with a flow rate of $40 \mathrm{ml} / \mathrm{min}$ from $25{ }^{\circ} \mathrm{C}$ to $600{ }^{\circ} \mathrm{C}$, with a heating rate of $10{ }^{\circ} \mathrm{C} / \mathrm{min}$. Around $10 \mathrm{mg}$ of hemp powders were used for each run. The purpose of this step was to study the decomposition of hemp powders within the temperature range and thus evaluate the effectiveness of calcium hydroxide treatment on the removal of hemicellulose.

TGA was also conducted on 7-day paste mixtures under nitrogen atmosphere, with a flow rate of $40 \mathrm{ml} / \mathrm{min}$ from $25^{\circ} \mathrm{C}$ to $1100^{\circ} \mathrm{C}$. The temperature profile includes increasing from room temperature to $105^{\circ} \mathrm{C}$ by $20^{\circ} \mathrm{C} / \mathrm{min}$ and then keeping the temperature at $105^{\circ} \mathrm{C}$ for $12 \mathrm{~h}$ to remove the evaporable water in the sample. Subsequently, the sample was heated from $105^{\circ} \mathrm{C}$ to $1100^{\circ} \mathrm{C}$ by $20^{\circ} \mathrm{C} / \mathrm{min}$, and then the temperature was kept at $1100^{\circ} \mathrm{C}$ for $6 \mathrm{~h}$ to extract all chemically bound water (CBW). Around $20 \mathrm{mg}$ paste sample was used for each run. The TGA tests were also conducted on pure cement powder and each type of hemp powders by adopting the same test procedure in order to correct the weight loss between $105^{\circ} \mathrm{C}$ and $1100{ }^{\circ} \mathrm{C}$ for chemically bound water calculation.

For cement paste without hemp powders, the calculation of chemically bound water (CBW) is regularly defined as the weight loss of the tested cement paste between $105^{\circ} \mathrm{C}$ and $1100{ }^{\circ} \mathrm{C}$, corrected for the loss on ignition (LOI) of the dry cement powder itself (Cao et al. 2015; Feng et al. 2004). However, for cement pastes with hemp powders, the calculation of chemically bound water is more complicated and needs to be additionally corrected to take account for the decomposition of hemp powders involved. In this study, 
the detailed procedures of the $\mathrm{CBW}$ correction and the corresponding calculation of degree of hydration (DoH) for cement pastes with hemp powers are shown in the Appendix.

\subsubsection{Fourier Transform Infrared Spectroscopy Analysis}

Fourier transform infrared spectroscopy (FTIR) test was conducted on pure cement powder and 7-day cement pastes by using a PerkinElmer Spectrum $100^{\circledR}$ series spectrometer (Shelton, Connecticut). The sampling technique of Attenuated Total Reflection (ATR) was adopted to enable samples to be examined directly without further preparation (Elmer 2005). The background spectrum was collected at ambient atmosphere, and then the samples were directly analyzed. The spectra were recorded in the range of 650-4000 $\mathrm{cm}^{-1}$ with the resolution of $4 \mathrm{~cm}^{-1}$ (Horgnies et al. 2013). The purpose of the FTIR test is to evaluate the effect of hemp powders on cement hydration qualitatively by observing the change of functional groups of cement pastes.

\subsubsection{Scanning Electron Microscopy Analysis}

Scanning electron microscopy (SEM) analysis was conducted on the powdered cement pastes using NOVA NANOSEM 600 ${ }^{\mathrm{TM}}$ provided by FEI (Hillsboro, Oregon). Before testing, in order to suppress charging effect, gold sputtering was applied to the surface of specimens. While testing, the Everhart Thornley detector (ETD) in the secondary electron mode was adopted. The beam current and voltage were $0.32 \mathrm{nA}$ and $10 \mathrm{kV}$, respectively. The purpose of SEM analysis is to observe the microstructure of cement pastes with hemp powders and then identify the effect of hemp powders on cement hydration. 


\subsection{Results and Discussions}

\subsubsection{Thermogravimetric Analysis on Hemp Powders}

The TGA test has been applied to various types of hemp powders as listed in Table 2.1. The TGA results on fine hemp powders (PU, PTN, and PTW) and coarse hemp powders (RU, RTN, RTW) are shown in Fig. 2.2(a) and Fig. 2.2(b), respectively. For each figure, the weight loss and the weight loss rate (denoted as derivative weight $(\% / \mathrm{min})$ ) are plotted.

In both figures, it can be seen that there is a large weight loss between 200 and 300 ${ }^{\circ} \mathrm{C}$, which is indicative of high hemicellulose content (Lv et al. 2010; Yang et al. 2007). Even a clear shoulder peak at $200-300{ }^{\circ} \mathrm{C}$ exists in DTGA curves for both figures, which is mainly attributed to the decomposition of hemicellulose (Wang et al. 2016). Between 200 and $300{ }^{\circ} \mathrm{C}$, the weight losses of PU, PTN, and PTW are $22.53 \%, 17.35 \%$, and $16.04 \%$, respectively, and the weight losses of RU, RTN and RTW are $21.87 \%, 17.00 \%$ and $15.18 \%$, respectively, as shown in Table $\mathbf{2 . 5}$. Compared to untreated hemp powders, for chemically treated hemp powders, the hemicellulose content decreases, and also the shoulder peaks in DTGA curves become less obvious. In addition, both PTW and RTW have much smoother DTGA curves at $200-300^{\circ} \mathrm{C}$ than PTN and RTN. It can be attributed to the washing process after the chemical treatment that further removes hemicellulose. The weight loss of fine hemp powders is slightly more than that of the coarse hemp powders, which may be because fine hemp powders with the larger specific surface area are much easier to be decomposed than coarse hemp powders.

From both figures, a significant peak can be seen between 300 and $400{ }^{\circ} \mathrm{C}$ on the derivative weight curve, which is mainly due to the decomposition of cellulose (Yang et al. 
2007). In this temperature range, the weight losses of PU, PTN, and PTW are 18.68\%, $21.12 \%$ and $23.40 \%$, respectively, and the weight losses of RU, RTN and RTW are $19.03 \%$, 23.92\% and 26.25\%, respectively, as shown in Table $\mathbf{2 . 5}$. It can be seen that the weight loss of cellulose correlates to the weight loss of hemicellulose. That is because chemical treatment and washing process remove some hemicellulose, resulting in the increased relative content of cellulose.

Bilba et al. reported that hemicellulose could be decomposed into saccharides in an alkali medium that can have a negative impact on cement hydration (Bilba et al. 2003). The TGA results indicate that the chemical treatment and the further washing process can assist the removal of hemicellulose, which is helpful to minimize the set delay effect of the hemp powders. By comparison of the weight losses, it is expected that the descending order of set delay effect is PU, PTN, and PTW for fine hemp powders, and RU, RTN, and RTW for coarse hemp powders. In addition, the set delay effect on the hydration of RU, RTN, and RTW is expected to be less than that of PU, PTN, and PTW, respectively, due to the smaller specific surface area.

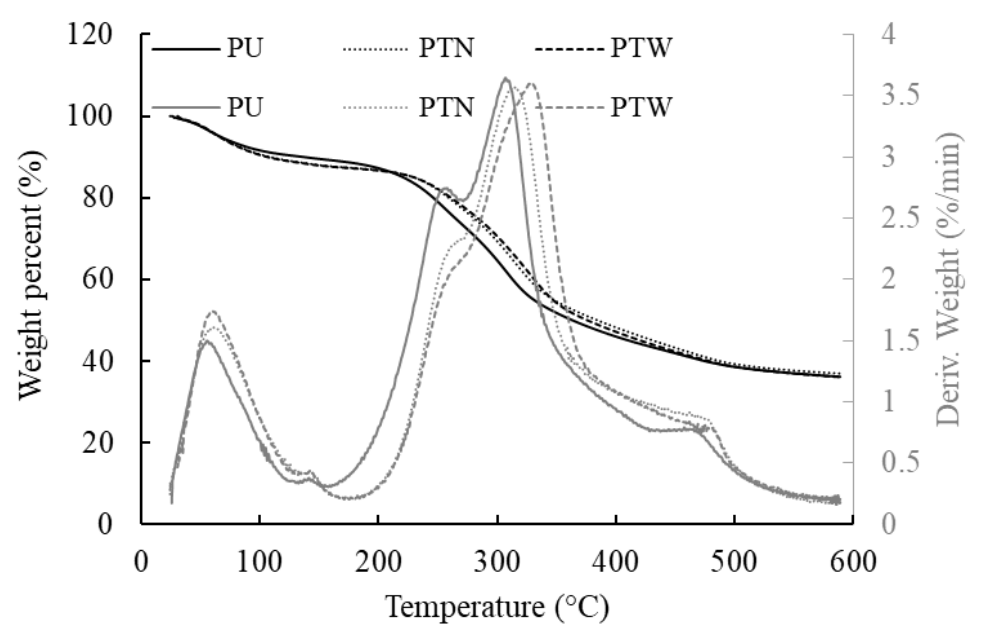

(a) 


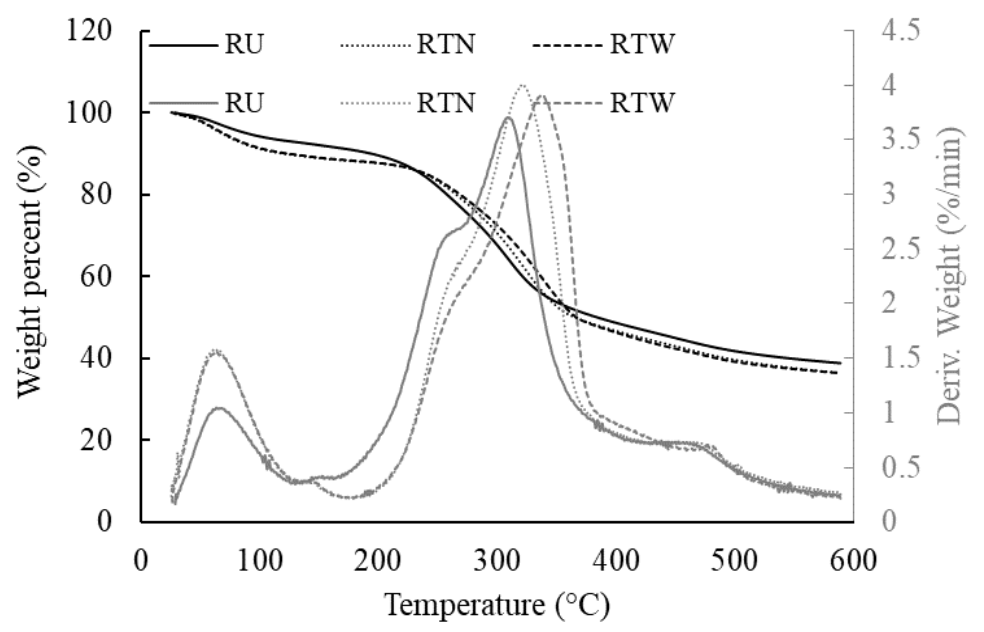

(b)

Fig. 2.2. TGA and DTGA curves of (a) fine; and (b) coarse hemp

powders.

Table 2.5 Weight loss $\left(W_{L}\right)$ of all types of hemp powders

\begin{tabular}{lcc}
\hline Sample & \multicolumn{2}{c}{$W_{L}(\%)$} \\
\cline { 2 - 3 } & $200-300{ }^{\circ} \mathrm{C}$ & $300-400{ }^{\circ} \mathrm{C}$ \\
\hline PU & 22.53 & 18.68 \\
PTN & 17.35 & 21.12 \\
PTW & 16.04 & 23.40 \\
RU & 21.87 & 19.03 \\
RTN & 17.00 & 23.92 \\
RTW & 15.18 & 26.25 \\
\hline
\end{tabular}

2.3.2 Isothermal Calorimetry and Thermogravimetric Analysis on Cement Pastes

Based on the calorimetric analysis, the heat evolution and heat evolution rate during hydration of Portland cement pastes without and with hemp powders are shown in Fig. 2.3(a) and Fig. 2.3(b), respectively. The hydration time corresponding to the peaks in Fig. 2.3(b) is listed in Table 2.6. The degree of hydration (DoH) of 7-day cement paste is calculated according to the procedure introduced in the Appendix and summarized in Fig.

2.4 . 
From Fig. 2.3(b), two peaks next to each other (corresponding to $\mathrm{C}_{3} \mathrm{~S}$ (the $1^{\text {st }}$ peak from the left side) and $\mathrm{C}_{3} \mathrm{~A}$ hydration (the $2^{\text {nd }}$ peak), respectively) of the control sample can be clearly seen; however, for any other sample, the second peak disappears, showing the $\mathrm{C}_{3} \mathrm{~A}$ hydration and ettringite conversion are much affected. This may be because saccharides from hemp powders prevent the formation of ettringite. It has been reported that saccharides influence the morphological evolution of hydrating aluminate particles, such as $\mathrm{C}_{3} \mathrm{~A}$ (Smith et al. 2011). Moreover, the microstructure analysis introduced in this study shows the formation of needle-like ettringites is much influenced by hemp powders.

Compared to the control, Fig. 2.3(a) and Fig. 2.3(b) show that the heat evolution and heat evolution rate of other samples with hemp powders are all reduced, and Table $\mathbf{2 . 6}$ shows that the hydration time corresponding to the maximum peak of heat evolution rate curve increases (except for PU10 and PTN10). That indicates the addition of hemp powders in cement delays the hydration, which is supported by the reduced degree of hydration (DoH) at 7 days as shown in Fig. 2.4. For PU10 and PTN10, the heat evolution amount (Fig. 2.3(a)) is very low, and no peaks exist in their heat evolution rate curve (Fig. 2.3(b)). The calculated DoH values shown in Fig. 2.4 are very small. When 10\% of the cement powder is replaced, the delay effect of hemp powders is so significant that the dormant period of the samples is very much extended.

The delay effect of hemp powders on cement hydration could be mainly due to the fact that some saccharides are possibly leached out (Vaickelionis and Vaickelioniene 2006). The delaying mechanism of saccharides for cement hydration has not been identified clearly, however, some possible reasons are proposed. One reason is that saccharides can form a complex with the metal ions present in the cement through chelation (Chakraborty 
et al. 2013). A protective layer around the partially reacted cement grain is formed to prevent further hydration of cement, which can delay the nucleation and the growth of the hydrated products (Jo and Chakraborty 2015). The second reason may be that some saccharides are unstable in cement paste and can be degraded into some sugar acids, which can inhibit cement hydration (Kochova et al. 2017). The third possible reason can be that organic retarders have strong calcium binding capacity that can prevent the formation of calcium-silicate-hydrate (C-S-H) (Kochova et al. 2017).



(a)

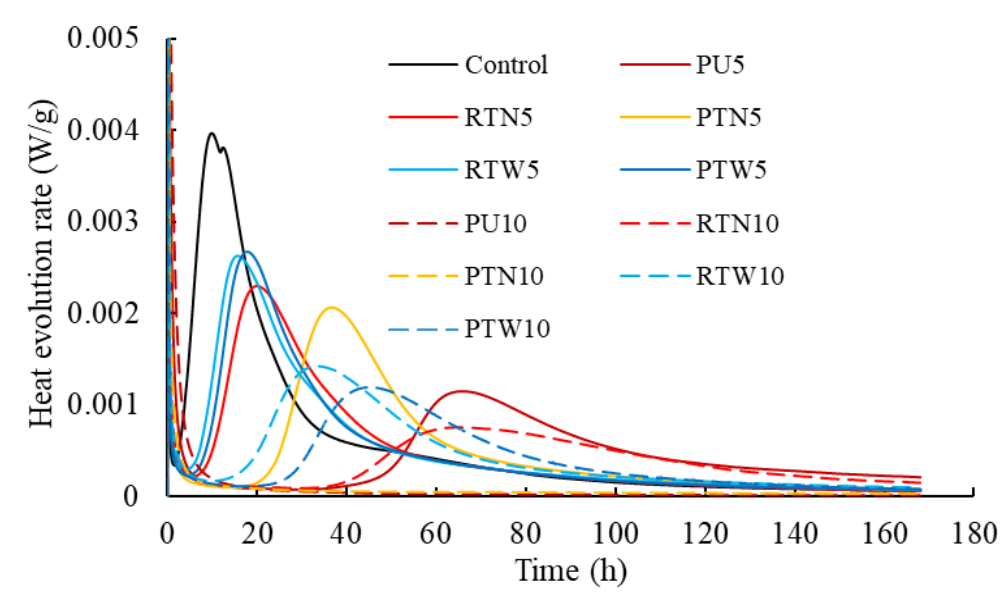

(b) 
Fig. 2.3. (a) Heat evolution; and (b) heat evolution rate during hydration of Portland cement paste without and with hemp powders.

Table 2.6 Hydration time corresponding to peaks of heat evolution rate curves

\begin{tabular}{lcc}
\hline Sample & Peak 1 (h) & Peak 2 (h) \\
\hline Control & 9.91 & 12.45 \\
PU5 & 65.72 & - \\
RTN5 & 20.01 & - \\
PTN5 & 36.64 & - \\
RTW5 & 15.74 & - \\
PTW5 & 18.01 & - \\
PU10 & - & - \\
RTN10 & 65.15 & - \\
PTN10 & - & - \\
RTW10 & 33.56 & - \\
PTW10 & 45.37 & \\
\hline
\end{tabular}

Note: M-dashes indicate no peak.

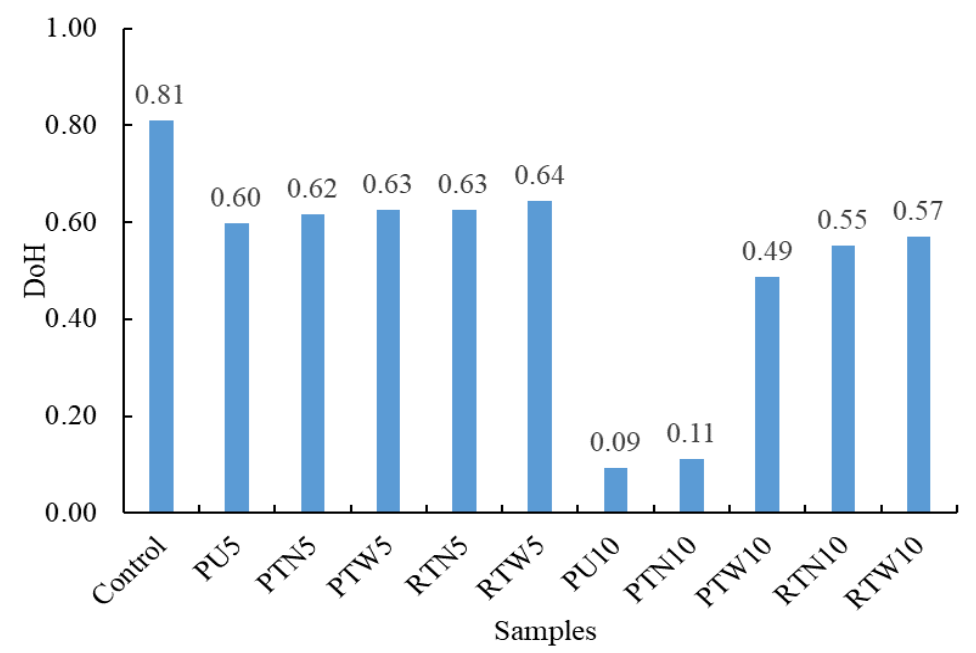

Fig. 2.4. Degree of hydration of 7-day cement paste samples.

\subsubsection{The Effect of Replacement Content on Cement Hydration}

In this study, $5 \%$ and $10 \%$ hemp powders were used to replace cement, respectively. Since for cement pastes with any type of hemp powders, the effect of replacement content on cement hydration is similar, RTN incorporated cement pastes are taken as an example for analysis. The heat evolution and heat evolution rate of RTN incorporated cement paste 
with different replacement contents are shown in Fig. 2.5(a) and Fig. 2.5(b), respectively. It can be noted that compared to RTN5, the heat evolution and heat evolution rate of RTN10 is lower. Also, Table 2.6 and Fig. 2.4 show that with the increase of replacement content, the hydration time corresponding to the maximum peak of heat evolution rate curve increases, and the DoH value decreases. This is not only because higher replacement content can dilute cement and thus undoubtedly reduce the heat evolution, but also more hemp powders can be possibly decomposed to generate more saccharides in cement paste, inhibiting cement hydration.

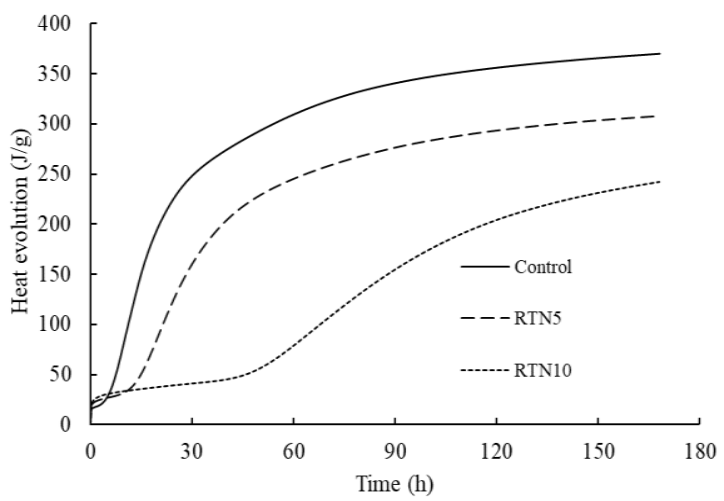

(a)



(b)

Fig. 2.5. (a) Heat evolution; and (b) heat evolution rate during hydration of RTNincorporated cement paste.

\subsubsection{The Effect of Treatment Method on Cement Hydration}

In this study, different treatment methods were applied to hemp powders. The cement pastes with 5\% fine hemp powders are taken as an example for analysis. Fig. 2.6(a) and Fig. 2.6(b) plot the heat evolution and heat evolution rate of the pastes with 5\% fine hemp powders, respectively. PTN5 and PTW5 both have higher heat evolution amount and heat evolution rate than those of PU5, and PTW5 has the highest amount among the three. Moreover, the hydration time corresponding to the maximum peak of the heat evolution 
rate curve is reduced, and the corresponding DoH value is improved, as shown in Table 2.6 and Fig. 2.4, respectively. This indicates that compared to untreated hemp powders (PU), the addition of treated hemp powders (PTN or PTW) to cement paste can mitigate the delay effect on the hydration of cement. The reason can be after calcium hydroxide treatment, much hemicellulose, lignin, and other extractives that can be decomposed into saccharides are removed from hemp powders (Lu and Oza 2011; Sawpan et al. 2011). This is also confirmed by the TGA test on hemp powders in this research. Compared to nonwashed treated hemp powders $(\mathrm{PTN})$, the washing process after chemical treatment can further mitigate the delay effect on the hydration of cement, resulting in a higher degree of hydration for washed treated hemp powders (PTW). This can be attributed to the further removal of hemicellulose during the washing process. This can also be due to the removal of some remaining saccharides during washing.



(a)

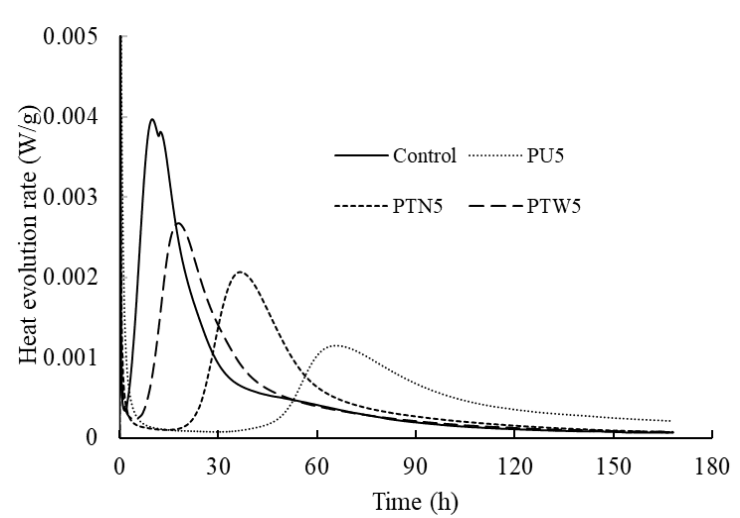

(b)

Fig. 2.6. (a) Heat evolution; and (b) heat evolution rate during hydration of portland cement paste with 5\% fine hemp powders.

\subsubsection{The Effect of Hemp Powder Size on Cement Hydration}

To study the size effect, cement pastes with $10 \%$ washed treated hemp powders are compared. The heat evolution and heat evolution rate of Portland cement paste with $10 \%$ 
washed treated hemp powders is shown in Fig. 2.7(a) and Fig. 2.7(b), respectively. It can be seen that compared to RTW10, PTW10 can lower the heat evolution amount and heat evolution rate. Moreover, Table 2.6 and Fig. 2.4 demonstrate that PTW10 has an increased hydration time corresponding to the maximum peak of the heat evolution rate curve and a lower DoH value, respectively. This indicates that the addition of fine hemp powders (PU, PTN, and PTW) can intensify the delay effect on the hydration of cement compared to coarse hemp powders (RU, RTN, and RTW). The possible reason may be that finer hemp powders (PU, PTN, and PTW) have higher specific surface area than coarse hemp powders (RU, RTN, and RTW), and they can be much easier to be dissipated in cement paste to produce saccharides, delaying the hydration of cement.

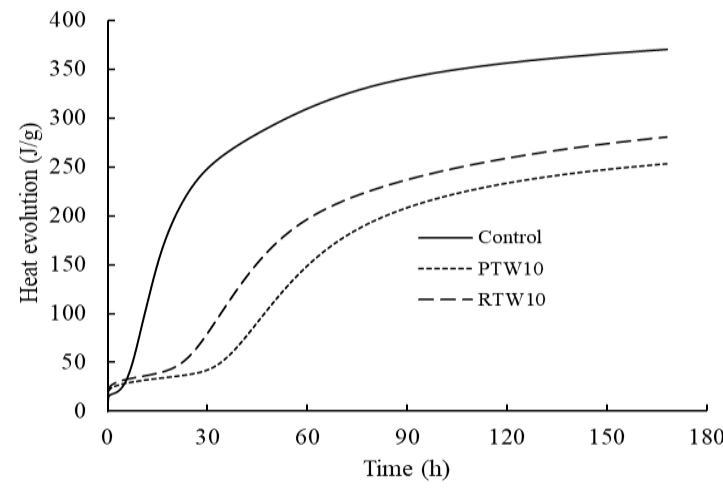

(a)

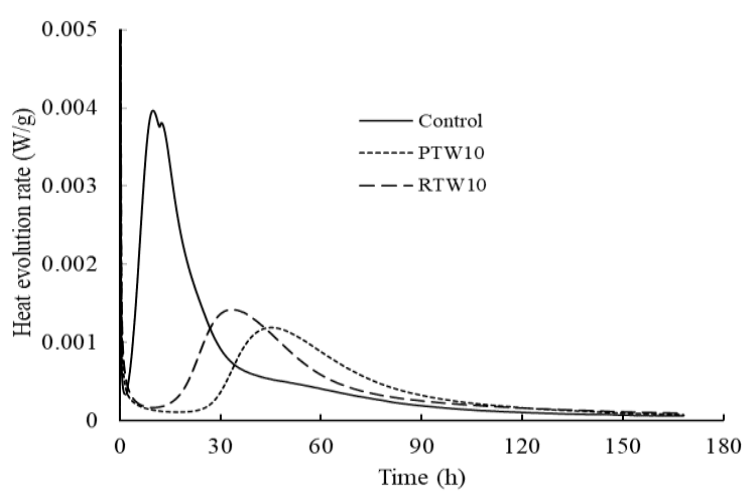

(b)

Fig. 2.7. (a) Heat evolution; and (b) heat evolution rate during hydration of portland cement paste with $10 \%$ washed treated hemp powders.

\subsubsection{FTIR Analysis on Cement Pastes}

The FTIR spectra of original Portland cement (OPC) and hydrated cement pastes at 7 days are shown in Fig. 2.8. There are four important regions that include water region (>1600 $\left.\mathrm{cm}^{-1}\right)$, carbonate region $\left(1400-1450 \mathrm{~cm}^{-1}\right)$, sulfate region $\left(1100-1150 \mathrm{~cm}^{-1}\right)$, and 
silicate region $\left(<1000 \mathrm{~cm}^{-1}\right)($ Mollah et al. 2000). The FTIR spectral data of each region are shown in Table 2.7.

\section{Water region}

From Fig. 2.8(a), it is shown that for OPC, there are no significant peaks in the water region. However, for all hydrated cement pastes (Fig. 2.8(b-1)), three important peaks appear in this region, and the corresponding spectral data are shown in Table 2.7. The first peak appears between 3612 and $3645 \mathrm{~cm}^{-1}$, which corresponds to the $\mathrm{OH}$ band from $\mathrm{Ca}(\mathrm{OH})_{2}$ (Mollah et al. 2000; Ylmén et al. 2009). This is attributed to the hydration of $\mathrm{C}_{3} \mathrm{~S}$ and $\mathrm{C}_{2} \mathrm{~S}$. The second peak appears between 3409 and $3435 \mathrm{~cm}^{-1}$, which corresponds to hydrogen-bonded $\mathrm{OH}$ species $(\mathrm{OH}-\mathrm{OH})$ adsorbed on the surfaces (Mollah et al. 2000). This is due to the symmetric and asymmetric stretching vibration ( $v_{1}$ and $\left.v_{3}\right)$ of $\mathrm{H}_{2} \mathrm{O}$ in the hydrated cement paste (Chakraborty et al. 2013; Choudhary et al. 2015; Ylmén et al. 2009). The third peak appears between 1641 and $1670 \mathrm{~cm}^{-1}$, which may be attributed to the bending vibration $v_{2}$ of water in sulphates, mainly gypsum (Ylmén et al. 2009).

\section{Carbonate region}

For OPC, Fig. 2.8(a) does not show any significant peaks in the carbonate region. However, for all hydrated cement pastes (Fig. 2.8(b-1)), a peak between 1416 and 1425 appears, which is due to the reaction of atmospheric $\mathrm{CO}_{2}$ with the calcium hydroxide produced by cement hydration (Liu and Sun 2013).

\section{Sulfate region}

The sulfates present in OPC are gypsum $\left(\mathrm{CaSO}_{4} \cdot 2 \mathrm{H}_{2} \mathrm{O}\right)$, hemihydrate $\left(\mathrm{CaSO}_{4} \cdot 0.5 \mathrm{H}_{2} \mathrm{O}\right)$ and anhydrite $\left(\mathrm{CaSO}_{4}\right)$, and the sulfate region in FTIR spectrum is located between $1100-1150 \mathrm{~cm}^{-1}$, corresponding to the $v_{3}$ vibration of the $\mathrm{SO}_{4}{ }^{2-}$ group in sulphates 
(Choudhary et al. 2015; Ylmén et al. 2009). Fig. 2.8(a) shows that two peaks $\left(1143 \mathrm{~cm}^{-1}\right.$ and $1126 \mathrm{~cm}^{-1}$ listed in Table 2.7) appear in the sulfate region of OPC, which may be because different forms of sulfates lead to different peaks. Upon hydration, these two peaks become one peak that is between 1114 and $1120 \mathrm{~cm}^{-1}$ for all hydrated cement pastes, as shown in Fig. 2.8(b-l) and Table 2.7. The shift of sulfate band towards a lower wavenumber is due to the formation of ettringite (Mollah et al. 2000).

\section{Silicate region}

Fig. 2.8(a) shows that OPC has a significant peak at $917 \mathrm{~cm}^{-1}$ in the silicate region, which is due to $\mathrm{Si}-\mathrm{O}$ asymmetric stretching vibration $\left(v_{3}\right)$ of $\mathrm{C}_{3} \mathrm{~S}$ and $\mathrm{C}_{2} \mathrm{~S}$ phase (Choudhary et al. 2015). For hydrated cement pastes (except for PU10 and PTN110), this peak significantly shifts towards a higher wavenumber that is between 954 and $965 \mathrm{~cm}^{-1}$ as shown in Table 2.7. The shifting of the Si-O stretching vibration is indicative of the polymerization of silicate units $\left(\mathrm{SiO}_{4}{ }^{2-}\right)$, with the formation of $\mathrm{C}-\mathrm{S}-\mathrm{H}$ phase as a result of cement hydration (Govin et al. 2006; Mollah et al. 2000; Peschard et al. 2004). However, Fig. 2.8(h) shows the silicate peak of PU10 does not shift and Fig. 2.8(i) shows the peak of PTN10 only shifts $6 \mathrm{~cm}^{-1}$, which may be because the degree of hydration for these two samples is so low that very few $\mathrm{C}-\mathrm{S}-\mathrm{H}$ is formed. This is confirmed by IC and TGA tests that PU10 and PTN10 are still in the dormant period after 7 days. 


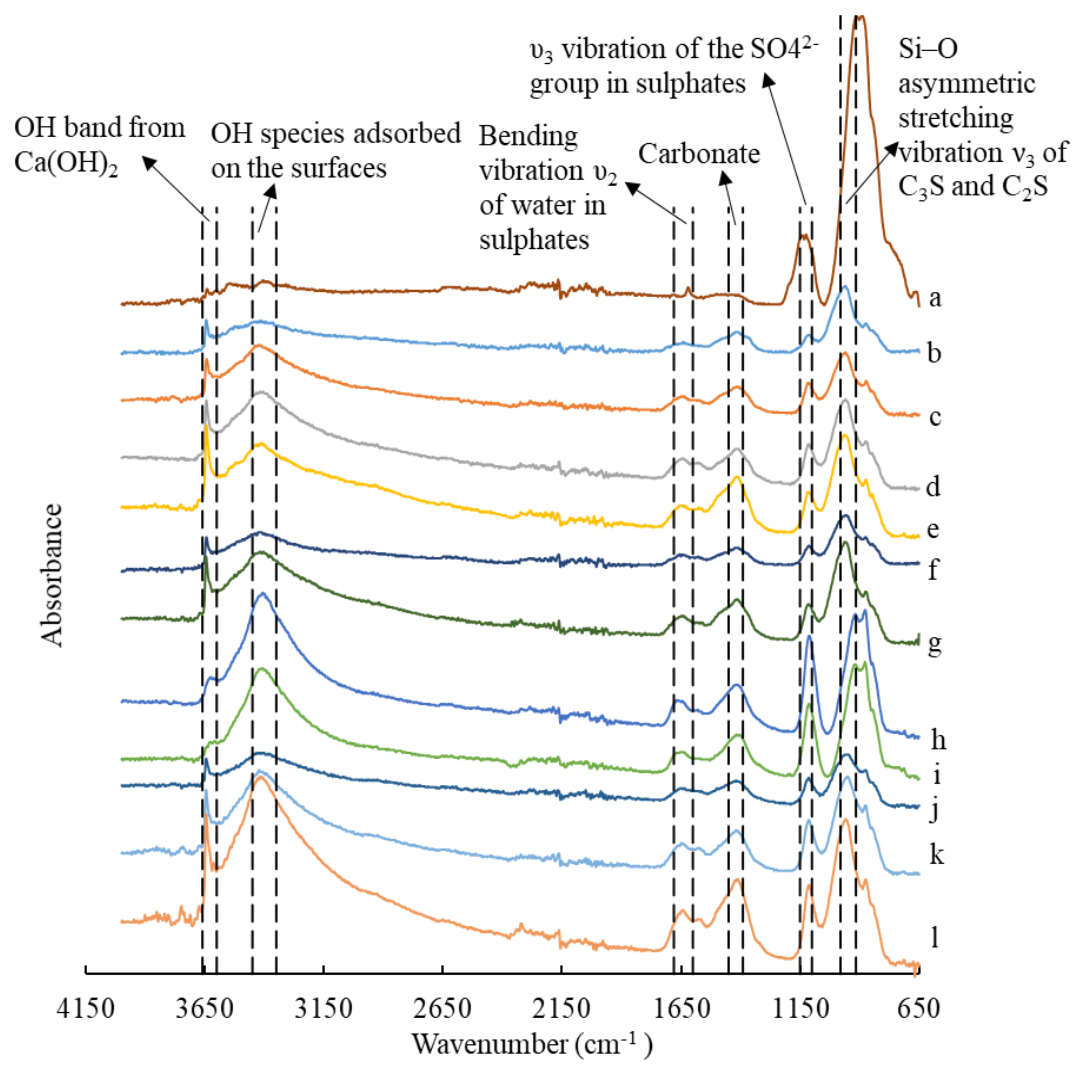

Fig. 2.8. FTIR spectra of (a) OPC; (b) control; (c) PU5; (d) PTN5; (e) PTW5; (f) RTN5;

(g) RTW5; (h) PU10; (i) PTN10; (j) PTW10; (k) RTN10; and (1) RTW10.

Table 2.7 FTIR spectral data for original portland cement and hydrated cement pastes

\begin{tabular}{lcccccc}
\hline Samples & \multicolumn{3}{c}{ Water region } & $\begin{array}{c}\text { Carbonate } \\
\text { region }\end{array}$ & $\begin{array}{l}\text { Sulfate } \\
\text { region }\end{array}$ & $\begin{array}{c}\text { Silicate } \\
\text { region }\end{array}$ \\
\cline { 2 - 7 } & Peak 1 & Peak 2 & Peak 3 & Peak 1 & Peak 1 & Peak 1 \\
\hline OPC & - & - & - & - & $1143 \& 1126$ & 917 \\
Control & 3644 & 3419 & 1641 & 1424 & 1118 & 962 \\
PU5 & 3643 & 3422 & 1650 & 1420 & 1119 & 961 \\
PTN5 & 3644 & 3419 & 1648 & 1424 & 1117 & 960 \\
PTW5 & 3644 & 3419 & 1658 & 1420 & 1120 & 965 \\
RTN5 & 3644 & 3427 & 1657 & 1425 & 1115 & 961 \\
RTW5 & 3645 & 3418 & 1649 & 1420 & 1118 & 964 \\
PU10 & 3626 & 3409 & 1670 & 1424 & 1114 & 917 \\
PTN10 & 3612 & 3414 & 1653 & 1419 & 1114 & 923 \\
PTW10 & 3645 & 3435 & 1655 & 1422 & 1115 & 964 \\
RTN10 & 3645 & 3423 & 1650 & 1421 & 1114 & 954 \\
RTW10 & 3645 & 3419 & 1643 & 1416 & 1114 & 959 \\
\hline
\end{tabular}

Note: M-dashes indicate no peak. 


\subsubsection{Microstructure}

In order to examine the effect of untreated and chemically treated hemp powders on the microstructure of cement paste, the control, PU10, PTN10, and PTW10 samples at 7 days are taken as an example for analysis. In addition, the SEM image on unhydrated cement powders is also adopted to assist analysis. For unhydrated cement powders, some large irregular particles can be clearly seen, as shown in Fig. 2.9(a). For the control cement paste, Fig. 2.9(b) shows that some needle-like ettringites and C-S-H are formed after cement hydration. For PU10, some large unhydrated cement particles and rod-like ettringites can be seen in Fig. 2.9(c). This could be due to large amounts of decomposition products (most possibly much saccharides) of untreated hemp powders delaying the hydration of cement, as confirmed by TGA and IC tests in this study. Moreover, the seriously delayed cement hydration prevent the further development of rod-like ettringites into needle-like ettringites. It has been reported that at a very early stage, ettringites are formed as hexagonal rods, and the relatively slender ettringites can be observed with the hydration progress (Liu 2014). Also, Cody et al. reported that the presence of sugars can lead to the morphology of ettringites to be short thick hexagonal prisms rather than needles (Cody et al. 2001). For PTN10, many unhydrated cement particles are clearly shown in Fig. 2.9(d). Compared to PU10, PTN10 has some small needle-like ettringites instead of rodlike ettringites on the surface, which indicates that some needle-like ettringites start to form. The reason may be chemically treated hemp powders have fewer saccharides inside, which makes the hydration of cement less delayed. For PTW10, although a small quantity of unhydrated cement particles can still be identified, they are not obvious in Fig. 2.9(e). 
Compared to PU10 and PTN10, more hydration products are formed, and the hydration of PTW10 seems to be the least delayed.

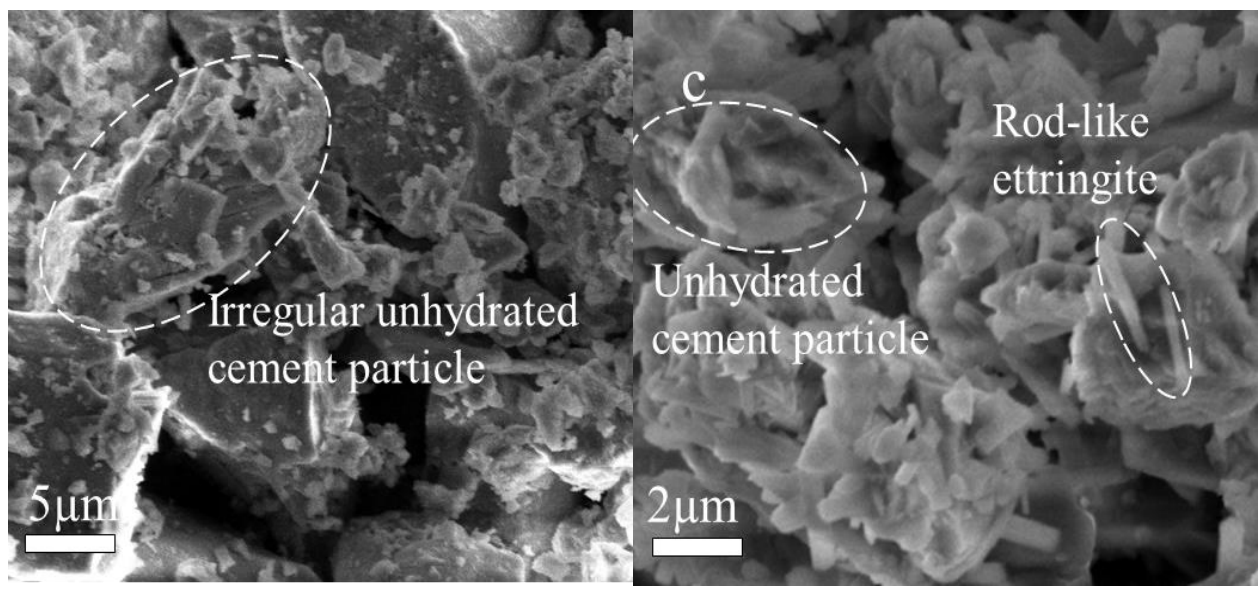

(a)

(b)

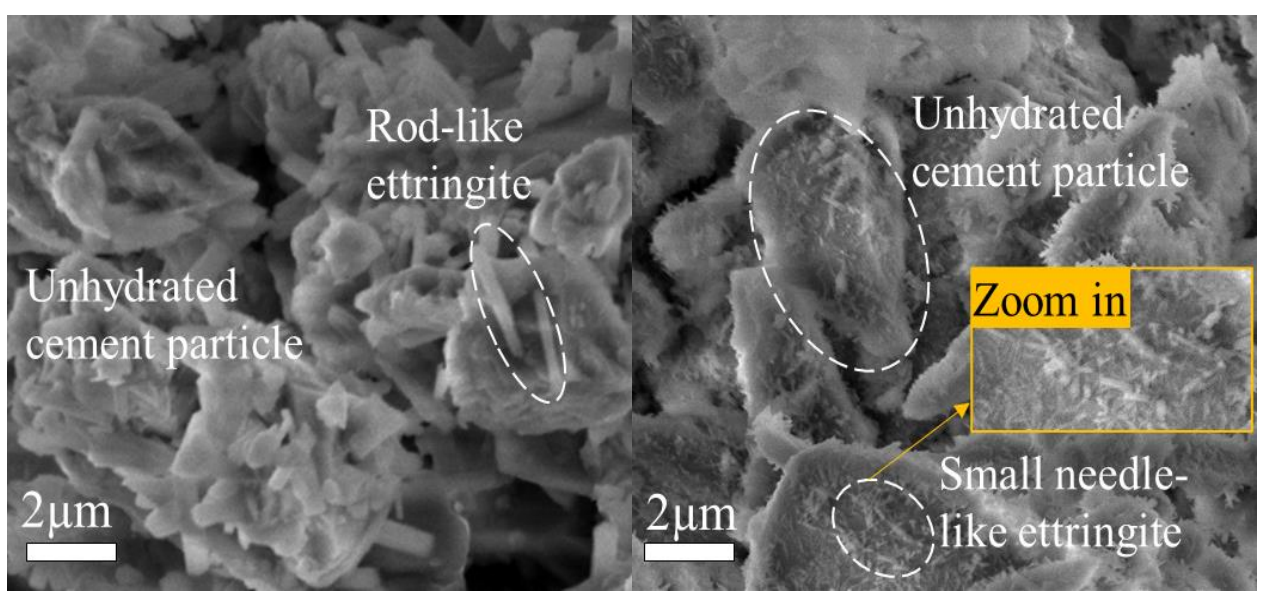

(c)

(d)

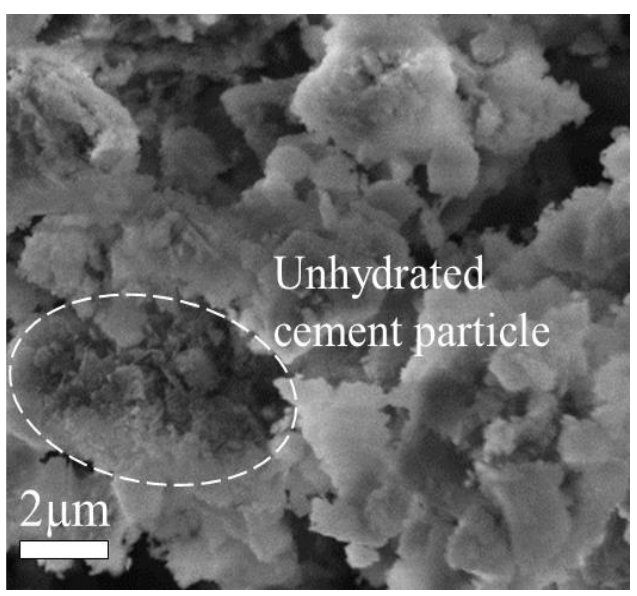


(e)

Fig. 2.9. Microstructure of (a) unhydrated cement powder; (b) control; (c) PU10; (d) PTN10; and (e) PTW10.

\subsection{Conclusions}

In this research, untreated and calcium hydroxide treated hemp powders were used to partially replace cement. Compared to pure cement paste, IC test shows that the incorporation of hemp powders in cement paste can reduce heat evolution amount and slow down heat evolution rate; also, the degree of hydration $(\mathrm{DoH})$ calculated based on TGA test matches the IC results. This confirms the delaying effects of hemp powders on cement hydration. SEM analysis shows that the formation of hydration products are significantly influenced if hemp powders involved.

The research also shows that the $10 \%$ replacement content (by weight of cement) delays the hydration of cement significantly. Particularly, for PU10 (untreated fine powders) and PTN10 (treated but non-washed fine powders) samples, the hydration is almost completely inhibited, and the degree of hydration is significantly low compared to others (e.g. 5\% replacement by weight of cement). This indicates that $10 \%$ is the limit replacement if hemp powders are used. If the volume fraction of aggregates in concrete is assumed as $60 \%-80 \%$ and the specific gravity of hemp powder is approximately assumed as 1 , the dosage limit of hemp powders by volume of concrete will be calculated as $2.24 \%-4.48 \%$ (10\% dosage limit by weight of cement).

Compared to the pastes with untreated hemp powders, treated hemp powders can reduce the delay effect when used. Also, the washed treated hemp powders had the minimum delay effect on cement hydration. The reduced delay effect may be attributed to 
the fact that much hemicellulose is removed after calcium hydroxide treatment and washing process, as confirmed by TGA test in this study.

In addition, the study also shows that fine hemp powders can delay the hydration of cement paste more than coarse hemp powders, which can be attributed to the higher specific surface area of fine hemp powders that can be easily decomposed into saccharides to delay the hydration of cement.

Generally, regardless of replacement content, treatment method, and hemp powder size, the delaying effect of hemp powders on cement hydration is obvious, which can possibly reduce the mechanical properties of cementitious materials significantly. However, hemp powders can be useful in serving as powder-type retardation agents to adjust cement hydration rate as needed, particularly in some extreme occasions where rapid hydration needs to be avoided. 


\section{CHAPTER 3 IMPACT OF THERMALLY MODIFIED WOOD ON MECHANICAL PROPERTIES OF MORTAR}

\subsection{Introduction}

In addition to the lignocellulosic powders introduced in Chapter 2, some lignocellulosic biomass wastes exist in the form of chips with a larger size than powders. They are appropriate to partially replace sand in cementitious materials due to the similar size. However, similar to powders, some components (hemicellulose, lignin, and extractives) of lignocellulosic chips can be degraded under alkali condition, which can not only delay cement hydration but also negatively affect the bonding with cementitious matrix and thus deteriorate the mechanical properties of cementitious composites (Vo and Navard 2016). To mitigate degradation and debonding, lignocellulosic chips need to be modified. Thermal treatment as a physical treatment method has been shown to improve the mechanical properties of lignocellulosic biomass-cement composites (Wei and Meyer 2014). This is because some undesirable components of lignocellulosic biomass can be removed at a higher temperature when they start to degrade (Kabir et al. 2012).

In this chapter, softwood chips were torrefied under high $\left(260^{\circ} \mathrm{C}\right)$ and low $\left(220^{\circ} \mathrm{C}\right)$ temperatures, respectively. Different substitution amounts (5\% and $10 \%$ by weight of sand) of the wood chips were used in mortars. Flowability, compressive strength, flexural strength, modulus of elasticity, and the toughness of mortars were investigated. The 
purpose of this study is to identify the effect of the addition of waste ground wood chips on mortar and the possibility of the torrefaction treatment of ground wood chips to positively affect mortar in terms of mechanical properties.

\subsection{Materials and Experiments}

\subsubsection{Ground Wood Preparation}

Three types of waste ground wood chips were used in this study. They are named as the original wood chip (OW, non-torrefied), highly torrefied wood chip (HTW), and lightly torrefied wood chip (LTW), as shown in Fig. 3.1.



Fig. 3.1. Wood chips: (a) OW; (b) HTW; (c) LTW

OW is from softwood pine, and its properties is shown in Table 3.1 (Peng et al. 2013). HTW and LTW were obtained by torrefaction treatment under the corresponding temperature of $260^{\circ} \mathrm{C}$ and $220^{\circ} \mathrm{C}$, respectively, for $20-60$ minutes.

Table 3.1 Properties of pine

\begin{tabular}{ccc}
\hline \multicolumn{2}{c}{ Properties } & Value (\%) \\
\hline Chemical composition & Cellulose & 36.7 \\
& Hemicellulose & 26.3 \\
& Lignin & 33.6 \\
Elemental analysis & Carbon & 51.2 \\
& Hydrogen & 6.0 \\
& Oxygen & 42.2 \\
& Nitrogen & 0.1 \\
Proximate analysis & Volatile matter & 82.8
\end{tabular}


Fixed carbon $\quad 16.8$

Ash $\quad 0.4$

The size of the waste ground wood chips was made according to the ASTM standard sand as specified by ASTM C778 (Standard 2012), and were prepared by passing through the No.20 $(850 \mu \mathrm{m})$ sieve and retaining on the No.30 $(600 \mu \mathrm{m})$ sieve.

In order to study the influence of torrefaction treatment on removal of hemicellulose, lignin, and other impurities, thermogravimetric analysis was conducted on all three waste wood chips (shown in Fig. 3.2). During the test, SDT Q600 (by TA Instruments) was used with the sample size of about $10 \mathrm{mg}$ in each test. The temperature was set to increase from room temperature (around $25^{\circ} \mathrm{C}$ ) to $300{ }^{\circ} \mathrm{C}$ with the rate of 10 ${ }^{\circ} \mathrm{C} / \mathrm{min}$. The change in the sample weight was continuously monitored during the test. Fig. 3.2 shows that the weight losses from $100^{\circ} \mathrm{C}$ to $220^{\circ} \mathrm{C}$ are found to be around $1.40 \%(\mathrm{OW})$, $1.00 \%$ (HTW), and $1.20 \%$ (LTW), which indicates that wood chips degrade slightly at 220 ${ }^{\circ} \mathrm{C}$. From $220{ }^{\circ} \mathrm{C}$ to $260{ }^{\circ} \mathrm{C}$, the weight losses are around $2.00 \%, 0.70 \%$, and $1.60 \%$, which indicates that certain amounts of substances degrade at $260{ }^{\circ} \mathrm{C}$. By comparison, the descending order of the weight loss is OW, LTW, HTW. The lower weight loss indicates more substances have been removed from wood chips in the process of torrefaction treatment. It has been reported that the pyrolysis of lignin can happen slowly under a temperature range from 150 to $900{ }^{\circ} \mathrm{C}$; the pyrolysis of hemicellulose and cellulose can occur at $220-315^{\circ} \mathrm{C}$ and $315-400{ }^{\circ} \mathrm{C}$, respectively (Yang et al. 2007). Therefore, the weight loss from $100^{\circ} \mathrm{C}$ to $260^{\circ} \mathrm{C}$ is mainly attributed to the pyrolysis of lignin and hemicellulose. By torrefaction treatment, some hemicellulose and lignin are removed for LTW, and higher amounts of both lignin and hemicellulose are removed for HTW. It has been reported that the presence of hemicellulose and lignin in fibers will negatively affect the mechanical 
properties of fiber reinforced concrete (Vo and Navard 2016). Therefore, in this study, the decrease in lignin and hemicellulose in thermal treated chips can contribute positively to mortar.

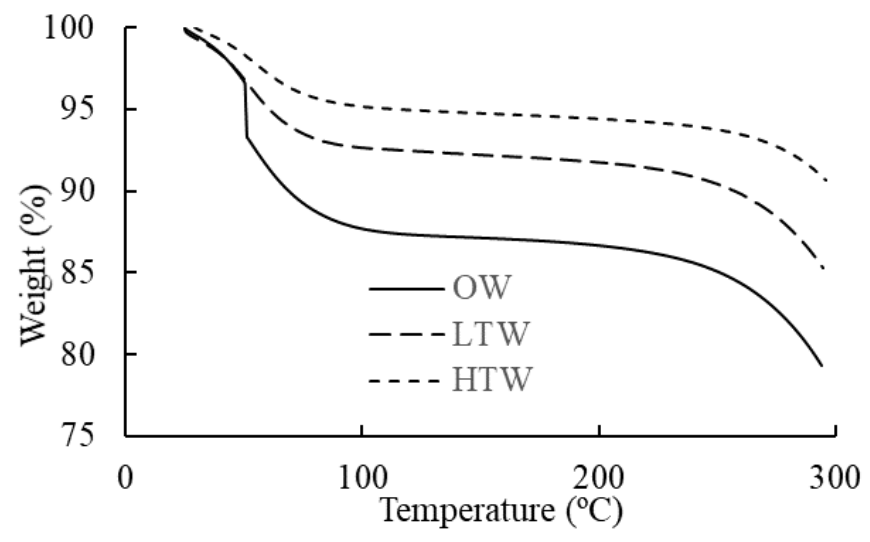

Fig. 3.2. Thermogravimetric analysis on OW, HTW, and LTW

Fourier transform infrared spectroscopy (FTIR) test was conducted by using spectrum 100 series spectrometer to study the effect of torrefaction temperature on the components of wood chips by examining the change of functional groups. The spectra were recorded in the range of $650-4000 \mathrm{~cm}^{-1}$ with the resolution of $4 \mathrm{~cm}^{-1}$, and the FTIR curve is shown in Fig. 3.3. The peak at "a" represents O-H group indicating large amounts of hydroxyl groups in wood chips. The peak of O-H group decreases with the increase of torrefaction temperature, and the similar conclusion was obtained by Mei et al. (Mei et al. 2016). This may be attributed to the dehydration of wood chips, and more and more water are removed with the increase of torrefaction temperature (Chen et al. 2015; Chen et al. 2012). The peak at "b" represents $\mathrm{C}-\mathrm{H}$ group indicating the presence of alkanes (Gao et al. 2012), which is attributed to the aliphatic fractions of wax (Shang et al. 2012). With the increase of torrefaction temperature, more and more $\mathrm{C}-\mathrm{H}$ groups are broken (Chen et al. 2012; Mei et al. 2016). The decomposition of wax from wood chips can contribute to its 
strength (Andiç-Çakir et al. 2014), which can be expected to be conducive to the mechanical properties of mortar. The peak at "c" represents $\mathrm{C}=\mathrm{O}$ group indicating the existence of ketones and aldehydes (Gao et al. 2012; Mei et al. 2016), which is due to carboxyl groups in cellulose and hemicellulose (Chen et al. 2015; Shang et al. 2012). For torrefied wood chips, this peak decreases in intensity, which is in good agreement with the previous studies (Chen et al. 2015; Chen et al. 2012). The decrease of this peak may be mainly because some hemicellulose can be decomposed under thermal treatment, as evidenced by TGA test. The peak at " $\mathrm{d}$ " represents $\mathrm{C}=\mathrm{C}$ group indicating aromatic ring skeleton vibrations (Gao et al. 2012). With the increase of torrefaction temperature, the peak increases, which is because torrefaction treatment results in the cleavage of ether bond in lignin and the condensation of lignin by linking carbons directly (Park et al. 2013). Chang et al. conducted FTIR test and concluded that the carbohydrate (mainly hemicellulose) decomposition predominates over lignin decomposition after torrefaction treatment (Chang et al. 2012). In general, FTIR test confirms the decomposition of hemicellulose, lignin, and wax caused by torrefaction, which will be beneficial to the mechanical properties of mortar.

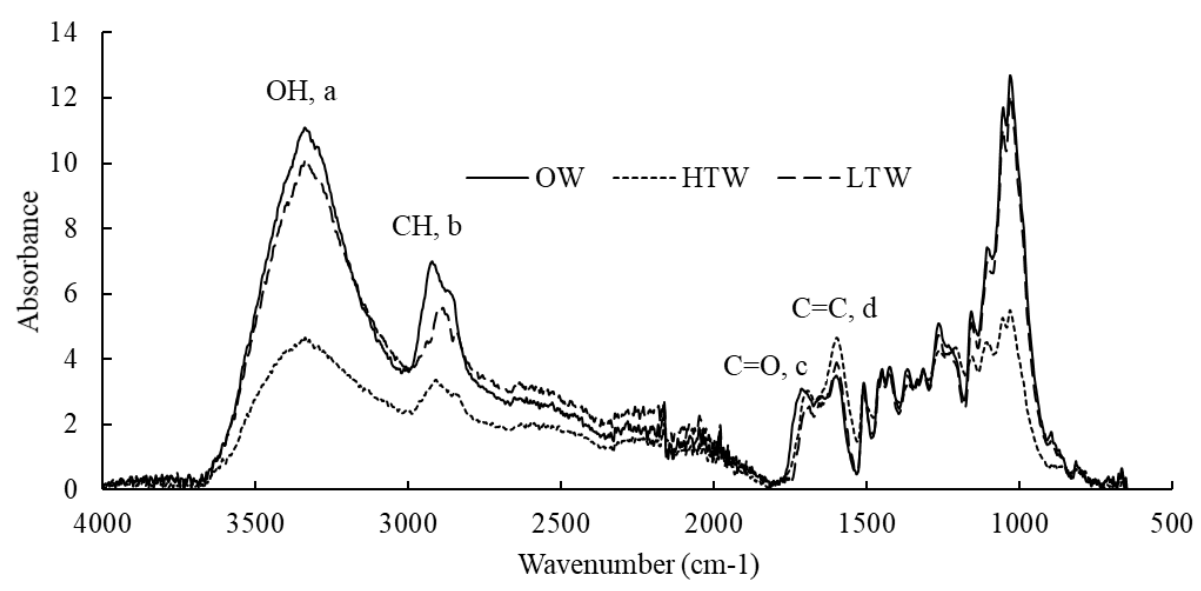

Fig. 3.3. FTIR chart of OW, HTW, and LTW 


\subsubsection{Mortar Sample Preparation}

Ground waste wood chips (shown in section 3.2.1), type I/II Portland cement (see Table 2.2 and

Table 2.3 (Shang and Sun 2019)), silica sand (ASTM C778), and tap water were used. In order to study the feasibility of using the proposed waste wood chips in concrete, wood chips were used to replace $5 \%$ and $10 \%$ of the silica sand (by weight). Seven different samples were made and studied (listed in Table 3.2).

Table 3.2 Prepared mortar samples

\begin{tabular}{lccccc}
\hline \multirow{2}{*}{ Designation } & Wood chip type & \multicolumn{4}{c}{ Mix proportion } \\
\cline { 3 - 6 } & & Water & Cement & Sand & Ground wood \\
\hline Control & - & 0.5 & 1 & 2.25 & - \\
W05 & OW & 0.5 & 1 & 2.1375 & 0.1125 \\
H05 & HTW & 0.5 & 1 & 2.1375 & 0.1125 \\
L05 & LTW & 0.5 & 1 & 2.1375 & 0.1125 \\
W10 & OW & 0.5 & 1 & 2.025 & 0.225 \\
H10 & HTW & 0.5 & 1 & 2.025 & 0.225 \\
L10 & LTW & 0.5 & 1 & 2.025 & 0.225 \\
\hline
\end{tabular}

Two different mixing procedures were used based on the presence of ground wood chips. For plain mortar (without ground wood chips), sand and cement were dry mixed for 1 minute and then water was added to mix for 3 minutes. The mixture was then left alone for 2 minutes, and then continued to mix for another 3minutes. For mortar with ground wood chips, the sand and the wood chips were mixed first for 1 minute; And the cement was added to the mix for another 1 minute. After introducing water to the dry mix, the mixing procedure used for plain mortar was followed. $2 \times 2 \times 2$ in cubes and $1 \times 1 \times 10$ in beams were cast following series of experiments. The specimens were sealed for the first 24 hours and then were demolded. The calculated density, bulk density, and porosity of mortars were shown in Table 3.3. The mortar samples were kept in a moisture room with $100 \%$ humidity and $22^{\circ} \mathrm{C}$ till testing. 
Table 3.3 Basic parameters of mortar samples

\begin{tabular}{lccc}
\hline Designation & $\begin{array}{c}\text { Wet bulk } \\
\text { density }\left(\mathrm{g} / \mathrm{cm}^{3}\right)\end{array}$ & $\begin{array}{c}\text { Calculated } \\
\text { Density }\left(\mathrm{g} / \mathrm{cm}^{3}\right)\end{array}$ & Porosity (\%) \\
\hline Control & 2.23 & 2.25 & 0.9 \\
W05 & 1.78 & 2.21 & 19.28 \\
W10 & 1.72 & 2.16 & 20.44 \\
H05 & 1.98 & 2.20 & 10.14 \\
H10 & 1.86 & 2.16 & 13.83 \\
L05 & 1.99 & 2.20 & 9.69 \\
L10 & 1.93 & 2.16 & 10.59 \\
\hline
\end{tabular}

\subsubsection{Flowability Test}

Flowability test provides information about the workability of mortar. A flow table was used in the test, and the flowability test was conducted according to the procedures specified in ASTM C1437 (ASTMC1437-13). Based on the original base diameter and the diameter of mortar pie after tamping, flowability can be calculated using Eq. (3.1):

$$
F l=\frac{A^{\prime}-A}{A} \times 100 \%
$$

where $F l$ is flowability; $A$ is the original base diameter $(100 \mathrm{~mm}) ; A$ ' is diameter of mortar pie after tamping.

\subsubsection{Mechanical Tests}

\subsubsection{Compressive Test}

A universal testing machine and $2 \times 2 \times 2$ in cubes were used for compressive test. Based on the maximum load $(F)$ obtained from this test, compressive strength is calculated using Eq. (3.2):

$$
\sigma_{c}=\frac{F}{A}
$$

where $\sigma_{c}$ is compressive strength; $F$ is maximum load; $A$ is cross area of a cube $\left(2 \times 2 \mathrm{in}^{2}\right)$. 


\subsubsection{Flexural Test}

Flexural strength is one way to characterize tensile strength. In this study, a universal testing machine and $1 \times 1 \times 10$ in beams were used. A testing configuration can be seen in Fig. 3.4(a). From the flexural test, a typical load-deflection curve can be obtained directly, as shown in Fig. 3.4(b). Based on the maximum load from flexural test, flexural strength is calculated using Eq. (3.3):

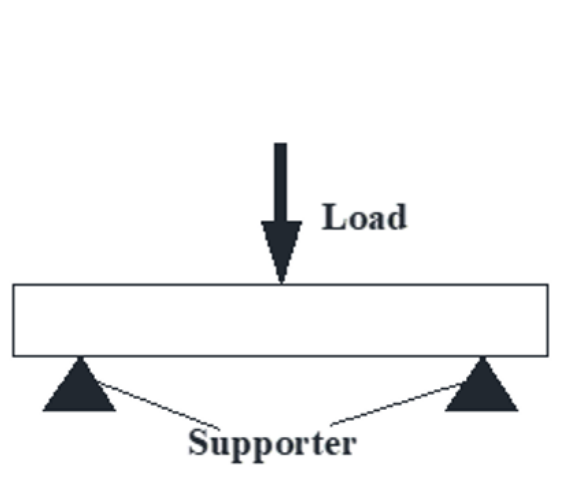

(a)

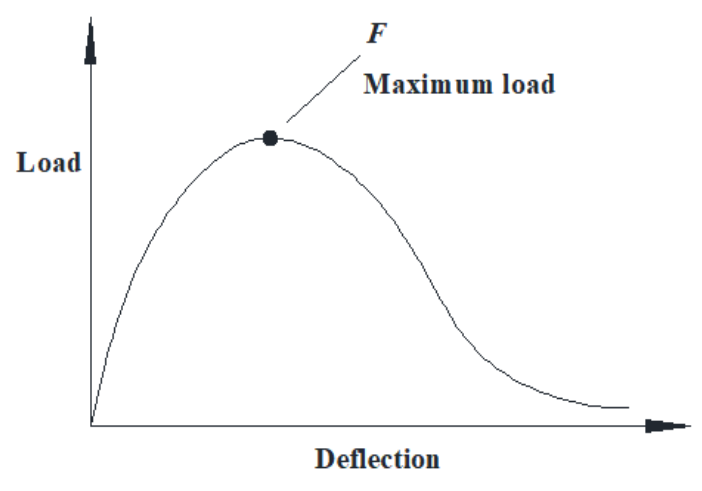

(b)

Fig. 3.4. Testing configuration (a) and typical load-deflection curve (b) of flexural test

$$
\sigma_{f}=\frac{3 F L}{2 b h^{2}}
$$

where $\sigma_{f}$ is flexural strength; $F$ is maximum load; $L$ is length of a beam; $b$ is width of a beam; $h$ is height of a beam.

Based on the load-deflection curve from flexural test, the data baetween $10 \% \mathrm{~F}$ and $40 \% F$ are fitted into a straight line. Then, the slope of the fitted straight line can be obtained, by which the static modulus of elasticity is calculated using Eq. (3.4):

$$
E_{S}=\frac{m l^{3}}{4 b h^{3}}
$$

where $E_{s}$ is static modulus of elasticity; $l$ is length of a beam; $m$ is slope of the fitted straight line; $b$ is width of a beam; $h$ is height of a beam. 
In order to observe energy absorption capacity and the post-peak behavior of the samples, flexural toughness $(F T)$ and toughness index (TI) were further calculated based on the flexural test. $F I$ is defined as the ratio between the absorbed energy during flexural test and area of the broken section, and $T I$ is defined as the ratio between area under the load-deflection curve and area under the curve up to maximum load(Chakraborty et al. 2013; $\mathrm{Li}$ et al. 2006). The area under the load-deflection curve represents the absorbed energy during flexural test.

\subsubsection{Resonance Frequency Test}

$1 \times 1 \times 10$ in beams were used for resonance frequency test to obtain the dynamic modulus of the specimen. This helps to understand the influence of ground wood chips on the elastic behavior of the mortar. The dynamic modulus of elasticity $\left(E_{d}\right)$ can be calculated using Eq. (3.5) (ASTM 2008).

$$
E_{d}=D M n^{2}
$$

where $E_{d}$ is dynamic modulus of elasticity; $M$ is mass of specimen, $\mathrm{kg} ; n$ is fundamental longitudinal resonance frequency, $\mathrm{Hz} ; D$ is $4(L / b t) ; L$ is length of specimen, $\mathrm{m} ; t$ and $b$ are dimensions of cross section of specimen, $\mathrm{m}$.

\subsubsection{SEM Imaging}

Scanning electron microscopy (SEM) is used to study the microstructure of ground wood chips and mortar. VEGA3 provided by TESCAN and NOVA NANOSEM 600 provided by FEI are used for this purpose.

In this study, sputtering was applied to the surfaces of specimens before testing. Mortar specimens with the thickness of $0.5 \mathrm{~mm}$ were prepared. They were first polished by using sand paper and then cleaned by using ultrasonic bath before gold coating. Secondary 
electron detector at $20 \mathrm{kV}$ was used to observe the surfaces of ground wood chips. Secondary electron detector at $5 \mathrm{kV}$ was used to observe the polished surfaces of mortar and mainly examine the area around wood chips, namely the wood chip-matrix interface.

\subsection{Results and Discussions}

\subsubsection{Flowability}

The Flowability of the tested mortars is shown in Table 3.4. Compared to the control sample, mortar with ground wood chips has much lower flowability, especially for those with $10 \%$ replacement level. It was also reported that the addition of natural fibers in mortar can decrease the flowability of mortars; also, the flowability decreases with the increase of fiber content (Chakraborty et al. 2013; Dawood and Ramli 2012). The decrease of flowability in this research is due to the fact that wood chips can absorb some water, resulting in less water available for mortar to flow (Çomak et al. 2018). Another reason may be the irregular particles of wood chips lead to decreased flowability. This experiment indicated that the flowability is acceptable if 5\% sand is replaced with ground wood chips; however, when the replacement level is increased to $10 \%$, admixtures, such as superplasticizer, is needed to achieve the desirable flowability.

Table 3.4 Flowability of mortar

\begin{tabular}{lc}
\hline Designation & Flowability $(\%)$ \\
\hline Control & $130 \pm 2$ \\
W05 & $92 \pm 3$ \\
W10 & $9 \pm 1$ \\
H05 & $86 \pm 1$ \\
H10 & $18 \pm 1$ \\
L05 & $82 \pm 2$ \\
L10 & $8 \pm 1$ \\
\hline
\end{tabular}




\subsubsection{Compressive and Flexural Strength}

The compressive strength and flexural strength of mortars are shown in Fig. 3.5 and Fig. 3.6, respectively. Compared to the control, the compressive strength and flexural strength of all the composite mortars decrease significantly. The decrease of strength in this study may be attributed to the bonding between wood chips and the mortar matrix, which will be clarified in detail in following sections. Similar conclusion was obtained by Gil et al. who attributed the decrease of the compressive strength of mortar to a poor adhesion at the interfacial face (Gil et al. 2017). In general, mortars with HTW or LTW (except for L10) have higher compressive strength and flexural strength than mortars with OW. In this study, several reasons can be responsible for the improvement of mechanical properties: (1) heat treatment can eliminate the organic components, such as the water soluble sugar within fibers (Sellami et al. 2013); (2) thermal treatment can improve the crystallization of cellulose (Wei and Meyer 2014); (3) another possible reason may be the relative smooth surface of OW as compared to HTW or LTW, resulting in weak bonding between wood chips and mortar.

From Fig. 3.5 and Fig. 3.6, it is shown that for mortars with 10\% HTW or OW, the compressive and flexural strengths exhibit comparable or better values than those with 5\%. However, for L10, its compressive strength and flexural strength are both significantly lower than those of L05. The reason may be the occurrence of alkaline hydrolysis, which will generate much saccharides retarding the hydration of cement (Chakraborty et al. 2013; Jo and Chakraborty 2015; Kochova et al. 2017). In case of LTW, the external surface is damaged by torrefaction as confirmed by SEM; in addition, even if all these three kinds of wood chips have the same size range, LTW used in this study has more finer chips than the 
others. This will make LTW more easily contact with alkaline solution and thus is more prone to alkaline hydrolysis, which will deteriorate the strength of mortar by means of affecting the hydration of cement. For L05, because a small amount of LTW is used, the strength of mortar is not largely reduced; for L10, too much LTW reduced the strength significantly.

Also, by comparison, for all the mortars, it's shown that flexural strength decreased around $30-40 \%$, which is less than the reduction amount of compressive strength (around $50-70 \%)$. It can be concluded that the application of ground wood chips in mortar will deteriorate the compressive strength more than flexural strength.

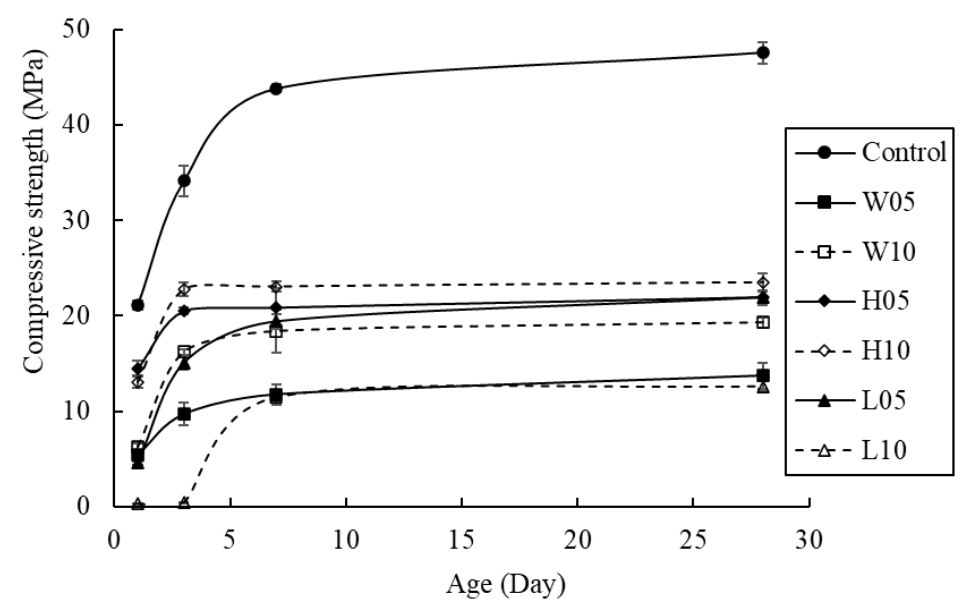

Fig. 3.5. Compressive strength of mortar samples (error bar is from standard deviation, which is applicable to all related figures in this study) 


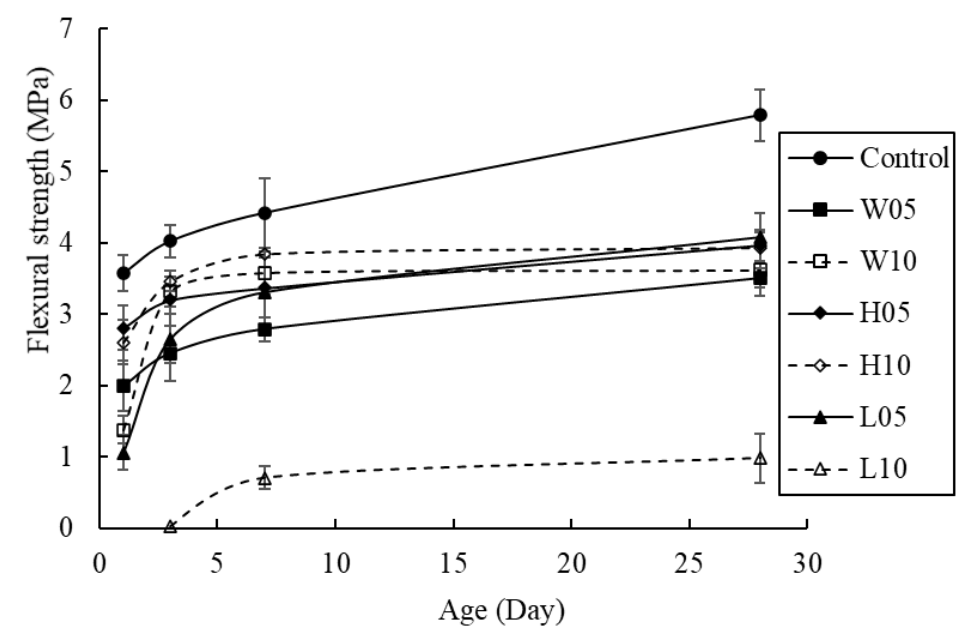

Fig. 3.6. Flexural strength of mortar samples*

*Note: For L10, 1-day beam was very weak and almost has no flexural strength. It's very hard to get 1-day flexural strength accurately. The reason applies to Fig. 3.7 through Fig. 3.10 with missing data.

\subsubsection{Static and Dynamic Modulus of Elasticity}

The static modulus of elasticity and dynamic modulus of elasticity are shown in Fig. 3.7 and Fig. 3.8, respectively. Compared to the control, the static and dynamic modulus of elasticity of mortars with ground wood chips decrease significantly. This is similar to the results reported by other researchers $[3,36]$. In this study, mortars with HTW or LTW (except for L10) have higher static and dynamic modulus than mortar with OW. L05 has good static and dynamic moduli; however, L10 has the lowest static and dynamic modulus. All these results here are consistent with those obtained for strength, and the reasons remain the same.

The relationship between dynamic modulus and static modulus has been investigated by many researchers. Diógenes et al. suggested that the dynamic modulus is usually 20, 30 and 40 percent higher than the static modulus (Diógenes et al. 2011). In this 
study, by comparison, for most cases, the dynamic modulus of elasticity is $30-90 \%$ higher than the static modulus of elasticity.

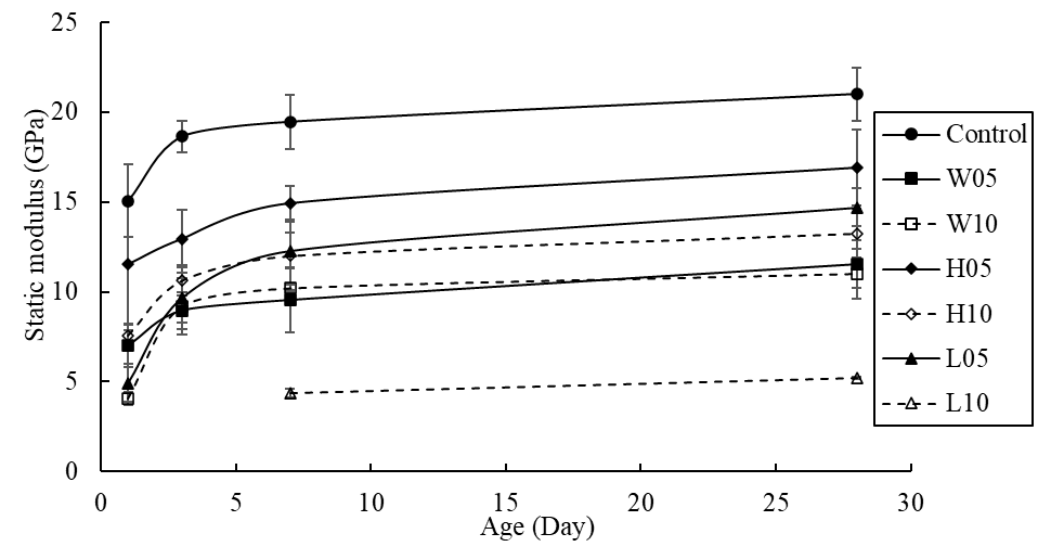

Fig. 3.7. Static modulus of elasticity of mortar samples

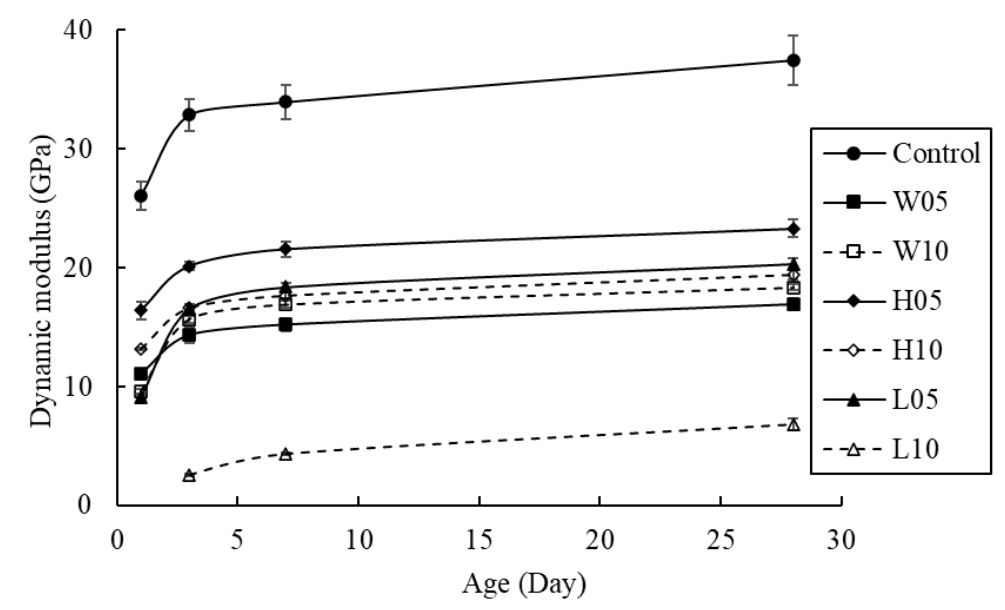

Fig. 3.8. Dynamic modulus of elasticity of mortar samples

\subsubsection{Toughness}

The flexural toughness and toughness index are shown in Fig. 3.9 and Fig. 3.10, respectively. Compared to the reference, mortars with ground wood chips have at least comparable or higher flexural toughness and toughness index, indicating better energy absorption capacity and post-peak behavior. Also, for most cases, toughness index and flexural toughness increase with the increase of ground wood chips. Therefore, mortar will 
be more ductile by using ground wood chips in mortar. This is similar to the findings by Chakraborty et al. and $\mathrm{Li}$, et al. who concluded that flexural toughness and toughness index could be increased with the incorporation of jute fibers or coir fibers in mortar (Chakraborty et al. 2013; Li et al. 2007). The reason may be attributed to the ability of arresting cracks of wood chips at micro- and macro- levels that leads to a more ductile failure mode with higher toughness (Elsaid et al. 2011).

Mortar with OW has higher flexural toughness and toughness index than mortar with HTW or LTW. This may be attributed to much weaker bonding between OW and mortar. In view of this, it is a good practice to use OW rather than HTW or LTW to enhance energy absorption capacity and post-peak behavior at the expense of strength.

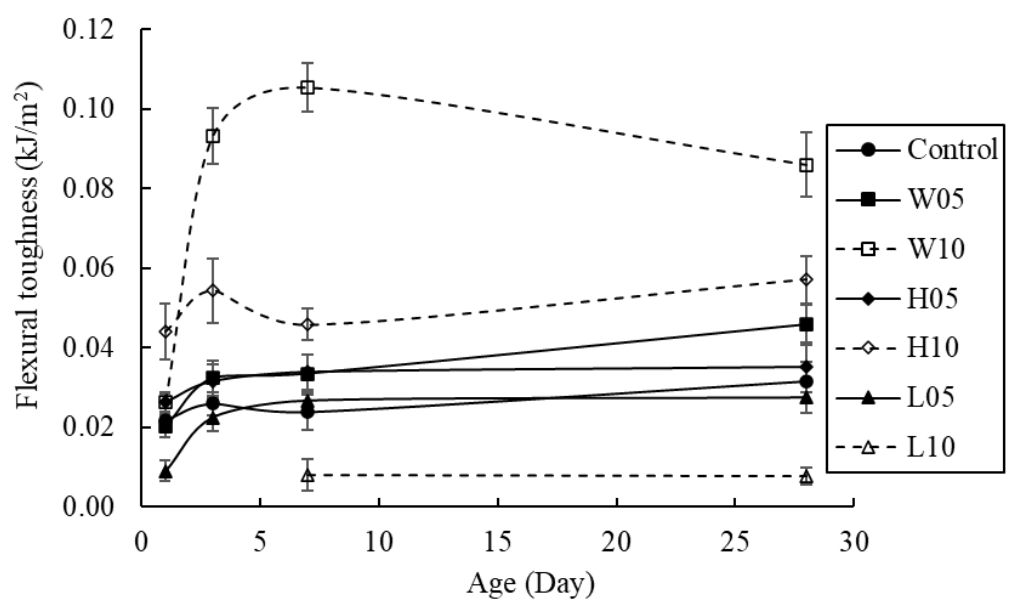

Fig. 3.9. Flexural toughness of mortar samples 




Fig. 3.10. Toughness index of mortar samples

\subsubsection{Microstructure}

The SEM imaging observation of the surface texture of ground wood chips is shown in Fig. 3.11. Fig. 3.11(a) shows that the surface of OW remains intact and seems to be smooth. However, Fig. 3.11(b) and (c) show that the surfaces of HTW and LTW after torrefaction become much rougher. This is attributed to decomposition of some components of OW. It can be confirmed by the results from TGA test that lignin will be decomposed for LTW, and both lignin and hemicellulose will be decomposed for HTW.
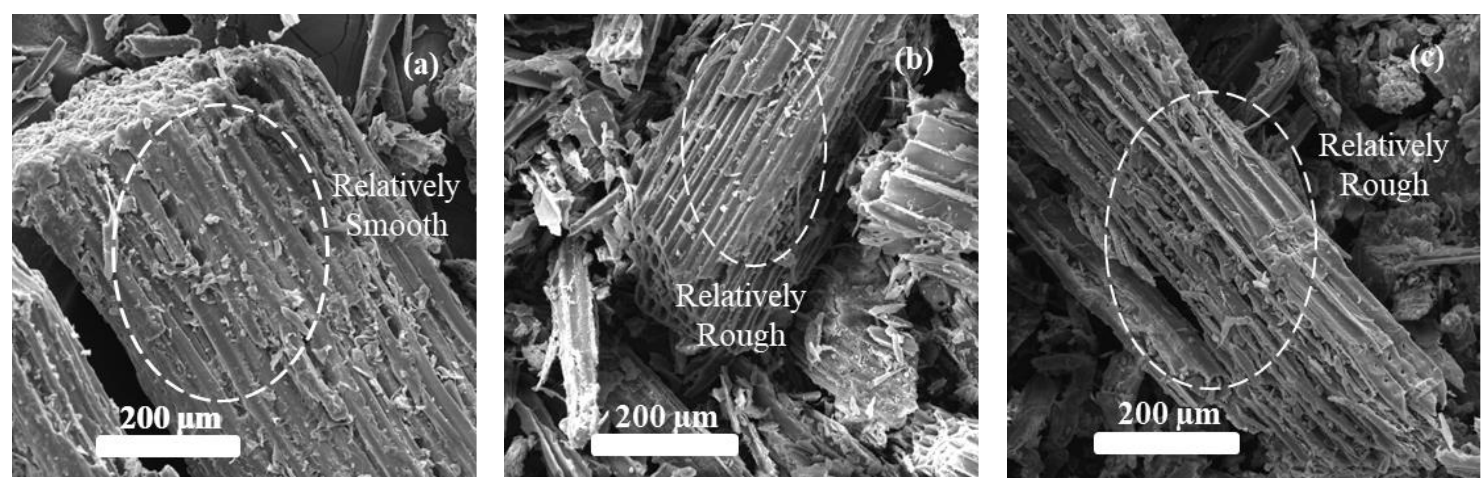

Fig. 3.11. Surface texture of (a) OW; (b) HTW; (c) LTW

The SEM images on mortar with ground wood chips are shown in Figs. 3.12-3.14.

From Fig. 3.12(a), the interface between matrix and OW can be clearly seen; however, 
from Fig. 3.13(a) and Fig. 3.14(a), the matrix and HTW or LTW combines well and the interface is not so clear. This can be attributed to the fact that HTW and LTW have much rougher surface texture than OW, which result in better bonding. That is why the compressive strength, flexural strength, static modulus of elasticity, and dynamic modulus of elasticity of HTW and LTW are higher than those for OW. As reported by Coutts, strong bonding between fiber and matrix results in a brittle material with high strength; however, a weak bonding results in a tough material lacking strength (Coutts and Kightly 1984). Therefore, compared to HTW and LTW, mortar with OW has higher flexural toughness and toughness index.

Some particular areas, marked by red circle, on the interfaces in Figs. 3.12(a), 3.13(a), and 3.14(a) are magnified, as shown in Figs. 3.12(b), 3.13(b), and 3.14(b), correspondingly. From Figs. 3.12(b), 3.13(b), and 3.14(b), it's shown that the interfaces between matrix and wood chips are loose, and even some cracks exist on the interfaces, which will decrease the mechanical properties of mortar. Therefore, the mechanical properties of mortar with ground wood chips become worse as compared to mortar without ground wood chips. But one advantage is that the toughness of mortar with ground wood chips improves. As reported by Toledo that a weak matrix in the vicinity of fiber can yield or crack, which can be favorable to the ductility (Toledo Filho et al. 2000). At micro-level, fibers inhibit the initiation of cracks; at macro-level, fibers provide effective bridging and impart sources of toughness and ductility (Dawood and Ramli 2010). 


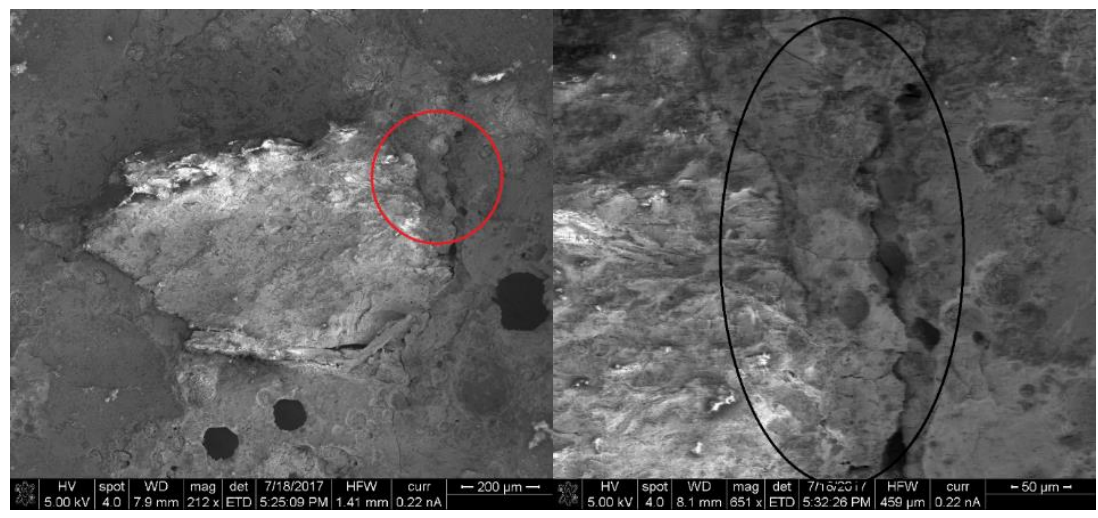

Fig. 3.12. (a) SEM image of mortar with OW; (b) Interface between matrix and OW (marked by black ellipse)

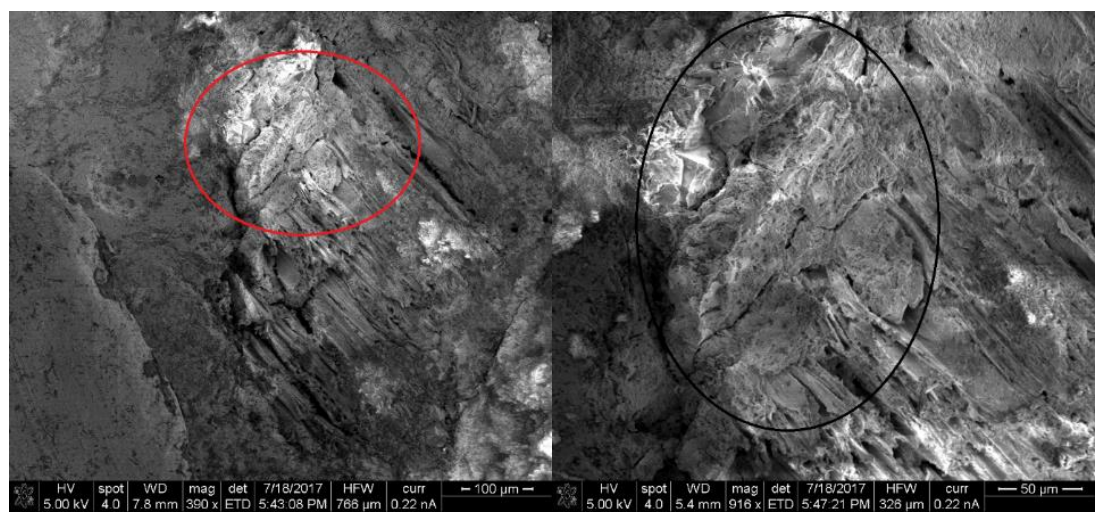

Fig. 3.13. (a) SEM image of mortar with HTW; (b) Interface between matrix and HTW (marked by black ellipse)

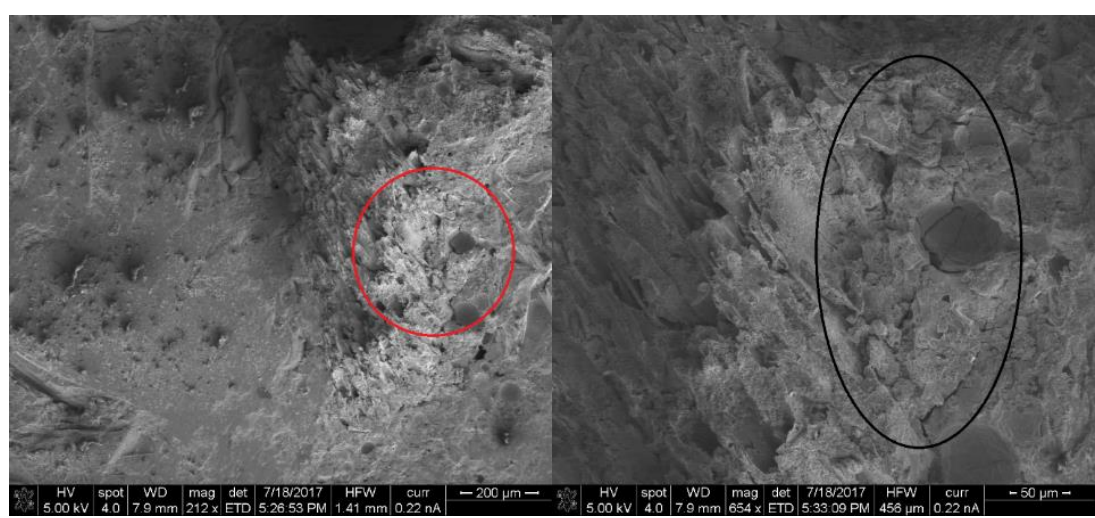

Fig. 3.14. (a) SEM image of mortar with LTW; (b) Interface between matrix and LTW (marked by black ellipse) 


\subsection{Conclusions}

In this study, ground wood chips were used to partially replace sand in mortar. Several important properties including flowability, and mechanical properties, etc. are investigated.

Because wood chips absorb large amounts of water resulting in less water available for mortar to flow, mortar with wood chips has lower flowability as compared to the reference. The flowability is acceptable if $5 \%$ (by weight) sand is replaced with ground wood chips; however, admixtures, such as superplasticizer, is needed to achieve the desirable flowability if $10 \%$ (by weight) sand is replaced.

Compared to the reference, the compressive strength, flexural strength, static modulus of elasticity, and dynamic modulus of elasticity of mortar with ground wood chips decreases significantly. This is due to the weak bonding between ground wood chips and mortar. The SEM study shows that the interfaces between matrix and chips are loose and even some cracks exist on the interfaces, which will deteriorate strength and modulus. However, mortar with ground wood chips has at least comparable or higher flexural toughness and toughness index, indicating better energy absorption capacity and post-peak behavior. This is mainly attributed to the ability of arresting cracks of wood chips at microand macro- levels and loose interfaces between matrix and wood chips.

In addition, mortar with HTW or LTW has better strength and modulus of elasticity than OW. However, mortar with OW has higher flexural toughness and toughness index than HTW or LTW. The SEM test shows that HTW or LTW has rougher surfaces than OW, which will result in good bonding contributing to strength. 
Based on the results in this study, for OW and HTW, the $10 \%$ replacement content can lead to a much higher toughness of mortar than $5 \%$ replacement content while maintaining the strength at the same level; however, for LTW, 5\% replacement content is much better than $10 \%$ replacement content. If the volume fraction of aggregates in concrete is assumed as $60-80 \%$ and the specific gravity of wood chips is approximately assumed as 1 , the $5 \%$ and $10 \%$ replacement contents by weight of sand can be converted roughly into $2.5-5 \%$ and $5-10 \%$ by volume of concrete, respectively. Therefore, $5-10 \%$ by volume of concrete can be the recommended value for OW and HTW, and $2.5-5 \%$ by volume of concrete can be the recommend value for LTW. 


\section{CHAPTER 4 IMPACT OF CHEMICAL TREATMENT ON THE PHYSICOCHEMICAL AND MECHANICAL PROPERTIES OF KENAF FIBERS}

\subsection{Introduction}

From the powders and chips introduced in Chapter 2 and Chapter 3, the next three chapters (Chapter 4, Chapter 5, and Chapter6) switch to address another form of lignocellulosic biomass that has a large length/diameter ratio, which is lignocellulosic fibers. Lignocellulosic fibers are normally used to reinforce cementitious materials, not replace any constituent. Many kinds of lignocellulosic fibers, such as hemp fiber (Awwad et al. 2012), kenaf fiber (Elsaid et al. 2011), and sisal fiber (de Andrade Silva et al. 2010), have been used as potential alternate reinforcement in cementitious materials. Given the availability of kenaf fibers at the Conn Center for Renewable Energy Research at the University of Louisville, in this study, they are selected. This chapter (Chapter 4) mainly focuses on the characterization of kenaf fibers, and the consequent Chapter 5 and Chapter 6 will focus on their application to improve the shrinkage, crack resistance, and flexural properties of cementitious materials.

When kenaf fibers are incorporated into cementitious materials, the common

problems (see Chapter 1) associated with lignocellulosic biomass will appear. In order to better exploit kenaf fibers in cementitious materials, they can be chemically modified prior to the application. Because all the chemical components in cementitious materials are 
inorganic substances, to eliminate the interruption of utilized chemicals, some inorganic chemicals are preferably selected to treat kenaf fibers. In this study, alkali (sodium hydroxide) is firstly used. In addition, many researchers tend to adopt two-stage treatment (alkaline treatment followed by another treatment) to modify lignocellulosic fibers to achieve better results (Goriparthi et al. 2012; Joseph et al. 1996; Li et al. 2009; Mohammed et al. 2017; Nayak and Mohanty 2018). Therefore, in this study, in addition to the solely alkaline treatment, the pretreated kenaf fibers with sodium hydroxide are further treated by some oxidizing agents (potassium permanganate, potassium dichromate, hydrogen peroxide, and sodium chlorite).

After the raw and chemically treated kenaf fibers were prepared well, a series of tests (chemical composition analysis, thermogravimetric analysis, fourier transform infrared spectroscopy analysis, moisture sorption measurement, scanning electron microscopy test, X-ray diffraction test, and single fiber tensile test) were conducted to examine the physicochemical and mechanical properties of kenaf fibers. The purpose of this study is to find out the characteristics of raw and chemically treated kenaf fibers, and eventually by comparing different chemical treatments identify better chemical treatments that can be used to improve the shrinkage, crack resistance, and mechanical properties of kenaf fiber reinforced cementitious materials.

\subsection{Materials and Methods}

\subsubsection{Fiber Preparation}

\subsubsection{Acid Hydrolysis}

Kenaf stalks were obtained from ECOBRIDGE, LLC., Louisville, KY. The bast fibers from the kenaf stalks were separated using an acid retting process. Acid hydrolysis 
by sulfuric acid $\left(\mathrm{H}_{2} \mathrm{SO}_{4}, 95-98 \%\right.$ purity) was adapted for retting of kenaf stalks by using a digester (Manufacturer: M/K systems Inc) (Fonseca et al. 2014). In this process, the utilization content of sulfuric acid is $4 \%$ (by weight) of dry kenaf stalks, and the ratio of kenaf stalks to solution is set to be 1:5 (by weight). The procedure of acid hydrolysis includes three steps: firstly, the reaction temperature was increased from room temperature to $140{ }^{\circ} \mathrm{C}$ in $50 \mathrm{~min}$; then, the reactor was kept at $140{ }^{\circ} \mathrm{C}$ for $1 \mathrm{~h}$; after which the reactor started to cool down. When the temperature of the reactor was low enough, kenaf stalks were taken out of reactor. After acid hydrolysis, kenaf fibers was easily peeled off kenaf cores by hand. These sulfuric acid hydrolyzed kenaf fibers were washed multiple times until neutral and then dried in air for $24 \mathrm{~h}$, followed by $105^{\circ} \mathrm{C}$ for $4 \mathrm{~h}$ in oven, which is referred to as the reference, denoted as RKF.

\subsubsection{Alkaline Treatment}

To further improve the properties of the fibers, these acid hydrolyzed kenaf fibers were treated with alkali. Acid hydrolyzed kenaf fibers were treated by 5\% sodium hydroxide solution ( $\mathrm{NaOH}, 97 \%$ purity, Sigma-Aldrich Corporation) for $1 \mathrm{~h}$ at room temperature, with the $\mathrm{pH}$ slightly higher than $14\left(\left[\mathrm{OH}^{-}\right]\right.$concentration:1.25mol/L). The ratio of kenaf fibers to solution was 1:20 (by weight), which is followed by the following treatments. After treatment, kenaf fibers were washed by distilled water until neutral and then dried in air for $24 \mathrm{~h}$, followed by $105^{\circ} \mathrm{C}$ for $4 \mathrm{~h}$ in oven, which is denoted as AKF.

\subsubsection{Alkaline-Potassium Permanganate Treatment}

Alkaline pretreated kenaf fibers were further treated by $0.02 \%$ of potassium permanganate $\left(\mathrm{KMnO}_{4}, 0.1 \mathrm{~N}, 0.02 \mathrm{M}\right.$, Ricca Chemical Company) for $2 \mathrm{~min}$ at room temperature, with the $\mathrm{pH}$ of 8.98 . After treatment, kenaf fibers were washed by distilled 
water until neutral and then dried in air for $24 \mathrm{~h}$, followed by $105^{\circ} \mathrm{C}$ for $4 \mathrm{~h}$ in oven, which is denoted as APPKF.

\subsubsection{Alkaline-Potassium Dichromate Treatment}

Alkaline pretreated kenaf fibers were further treated by $0.02 \%$ of potassium dichromate $\left(\mathrm{K}_{2} \mathrm{Cr}_{2} \mathrm{O}_{7}, \geq 99 \%\right.$ purity, Sigma-Aldrich Corporation) for $2 \mathrm{~min}$ at room temperature, with the $\mathrm{pH}$ of 6.33. After treatment, kenaf fibers were washed by distilled water until neutral and then dried in air for $24 \mathrm{~h}$, followed by $105^{\circ} \mathrm{C}$ for $4 \mathrm{~h}$ in oven, which is denoted as APDKF.

\subsubsection{Alkaline-Hydrogen Peroxide Treatment}

Alkaline pretreated kenaf fibers were further treated by $10.8 \mathrm{ml}$ of hydrogen peroxide $\left(\mathrm{H}_{2} \mathrm{O}_{2}, 50 \%\right.$ purity, v/v, Sigma-Aldrich Corporation) for $100 \mathrm{ml}$ of solution for $2 \mathrm{~h}$ at $85^{\circ} \mathrm{C}$, with the $\mathrm{pH}$ of 6.5 . After treatment, kenaf fibers were washed by distilled water until neutral and then dried in air for $24 \mathrm{~h}$, followed by $105^{\circ} \mathrm{C}$ for $4 \mathrm{~h}$ in oven, which is denoted as AHPKF.

\subsubsection{Alkaline-Sodium Chlorite Treatment}

Alkaline pretreated kenaf fibers were further treated by sodium chlorite $\left(\mathrm{NaClO}_{2}\right.$, $77.5 \%-82.5 \%$ purity, VWR Company, sodium chlorite : water $=1: 25$,) for $2 \mathrm{~h}$ at $70{ }^{\circ} \mathrm{C}$, with the $\mathrm{pH}$ of 11.10. After treatment, kenaf fibers were washed by distilled water until neutral and then dried in air for $24 \mathrm{~h}$, followed by $105^{\circ} \mathrm{C}$ for $4 \mathrm{~h}$ in oven, which is denoted as ASCKF. 


\subsubsection{Chemical Composition Analysis}

The cellulose, hemicellulose, lignin, and extractives of kenaf fibers were determined by using National Renewable Energy Laboratory (NREL) standard (Sluiter et al. 2008; Sluiter et al. 2005). The test was conducted in two steps.

Firstly, the water and ethanol extractives were analyzed by using Soxhlet method. In this study, 3g kenaf fibers were prepared in Soxhlet apparatus. Firstly, water extraction was conducted for 6 hours, and then ethanol extraction was conducted for 16 hours. The amount of extractives is the sum of water extractives and ethanol extractives.

Then the cellulose, hemicellulose, and lignin were analyzed on the extractives-free kenaf fibers. 300mg extractives-free kenaf fibers were firstly acid hydrolyzed using $3 \mathrm{ml}$ $72 \%$ sulfuric acid for $1 \mathrm{~h}$ at the temperature of $30^{\circ} \mathrm{C}$. Then dilute the sulfuric acid to a $4 \%$ concentration by adding $84 \mathrm{ml}$ deionized water, and the samples were kept at the temperature of $121^{\circ} \mathrm{C}$ for $1 \mathrm{~h}$. Upon the completion of acid hydrolysis, the acid insoluble residues were filtered out and reserved for acid-insoluble lignin determination. The produced hydrolysate was analyzed by High Performance Liquid Chromatography (HPLC) test, based on which the cellulose and hemicellulose of kenaf fibers can be determined.

The lignin of kenaf fibers is comprised of acid-insoluble lignin and acid-soluble lignin, and they are determined by using different methods. The acid-soluble lignin was calculated by using the UV-Vis absorbance of hydrolysate at the wavelength of $240 \mathrm{~nm}$ that was obtained by using UV-visible spectrophotometer. For the determination of acidinsoluble lignin, the reserved acid insoluble residues were firstly dried in an oven at $105 \pm 3{ }^{\circ} \mathrm{C}$ and then the dried acid insoluble residues were kept in a muffle furnace at the 
temperature of $575 \pm 25{ }^{\circ} \mathrm{C}$. The weight difference of the acid insoluble residues at $105 \pm 3{ }^{\circ} \mathrm{C}$ and $575 \pm 25{ }^{\circ} \mathrm{C}$ is simply defined as the amount of acid insoluble lignin.

\subsubsection{Thermo-gravimetric Analysis}

Kenaf fibers were ground into fine particles, and thermo-gravimetric analysis (TGA) was conducted to measure the weight loss of kenaf fibers when temperature varies. The test was performed under nitrogen atmosphere with a flow rate of $40 \mathrm{ml} / \mathrm{min}$ from $25^{\circ} \mathrm{C}$ to $600{ }^{\circ} \mathrm{C}$ at a heating rate of $10^{\circ} \mathrm{C} / \mathrm{min}$. Around $10 \mathrm{mg}$ of fibers was used for each run. The purpose was to study how much hemicellulose, lignin, and cellulose are decomposed with the temperature.

\subsubsection{Fourier Transform Infrared Spectroscopy Analysis}

Kenaf fibers were ground into fine particles for Fourier transform infrared spectroscopy (FTIR) analysis. The FTIR test was conducted by using Spectrum 100 series spectrometer. The spectra were recorded in the range of $650-4000 \mathrm{~cm}^{-1}$ with the resolution of $4 \mathrm{~cm}^{-1}$. The purpose of FTIR test was to observe the change of functional groups, which will help confirm the removal of hemicellulose, lignin, and other impurities of fibers.

\subsubsection{Moisture Sorption Measurement}

Around $0.5 \mathrm{~g}$ of kenaf fibers were dried in an oven at $105^{\circ} \mathrm{C}$ for $4 \mathrm{~h}$, and then the weight of initial dried kenaf fibers was measured and recorded as $W_{0}$. The moisture sorption test was conducted by using Temperature Humidity Chamber produced by Cincinnati SubZero company. Dried kenaf fibers were placed in the humidity chamber with $80 \%$ of relative humidity at $25^{\circ} \mathrm{C}$. After a given period, kenaf fibers were taken out of chamber. Then the weight of wet kenaf fibers was measured and recorded as $W_{t}$. Finally, the percentage of moisture sorption $\left(M_{t}\right)$ was calculated by using eq. (4.1) (Nayak and Mohanty 
2018). This above-mentioned process was repeated until the weight of kenaf fibers reaches to an equilibrium state.

$$
M_{t}=\frac{W_{t}-W_{0}}{W_{0}} \times 100
$$

where, $W_{t}$ is the weight of kenaf fibers after absorbing water; $W_{0}$ is the weight of initial dried kenaf fibers; $M_{t}$ is the percentage of moisture sorption.

\subsubsection{Scanning Electron Microscopy Test}

Scanning electron microscopy (SEM) test was conducted to examine the surface morphology of kenaf fibers. Secondary electron detector at $5 \mathrm{kV}$ was used to observe the change of surface morphology of fibers after treatment. The scanning electron microscope VEGA3 provided by TESCAN was used in this study.

\subsubsection{X-ray Diffraction Test}

X-ray diffraction (XRD) test was conducted to study the crystallinity of fibers, which is characterized by crystallinity index calculated based on peak intensities. The diffraction

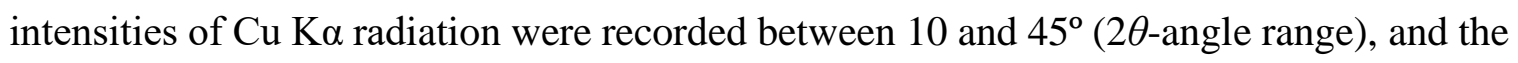
scanning speed is $0.02 \%$. The generator with a current of $40 \mathrm{~mA}$ and a voltage of $40 \mathrm{mV}$ was used. The crystallinity index $\left(I_{c}\right)$ was determined according to the Segal empirical method by using eq. (4.2) below (Mwaikambo and Ansell 2002). The crystallinity index indicates the order of the crystallites rather than the crystallinity of the crystallites. A high crystallinity index indicates the cellulose crystals are better oriented in kenaf fibers and is likely to result in stiff, strong fibers.

$$
I_{c}=\frac{\left(I_{(002)}-I_{(a m)}\right)}{I_{(002)}} \times 100
$$

where $I_{(002)}$ is the counter reading at peak intensity at a $2 \theta$ angle close to $22^{\circ}$ representing crystalline material in kenaf fibers; $I_{(\mathrm{am})}$ is the counter reading at peak intensity at a $2 \theta$ 
angle close to $18^{\circ}$ representing amorphous material in kenaf fibers; $I_{c}$ is the crystallinity index.

\subsubsection{Single Fiber Tensile Test}

Tensile strength of single kenaf fiber was measured according to the ASTM C155714. The test specimen was prepared in three steps: (1) a tab for mounting the specimen in the test machine was prepared from a thick sheet of paper; (2) a slot with the length of $25.4 \mathrm{~mm}$ (equal to the gauge length of the specimen) was cut in the middle of the tab; (3) a single randomly selected kenaf fiber was centered in the slot, with each end taped to the corresponding end of the slot. The dimension of the test specimen was presented in Fig. 4.1. Both sides of the tab were cut at the mid-gauge after mounting in the test machine. This test was conducted by using MTI universal testing systems. The cross-head speed was set to $8 \times 10^{-6} \mathrm{~m} / \mathrm{s}(0.48 \mathrm{~mm} / \mathrm{min})$. Through this test, the maximum force $(F)$ that a single kenaf fiber can bear would be obtained. For each kind of kenaf fibers, a total of 20 specimens were tested, and finally the average maximum force $\left(F_{\text {avg }}\right)$ will be used as representative value.

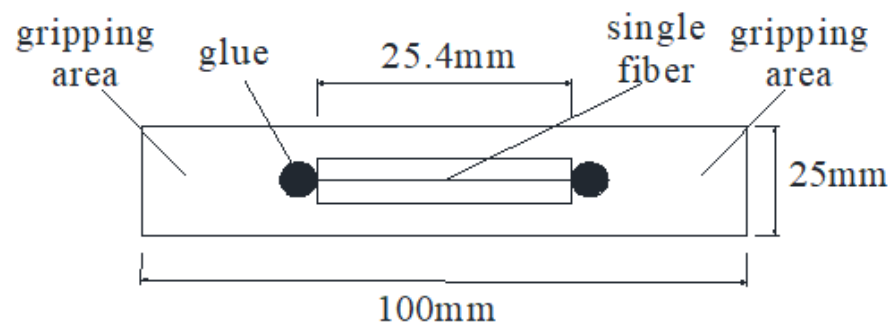

Fig. 4.1. Single fiber tensile test specimen

In this study, single kenaf fibers were assumed to have circular cross sections. The diameter $(d)$ of single kenaf fiber was evaluated by scanning electron microscopy (SEM) test. For each single kenaf fiber, three positions (middle point and both ends) were measured, and the actual diameter of single kenaf fiber was represented by the average 
value. A total of 20 specimens were used for each kind of kenaf fibers (treated with different solutions), and the average diameter $\left(d_{\mathrm{avg}}\right)$ was calculated. Eventually, based on the average maximum force $\left(F_{\mathrm{avg}}\right)$ and diameter $\left(d_{\mathrm{avg}}\right)$ of each kind of kenaf fibers, the tensile strength can be calculated by using eq. (4.3).

$$
f_{k f t}=\frac{4 F_{a v g}}{\pi d_{a v g}^{2}}
$$

where $f_{k f t}$ is the tensile strength of single kenaf fiber; $F_{\text {avg }}$ is the average tensile force of single kenaf fiber; $d_{\text {avg }}$ is the average diameter of single kenaf fiber.

\subsection{Results and Discussions}

\subsubsection{Chemical Composition}

The cellulose, hemicellulose, lignin, and extractives of raw and chemically treated kenaf fibers are shown in the Table 4.1. It's shown that compared to RKF, chemical treatment can remove some hemicellulose, lignin, and extractives, and increase the cellulose content. Kabir et al. showed that most of cellulose is crystalline and can be harder to decompose than hemicellulose and lignin (Kabir et al. 2013). It has been reported that cellulose provides mechanical strength to the fibers, and from the viewpoint of chemical composition, the strength of fibers can be increased with the increasing cellulose content (Petroudy 2017). Therefore, the chemically treated kenaf fibers can possibly have higher strength than RKF because of higher cellulose content. Additionally, when plant fibers are applied to concrete, the hemicellulose and lignin have been reported to delay cement hydration (Jo and Chakraborty 2015; Kochova et al. 2017). The removal of hemicellulose and lignin can mitigate the delaying effect, so chemically treated kenaf fibers are expected to exhibit better than RKF for the application in concrete. 
Table 4.1 also shows that APPKF and APDKF have the similar chemical composition, and AHPKF and ASCKF have the similar chemical composition. Compared to AKF, APPKF and APDKF have slightly increased cellulose content because of the slight removal of hemicellulose, lignin, and extractives. However, AHPKF and ASCKF have much higher cellulose content than AKF, which is believed to attributed to the removal of much lignin and a little hemicellulose. The reason can be attributed to the fact that hydrogen peroxide and sodium chlorite are bleaching chemicals and they can exert delignification on kenaf fibers (Kabir et al. 2012; Mussatto et al. 2008; Siqueira et al. 2013). Of all chemically treated kenaf fibers, AHPKF has the maximum cellulose content, which is believed to result in the strongest fibers among all samples.

Table 4.1 Chemical composition of raw and chemically treated kenaf fibers

\begin{tabular}{lcccc}
\hline Samples & $\begin{array}{c}\text { Cellulose } \\
(\%)\end{array}$ & $\begin{array}{c}\text { Hemicellulose } \\
(\%)\end{array}$ & $\begin{array}{c}\text { Lignin } \\
(\%)\end{array}$ & $\begin{array}{c}\text { Extractives } \\
(\%)\end{array}$ \\
\hline RKF & 56.81 & 13.59 & 18.27 & 7.87 \\
AKF & 65.24 & 10.42 & 15.93 & 6.56 \\
APPKF & 68.77 & 8.94 & 15.18 & 5.16 \\
APDKF & 67.78 & 10.18 & 14.64 & 5.30 \\
AHPKF & 79.30 & 9.69 & 7.22 & 5.59 \\
ASCKF & 75.92 & 9.03 & 8.03 & 6.95 \\
\hline
\end{tabular}

\subsubsection{TGA Analysis}

The TGA and DTGA curves of kenaf fibers are shown in Fig. 4.2. The decomposition of hemicellulose mainly happened at 220-315 ${ }^{\circ} \mathrm{C}$ (Yang et al. 2007). High weight loss is indicative of high hemicellulose content. Compared to the weight loss of RKF (14.62\%), the weight loss $\left(W_{L}\right)$ of AKF, APPKF, APDKF, AHPKF, and ASCKF reduces to $8.42 \%, 7.25 \%, 7.29 \%, 7.87 \%$, and $13.17 \%$ respectively, as shown in Table 4.2. That indicates much hemicellulose is removed from the original fibers after chemical 
treatment. This is evidenced by Fig. 4.2(b), a clear bump disappears for chemically treated fibers compared to RKF. Similar conclusion was obtained by Kabir et al (Kabir et al. 2013). Compared to AKF, the weight loss of APPKF, APDKF, and AHPKF is lower, indicating further chemical treatment results in the removal of more hemicellulose. However, the weight loss of ASCKF is increased compared to that of AKF. This cannot be attributed to the increased hemicellulose content, because the chemical composition analysis of ASCKF indicates that ASCKF have less hemicellulose and more cellulose than AKF. Instead, it could be after the removal of much hemicellulose and lignin that act as a protective layer of fibers, some sodium chlorite crystals lay on the surface of ASCKF and even penetrate into ASCKF, which increase the thermal conductivity of ASCKF and thus reduce its thermal stability.

The cellulose mainly decomposes at $315-400{ }^{\circ} \mathrm{C}$ with the maximum weight loss (Yang et al. 2007). The weight loss $\left(W_{L}\right)$ is shown in Table 4.2. It is shown that the weight loss of AKF (62.12\%), APPKF (65.17\%), APDKF (63.13\%), and AHPKF (63.10\%) is higher than that of $\operatorname{RKF}(52.68 \%)$, which indicates the relative content of cellulose is higher after chemical treatment because of the removal of hemicellulose. Furthermore, compared to solely alkaline treatment, the further chemical treatments by $\mathrm{KMnO}_{4}, \mathrm{~K}_{2} \mathrm{Cr}_{2} \mathrm{O}_{7}$, and $\mathrm{H}_{2} \mathrm{O}_{2}$ will result in much higher cellulose content in kenaf fibers. However, the weight loss of ASCKF (51.29\%) is much reduced compared to that of AKF (62.12\%). The chemical composition analysis indicates that the cellulose content of ASCKF is increased significantly. The reduced weight loss of ASCKF at 315-400 ${ }^{\circ} \mathrm{C}$ maybe because some cellulose has decomposed in advance (at $220-315{ }^{\circ} \mathrm{C}$ ) due to the reduced thermal stability. 
The thermal decomposition of lignin occurs over a wider temperature range than cellulose and hemicellulose, which is because various oxygen functional groups in lignin decompose at different temperatures (Correia et al. 2016; Kabir et al. 2013). Yang reported that the decomposition of lignin happened slowly mainly from 160 to $900{ }^{\circ} \mathrm{C}$, but at a very low mass loss rate (Yang et al. 2007). Therefore, in the process of hemicellulose and cellulose decomposition, the decomposition of lignin also occurs.

Generally, compared to raw kenaf fibers, after alkaline treatment, much hemicellulose and lignin can be removed. Also, compared to solely alkaline treatment, alkali-potassium permanganate treatment, alkali-potassium dichromate treatment, and alkali-hydrogen peroxide treatment can further remove some hemicellulose of kenaf fibers, resulting in higher cellulose content. This is consistent with the chemical composition analysis result.

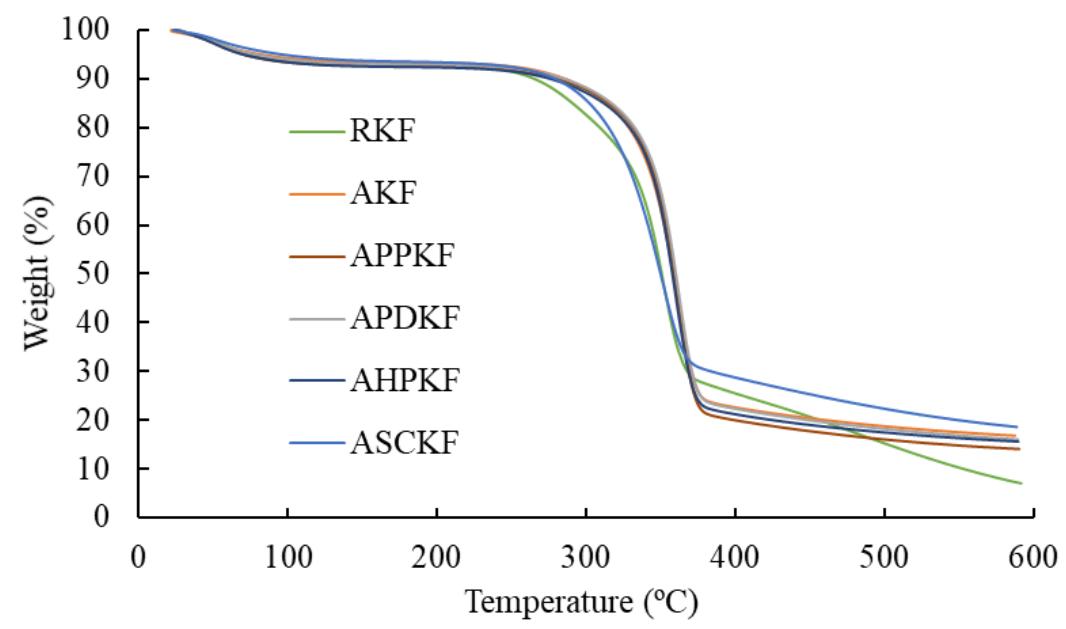

(a) 


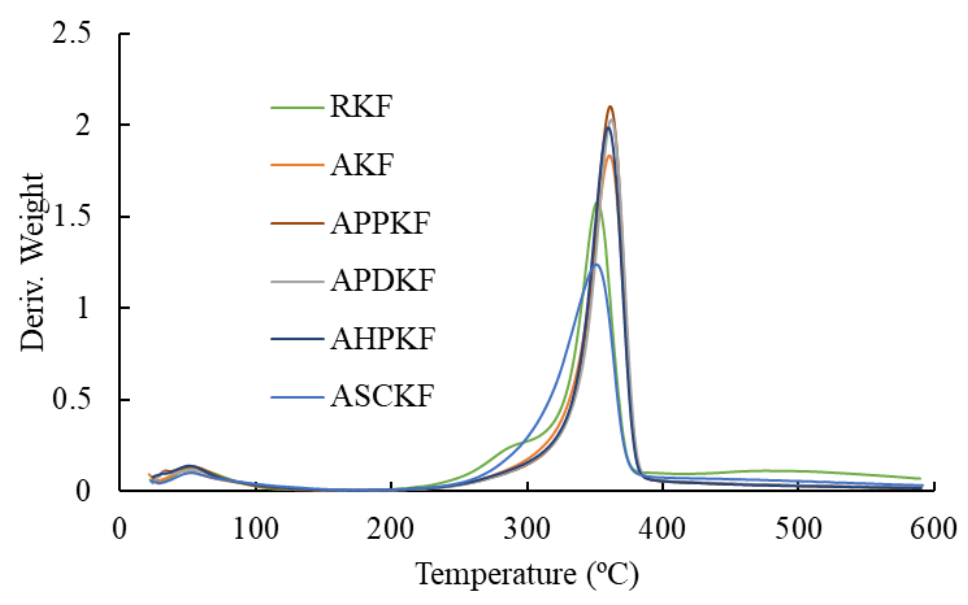

(b)

Fig. 4.2. (a) TGA and (b) DTGA curves of raw and chemically treated kenaf fibers

Table 4.2 Weight loss $\left(W_{L}\right)$ of raw and chemically treated kenaf fibers

\begin{tabular}{lcc}
\hline Sample & $220-315{ }^{\circ} \mathrm{C}\left(W_{L}(\%)\right)$ & $315-400{ }^{\circ} \mathrm{C}\left(W_{L}(\%)\right)$ \\
\hline RKF & 14.62 & 52.68 \\
AKF & 8.42 & 62.12 \\
APPKF & 7.25 & 65.17 \\
APDKF & 7.29 & 63.13 \\
AHPKF & 7.87 & 63.10 \\
ASCKF & 13.17 & 51.29 \\
\hline
\end{tabular}

\subsubsection{FTIR Analysis}

The FTIR spectra of raw and chemically treated kenaf fibers is shown in Fig. 4.3, by which the change in functional groups can be clearly identified. The peak positions and the possible assignments of functional groups for each sample are shown in Table 4.3.

The peak at "a" (between 3600 and $3000 \mathrm{~cm}-1$ ) represents the $\mathrm{O}-\mathrm{H}$ stretching vibration and hydrogen bond of hydroxyl groups assigned to intramolecular or intermolecular hydrogen bonding and free OH hydroxyl (Célino et al. 2013). The peak at "b" (between 3000 and $2500 \mathrm{~cm}^{-1}$ ) represents $\mathrm{C}-\mathrm{H}$ stretching vibration of methyl and methylene groups in cellulose and hemicellulose (Saha et al. 2010). The peak at "c" 
(between 2000 and $\left.1693 \mathrm{~cm}^{-1}\right)$ represents the stretching vibration of carbonyl group $(\mathrm{C}=\mathrm{O})$ indicating the existence of ketones and aldehydes (Gao et al. 2012; Mei et al. 2016). It suggests that this peak is due to carboxylic acid and ester components of hemicellulose (Saha et al. 2010). The peak at "d" (between 1693 and $1607 \mathrm{~cm}^{-1}$ ) is due to absorbed water in fibers (Ray and Sarkar 2001). The peaks at "e" (between 1607 and $1526 \mathrm{~cm}^{-1}$ ) and at "f" (between 1526 and $1486 \mathrm{~cm}^{-1}$ ) are due to $\mathrm{C}=\mathrm{C}$ stretching of aromatic ring of the lignin (Célino et al. 2013; De Rosa et al. 2010; Ray and Sarkar 2001). The peaks at "g” (between 1486 and $1438 \mathrm{~cm}^{-1}$ ) and at "h" (between 1438 and $1395 \mathrm{~cm}-1$ ) are attributed to $\mathrm{CH}_{2}$ bending present in cellulose, hemicellulose, and lignin, etc. (De Rosa et al. 2010; Le Troedec et al. 2008; Ray and Sarkar 2001; Sawpan et al. 2011). The peak at " $i$ " (between 1395 and $1347 \mathrm{~cm}^{-1}$ ) is attributed to CH bending (De Rosa et al. 2010; Le Troedec et al. 2008). The peak at " $\mathrm{j}$ " (between 1347 and $1286 \mathrm{~cm}^{-1}$ ) is attributed to the bending of C-O groups of the aromatic ring in polysaccharides (De Rosa et al. 2010). The peak at "k" (between 1286 and $1184 \mathrm{~cm}^{-1}$ ) is attributed to the $\mathrm{C}-\mathrm{O}$ stretching vibration of acetyl group in hemicellulose and lignin (De Rosa et al. 2010; Sawpan et al. 2011). The peak at "l" (between 1184 and $1140 \mathrm{~cm}^{-1}$ ) is attributed to C-O-C asymmetrical stretching in cellulose and hemicellulose (Le Troedec et al. 2008). The strong peak at "m" (between 1140 and $\left.912 \mathrm{~cm}^{-1}\right)$ is attributed to C-O stretching vibration which belongs to polysaccharide in cellulose (Liu et al. 2009). The peak at " $\mathrm{n}$ " (between 912 and $840 \mathrm{~cm}^{-1}$ ) is attributed to $\beta$ Glucosidic linkage in cellulose (Célino et al. 2013).The peak at "o" (between 840 and 650 cm-1) is attributed to C-OH out-of-plane bending in cellulose (Le Troedec et al. 2008).

Fig. 4.3 shows that compared to RKF, the peaks at "c" and "k" for AKF disappear, which is mostly due to the removal of hemicellulose after alkaline treatment. This is 
consistent with the result obtained by Senthamaraikannan and Kathiresan (Senthamaraikannan and Kathiresan 2018). Furthermore, the chemical composition analysis and TGA result in this study confirm the removal of hemicellulose and lignin. Because much hemicellulose can be removed by sodium hydroxide, these two peaks at "c" and " $\mathrm{k}$ " are also absent for APPKF, APDKF, AHPKF, and ASCKF. By making a comparison between the FTIR spectra of AKF, APPKF, APDKF, AHPKF, and ASCKF, no significant differences are observed except for the change of peak intensity. This indicates that after alkaline pretreatment, the further treatment of potassium permanganate, potassium dichromate, hydrogen peroxide, and sodium chlorite does not introduce or remove any functional groups of kenaf fibers.



Fig. 4.3. FTIR spectra of raw and chemically treated fibers 
Table 4.3 FTIR spectral data for raw and chemically treated kenaf fibers

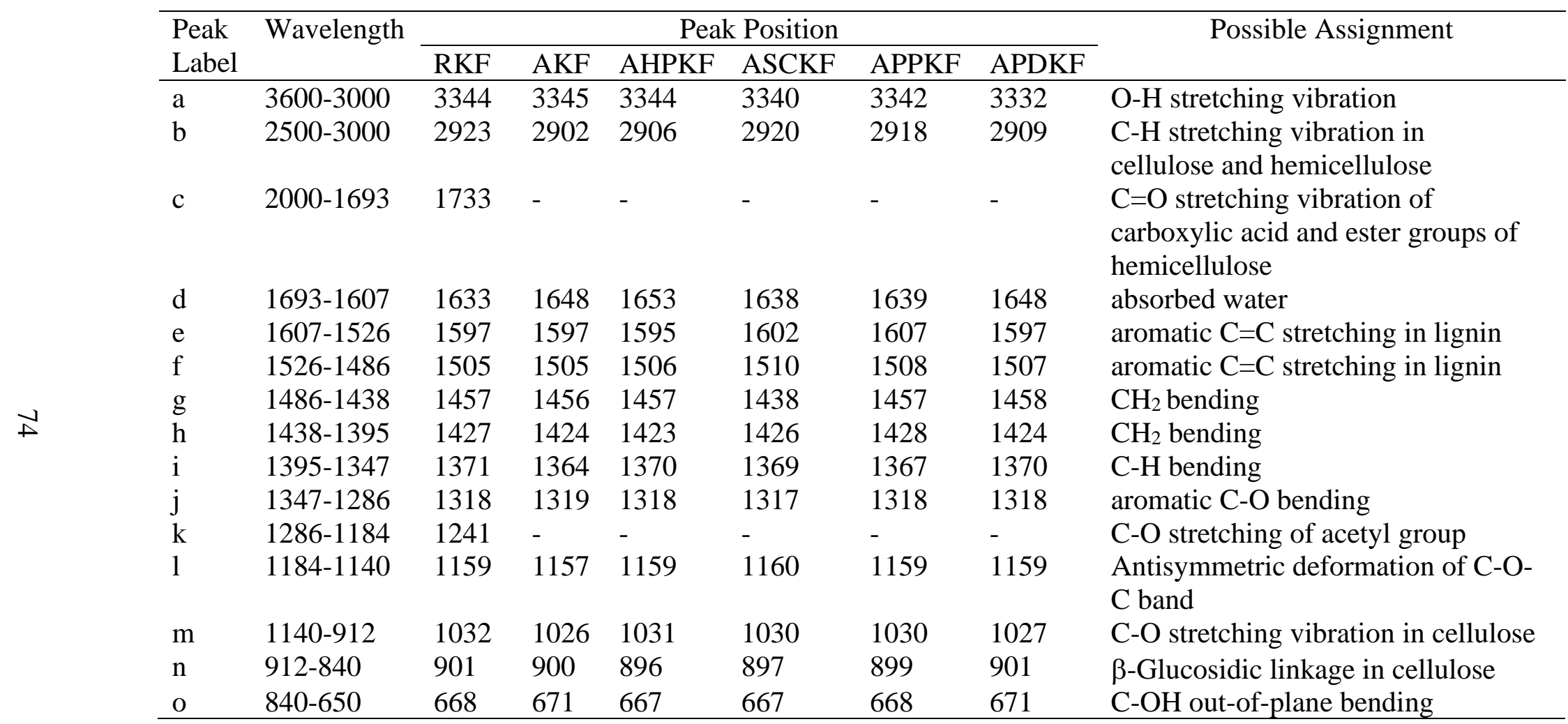

Note: "-" indicates the disappearance of the peak 


\subsubsection{Moisture Sorption Analysis}

Moisture sorption kinetics of raw and chemically treated kenaf fibers is shown in

Fig. 4.4. The weight of kenaf fibers increases with the time up to $480 \mathrm{~min}$ when a relative equilibrium state is reached. The weights of kenaf fibers were recorded at 10, 30, 60, 240, and 480 min after being immersed in the humidity chamber. It is shown that after chemical treatments, the moisture sorption capacity of kenaf fibers decreases, which may be mainly attributed to the chemical and physical changes linked to the removal of cementing materials (Alix et al. 2009). It has been suggested that the hydrophilic nature of plant fibers is mainly attributed to the presence of hemicellulose and cellulose (Correia et al. 2016). Moreover, compared to cellulose, hemicellulose is more hydrophilic and has more capacity to absorb water (Berry and Roderick 2005; Zhang et al. 2011). The removal of hemicellulose and other extractives may lead to the reduced moisture sorption. Pejic et al. also reported that the removal of lignin decreased the moisture sorption of sodium chlorite modified hemp fibers by removing the easily accessible non-cellulosic moisture-absorbing materials (Pejic et al. 2008). In this study, the removal of much hemicellulose, lignin, and extractives after chemical treatment has been confirmed by chemical composition analysis, TGA, and FTIR test, which is believed to be the reason for reducing moisture sorption capacity. The further chemical treatments after alkaline pretreatment seem to reduce the moisture sorption capacity more compared to solely alkaline treatment, with alkalinehydrogen peroxide treatment and alkaline-sodium chlorite treatment reducing the most. 


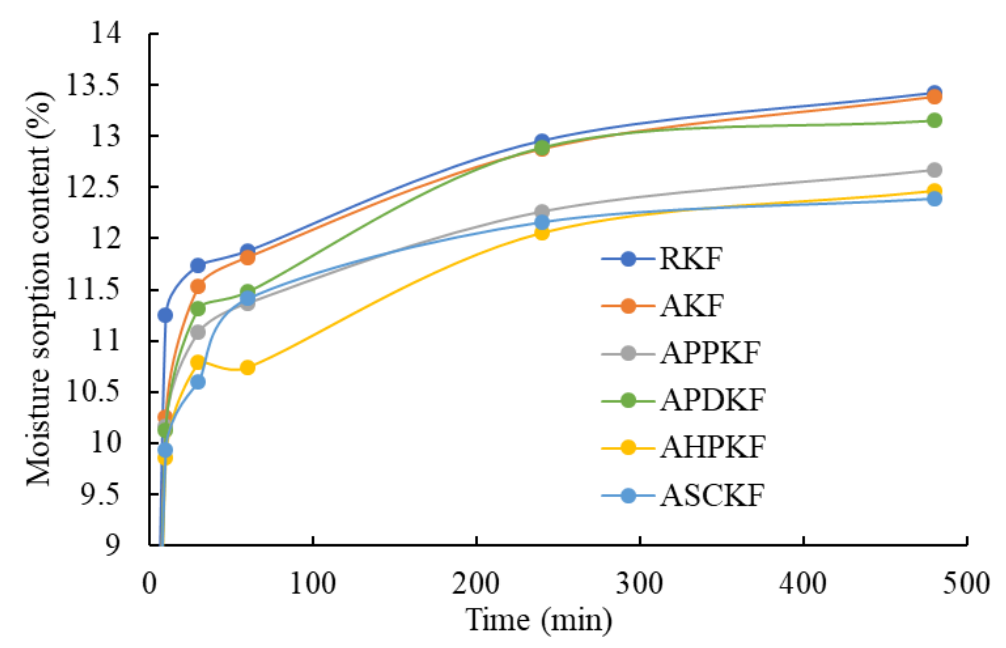

Fig. 4.4. Moisture sorption kinetics of raw and chemically treated kenaf fibers

\subsubsection{SEM Analysis}

The surface morphology of raw and chemically treated kenaf fibers is shown in Fig. 4.5. From Fig. 4.5(a), the raw kenaf fibers (RKF) show smooth and compact surface morphology. It has been reported that the removal of lignin by alkaline treatment is difficult, because lignin has a strong chain of $\mathrm{C}-\mathrm{C}$ bonds and aromatic groups (Lazic et al. 2017). Reddy et al also indicated that hemicellulose is much more sensitive to the action of sodium hydroxide at room temperature than lignin or cellulose (Reddy et al. 2013). Therefore, the removal of hemicellulose is expected to change the surface morphology of kenaf fibers. But from the SEM test, it can be seen that the surface of alkaline treated kenaf fibers (AKF) only seems to be a little bit rougher, not obvious, as shown in Fig. 4.5(b). Moreover, compared to Fig. 4.5(b), even if $\mathrm{KMnO}_{4}, \mathrm{~K}_{2} \mathrm{Cr}_{2} \mathrm{O}_{7}, \mathrm{H}_{2} \mathrm{O}_{2}$, and $\mathrm{NaClO}_{2}$ can further remove the hemicellulose, lignin and extractives after alkaline treatment, they seem not to result in much rougher surface of kenaf fibers. 

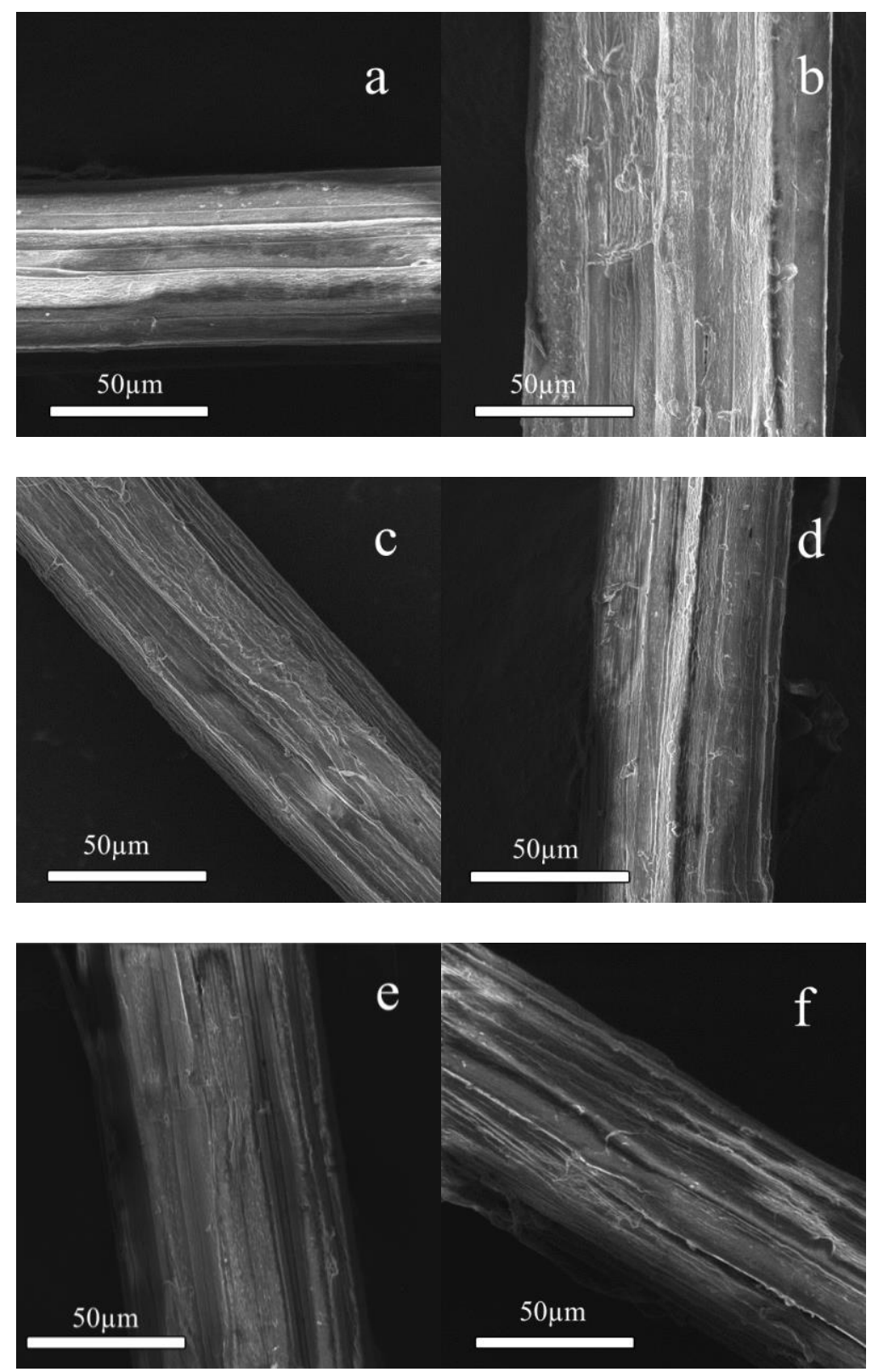

Fig. 4.5. Surface morphology of (a) RKF; (b) AKF; (c) APPKF; (d) APDKF; (e)

$$
\text { AHPKF; (f) ASCKF }
$$

\subsubsection{XRD Analysis}

The XRD curves of raw and chemically treated kenaf fibers are shown in Fig. 4.6. An intense peak at around $2 \theta=22^{\circ}$ for all samples are observed, which corresponds to the crystallinity region of cellulose in kenaf fibers. The intensity of crystalline peak of 
chemically treated kenaf fibers is higher than that of untreated fibers, which indicates a higher degree of crystallinity in the treated fiber as indicated by Razak et al (Razak et al. 2014). A valley is observed at around $2 \theta=18^{\circ}$, which is indicative of amorphous region of cellulose in kenaf fibers.

The crystallinity index is calculated based on Eq. (4.2), and the result is shown in Table 4.4. The crystallinity index characterizes the order of the crystallite packing rather than the intrinsic crystallinity (Mwaikambo and Ansell 2002), and it is useful only on a comparison basis (Beckermann and Pickering 2008). A high crystallinity index is likely to yield stiff, strong fibers. As compared to RKF, the crystallinity index of AKF, APPKF, APDKF, AHPKF, and ASCKF is increased significantly. Similar conclusions were also obtained by many researchers (Le Troedec et al. 2008; Razak et al. 2014; Reddy et al. 2013; Senthamaraikannan and Kathiresan 2018). This is mainly because some hemicellulose, lignin and other impurities are removed after chemical treatment, leading to better packing of cellulose chains. Sinha and Rout indicated that the removal of hemicellulose (normally separating the cellulose chains) will lead to the formation of new hydrogen bonds between certain of the cellulose chains (Sinha and Rout 2009). After chemical treatment, the crystalline regions of cellulose will be rearranged, which leads to a more crystalline nature of fibers (Reddy et al. 2013).

As compared to AKF, the crystallinity index of APDKF, AHPKF, and ASCKF increases. This may be attributed to the fact that after alkaline treatment, the surface of kenaf fibers becomes more reactive for potassium dichromate treatment, hydrogen peroxide treatment, and sodium chlorite treatment, which will lead to the further removal of non-cellulosic substances. On the contrary, the crystallinity index of APPKF is lower 
than that of AKF. This may be because the use of potassium permanganate increases the amorphous cellulose of kenaf fibers. Sawpan et al indicated that the reaction between chemical reagents with cellulose takes place mainly in the amorphous cellulose regions or at the edges of crystalline cellulose regions; the chemical reagents will open the hydrogenbonded cellulose chains by reacting with the chain ends on the surface of crystallites, as they cannot diffuse into crystalline region, which will make cellulose transfer from crystalline to amorphous state; eventually, the reagents will diffuse into this newly produced amorphous cellulose, reacting with the crystalline cellulose and simultaneously generating more amorphous cellulose (Sawpan et al. 2011).

Hydrogen peroxide and sodium chlorite are two kinds of bleaching agents and can be used to remove the lignin of plant fibers. Compared to other treatments, hydrogen peroxide and sodium chlorite treatments can increase the relative content of cellulosic substances by removing much lignin. In this study, the crystallinity indices of AHPKF and ASCKF are higher than other samples. Overall, of all treatments, alkali-hydrogen peroxide treatment exhibits the best in improving the crystallinity index of kenaf fibers.

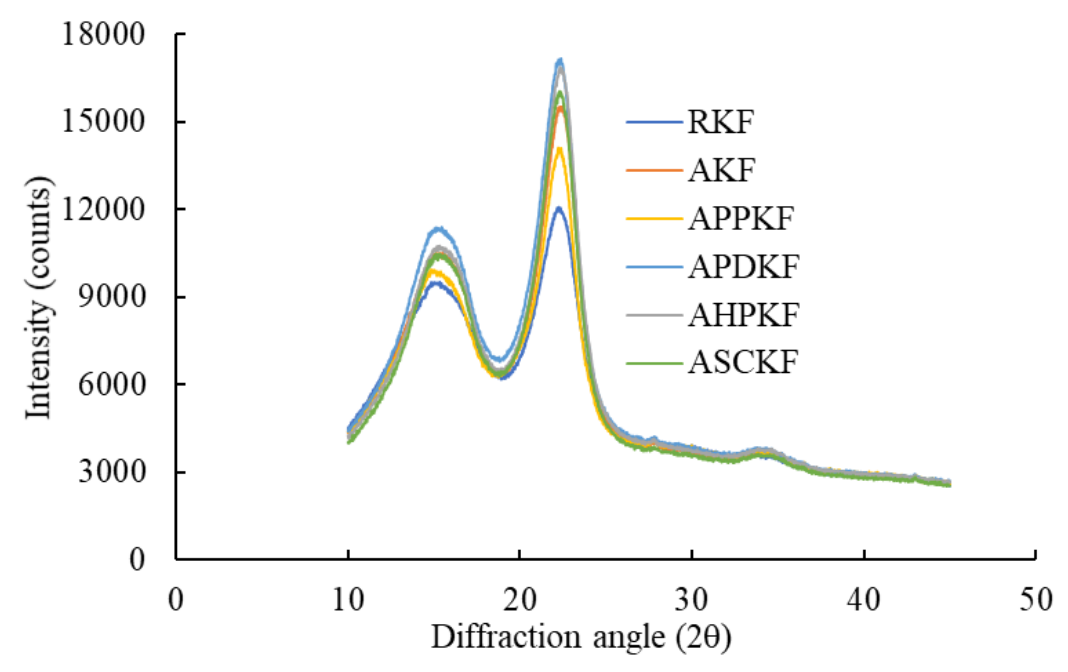

Fig. 4.6. XRD curves of raw and chemically treated kenaf fibers 
Table 4.4 Crystallinity index of raw and chemically treated kenaf fibers

\begin{tabular}{lc}
\hline Sample & Crystallinity index $\left(I_{c}\right)$ \\
\hline RKF & 48.85 \\
AKF & 59.54 \\
APPKF & 55.67 \\
APDKF & 60.50 \\
AHPKF & 61.96 \\
ASCKF & 60.79 \\
\hline
\end{tabular}

\subsubsection{Single Fiber Tensile Test}

The average diameter of raw and chemically treated kenaf fibers is shown in Table 4.5. Because the removal of hemicellulose, lignin, and other impurities, the diameter of chemically treated kenaf fibers is reduced, which indicates that kenaf fibers become much finer after chemical treatment. The diameter reduction after chemical treatment was also reported by Saha et al (Saha et al. 2010). From Table 4.5, it is also shown that alkaline treatment, alkaline-potassium treatment, and alkaline-potassium dichromate do not reduce the diameter significantly; however, for alkaline-hydrogen peroxide treatment and alkaline-sodium chlorite treatment, the diameter is reduced more than the other treatments because of the removal of more lignin. Therefore, of all chemical treatments, alkalinehydrogen peroxide and alkaline-sodium chlorite treatments can result in the finest fibers.

The strength of raw kenaf fiber (RKF) is $423.01 \mathrm{Mpa}$, which is consistent with the result summarized by Mahjoub et al (Mahjoub et al. 2014). In this study, after alkaline treatment, the tensile strength of kenaf fibers is slightly improved. Similar conclusions are obtained by Senthamaraikannan and Kathiresan who reported that $5 \% \mathrm{NaOH}$ treatment slightly improved the tensile strength of fibers (Senthamaraikannan and Kathiresan 2018). This intrinsic reason may be the increased cellulose content and also the increased crystallinity index as a result of the removal of hemicellulose, lignin, and extractives. From 
Table 4.5, it is also concluded that after alkaline pretreatment, the further chemical treatment by other chemicals can improve the tensile strength more. The alkalinepotassium dichromate treatment, alkaline-potassium permanganate treatment, and alkalinesodium chlorite treatment only improve the tensile strength slightly. Alkaline-hydrogen peroxide treatment improves the tensile strength more significantly.

Table 4.5 Tensile strength of raw and chemically treated single kenaf fibers

\begin{tabular}{lccc}
\hline Sample & Diameter $(\mu \mathrm{m})^{*}$ & Tensile force $(\mathrm{N})^{*}$ & Tensile strength $(\mathrm{Mpa})^{*}$ \\
\hline RKF & $83.24 \pm 13.47$ & $2.30 \pm 0.70$ & $423.01 \pm 117.56$ \\
AKF & $79.67 \pm 12.85$ & $2.16 \pm 0.77$ & $433.43 \pm 143.19$ \\
APPKF & $75.30 \pm 11.44$ & $1.89 \pm 0.47$ & $425.00 \pm 95.74$ \\
APDKF & $77.90 \pm 18.72$ & $2.06 \pm 0.61$ & $432.50 \pm 103.03$ \\
AHPKF & $62.99 \pm 11.26$ & $1.57 \pm 0.43$ & $503.02 \pm 121.89$ \\
ASCKF & $65.58 \pm 10.18$ & $1.51 \pm 0.37$ & $447.28 \pm 98.77$ \\
\hline
\end{tabular}

* average value \pm standard deviation

\subsection{Conclusions}

In this study, kenaf fibers were treated by several inorganic chemicals (sodium hydroxide, potassium permanganate, potassium dichromate, hydrogen peroxide, and sodium chlorite) to remove some hemicellulose, lignin, and extractives. After chemical treatment, some hemicellulose, lignin, and extractives of kenaf fibers can be removed, as evidenced by chemical composition analysis, TGA, and FTIR test. Moreover, the reduction in moisture sorption and the improvement in crystallinity index and tensile strength are observed. However, the roughness of surface morphology seems not to be improved significantly after chemical treatment. These chemically treated kenaf fibers are expected to have more potential to improve the crack resistance, durability, and mechanical properties of kenaf fiber reinforced concrete.

Compared to raw kenaf fibers, solely alkaline treatment can always lead to a relatively good result because of the removal of hemicellulose, lignin, and extractives, and 
also the increased crystallinity index. Compared to solely alkaline treatment, alkalinepotassium permanganate and alkaline-dichromate treatments have the similarly slight improvement in these properties of kenaf fibers; however, alkaline-hydrogen peroxide and alkaline-sodium chlorite treatments can lead to similarly significant improvement in these properties of kenaf fibers, with alkaline-hydrogen peroxide treatment exhibiting the best.

Even if solely alkaline treatment is not the best way to improve the properties of kenaf fibers, it seems to be a feasible choice from the point of economy. Compared to solely alkaline treatment, if much more improvement in the properties of kenaf fibers is required, the alkaline-hydrogen peroxide treatment can be a good choice. 


\section{CHAPTER 5 IMPACT OF MODIFIED KENAF FIBERS ON SHRINKAGE AND CRACKING OF CEMENT PASTES}

\subsection{Introduction}

Based on the study in Chapter 4, the process steps and conditions for chemical treatments were found to have great influences on kenaf fiber properties. Compared to raw kenaf fibers, chemical treatments can remove hemicellulose, lignin, and extractives, and also increase crystallinity index, tensile strength, and surface roughness of kenaf fibers, with alkaline-hydrogen peroxide treatment generally exhibiting the best. Besides, solely alkaline treatment can always lead to a relatively good result although it is not the best way to improve the properties of kenaf fibers, which seems to be a feasible choice from the point of economy. Therefore, raw kenaf fibers (RKF), alkaline treated kenaf fibers (AKF), and alkaline-hydrogen peroxide treated kenaf fibers (AHPKF) are preferably selected to be used in cementitious materials for study.

One main advantage of using kenaf fibers in cementitious materials is to control shrinkage and the corresponding cracking. Autogenous shrinkage and drying shrinkage are two important shrinkages of cementitious materials. Autogenous shrinkage is generally defined as the unrestrained bulk deformation of sealed cementitious materials under a constant temperature, without moisture or mass loss (Gao et al. 2014). Similar to autogenous shrinkage, drying shrinkage also occurs due to the loss of water; however, the 
difference lies in that drying shrinkage is mainly caused by external water evaporation (Khairallah 2009). If the autogenous shrinkage and drying shrinkage are restrained by adjunct materials or connected members, some tensile stresses will be developed in cementitious materials (Zhang et al. 2012). When the tensile stress exceeds the tensile strength, the cementitious materials will crack. In this study, the three types of kenaf fibers (RKF, AKF, and AHPKF) with the dosages of $0.25 \%$ and $0.5 \%$ (by weight of cement), respectively, were used to control shrinkage and cracking of cement pastes. Setting time, autogenous shrinkage test, drying shrinkage cracking test, and scanning electron microscopy analysis were conducted on cement pastes with and without kenaf fibers. The purpose of this study is to identify the effects of fiber type and fiber dosage on the autogenous shrinkage and drying shrinkage cracking of cement pastes.

\subsection{Materials and Experiments}

\subsubsection{Kenaf Fiber Preparation}

Kenaf stalks, as shown in Fig. 5.1(a), were obtained from ECOBRIDGE, LLC., Louisville, KY. They were chemically treated and characterized using the procedure introduced in Chapter 4. Based on that study, RKF (Fig. 5.1(b)), AKF (Fig. 5.1(c)), and AHPKF (Fig. 5.1(d)) were selected to be used in cementitious materials for study.








Fig. 5.1. Kenaf: (a) Stalk; (b) RKF; (c) AKF; (d) AHPKF

\subsubsection{Fiber Processing}

Before applying to cementitious materials, some extra work needs to be done with kenaf fibers to assure good dispersion in cementitious composites. In this study, all dry kenaf fibers were firstly cut into $10 \mathrm{~mm}$ in length. Then each 1 gram of dry kenaf fibers were processed for $3 \mathrm{~s}$ by using $200 \mathrm{~W}$ electric grinder from the brand of Kingtop. The agglomerated kenaf fibers were separated by the strong external rotating force. Kenaf fibers before and after processing are shown in Fig. 5.2.



Fig. 5.2. Kenaf fibers before and after processing: (a) RKF; (b) AKF; (c) AHPKF 


\subsubsection{Physicochemical and Mechanical Properties of Kenaf Fibers}

The physicochemical and mechanical properties of RKF, AKF, and AHPKF were studied in the previous study (Guo et al. 2019). The chemical composition, diameter, single fiber tensile strength, crystallinity index, and moisture sorption (under $80 \%$ relative humidity at $25^{\circ} \mathrm{C}$ ) of these fibers are shown in Table 5.1. The results show that RKF has the largest amount of hemicellulose, lignin, and extractives, the highest fiber diameter and moisture sorption, and the lowest cellulose content, crystallinity index, and tensile strength, which is followed by AKF and then AHPKF. In this study, given the low dosages of the fibers (only $0.25 \%$ and $0.5 \%$ by weight of cement), the water absorption of the fibers has a very minor impact on the w/c ratio and thus is not considered. The surface morphology of these fibers is shown in Fig. 5.3. It is shown that compared to RKF, AKF and AHPKF have the similar slightly rougher surface. 
Table 5.1 Physicochemical and mechanical properties of kenaf fibers

\begin{tabular}{|c|c|c|c|c|c|c|c|c|}
\hline \multirow{2}{*}{ Samples } & \multicolumn{4}{|c|}{ Chemical composition } & \multirow[t]{2}{*}{$\begin{array}{l}\text { Diameter } \\
(\mu \mathrm{m})^{*}\end{array}$} & \multirow{2}{*}{$\begin{array}{l}\text { Tensile } \\
\text { strength } \\
(\mathrm{Mpa})^{*}\end{array}$} & \multirow{2}{*}{$\begin{array}{c}\text { Crystallin } \\
\text { ity index } \\
(\%)\end{array}$} & \multirow{2}{*}{$\begin{array}{c}\text { Moisture } \\
\text { sorption } \\
(\%)\end{array}$} \\
\hline & $\begin{array}{c}\text { Cellulose } \\
(\%)\end{array}$ & $\begin{array}{l}\text { Hemicellulose } \\
(\%)\end{array}$ & $\begin{array}{l}\text { Lignin } \\
(\%)\end{array}$ & $\begin{array}{c}\text { Extractives } \\
(\%)\end{array}$ & & & & \\
\hline RKF & 56.81 & 13.59 & 18.27 & 7.87 & $83.24 \pm 13.47$ & $423.01 \pm 117.56$ & 48.85 & 13.42 \\
\hline AKF & 65.24 & 10.42 & 15.93 & 6.56 & $79.67 \pm 12.85$ & $433.43 \pm 143.19$ & 59.54 & 13.39 \\
\hline AHPKF & 79.30 & 9.69 & 7.22 & 5.59 & $62.99 \pm 11.26$ & $503.02 \pm 121.89$ & 61.96 & 12.47 \\
\hline
\end{tabular}






Fig. 5.3. Surface morphology of (a) RKF; (b) AKF; (c) AHPKF

\subsubsection{Sample Preparation}

Cement pastes were prepared by mixing kenaf fibers, type I/II Portland cement, and tap water. The chemical composition and the mineral clinker compounds of cement are shown in Table 2.2 and

Table 2.3 (Shang and Sun 2019). The w/c ratio was chosen as 0.5 in this study based on the ASTM C109. The fiber dosages were $0.25 \%$ and $0.5 \%$ by weight of cement. The mix proportions of cement pastes are listed in Table 5.2.

Two different mixing procedures were used based on the presence of kenaf fibers. For plain cement paste (without kenaf fibers), cement and water were mixed for 3 minutes. The mixture was then left alone for 2 minutes and then continued to mix for another 3minutes. For cement paste with kenaf fibers, firstly, kenaf fibers were gradually added to cement for a dry mix for 2 minutes. And then water was introduced to the dry mix that followed the procedures used for plain cement paste.

Table 5.2 Mix proportion of cement pastes

\begin{tabular}{lcccc}
\hline Sample & Water & $\begin{array}{c}\text { Cement } \\
\text { (Type I/II) }\end{array}$ & $\begin{array}{c}\text { kenaf } \\
\text { fiber }\end{array}$ & Specification \\
\hline Control & 0.5 & 1 & 0 & Cement paste with no kenaf fibers \\
RKF0.25 & 0.5 & 1 & 0.0025 & Cement paste with $0.25 \%$ RKF \\
AKF0.25 & 0.5 & 1 & 0.0025 & Cement paste with $0.25 \%$ AKF \\
\hline
\end{tabular}




\begin{tabular}{lcccc}
\hline AHPKF0.25 & 0.5 & 1 & 0.0025 & Cement paste with 0.25\% AHPKF \\
RKF0.5 & 0.5 & 1 & 0.005 & Cement paste with 0.5\% RKF \\
AKF0.5 & 0.5 & 1 & 0.005 & Cement paste with 0.5\% AKF \\
AHPKF0.5 & 0.5 & 1 & 0.005 & Cement paste with 0.5\% AHPKF \\
\hline
\end{tabular}

\subsubsection{Setting Test on Cement Pastes}

Setting of cement paste is a percolation process in which isolated or weakly bound particles are connected together by the formation of hydration products (Bentz 2008). Setting test was conducted on cement pastes by Vicat test, as specified in ASTM C191 (ASTM 2008). The initial setting time and the final setting time were recorded. For each sample, this test was repeated three times and the average value was adopted.

\subsubsection{Autogenous Shrinkage Test on Cement Pastes}

Autogenous shrinkage test was conducted based on the corrugated tube protocol by using Auto-Shrink system from Germann Instruments (GI) corporation, as shown in Fig. 5.4. The measurement procedure has been specified by ASTM C1698 (ASTM 2014) and also adopted by many researchers (Kawashima and Shah 2011; Liu et al. 2017). During the test, the fresh cement paste was firstly cast into the corrugated tubes and then vibrated on a vibration table to get rid of air inside as much as possible. Moisture loss can be avoided by encapsulating the paste. The stiffness of the corrugated tube in the radial direction is higher than that in the longitudinal direction, so its volumetric deformation can be transformed into linear deformation when cement paste is at a plastic state (Sant et al. 2011). A digital dilatometer was used to measure the linear autogenous deformation and the data was recorded every 10 min automatically starting approximately $30 \mathrm{~min}$ after water addition till 7 days. The room temperature was kept at $25 \pm 2{ }^{\circ} \mathrm{C}$ and the relative humidity was $30 \pm 5 \%$. 




Fig. 5.4. Dilatometer with corrugated mould for linear autogenous strain measurement

The measurement was zeroed to the final setting time, based on which the corresponding autogenous strain can be determined using Eqs. (5.1) and (5.2) (ASTM 2014). In this study, the measured autogenous strain curves for all samples (w/c=0.5) have the similar shapes. Fig. 5.5 gives an example of autogenous strain curve measured for RKF0.25. It is shown that during the 7days of testing, the autogenous strain firstly increases until the maximum value is reached, after which it gradually decreases. However, the measured autogenous strain still remains within the positive region. It should be noted that cement is a multi-phase material. Its hydration is a sophisticated process. Due to the different hydration rates of each clinker phase, volume expansion and shrinkage occurs simultaneously. For example, the quick hydration of $\mathrm{C}_{3} \mathrm{~A}$ contributes greatly to the volume expansion, but with the progress of hydration, the shrinkage caused by the hydration of $\mathrm{C}_{3} \mathrm{~S}$ and $\mathrm{C}_{2} \mathrm{~S}$ gradually take over, so that the volume starts to reduce (e.g. autogenous strain starts to decrease after the peak value). The maximum autogenous strain is a good indication of the material's capacity to overcome shrinkage. Once this peak point is reached, the sample starts to exhibit a shrinkage trend. Shrinkage percentage $(S P)$ is defined based on the maximum autogenous strain using Eq. (5.3) to measure how much the accumulated expansion can be lost after a period of time. A higher $S P$ indicates that the accumulated expansion at early stage is released quickly at later stage. Since the accumulated expansion is beneficial to compensate the shrinkage in the long run, the quick releasing of the 
accumulated expansion represents a high risk of severe autogenous shrinkage in the long run.

$$
\begin{gathered}
L(\mathrm{t})=L_{\mathrm{ref}}+R(\mathrm{t})-2 \cdot L_{\mathrm{plug}} \\
\varepsilon=\frac{L(\mathrm{t})-L\left(\mathrm{t}_{\mathrm{fs}}\right)}{L(\mathrm{t})} \cdot 10^{6}
\end{gathered}
$$

where $L(\mathrm{t})$ is the length of sample at time $t, \mathrm{~mm} ; L_{\text {ref }}$ is the length of reference bar $(425 \pm 0.5 \mathrm{~mm}) ; R(\mathrm{t})$ is the reading of length gauge with specimen in the dilatometer, $\mathrm{mm} ; L_{\mathrm{plug}}$ is the average length of end plugs, $\mathrm{mm}$; $t_{\mathrm{fs}}$ is the final setting time, $\min ; L\left(\mathrm{t}_{\mathrm{fs}}\right)$ is the length of sample at final setting time, $\mathrm{mm} ; \varepsilon$ is the autogenous strain, $\mu \mathrm{m} / \mathrm{m}$.

$$
S P=\frac{\varepsilon_{\mathrm{t}}-\varepsilon_{\max }}{\varepsilon_{\max }} \cdot 100 \%
$$

where $\varepsilon_{t}$ is the autogenous strain at time $t ; \varepsilon_{\max }$ is the maximum autogenous strain; $S P$ is the shrinkage percentage.



Fig. 5.5. Autogenous strain curve for RKF0.25 ( $\mathrm{t}_{\mathrm{fs}}$ : the final setting time; $\mathrm{t}_{\max }$ : the time corresponding to the maximum autogenous strain)

\subsubsection{Drying Shrinkage Cracking Test on Cement Pastes}

Being different from autogenous shrinkage, drying shrinkage is caused by external water evaporation. The cracking on the specimens are caused by the restrains from the steel 
plate when the volume of the paste sample starts to change. The drying shrinkage cracking is considered as one of the most important factors that affect the durability of concrete in the long run. The drying shrinkage cracking test was conducted using the procedure shown below. Firstly, $1 \times 0.5 \times 11.25$ in (Width $\times$ Height $\times$ Length) paste beams were cast, as shown in Fig. 5.6(a). After $20 \mathrm{~min}$ from cement contacted with water, the cast samples were placed in the oven (taken as the time of zero). From then, the samples were checked every 15 min until the first crack appeared on the sample surface, and it was recorded as the initial cracking time. After $2 \mathrm{~h}$, samples were demolded in order to accelerate the water evaporation to promote cracking, as shown in Fig. 5.6(b). The length, width, and depth of each crack on samples were measured using a crack width comparator every $6 \mathrm{~h}$ in the first $12 \mathrm{~h}$ and then every $12 \mathrm{~h}$ until $72 \mathrm{~h}$. It should be noted that 5 width values were recorded along the length of each crack, and the average width was adopted for each crack. Meanwhile, the cracking patterns of all samples were captured using a digital camera and then processed using Matlab Software.

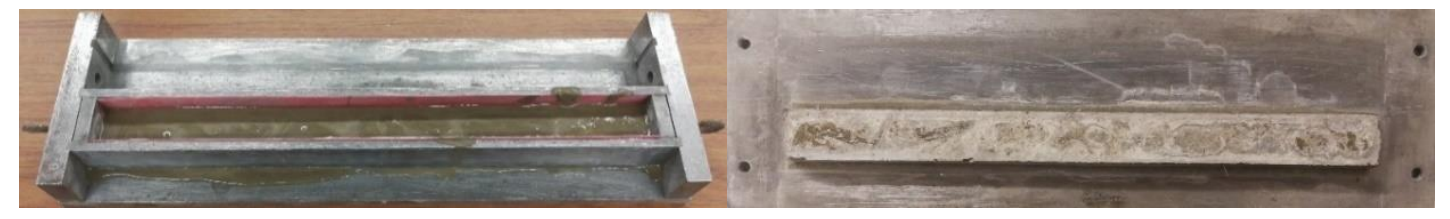

(a)

Fig. 5.6. Sample (a) casting and (b) demolding

Based on the measurement, for each specimen, the initial cracking time $\left(T_{\mathrm{ic}}\right)$ was determined when the specimen firstly cracks; the number of cracks $\left(N_{\mathrm{c}}\right)$ was recorded with testing time; the total cracking length $\left(L_{\mathrm{c}}\right)$ was obtained by summing up the length of each crack; the maximum cracking width $\left(W_{\mathrm{mc}}\right)$ and the maximum cracking depth $\left(D_{\mathrm{mc}}\right)$ were recorded using the maximum values of width and depth, respectively, of all cracks on each 
specimen. The total cracking area $\left(A_{\mathrm{c}}\right)$ of each specimen is calculated as follows. Firstly, for each crack on a specimen, the crack was divided into five parts along its direction, and five width values and corresponding lengths were recorded. The cracking area of each part was obtained by multiplying its width with length, and then the cracking areas of these five parts were summed up to obtain the cracking area of each crack on a specimen. Lastly, the cracking areas of all cracks on a specimen were summed up to obtain the total cracking area on a specimen. Since the drying shrinkage cracking test was repeated three times for each mix proportion, for all parameters used in this study, the average values of three specimens were finally adopted.

\subsubsection{Scanning Electron Microscopy Analysis}

Scanning electron microscopy (SEM) analysis was conducted on the cement pastes with and without kenaf fibers using NOVA NANOSEM $600^{\mathrm{TM}}$ provided by FEI. The specimens with the thickness of $5 \mathrm{~mm}$ were prepared. They were firstly polished by using sandpaper and then cleaned by using ultrasonic bath. Before testing, in order to suppress charging effect, gold sputtering was applied to the surface of the specimen. During testing, the Everhart Thornley detector (ETD) in the secondary electron mode was adopted. The beam current and voltage were $80 \mathrm{pA}$ and $10 \mathrm{kV}$, respectively.

\subsection{Results and Discussions}

\subsubsection{Setting Time}

For all samples, the initial setting time $\left(t_{\mathrm{is}}\right)$ and the final setting time $\left(t_{\mathrm{fs}}\right)$ are listed in Table 5.3. It is shown that in general, the addition of kenaf fibers to cement pastes can lead to slightly increase of the setting time, which indicates that kenaf fibers can delay the setting of cement pastes a little. Several researchers have reported that the delaying effect 
is mainly caused by the hemicellulose, lignin, and extractives of plant fibers (Bilba et al. 2003; Jo and Chakraborty 2015; Vaickelionis and Vaickelioniene 2006). These organic components can delay cement hydration by forming a protective layer around the partially hydrated cement grains or forming a chelate complex with the cations present in the hydrated cement (Jo and Chakraborty 2015). In addition, it was also reported that hemicellulose and lignin are soluble in the alkali solution (John and Anandjiwala 2008; John and Thomas 2008). They can be decomposed into numerous sugars and carboxylic acids when subjected to the alkaline environment of concrete, which can further delay cement hydration (Bilba et al. 2003; Jongvisuttisun and Kurtis 2015; Vaickelionis and Vaickelioniene 2006; Wei and Meyer 2014; Xie et al. 2016).

Of all three types of kenaf fibers, regardless of $0.25 \%$ or $0.5 \%$ fiber dosage, cement pastes with RKF have the longest setting time, which indicates that RKF delays cement hydration the most. This is because RKF has the largest amount of hemicellulose, lignin, and extractives, as shown in Table 5.1. However, by comparing AKF with AHPKF, although AHPKF has less hemicellulose, lignin, and extractives than AKF, AHPKF lead to similar or slightly increased setting time. The reason can be of all three types of kenaf fibers, AHPKF has the least fiber diameter (see Table 5.1), which indicates the largest surface area to contact with cement pastes so that extractives etc. are easily released to delay cement hydration.

Table 5.3 Comparison of initial setting time ( $\left.\mathrm{t}_{\mathrm{is}}\right)$ and final setting time $\left(\mathrm{t}_{\mathrm{fs}}\right)$ of all samples

\begin{tabular}{lcc}
\hline Samples & $t_{\text {is }}(\mathrm{h})^{*}$ & $t_{\mathrm{fs}}(\mathrm{h})^{*}$ \\
\hline Control & $5.14 \pm 0.32$ & $7.08 \pm 0.38$ \\
RKF0.25 & $5.78 \pm 0.59$ & $8.13 \pm 0.60$ \\
AKF0.25 & $5.14 \pm 0.23$ & $7.35 \pm 0.45$ \\
AHPKF0.25 & $5.19 \pm 0.22$ & $7.42 \pm 0.38$ \\
RKF0.5 & $5.78 \pm 0.25$ & $8.25 \pm 0.25$ \\
\hline
\end{tabular}




\begin{tabular}{lll}
\hline AKF0.5 & $4.86 \pm 0.13$ & $7.17 \pm 0.52$ \\
*HPKF0.5 & $5.36 \pm 0.57$ & $7.75 \pm 0.66$ \\
\hline average value \pm standard deviation &
\end{tabular}

\subsubsection{Autogenous Shrinkage Test}

\subsubsection{Autogenous Length Change}

In this study, autogenous length change curves of all samples $(\mathrm{w} / \mathrm{c}=0.5)$ are similar, and take AHPKF0.25 for example, as shown in Fig. 5.7. The curve can be divided into five stages by four critical times $\left(t_{1}, t_{2}, t_{3}\right.$, and $\left.t_{4}\right)$. In stage I $\left(0 \sim t_{1}\right)$, the length of samples decreases significantly; in stage II $\left(t_{1} \sim t_{2}\right)$, the length of samples stops decreasing and remains unchanged; in stage III $\left(t_{2} \sim t_{3}\right)$, the length of samples increases; in stage IV $\left(t_{3} \sim t_{4}\right)$, the length of samples remains unchanged again; and in stage $\mathrm{V}$ (after $t_{4}$ ), the length of samples decreases continuously.

In order to find out the physical meanings of each stage, the four times $t_{1}, t_{2}, t_{3}$, and $t_{4}$ of all samples are summarized in Table 5.4 and then compared with the initial setting time and final setting time listed in Table 5.3. It is shown that the stage II $\left(t_{1} \sim t_{2}\right)$ is in the vicinity of the initial setting, and in stage III $\left(t_{2} \sim t_{3}\right)$, the final setting is reached. Therefore, in the stage I, the samples have not started initial setting yet and are still in the fluid state. The volume decrease in this stage may result from the dissolution and dissipation of cement particles or some intermediate reactions rather than the hydration of $\mathrm{C}_{3} \mathrm{~S}$ or $\mathrm{C}_{3} \mathrm{~A}$ during the dormant period of cement hydration (Bullard et al. 2011; Yang et al. 2017). Since the rigid skeleton has not been developed during the setting period, the shrinkage does not result in tensile stress and is of little significance in early-stage cracking. Around the stage II, the initial setting gradually starts, and more hydration products begin to form. A balance between shrinkage and expansion is reached in this stage. In the stage III, the driving force 
of expansion apparently exceeds that of shrinkage. The expansion phenomenon has been observed for cementitious materials with high w/c ratio by many other researchers (Baroghel-Bouny and Kheirbek 2000; Baroghel-Bouny et al. 2006; Van Bunderen et al. 2019). Baroghel-Bouny et al. reported that the expansion is probably related to the amount and the size of various hydration products $\left(\mathrm{Ca}(\mathrm{OH})_{2}\right.$, inner C-S-H, AFt, etc) (BaroghelBouny et al. 2006). The crystal growth of hydration products can generate a crystallization pressure on the pore wall, which can result in the expansion of the microstructure (Van Bunderen et al. 2019). Another possible mechanism for the expansion can be the reabsorption of external or internal bleeding water (Marušić and Štirmer 2016; Mohr and Hood 2010; Şahmaran et al. 2009). In the stage IV, the final setting has passed for a long time. With cement hydration progresses, the crystal growth gradually slows down and the water re-absorption is gradually completed, so that the driving force of expansion is reduced. Meanwhile, the chemical shrinkage can create some pores in gradually hardened cement pastes to reduce the internal relative humidity, a process known as self-desiccation (Bentz 2008). The self-desiccation can lead to the autogenous shrinkage that balances the expansion. Therefore, the external expansion phenomenon ceases, and a balance between shrinkage and expansion is reached again in this stage. In the stage $\mathrm{V}$, the hydration gradually reaches a steady state, and the formation of hydration products becomes very slowly, so that the driving force of expansion is very small. The self-desiccation gradually exceeds the expansion and is mainly responsible for the shrinkage. 


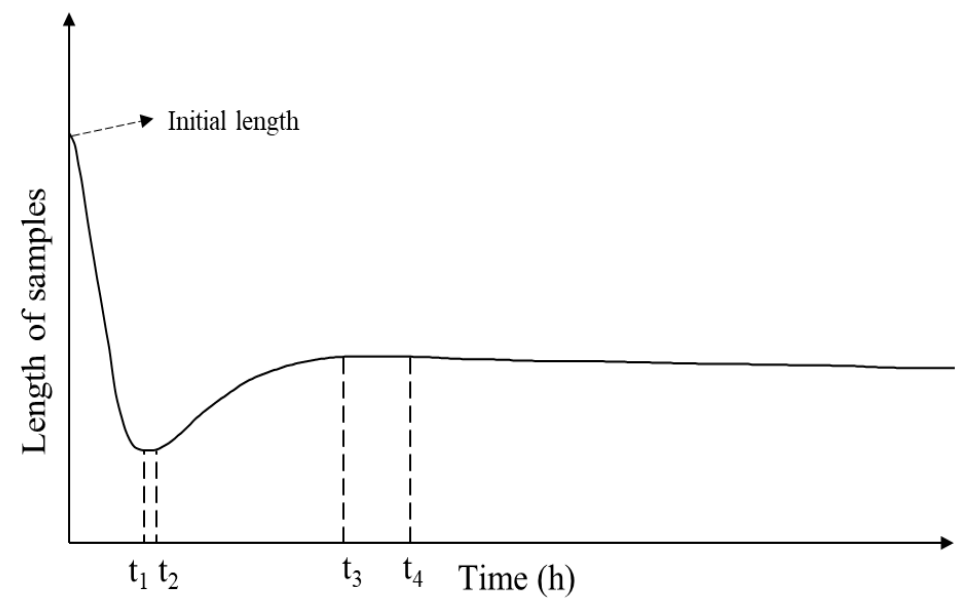

Fig. 5.7. Autogenous length change curve for AHPKF0.25

Table 5.4 The $\mathrm{t}_{1}, \mathrm{t}_{2}, \mathrm{t}_{3}$, and $\mathrm{t}_{4}$ of all samples

\begin{tabular}{lcccc}
\hline Samples & $t_{1}(\mathrm{~h})$ & $t_{2}(\mathrm{~h})$ & $t_{3}(\mathrm{~h})$ & $t_{4}(\mathrm{~h})$ \\
\hline Control & 4.50 & 4.67 & 16.67 & 18.17 \\
RKF0.25 & 6.00 & 6.83 & 29.17 & 31.67 \\
AKF0.25 & 4.83 & 5.67 & 17.33 & 17.67 \\
AHPKF0.25 & 4.50 & 5.00 & 15.33 & 18.83 \\
RKF0.5 & 4.33 & 5.17 & 24.50 & 28.5 \\
AKF0.5 & 3.83 & 4.67 & 15.17 & 21.5 \\
AHPKF0.5 & 4.50 & 5.17 & 23.33 & 23.83 \\
\hline
\end{tabular}

\subsubsection{Autogenous Strain and Shrinkage Percentage}

The autogenous strain is calculated by using Eqs. (5.1) and (5.2), and the obtained autogenous strain curves of all samples are shown in Fig. 5.8. It can be seen that after 7days, the autogenous strain is still positive, which indicates that even though the volume of the specimen starts to reduce after the maximum autogenous strain, the length of the specimen at 7 days is still longer than that at the final setting. However, it is believed that the autogenous strain will reduce to a negative value if the testing is prolonged. Darquennes et al. reported that this expansion stage (when strain is positive) is significant because it can delay the occurrence of autogenous shrinkage (Darquennes et al. 2011). Moreover, a part 
of autogenous shrinkage can be compensated by the volume expansion in this stage. As mentioned in section 5.3.2.1, the crystal growth of hydration products (e.g. quick hydration of $\mathrm{C}_{3} \mathrm{~A}$ ) or re-absorption of bleeding water can provide the driving force of expansion, and the self-desiccation can provide the driving force of shrinkage. For the pastes without fibers in this study, when the driving force of expansion is more than the driving force of shrinkage, so the expansion can be seen at early stage. For the pastes with fibers, kenaf fibers firstly absorb water and then release water during self-desiccation, which can mitigate self-desiccation and thus reduce the driving force of shrinkage. Moreover, $0.5 \%$ kenaf fibers are more effective in reducing self-desiccation than $0.25 \%$ kenaf fibers. This is what we can see from Fig. $\mathbf{5 . 8}$ that $0.5 \%$ kenaf fibers can increase the expansion obviously. After the maximum strain is reached, the specimens exhibit a shrinkage trend. One reason is due to the slowed crystal growth of hydration products. Another reason is that with the hydration progresses, the pore structure of cement pastes is denser and the relative humidity is lower, so the self-desiccation is becoming more aggravating. Meanwhile, with more and more water is drained from kenaf fibers, the water supply ability of kenaf fibers to reduce the self-desiccation and thus the driving force of shrinkage is decreasing. Therefore, the influence of kenaf fibers on expansion is even more significant than on shrinkage.

Fig. 5.8 also shows that the autogenous strain curves include ascending and descending parts, which indicates that after final setting, the degree of expansion of cement pastes increases until the maximum autogenous strain is reached. The maximum expansion corresponding to the peaks in Fig. $\mathbf{5 . 8}$ is taken as the reference, after which the specimens exhibit a shrinkage trend (as shown by the descending part of curves). This descending part 
of curves is mainly dominated by the self-desiccation and the crystal growth of hydration products. Assuming a linear line is drawn using the two points corresponding to the maximum strain and the strain at 7 days, the slope of the control specimen is -1.65 $\mu \mathrm{m} /(\mathrm{m} \cdot \mathrm{h})$; however, the slope of specimens with $0.25 \%$ and $0.5 \%$ kenaf fibers varies from -1.33 to $-1.20 \mu \mathrm{m} /(\mathrm{m} \cdot \mathrm{h})$ and from -1.28 to $-1.17 \mu \mathrm{m} /(\mathrm{m} \cdot \mathrm{h})$, respectively. These descending parts of strain curves have similar slopes although a slight difference exists. This can be due to the fact that in this stage, the effect of fibers on the above mentioned two factors (self-desiccation and crystal growth) is not so significant. This may not indicate that the influence of fibers on autogenous shrinkage is almost the same. In this study, different fibers can lead to different autogenous strain values, implying different autogenous shrinkage potentials.

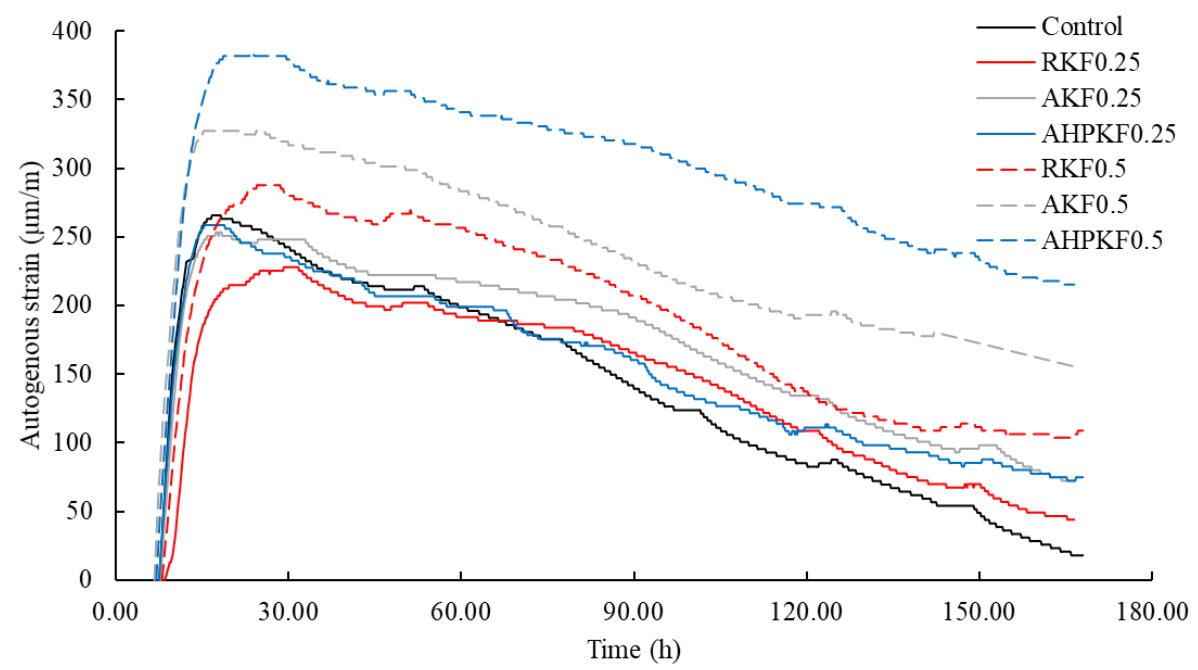

Fig. 5.8. The autogenous strain curves of all samples

Based on Fig. 5.8, the maximum autogenous strains $\left(\varepsilon_{\max }\right)$ and shrinkage percentages $(S P)$ of all samples are recorded and listed in Table 5.5. It is believed that cement pastes with a larger maximum autogenous strain have more capacity to compensate 
the shrinkage in the long run. Moreover, a lower $S P$ is indicative of a lower autogenous shrinkage.

Table 5.5 The maximum autogenous strain $\left(\varepsilon_{\max }\right)$ and shrinkage percentage (SP) of all samples

\begin{tabular}{lcc}
\hline Samples & $\varepsilon_{\max }(\mu \mathrm{m} / \mathrm{m})$ & $S P(\%)$ \\
\hline Control & 265.75 & 93.20 \\
RKF0.25 & 227.90 & 79.55 \\
AKF0.25 & 253.32 & 71.43 \\
AHPKF0.25 & 258.52 & 70.99 \\
RKF0.5 & 287.64 & 62.16 \\
AKF0.5 & 327.01 & 52.91 \\
AHPKF0.5 & 384.22 & 43.99 \\
\hline
\end{tabular}

\subsubsection{The Effect of Fiber Dosage on Autogenous Shrinkage}

Table 5.5 shows that compared to the control, $0.25 \%$ RKF leads to less $\varepsilon_{\max }$ and $0.25 \%$ AKF or $0.25 \%$ AHPKF leads to similar $\varepsilon_{\max }$. The reason can be $0.25 \%$ kenaf fibers have the slight delaying effect on cement hydration, as discussed in section 5.3.1, which disturbs the crystal growth of hydration products that is responsible for the expansion. Therefore, the expansion phenomenon of cement pastes with $0.25 \%$ kenaf fibers seems to be slightly reduced compared to the control. However, Table 5.5 shows that compared to the control, $0.5 \%$ kenaf fibers can increase $\varepsilon_{\max }$ significantly. The occurrence of expansion phenomenon is the resultant effect of expansion and shrinkage. $0.5 \%$ kenaf fibers have similar delaying effect on cement hydration to $0.25 \%$ kenaf fibers (shown in section 5.3.1), which can possibly lead to the similar disturbing effect on crystal growth of hydration products and thus the similar reduced expansion force. However, $0.5 \%$ kenaf fibers can provide more fibers to restrain the shrinkage of samples than $0.25 \%$ kenaf fibers and thus make the shrinkage less. Therefore, cement pastes with $0.5 \%$ kenaf fibers can exhibit much more expansion than those with $0.25 \%$ kenaf fibers. 
Table 5.5 also shows that compared to the control, regardless of $0.25 \%$ or $0.5 \%$ kenaf fibers, the $S P$ of all samples is reduced. Moreover, cement pastes with $0.5 \%$ kenaf fibers have lower $S P$ than those with $0.25 \%$ kenaf fibers. Therefore, it can be concluded that kenaf fibers can mitigate autogenous shrinkage of cement pastes, with $0.5 \%$ fiber dosage reducing more than $0.25 \%$ fiber dosage. The reason can be more kenaf fibers provide more water for internal curing during self-desiccation that can reduce the capillary tension in the pore solution and thus reduce the autogenous shrinkage (Bentz and Weiss 2011; Jongvisuttisun et al. 2013). The internal curing strategy is effective because the distance that water travels to the surrounding voids is reduced compared to traditional external curing (Kawashima and Shah 2011). In addition, more kenaf fibers can provide the hardened cement pastes with greater shrinkage resistance, resulting in less shrinkage (Saje et al. 2010).

\subsubsection{The Effect of Fiber Type on Autogenous Shrinkage}

Table 5.5 shows that among all three types of kenaf fibers (RKF, AKF, and AHPKF), RKF can lead to the lowest $\varepsilon_{\max }$ and highest $S P$, indicating RKF reduces the autogenous shrinkage the least. One reason can be RKF has the largest delaying effect on cement hydration, as discussed in section 5.3.1, which can exert the most negative effect on the crystal growth of hydration products and thus the expansion. Another reason may be because of the least internal curing efficiency of RKF. Jongvisuttisun indicated that the internal curing efficiency is more related to the physical morphology than chemical composition of fibers (Jongvisuttisun 2014). The removal of hemicellulose and lignin by alkaline treatment can increase cell wall porosity (Mwaikambo and Ansell 2003; Shi et al. 2018), which can alter the moisture 
transportation rate from the lumen and cell wall to the surrounding cement pastes (Jongvisuttisun 2014). The third reason can be that RKF has higher fiber diameter than AKF and AHPKF, as shown in Table 5.1. It was reported that at a given fiber volume fraction, coarser fibers can have smaller surface area and less number of fibers to bond with the cementitious matrix (Banthia and Gupta 2006). In addition, the relatively smoother surface texture of RKF (as shown in Fig. 5.3) can lead to the reduced fiber-matrix bonding, which can reduce the pull-out resistance of fibers from the matrix (Toledo Filho et al. 2009). Therefore, RKF is believed to be not as effective as $\mathrm{AKF}$ and $\mathrm{AHPKF}$ in reducing the autogenous shrinkage of cement pastes.

By comparing AKF and AHPKF, AHPKF can lead to higher $\varepsilon_{\max }$ and lower $S P$ than $\mathrm{AKF}$, indicating better reduction in autogenous shrinkage. Considering AHPKF has the similar or slightly higher delaying effect on cement hydration and also the similar surface texture to AKF, the reason can be AHPKF has much smaller fiber diameters than AKF (see Table 5.1), and also possibly higher internal curing efficiency that needs to be further verified.

\subsubsection{Drying Shrinkage Cracking Test}

\subsubsection{Cracking Pattern}

To check the effect of adding kenaf fibers on the drying shrinkage cracking of cement pastes, the cracking patterns of all samples are firstly examined, as shown in Fig. 5.9. Due to the different restraints along the length and width of the beams, transverse parallel cracks are formed on the surface of samples (Chen and Baker 2004). From the figure, it can be seen that compared to the control (Fig. 5.9(a)), the addition of kenaf fibers can decrease the number of cracks $\left(N_{c}\right)$ on the surface of samples, and also for some samples with fibers, 
some cracks do not extended to the full width of the specimen. This indicates that kenaf fibers can play an important role in controlling shrinkage cracking.

\begin{tabular}{|l|l|l|l|l|l|}
\hline$\# 1$ & & & & & \\
\hline$\# 2$ & & & & & \\
\hline \hline$\# 3$ & & & & & \\
\hline \hline
\end{tabular}

(a)

\begin{tabular}{|l|l|l|l|}
\hline$\# 1$ & & & \\
\hline \hline$\# 2$ & 1 & & \\
\hline \hline$\# 3$ & & & \\
\hline
\end{tabular}

(c)

\begin{tabular}{|l|l|l|}
\hline$\# 1$ & & \\
\hline \hline$\# 2$ & & \\
\hline \hline$\# 3$ & & \\
\hline
\end{tabular}

(e)

\begin{tabular}{|l|l|}
\hline$\# 1$ & \\
\hline \hline$\# 2$ & \\
\hline \hline$\# 3$ & \\
\hline \hline
\end{tabular}

(g)

\begin{tabular}{|l|l|l|l|}
\hline$\# 1$ & & & \\
\hline \hline$\# 2$ & & & \\
\hline \hline$\# 3$ & & & \\
\hline
\end{tabular}

(b)

\begin{tabular}{|l|l|l|l|l|}
\hline$\# 1$ & & & \\
\hline \hline$\# 2$ & & & & \\
\hline \hline$\# 3$ & & & & \\
\hline
\end{tabular}

(d)

\begin{tabular}{|l|l|l|}
\hline$\# 1$ & & \\
\hline \hline$\# 2$ & & \\
\hline \hline$\# 3$ & & \\
\hline
\end{tabular}

(f)

Fig. 5.9. Cracking pattern of (a) Control; (b) RKF0.25; (c) RKF0.5; (d) AKF0.25; (e)

AKF0.5; (f) AHPKF0.25; and (g) AHPKF0.5.

\subsubsection{Cracking Parameters}

The initial cracking time $\left(T_{i c}\right)$ of all samples is summarized in Table 5.6. A longer initial cracking time is indicative of a delayed shrinkage cracking. It should be noted that the $T_{i c}$ of AHPKF0.5 is absent in Table 5.6 because one of the three AHPKF0.5 samples did not crack during the observing window, so that the average initial cracking time cannot be calculated. This in turn indicates $0.5 \%$ of AHPKF fibers are very effective in minimizing cracking in the specimen caused by drying shrinkage. The number of cracks $\left(N_{c}\right)$, the total cracking length $\left(L_{c}\right)$, the total cracking area $\left(A_{c}\right)$, the maximum cracking width $\left(W_{m c}\right)$, and the maximum cracking depth $\left(D_{m c}\right)$ at $72 \mathrm{~h}$ of all samples are also listed in Table 5.6. It 
can be seen that adding fibers, either treated or non-treated, can minimize the crack numbers and reduce crack width, length, areas, and depth effectively.

Table 5.6 The $T_{i c}$ and $N_{c}, L_{c}, A_{c}, W_{m c}$, and $D_{m c}$ at $72 \mathrm{~h}$ of all samples

\begin{tabular}{lcccccc}
\hline Samples & $\begin{array}{c}T_{\mathrm{ic}} \\
(\mathrm{h})\end{array}$ & $N_{c}$ & $L_{c}(\mathrm{~mm})$ & $\begin{array}{c}A_{c} \\
\left(\mathrm{~mm}^{2}\right)\end{array}$ & $\begin{array}{c}W_{m c} \\
(\mathrm{~mm})\end{array}$ & $\begin{array}{c}D_{m c} \\
(\mathrm{~mm})\end{array}$ \\
\hline Control & 1.94 & 3.67 & 84.83 & 41.90 & 0.80 & 12.00 \\
RKF0.25 & 2.33 & 2.33 & 55.17 & 8.15 & 0.32 & 11.83 \\
AKF0.25 & 2.17 & 3.00 & 63.17 & 10.84 & 0.28 & 11.50 \\
AHPKF0.25 & 2.42 & 1.67 & 38.17 & 5.73 & 0.23 & 11.67 \\
RKF0.5 & 2.42 & 2.00 & 42.00 & 2.68 & 0.13 & 11.50 \\
AKF0.5 & 2.50 & 1.67 & 31.83 & 1.55 & 0.07 & 9.17 \\
AHPKF0.5 & - & 0.67 & 15.67 & 0.97 & 0.05 & 8.00 \\
\hline
\end{tabular}

Note: "-" indicates one of the three AHPKF0.5 samples does not crack, and the average initial cracking time cannot be calculated. All values listed in this table are the averages of three samples.

\subsubsection{The Effect of Fiber Dosage on Drying Shrinkage Cracking}

Regardless of the fiber type used, the effect of fiber dosage on drying shrinkage cracking is similar. Using pastes with RKF as examples, and the comparison of the number of cracks $\left(N_{c}\right)$, the total cracking length $\left(L_{c}\right)$, the total cracking area $\left(A_{c}\right)$, the maximum cracking width $\left(W_{m c}\right)$, and the maximum cracking depth $\left(D_{m c}\right)$ is plotted in Fig. 5.10. It shows that the addition of kenaf fibers can not only delay the shrinkage cracking but also reduce the cracking severity significantly. It is noted that in Fig. 5.10(e), all samples have almost equal maximum cracking depths at $72 \mathrm{~h}$, which is due to the fact that after $72 \mathrm{~h}$ of crack propagation, these cracks progressively reach the full depth of the samples. The increased shrinkage cracking resistance by kenaf fibers can be explained in several ways. Firstly, plant-based fibers can reduce tensile stress developed in cementitious materials through reinforcement and internal curing effects and also transfer tensile stress from the matrix to fibers (Jongvisuttisun and Kurtis 2015). Even, after cracking, plant-based fibers 
can bridge cracks and prevent them from developing. In addition, Qi et al. stated that some preferential bleeding channels along fibers can be formed, which supply water to replenish the drying surface and reduce the magnitude of capillary stress and thus reduce the shrinkage cracking (Qi et al. 2003).

Fig. 5.10 also shows that $0.5 \%$ fiber dosage can decrease $N_{\mathfrak{c}}, L_{\mathfrak{c}}, A_{\mathfrak{c}}, W_{\mathrm{mc}}$, and $D_{\mathrm{mc}}$ more than $0.25 \%$ fiber dosage, which indicates that $0.5 \%$ kenaf fibers exhibit better performance than $0.25 \%$ kenaf fibers in controlling shrinkage cracking. Similar conclusions were obtained by some other researchers who suggested that the number of cracks, the total crack area, and the maximum crack width can be reduced with the increase of fiber dosage (Banthia and Gupta 2006; Qi et al. 2003; Soleimani et al. 2013). This can also be seen from the cracking sections as shown in Fig. 5.11. For the control, after cracking, the sample is turned into two individual parts. However, for RKF0.25 and RKF0.5, some kenaf fibers are not broken while cracking and they serve as bridges between two cracked sections by increasing the tensile capacity. Moreover, $0.5 \%$ kenaf fibers (Fig. 5.11(c)) provide more fibers than 0.25\% kenaf fibers (Fig. 5.11(b)) to bridge cracks and thus control shrinkage cracking.

In order to identify the effect of kenaf fibers on controlling shrinkage cracking from the microscopic point of view, the SEM test was conducted on the control, RKF0.25, and RKF0.5, as shown in Fig. 5.12. The cracks on the samples are circled using dashed ellipses. For the control, the individual cracks can connect each other and then develop into major cracks, as shown in Fig. 5.12(a). However, for RKF0.25 and RKF0.5, some cracks stop propagating when they meet with kenaf fibers (see Fig. 5.12(b) and Fig. 5.12(c)). The 
kenaf fibers seem to serve as barriers that can block crack propagation, which can prevent the development of individual cracks into major cracks.

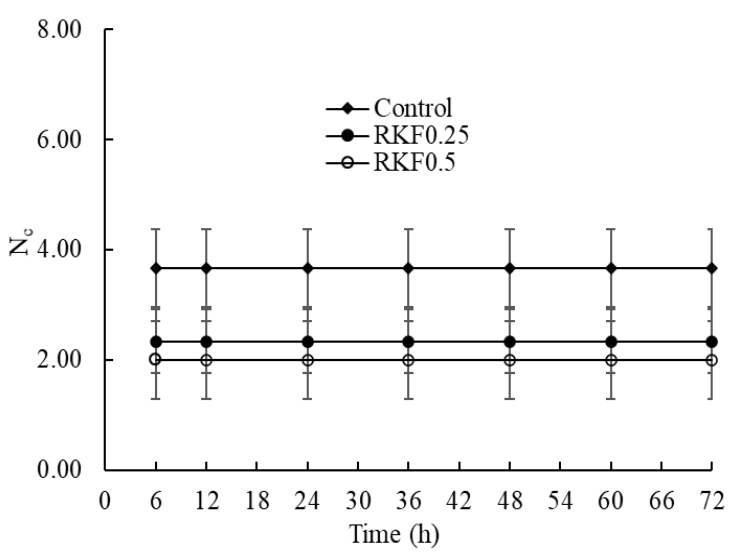

(a)

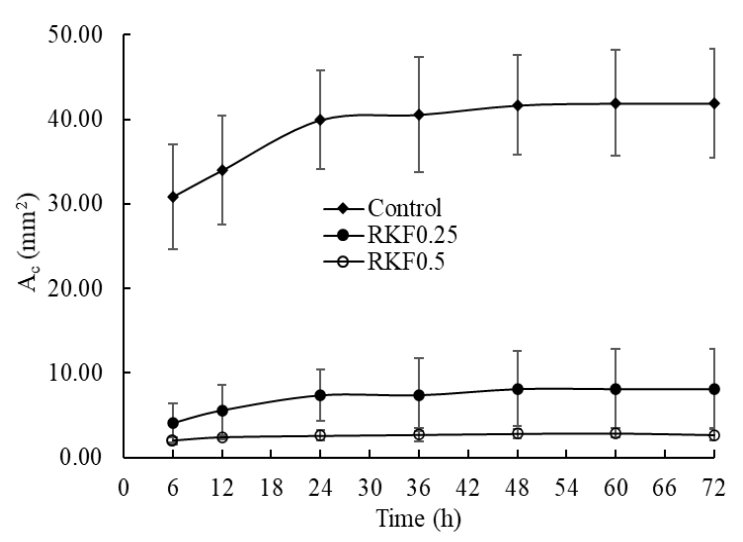

(c)

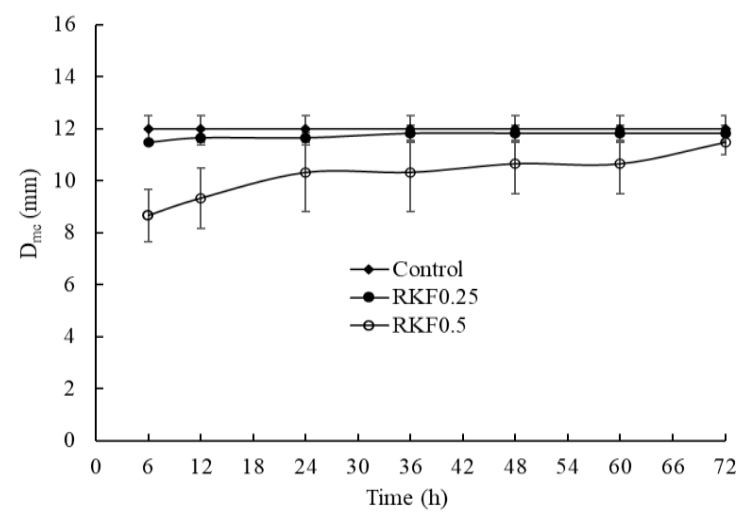

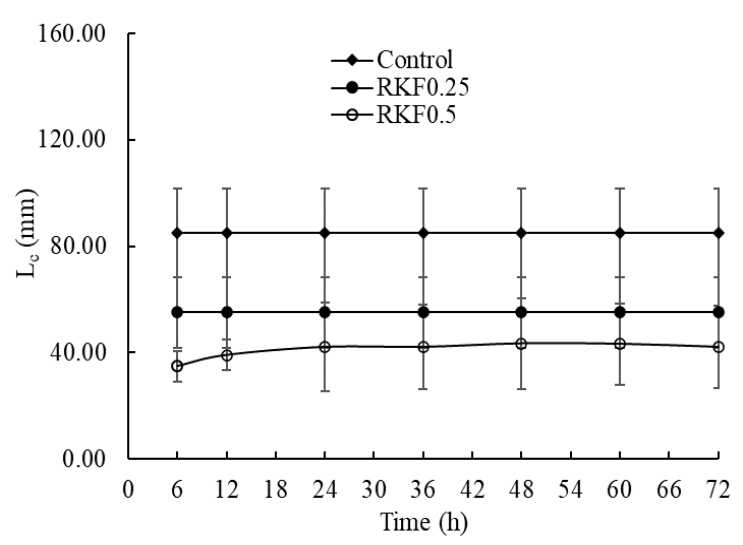

(b)

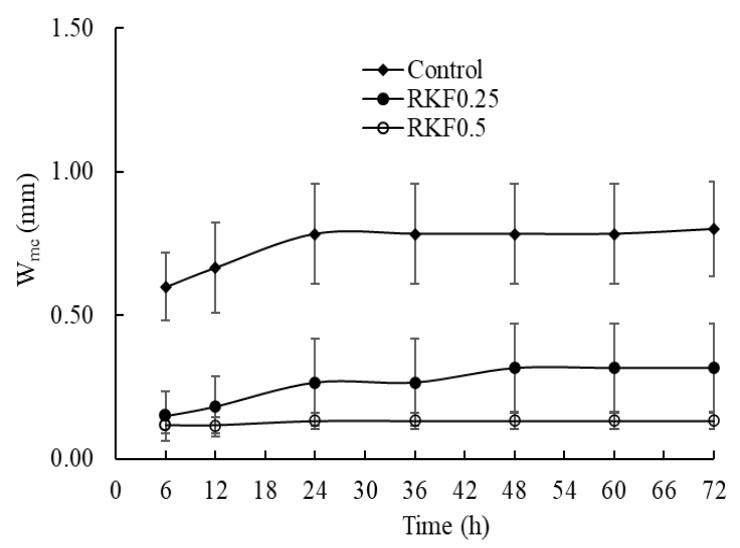

(d) 
(e)

Fig. 5.10. Comparison of (a) $N_{\mathrm{c}}$, (b) $L_{\mathrm{c}}$, (c) $A_{\mathrm{c}}$, (d) $W_{\mathrm{mc}}$ and (e) $D_{\mathrm{mc}}$ for the control, RKF0.25, and RKF0.5 (error bar is from standard deviation, which is applicable to all related figures in this study)



Fig. 5.11. The cracking section of (a) the control, (b) RKF0.25, and (c) RKF0.5

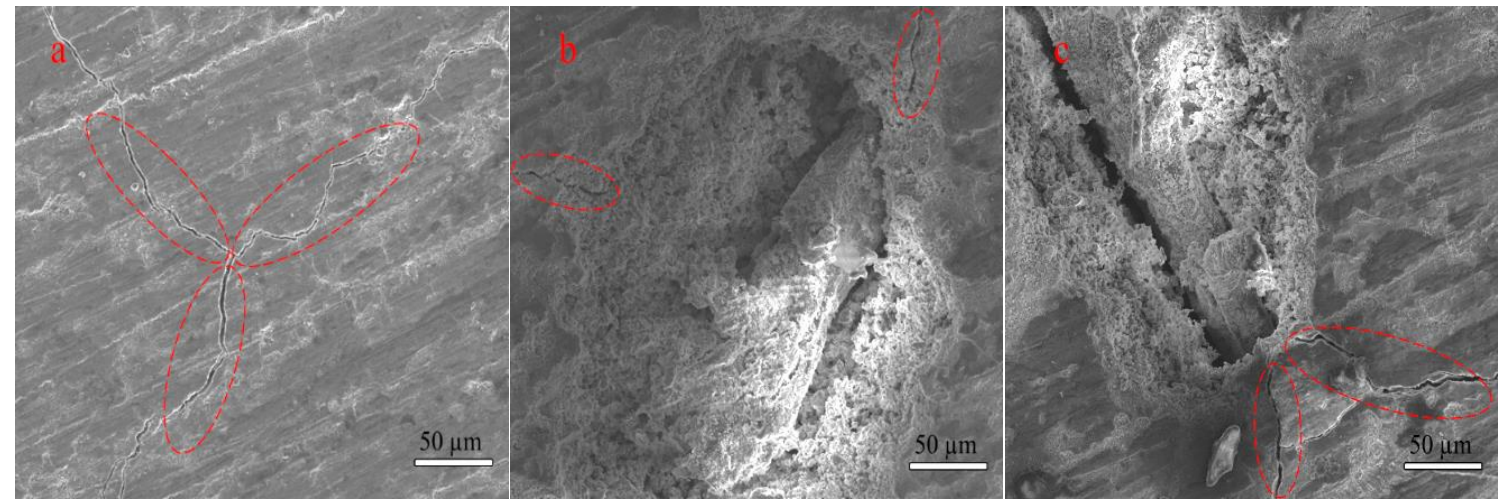

Fig. 5.12. Microstructure of the (a) control, (b) RKF0.25, and (c) RKF0.5 (Cracks are circled using dashed ellipses).

\subsubsection{The Effect of Fiber Type on Drying Shrinkage Cracking}

The effect of fiber type on drying shrinkage cracking is a little complicated and varies based on different fiber dosages. For cement pastes with $0.5 \%$ kenaf fibers, the comparisons of the number of cracks $\left(N_{\mathrm{c}}\right)$, the total cracking length $\left(L_{\mathrm{c}}\right)$, the total cracking 
area $\left(A_{\mathrm{c}}\right)$, the maximum cracking width $\left(W_{\mathrm{mc}}\right)$, and the maximum cracking depth $\left(D_{\mathrm{mc}}\right)$ are shown in Fig. 5.13. Among all three fiber types (RKF, AKF, and AHPKF), AHPKF is the most effective in decreasing $N_{\mathrm{c}}, L_{\mathrm{c}}, A_{\mathrm{c}}, W_{\mathrm{mc}}$, and $D_{\mathrm{mc}}$, which is followed by AKF and then RKF. One reason can be that, compared to RKF, the similar rougher surface of AKF and AHPKF (as shown in Fig. 5.3) can improve the shrinkage cracking resistance by improving the bonding between fibers and the matrix (Rahmani et al. 2012; Toledo Filho et al. 2009). Since AHPKF has the smallest diameter, which means the largest surface area and number of fibers among the three. This increases the chance of AHPKF fibers to go cross the given section or bridge the cracks to resist crack initiation and propagation.

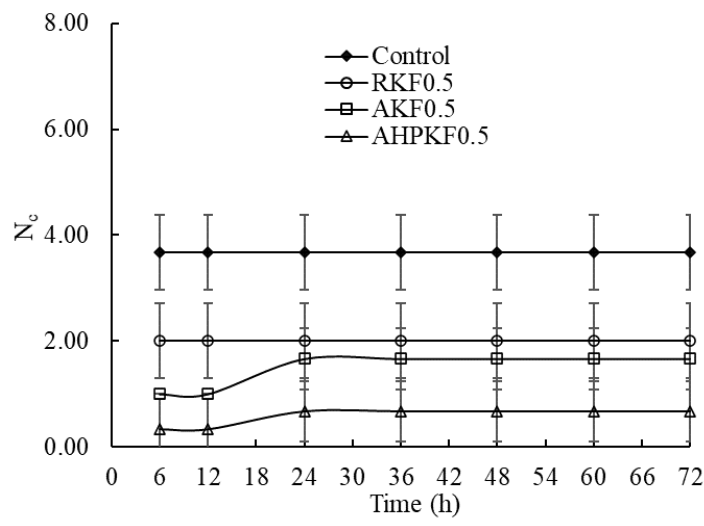

(a)

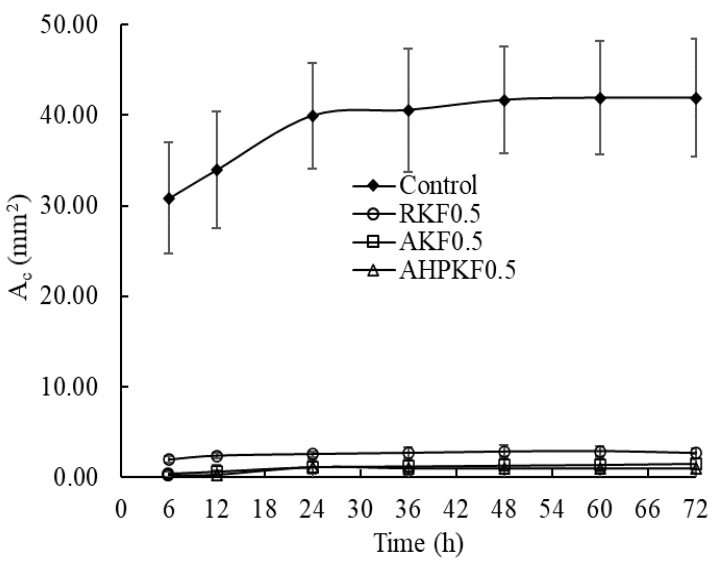

(c)

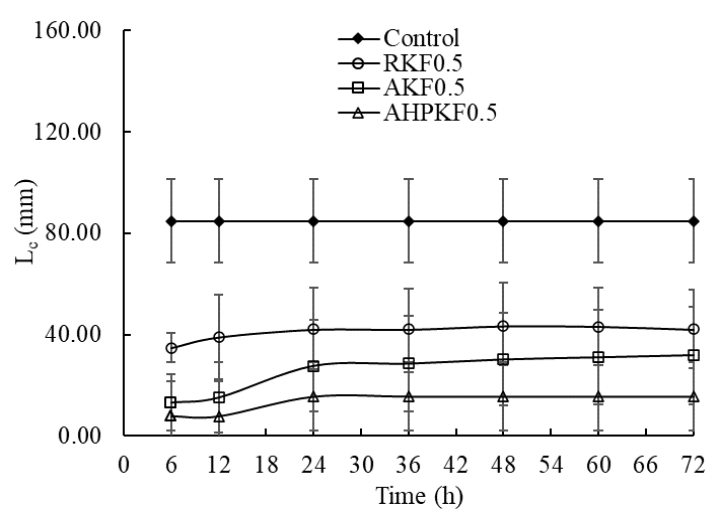

(b)

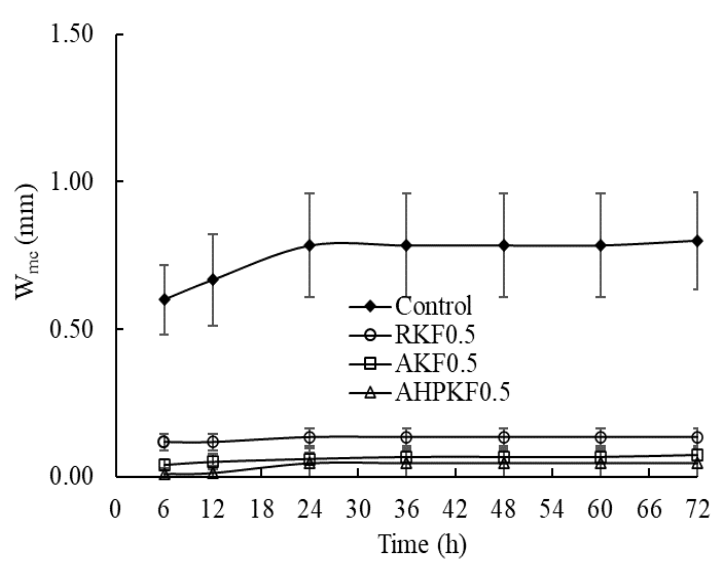

(d) 


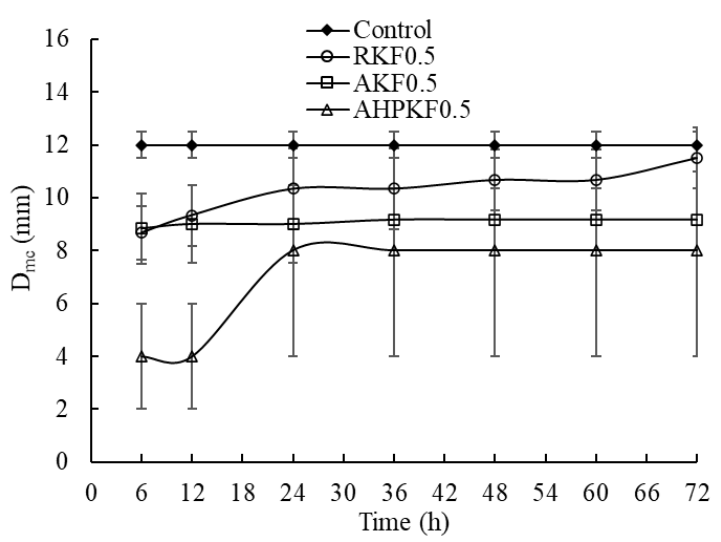

(e)

Fig. 5.13. Comparison of (a) $N_{\mathrm{c}}$, (b) $L_{\mathrm{c}}$, (c) $A_{\mathrm{c}}$, (d) $W_{\mathrm{mc}}$ and (e) $D_{\mathrm{mc}}$ for cement pastes with $0.5 \%$ kenaf fibers

For cement pastes with $0.25 \%$ kenaf fibers, the comparisons of the number of cracks $\left(N_{c}\right)$, the total cracking length $\left(L_{c}\right)$, the total cracking area $\left(A_{c}\right)$, the maximum cracking width $\left(W_{m c}\right)$, and the maximum cracking depth $\left(D_{m c}\right)$ are shown in Fig. 5.14. Fig. 5.14(e) shows that when $0.25 \%$ kenaf fibers are used, the fiber type almost does not have any effects on $D_{m c}$. Similar to cement pastes with $0.5 \%$ kenaf fibers, of all three fiber types, AHPKF is the most effective in decreasing $N_{c}, L_{c}, A_{c}$, and $W_{m c}$ (shown in Fig. 5.14(a-d)), which is indicative of the most shrinkage cracking resistance. However, by comparing RKF0.25 and AKF0.25, AKF0.25 lead to lower $T_{i c}$ (Table 5.6) and higher $N_{c}, L_{c}$, and $A_{c}$, but lower $W_{m c}$. This indicates that AKF0.25 samples seem to crack more easily than RKF0.25 samples; however, AKF0.25 has better control over the crack width than RKF025. This can be attributed to the relative rough surface texture of the fibers after alkaline treatment, which in turn enhance the bonding between the fiber and the paste matrix. 


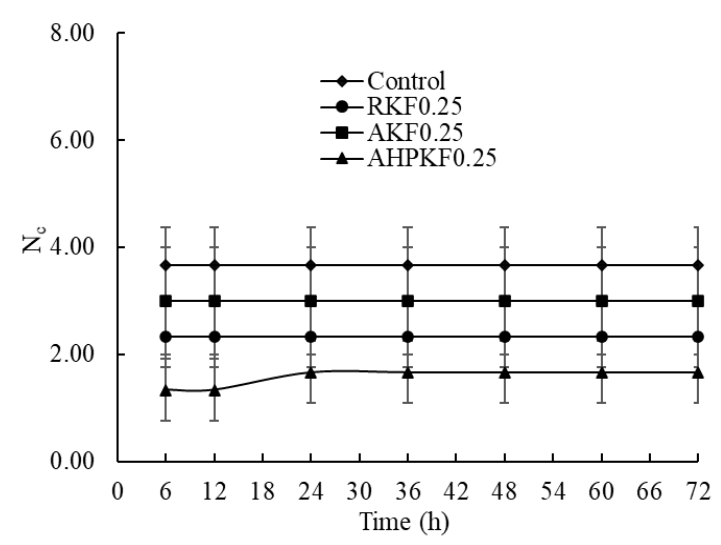

(a)

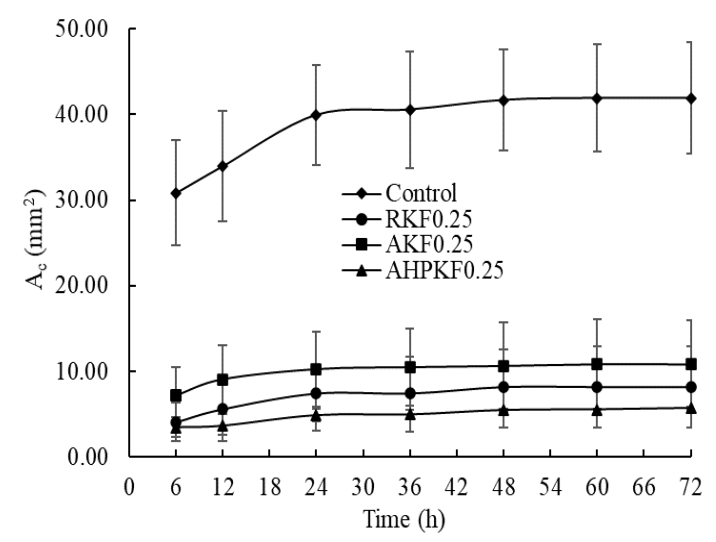

(c)



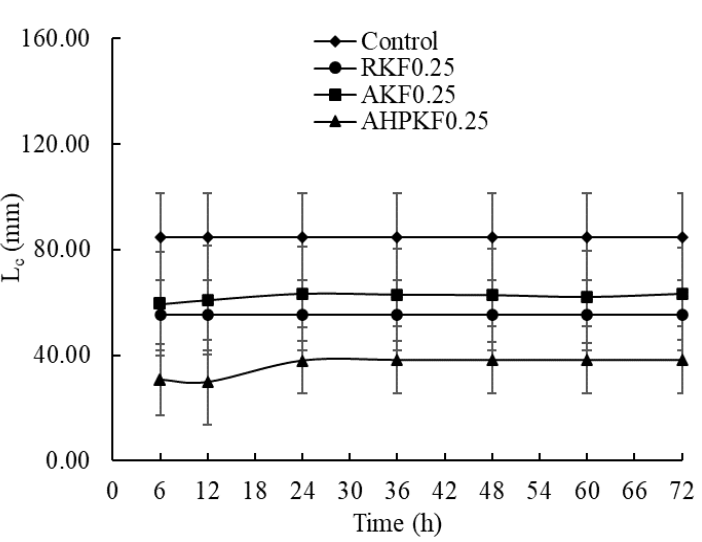

(b)

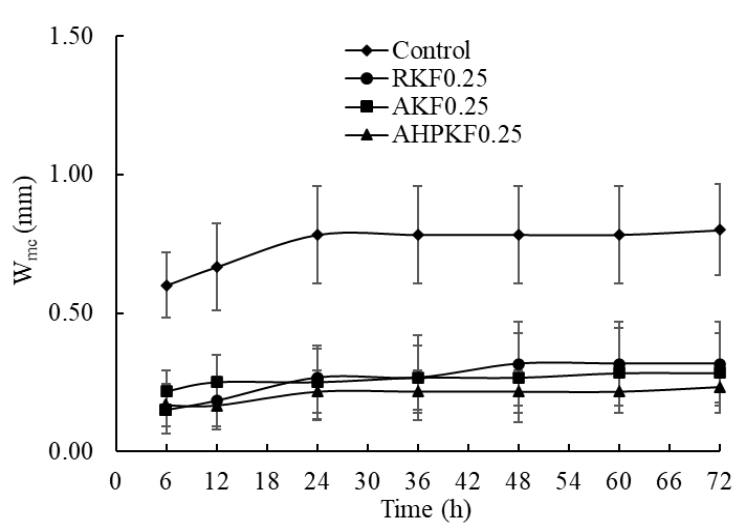

(d)

(e)

Fig. 5.14. Comparison of (a) $N_{\mathrm{c}}$, (b) $L_{\mathrm{c}}$, (c) $A_{\mathrm{c}}$, (d) $W_{\mathrm{mc}}$ and (e) $D_{\mathrm{mc}}$ for cement pastes with $0.25 \%$ kenaf fibers 


\subsection{Conclusions}

The setting, autogenous shrinkage, and drying shrinkage cracking of cement pastes with raw, alkaline treated, and alkaline-hydrogen peroxide treated kenaf fibers were investigated in this study. Some key conclusions are summarized below.

The addition of $0.25 \%$ or $0.5 \%$ kenaf fibers to cement pastes can have the similarly slight delaying effect on cement hydration in comparison with the control. Of all three types of kenaf fibers (RKF, AKF, and AHPKF), RKF can delay cement hydration the most, because RKF has the most hemicellulose, lignin, and extractives. Although AHPKF has the least hemicellulose, lignin, and extractives, AHPKF seems not to delay cement hydration the least. This is because AHPKF has the least fiber diameter, which indicates that AHPKF has the largest surface area to contact with cement pastes and extractives, etc. can be dissipated in cement pastes to delay cement hydration. Therefore, both fiber diameter and chemical composition of fibers should be considered in studying the effect of plant fibers on cement hydration.

The autogenous shrinkage test indicates that the autogenous strain firstly increases (expansion) until the maximum strain is reached. Samples with kenaf fibers, especially those with $0.5 \%$ fibers have significantly higher expansion compared to the control. After the maximum strain, the autogenous strain decreases, indicating a shrinkage trend. Samples with kenaf fibers have a relatively gradual decline, indicating a slower pace of shrinkage

Compared to the control, the application of kenaf fibers $(0.25 \%$ or $0.5 \%$ fiber dosage) to cement pastes can not only reduce the autogenous shrinkage potential as reflected by the increased autogenous strain, namely the increased degree of expansion, but also reduce the drying shrinkage cracking significantly, with $0.5 \%$ fiber dosage 
exhibiting better performance than $0.25 \%$ fiber dosage. The reduction in autogenous shrinkage is mainly because with the increase of fiber dosage, kenaf fibers can absorb more water for internal curing and also provide greater shrinkage resistance. The reduction in drying shrinkage cracking is mainly due to the fact that more kenaf fibers can provide more bleeding channels to replenish the drying surface, serve as more bridges to connect cracks, and block crack propagation. If the volume fraction of aggregates in concrete is assumed as $60-80 \%$ and the specific gravity of kenaf fibers is approximately assumed as $1,0.12$ $0.24 \%$ fiber dosage by volume of concrete ( $0.5 \%$ fiber dosage by weight of cement) can be a recommended value.

Of all three types of kenaf fibers, AHPKF can reduce autogenous shrinkage and drying shrinkage cracking the most. By comparing RKF and AKF, when $0.25 \%$ kenaf fibers are used, AKF can reduce autogenous shrinkage more but reduce drying shrinkage cracking less; however, when $0.5 \%$ kenaf fibers are used, AKF can reduce both autogenous shrinkage and drying shrinkage cracking more.

Through the study, it can be seen that the shrinkage and cracking of cement pastes can be controlled by kenaf fibers. Given that the chemicals used for fiber treatment are affordable and the amount of fiber usage is low, the slightly increased cost and energy consumption is acceptable. Moreover, the treatment process is still being optimized to further reduce the cost and energy consumption. Therefore, using kenaf fibers to control shrinkage and cracking has the potential to be applied on large scale for infrastructures such as pavements and sidewalks. 


\section{CHAPTER 6 EXPERIMENTAL AND FINITE ELEMENT ANALYSIS ON FLEXURAL BEHAVIOR OF MORTAR BEAMS WITH CHEMICALLY MODIFIED KENAF FIBERS}

\subsection{Introduction}

From the study in Chapter 5, the shrinkage and cracking of cementitious materials can be controlled well by kenaf fibers, especially chemically treated kenaf fibers. It is believed that kenaf fibers can be used to improve the flexural behavior of cementitious materials. Many researchers have demonstrated that alkaline treated lignocellulosic fibers can improve the strength and toughness of lignocellulosic fiber reinforced cementitious materials (Andiç-Çakir et al. 2014; Jo et al. 2016; Zhou et al. 2017). Besides, Tong et al. reported that the treated lignocellulosic fibers through the combination of $6 \%$ potassium hydroxide $(\mathrm{KOH})$ alkaline solution and $10 \%$ hydrogen peroxide $\left(\mathrm{H}_{2} \mathrm{O}_{2}\right)$ could effectively increase the cracking resistance more than untreated or solely $\mathrm{KOH}$ treated fibers (Tong et al. 2014). Therefore, following Chapter 5, raw kenaf fibers (RKF), alkaline treated kenaf fibers $(\mathrm{AKF})$, and alkaline-hydrogen peroxide treated kenaf fibers (AHPKF) were incorporated into mortars in this study to expect to improve the flexural behavior of the mortars.

In this study, the dosages of RKF, AKF, and AHPKF were $0.25 \%, 0.5 \%$, and $0.75 \%$ by weight of cement. Moreover, $0.2 \%$ (by weight of cement) superplasticizer was added 
into some of $0.75 \%$ fiber reinforced mortars to improve their flowability. Compressive test, flexural test, and scanning electron microscopy analysis were conducted on mortars with RKF, AKF, and AHPKF, respectively. The purpose of this study is to identify the effect of fiber type and fiber dosage and also the effect of superplasticizer on flexural behavior of mortars.

Lastly, finite element analysis (FEA) was carried out using the finite element software MSC MARC to simulate stress and strain distributions in mortar beams under flexure. The smeared cracking model was adopted to study the cracking of specimens, in which the cracking strain rather than cracking opening displacement was defined (Lu et al. 2005). The cracking strain, together with the stress, of specimens was examined in detail. The effect of fiber dosage on the load-bearing capacity and cracking strain of specimens was examined theoretically through FEA, which can provide some guidance for future research.

\subsection{Materials and Experiments}

\subsubsection{Kenaf Fiber Preparation and Processing}

Following the Chapter 5, raw kenaf fibers (RKF), alkaline treated kenaf fibers (AKF), and alkaline-hydrogen peroxide treated kenaf fibers (AHPKF) were selected and then processed using the procedure introduced in section 5.2.2 to ensure good dispersion in mortar. And the corresponding physicochemical and mechanical properties of these three types of kenaf fibers are shown in Table 5.1.

\subsubsection{Specimen Preparation}

The materials used in this study include type I/II Portland cement, polycarboxylatebased superplasticizer, kenaf fibers (RFK, AKF, and AHPKF), silica sand, and tap water. 
The chemical composition and the mineral clinker compounds of cement are shown in Table 2.2 and

Table 2.3, respectively (Shang and Sun 2019). The superplasticizer is SUPERFLO 2000 RM in accordance with Types A and F both in ASTM C494 and in AASHTO M194. In terms of kenaf fibers, three fiber dosages $(0.25 \%, 0.5 \%$, and $0.75 \%$ by weight of cement) are adopted. Moreover, for the fiber dosage of $0.75 \%$, some of specimens are mixed with $0.2 \%$ (by weight of cement) superplasticizer to improve flowability. The mix proportion (by weight) of all mortar specimens is listed in Table 6.1.

A standard Hobart mixer at the speed level of "1" (136 rpm) was used to prepare mortars (Ramezani et al. 2019). Three different mixing procedures were used based on the presence of kenaf fibers and superplasticizer. For plain mortars (without kenaf fibers and superplasticizer), sand and cement were dry mixed for 2 minutes, and then water was added to mix for 3 minutes. Afterward, the mixture was left rested for 2 minutes and then continued to mix for another 3 minutes. For mortars with kenaf fibers but without superplasticizer, sand and cement were first dry mixed for 2 minutes, during which kenaf fibers were gradually added into the mixture to ensure good dispersion. And then water was introduced to the dry mix that followed the procedures used for plain mortars. For mortars with both kenaf fibers and superplasticizer, the procedure is the same as the second one except for that the superplasticizer was pre-mixed with water.

For each case listed in Table 6.1, three $2 \times 2 \times 2$ in cubes and four $1 \times 1 \times 11.25$ in (width $\times$ height $\times$ length) beams were cast using stainless steel molds. The specimens were sealed for the first 24 hours and then were demolded. The cubes of each case were selected to estimate the density by dividing the weight of each cube by its volume, and then the 
average density of three cubes was adopted. The density of all cases is summarized in

Table 6.2. Afterward, all specimens including cubes and beams were cured in a moisture room with $100 \%$ humidity and $22^{\circ} \mathrm{C}$ till 28 days.

Table 6.1. Mix proportion (by weight) of mortars

\begin{tabular}{|c|c|c|c|c|c|c|}
\hline Specimens & Water & $\begin{array}{l}\text { Cem } \\
\text { ent }\end{array}$ & Sand & $\begin{array}{l}\text { Kenaf } \\
\text { fiber }\end{array}$ & $\begin{array}{l}\text { Superpla } \\
\text { sticizer }\end{array}$ & Specification \\
\hline Control & 0.5 & 1 & 2.25 & 0 & 0 & Mortar with no kenaf fibers \\
\hline RKF0.25 & 0.5 & 1 & 2.25 & 0.0025 & 0 & Mortar with $0.25 \%$ RKF \\
\hline AKF0.25 & 0.5 & 1 & 2.25 & 0.0025 & 0 & Mortar with $0.25 \%$ AKF \\
\hline AHPKF0.25 & 0.5 & 1 & 2.25 & 0.0025 & 0 & Mortar with $0.25 \%$ AHPKF \\
\hline RKF0.5 & 0.5 & 1 & 2.25 & 0.005 & 0 & Mortar with $0.5 \%$ RKF \\
\hline AKF0.5 & 0.5 & 1 & 2.25 & 0.005 & 0 & Mortar with $0.5 \%$ AKF \\
\hline AHPKF0.5 & 0.5 & 1 & 2.25 & 0.005 & 0 & Mortar with $0.5 \%$ AHPKF \\
\hline RKF0.75 & 0.5 & 1 & 2.25 & 0.0075 & 0 & Mortar with $0.75 \%$ RKF \\
\hline $\mathrm{AKF} 0.75$ & 0.5 & 1 & 2.25 & 0.0075 & 0 & Mortar with $0.75 \%$ AKF \\
\hline AHPKF0.75 & 0.5 & 1 & 2.25 & 0.0075 & 0 & Mortar with $0.75 \%$ AHPKF \\
\hline $\begin{array}{l}\text { RKF0.75P0. } \\
2\end{array}$ & 0.5 & 1 & 2.25 & 0.0075 & 0.002 & $\begin{array}{l}\text { Mortar with } 0.75 \% \text { RKF } \\
\text { and } 0.2 \% \text { superplasticizer }\end{array}$ \\
\hline $\begin{array}{l}\mathrm{AKF} 0.75 \mathrm{P} 0 . \\
2\end{array}$ & 0.5 & 1 & 2.25 & 0.0075 & 0.002 & $\begin{array}{l}\text { Mortar with } 0.75 \% \text { AKF } \\
\text { and } 0.2 \% \text { superplasticizer }\end{array}$ \\
\hline $\begin{array}{l}\text { AHPKF0.75 } \\
\text { P0.2 }\end{array}$ & 0.5 & 1 & 2.25 & 0.0075 & 0.002 & $\begin{array}{l}\text { Mortar with } 0.75 \% \text { AHPKF } \\
\text { and } 0.2 \% \text { superplasticizer }\end{array}$ \\
\hline
\end{tabular}

Table 6.2 Density of all specimens

\begin{tabular}{lc}
\hline Specimens & Density $\left(\mathrm{g} / \mathrm{cm}^{3}\right)^{*}$ \\
\hline Control & $2.22 \pm 0.03$ \\
RKF0.25 & $2.21 \pm 0.04$ \\
AKF0.25 & $2.18 \pm 0.04$ \\
AHPKF0.25 & $2.19 \pm 0.04$ \\
RKF0.5 & $2.19 \pm 0.04$ \\
AKF0.5 & $2.17 \pm 0.01$ \\
AHPKF0.5 & $2.18 \pm 0.05$ \\
RKF0.75 & $2.13 \pm 0.03$ \\
AKF0.75 & $2.14 \pm 0.03$ \\
AHPKF0.75 & $2.14 \pm 0.02$ \\
RKF0.75P0.2 & $2.19 \pm 0.02$ \\
AKF0.75P0.2 & $2.19 \pm 0.01$ \\
AHPKF0.75P0.2 & $2.21 \pm 0.05$ \\
\hline
\end{tabular}

*Note: The values are average value \pm standard deviation. 


\subsubsection{Compressive Test}

A universal testing machine and $2 \times 2 \times 2$ in mortar cubes were used for the compressive test, as shown in Fig. 6.1. Based on the maximum load $(F)$ obtained from this test, compressive strength is calculated using Eq. (6.1).
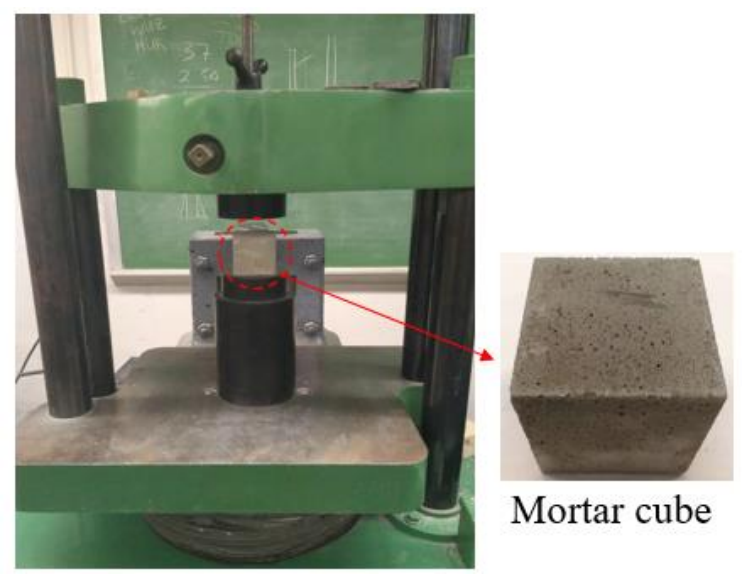

Mortar cube

Fig. 6.1. Universal testing machine for compressive test

$$
\sigma_{c}=\frac{F}{A}
$$

where $\sigma_{c}$ is compressive strength; $F$ is maximum load; $A$ is cross section area of a cube $\left(2 \times 2 \mathrm{in}^{2}\right)$.

\subsubsection{Flexural Test}

A universal testing machine and $1 \times 1 \times 11.25$ in mortar beams with the span length of 10 in between two supporters were used for the flexural test, as shown in Fig. 6.2. A load cell with the model of LCCA-750 (750 lbf capacity) produced by OMEGA ${ }^{\mathrm{TM}}$ was used to measure the force that a beam can bear. A Linear Variable Differential Transformer (LVDT) with the model of LD620-2.5 produced by OMEGA ${ }^{\mathrm{TM}}$ was used to record the deflection at mid-span of the beam. From the flexural test, the load-deflection curve can be obtained directly, and then based on the maximum load, flexural strength is calculated using Eq. (6.2). 


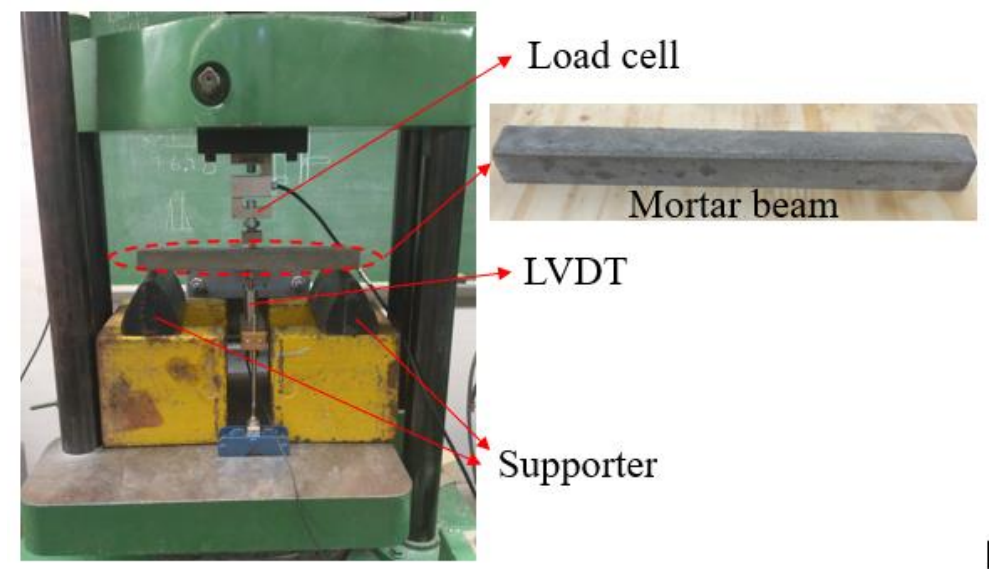

Fig. 6.2. Universal testing machine for flexural test

$$
\sigma_{f}=\frac{3 F l}{2 b h^{2}}
$$

where $\sigma_{f}$ is flexural strength; $F$ is maximum load; $l$ is span length of a beam; $b$ is width of a beam; $h$ is height of a beam.

Based on the load-deflection curve from the flexural test, the data between $10 \% \mathrm{~F}$ and $40 \% F$ are fitted into a straight line. Then, the slope of the fitted straight line can be obtained, by which the modulus of elasticity is calculated using Eq. (6.3).

$$
E=\frac{m l^{3}}{4 b h^{3}}
$$

where $E$ is modulus of elasticity; $l$ is span length of a beam; $m$ is slope of the fitted straight line; $b$ is width of a beam; $h$ is height of a beam.

Besides, based on the load-deflection curve from the flexural test, flexural toughness can also be calculated. The flexural toughness is obtained by calculating the area of the load-deflection curve, which is used to evaluate the energy absorption of mortar. In this study, the area of the load-deflection curve up to a net deflection of $1 / 150$ of the span length is defined as the flexural toughness conforming to ASTM C1609 (ASTM 2019). 


\subsubsection{Scanning Electron Microscopy Analysis}

Scanning electron microscopy (SEM) analysis was conducted on the fracture surfaces of mortar beams after the flexural test using VEGA3 provided by TESCAN. The specimens with a thickness of $5 \mathrm{~mm}$ were prepared. Before testing, to suppress the charging effect, gold sputtering was applied to the surface of the specimens. During testing, the secondary electron detector at $10 \mathrm{kV}$ was used to observe the fracture surfaces of mortar beams and also examine the area surrounding kenaf fibers.

\subsection{Finite Element Analysis}

To visually examine the stress and cracking strain within mortar beams under flexure, the finite element analysis was conducted to do simulation. The effect of fiber dosage on the loading bearing capacity and cracking strain was assessed, which may provide some insights and guidance for future study. The FEA processes are elaborated as follows.

\subsubsection{Mortar}

\subsubsection{Constitutive Relationship under Compression and Tension}

The stress-strain relationship of mortar under compression and tension is shown in

Fig. 6.3. The formulae for the compressive stress-strain relationship are shown in Eqs. (6.46.6) (Safdar et al. 2016; Zhang and Koizumi 2010). The compressive modulus of elasticity of mortar is related to its compressive strength, and it can be initially estimated using Eq. (6.7) given by ACI (2014). In this study, the crushing strain $\left(\varepsilon_{c u}\right)$ does not have a substantial effect on simulation, and it is defined as 0.005 that is slightly higher than the strain corresponding to peak compressive stress.

$$
\sigma_{c}=\frac{f_{c}^{\prime} \alpha\left(\frac{\varepsilon_{C}}{\varepsilon_{C}^{\prime}}\right)}{\alpha-1+\left(\frac{\varepsilon_{C}}{\varepsilon_{c}^{\prime}}\right)^{\alpha}}
$$




$$
\begin{gathered}
\alpha=\left(\frac{f_{c}^{\prime}}{\xi}\right)^{3}+1.55 \\
\varepsilon_{c}^{\prime}=\frac{2 f_{c}^{\prime}}{E_{c}} \\
E_{c}=4700 \sqrt{f_{c}^{\prime}}
\end{gathered}
$$

where $\sigma_{c}$ is compressive stress of mortar $(\mathrm{MPa}) ; \varepsilon_{c}$ is compressive strain of mortar; $E_{c}$ is compressive modulus of elasticity $(\mathrm{GPa}) ; \varepsilon_{c}{ }^{\prime}$ is compressive strain at peak compressive stress; $f_{c}$ ' is compressive strength of mortar (MPa). The coefficient of variability $\xi$ increases with increasing compressive strength of mortar. The literature suggests that when $f_{c}{ }^{\prime}=42.5$ $\mathrm{MPa}, \xi=32.4$ and when $f_{c}=88.0 \mathrm{MPa}, \xi=71.4$. For all other compressive strengths, $\xi$ can be calculated using the linear interpolation method (Zhang and Koizumi 2010). In this study, the tested compressive strength of mortar is $55.16 \mathrm{MPa}$, therefore, $\xi$ is calculated as 43.3.

In the tensional zone, before cracking the linear elasticity is used, which are defined by the tensile strength $\left(f_{\mathrm{t}}\right)$ and tensile modulus of elasticity $\left(E_{t}\right)$ assumed to be the same as the compressive modulus of elasticity $\left(E_{c}\right)$. However, the tensile strength of mortar is difficult to test, and the value is initially estimated using Eq. (6.8) (Safdar et al. 2016). When the tensile stress reaches the tensile strength of the mortar $f_{t}^{\prime}$, cracking occurs. After cracking, the tensile stress of mortar linearly reduces to zero at the strain $\varepsilon_{t u}$, and the slope of the descending curve is defined as the softening modulus $\left(E_{s}\right)$. In this study, the mortar behavior is considered independent of the reinforcement. For plain mortars, the softening modulus can be defined as a very large value to model the brittle failure behavior.

$$
f_{t}^{\prime}=0.23\left(f_{c}^{\prime}\right)^{2 / 3}
$$


where $f_{t}{ }^{\prime}$ is tensile strength of mortar $(\mathrm{MPa}) ; f_{c}{ }^{\prime}$ is compressive strength of mortar (MPa).



(a)

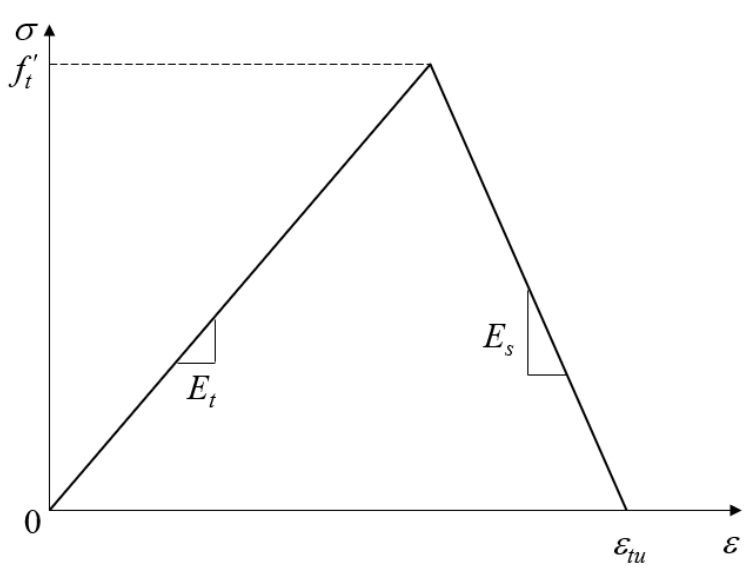

(b)

Fig. 6.3. Stress-strain relationship of mortar under (a) compression and (b) tension

\subsubsection{Yielding Criterion}

Mortar under compression is treated as quasi-brittle material, and the yielding function proposed by Buyukozuturk is used, as defined using Eqs. (6.9-6.12), which is already included in MSC.MARC (Buyukozturk 1977; Lu et al. 2005; Safdar et al. 2016; Teng et al. 2013).

$$
\begin{gathered}
f=\beta \sqrt{3} \bar{\sigma} I_{1}+\gamma I_{1}^{2}+3 J_{2}-\bar{\sigma}^{2} \\
I_{1}=\sigma_{11}+\sigma_{22}+\sigma_{33} \\
J_{2}=\frac{1}{2} S_{i j} S_{i j}, \quad S_{i j}=\left[\begin{array}{ccc}
\sigma_{11}-\sigma_{m} & \sigma_{12} & \sigma_{13} \\
\sigma_{21} & \sigma_{22}-\sigma_{m} & \sigma_{23} \\
\sigma_{31} & \sigma_{32} & \sigma_{33}-\sigma_{m}
\end{array}\right] \\
\sigma_{m}=\frac{1}{3}\left(\sigma_{11}+\sigma_{22}+\sigma_{33}\right)
\end{gathered}
$$

where $I_{1}$ and $J_{2}$ are first invariant of stresses and the second invariant of deviatoric stresses, respectively; $\beta$ and $\gamma$ are materials constants and equal to $\sqrt{3}$ and 0.2 , 
respectively; $\bar{\sigma}$ is one third of the yielding stress that is equal to one-third of the uniaxial compressive strength.

\subsubsection{Cracking}

Smeared crack model is adopted to study the cracking behavior of mortar by using the Cracking option in MSC MARC. The smeared crack model does not track individual "macro" cracks but treats a crack as a geometry entity instead (Barth and Wu 2006; Teng et al. 2013). It allows one crack at one integration point for one-dimensional elements, two orthogonal cracks for two-dimensional elements, and three orthogonal cracks for threedimensional elements. Constitutive calculations are performed independently at each integration point of the FEA model to consider the presence of cracks, and the cracks affect the stress associated with the integration point (Barth and Wu 2006). A crack initiates in a perpendicular direction to the maximum principal stress when the maximum principal stress reaches the tensile strength of the mortar (Al-Jelawy 2013).

To adopt the smeared crack approach, the relative displacement of the crack surface is represented by cracking strain that is defined as the difference between the total strain and the strain (considered to be merely elastic) of the mortar (Rots et al. 1985). The crack band theory relates the crack opening width with the cracking strain in the finite element analysis (Bažant and Oh 1983). When the cracking strain is assumed to be uniformly distributed over the crack band, the cracking strain of the mortar can be approximately calculated using Eq. (6.13) (Tao and Chen 2015; Yao and Wu 2016). It can be seen that a higher cracking strain is indicative of a higher crack opening width, and the cracking strain can be used to approximately evaluate the extent of cracking.

$$
w=\varepsilon^{c r} h
$$


where $h$ is the crack band width, $w$ is the crack opening width, and $\varepsilon^{c r}$ is the cracking strain.

\subsubsection{Shear Retention Factor}

During the post-cracking stage, the cracked mortar can still transfer shear forces through aggregate interlock or shear friction, which is termed as shear retention (Hu et al. 2004; Safdar et al. 2016). The use of reduced shear modulus not only improves the realism of the cracking representation but also removes some numerical difficulties caused by the singularity of the composite material's constitutive matrix (Hu and Schnobrich 1990). Numerous analytical results have shown that the shear retention value (between 0 and 1) does not seem to be critical but is greater than 0 to avoid numerical instability (Hu and Schnobrich 1990; Safdar et al. 2016). The value of 0.5 has been successfully adopted by Barth and $\mathrm{Wu}$ (Barth and $\mathrm{Wu} 2006)$, which is also used in this analysis.

\subsubsection{Poisson's Ratio}

The Poisson's ratio (v) of concrete under uniaxial compressive stress ranges from about $0.15-0.22$, with a representative value of 0.19 or 0.20 (Hu et al. 2004; Safdar et al. 2016). In this study, the Poisson's ratio of mortar is assumed to be 0.2 (Garzón-Roca et al. 2012).

\subsubsection{Kenaf Fibers}

The stress-strain curve of kenaf fibers exhibited linear behavior and brittle failure. In

Table 5.1, the tensile strength and diameter of kenaf fibers are listed. In the simulation, AKF reinforced mortar beams are taken as examples to be modeled. The modulus of elasticity of AKF obtained in this study is $44.69 \mathrm{GPa}$. The Poisson's ratio of kenaf fibers can be approximately defined as 0.324 (Mariselvam and Logesh). Mahjoub et al. 
summarized the density of kenaf fibers from different origins, and the range is between 0.6 and 1.5 (Mahjoub et al. 2014). In this study, the middle value 1.05 is used.

\subsubsection{Analytical Model}

A 3D simply supported beam was modeled using the nonlinear finite element software, MSC MARC, as shown in Fig. 6.4. The eight-node solid element (type 7) was used to model mortar. To improve the shear (or bending) characteristics, the assumed strain is flagged through the Geometric Properties option in MSC MARC (Marc 2010). Also, to eliminate stress concentration and simulate the actual situation, the supporters and the loading location are modeled using some narrow steel elements (type 7). The modulus of elasticity and Poisson's ratio of steel elements are defined as $200 \mathrm{GPa}$ and 0.3 . The displacement-controlled loading was applied to the mid-span of the beam in 50 steps.

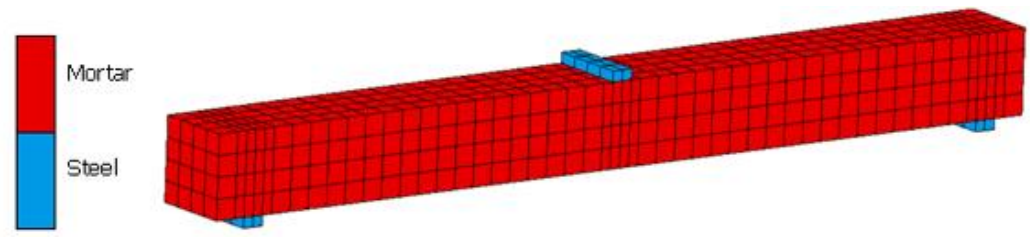

Fig. 6.4. Simply supported beam model

The contribution of kenaf fibers was taken into account in a homogenized way that kenaf fibers are assumed to be well dispersed in each mortar element. The orientation of fibers was considered along the longitudinal direction of mortar beams, and an efficiency factor 0.5 was used for the simplification to offset the random fiber distribution/orientation in reality (Georgiadi-Stefanidi et al. 2011). Kenaf fibers were modeled using rebars that are placed in the hollow isoparametric four-node membrane rebar element (type 147). Then the membrane rebar elements were embedded into solid mortar elements using the INSERT option. The reinforcement in a mortar element was schematically shown in Fig. 6.5. Since the mortar beam is discretized into mortar elements in several layers and a layer of fibers 
is arranged in each mortar element, the fibers are automatically arranged in several layers consistent with the mortar elements. It has to be noted that the stick-slip effect (pullout behavior) between fibers and mortar is not considered in this model.

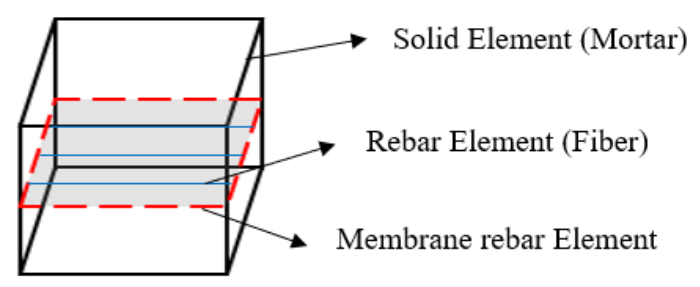

Fig. 6.5. Schematic of reinforcement in mortar

\subsection{Results and Discussions}

\subsubsection{Crack Pattern at Failure}

The crack pattern at failure (maximum load reached) of mortar specimens under compression is found to be greatly influenced by the fiber dosage rather than the fiber type. Take specimens with $0.25 \%, 0.5 \%$, and $0.75 \% \mathrm{AKF}$ as examples, together with the control, the crack pattern at failure of mortar cubes is compared in Fig. 6.6. Fig. 6.6(a) shows that the control cubes exhibit a typical brittle failure. The outer surface of the control cubes is stripped completely, and only the core part remains. Fig. 6.6(b) shows that although $0.25 \%$ AKF cannot prevent the occurrence of stripping, the remaining core part is enlarged. Fig. 6.6(c) shows that $0.5 \% \mathrm{AKF}$ continues to reduce the stripped part, and the remaining part is becoming larger and larger. Fig. 6.6(d) shows that when 0.75\% AKF is used, the mortar cubes fail differently that no stripping occurs, and the cubes remain intact except for some large developed cracks. Generally, with the increase of fiber dosage from 0 to $0.75 \%$, the mortar cubes tend to be more ductile since the reinforcing fibers can limit crack propagation and hold the mortar cubes together. 


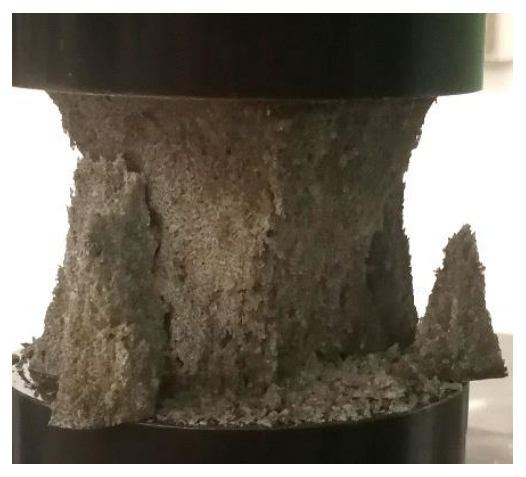

(a)

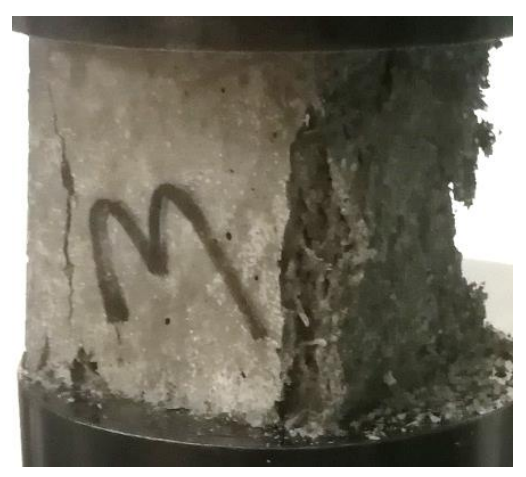

(c)



(b)

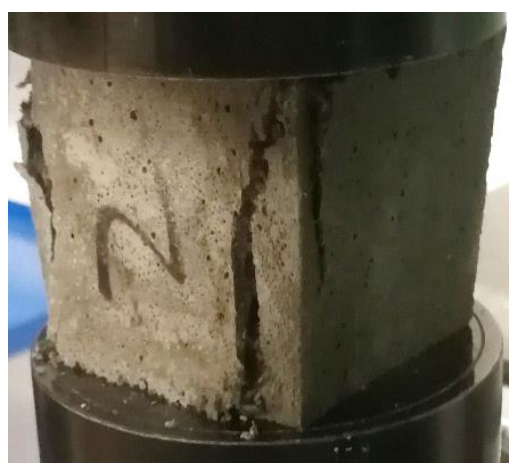

(d)

Fig. 6.6. Crack pattern of mortar cubes for (a) Control, (b) AKF0.25, (c) AKF0.5, and (d)

\section{AKF0.75}

The crack pattern of mortar beams is analyzed by examining the cracks on the side faces at the mid-span of beams immediately while cracking. Take specimens with $0.25 \%$, $0.5 \%$, and $0.75 \% \mathrm{AKF}$ as examples again, together with the control, the crack pattern is shown in Fig. 6.7. For the control, Fig. 6.7(a) shows that a single large crack exists obviously while the beams are broken. However, for mortar beams with $0.25 \%, 0.5 \%$, and 0.75\% AKF, Fig. 6.7(b-d) show that although the similar single crack remains, with the increase of fiber dosage, the length and width of cracks gradually decrease. This is because kenaf fibers can bridge the two broken sections of beams after cracking, and a higher fiber dosage leads the mortar beams to exhibit a more ductile failure pattern. 




(a)



(b)

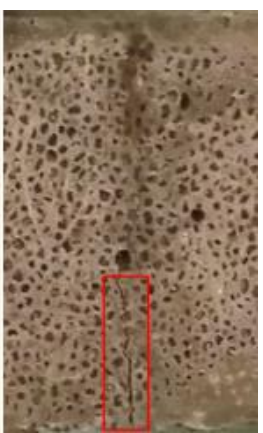

(d)

Fig. 6.7. Crack pattern of mortar beams for (a) Control, (b) AKF0.25, (c) AKF0.5, and (d) AKF0.75

\subsubsection{Compressive Strength and Flexural Strength}

The effects of fiber dosage and fiber type on compressive strength and flexural strength of all specimens are shown in Fig. 6.8(a) and Fig. 6.8(b), respectively. It is noted that in these figures, the three dashed lines are the upper bound (average+deviation), mean, and lower bound (average-deviation) values of the corresponding control mix. This notation also applies to Fig. 6.9.

First of all, regardless of fiber dosage and fiber type, Fig. 6.8 shows that compared to the control, the addition of kenaf fibers to mortar reduces the compressive strength and flexural strength of mortar. The reduction in strength is mainly due to the increased voids in mortar caused by kenaf fibers, which is evidenced by the reduced density (see Table 6.2). One way is that kenaf fibers can absorb some mixing water due to hydrophilic nature (Jo et al. 2016) and lower the flowability of mortar, which can lead to increased voids in mortar. Another way is that kenaf fibers themselves can introduce some voids because of the hollow structure (Ismail et al. 2019). Even the nanoindentation test performed in the interfacial transition zone around kenaf fibers revealed a significant volume fraction of porosity, a high percentage of low-density calcium silicate hydrate $(\mathrm{C}-\mathrm{S}-\mathrm{H})$, and a low 
percentage of high-density C-S-H (Zadeh and Bobko 2014), which is indicative of a poor fibers/matrix adhesion responsible for the reduced strength (Benmansour et al. 2014). This is also confirmed by the microstructure analysis shown in section 6.4 .5 of this study. Besides, kenaf fibers can easily clump in mortars and also can negatively affect cement hydration (Amel et al. 2014), both of which are not beneficial to the strength development of mortar. Through Fig. 6.8, it can also be seen that the compressive strength is more negatively affected than flexural strength by kenaf fibers.

With the increase of fiber dosage, Fig. 6.8 shows that both the compressive strength and flexural strength exhibit a descending trend. This is due to not only the reduced density (see Table 6.2) but also the increased possibility of agglomeration, which can deteriorate the strength.

Of all three types of fibers (RKF, AKF, and AHPKF), although no obvious difference can be seen in density (see Table 6.2), Fig. 6.8 indicates that in general, RKF seems to lead to the worst compressive strength and flexural strength. This is not only because AKF and AHPKF have less hemicellulose, lignin, and extractives than RKF (see Table 5.1) that can reduce the negative effect on cement hydration but also because AKF and AHPKF have a slightly rougher surface than RKF (see Fig. 5.3). Comparing AKF and AHPKF reinforced mortars, there is no significant difference in strength; however, mostly, AKF seems to perform a little better than AHPKF. 


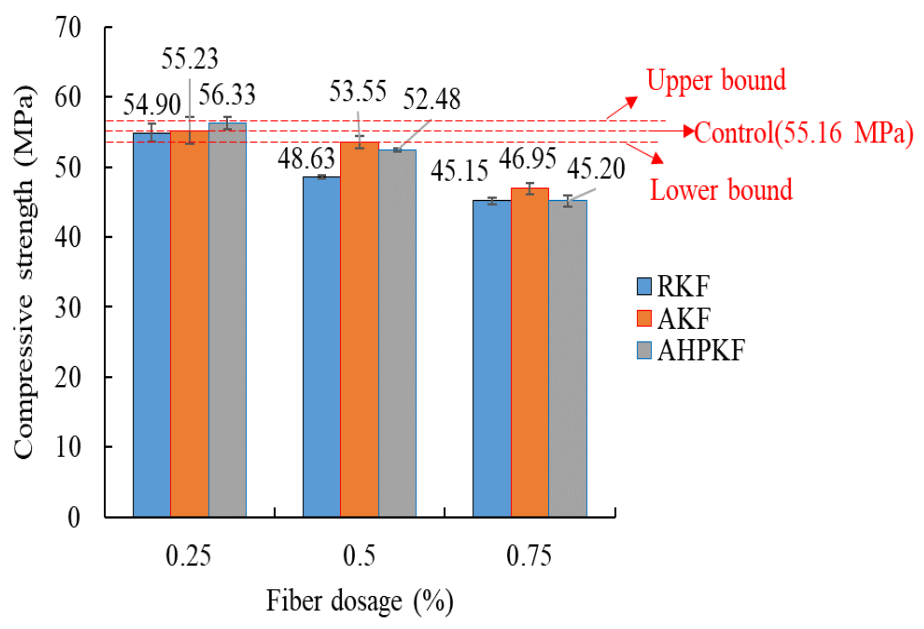

(a)



(b)

Fig. 6.8. Effect of fiber dosage and fiber type on (a) compressive strength and (b) flexural strength (error bar is from standard deviation, which is applicable to all related figures in this study)

\subsubsection{Modulus of Elasticity and Flexural Toughness}

The effects of fiber dosage and fiber type on modulus of elasticity and flexural toughness of all specimens are shown in Fig. 6.9(a) and Fig. 6.9(b), respectively. Fig. 6.9(a) shows that compared to the control, for mortars with kenaf fibers, the modulus of elasticity 
is not changed significantly and is still within the range of the control specimens. Moreover, the change of modulus of elasticity with the fiber dosage and fiber type is not obvious, and no clear trend can be seen.

However, Fig. 6.9(b) shows that mortars with kenaf fibers have higher flexural toughness than the control. The increase of flexural toughness is mainly due to the fact that after cracking, the stress is transferred from the matrix to the fibers, and the slippage of fibers relative to the matrix is the main reason for energy dissipation and higher toughness (Andiç-Çakir et al. 2014; Khan and Ali 2018). Similar conclusions that the presence of kenaf fibers in concrete decreases the compressive strength and flexural strength but increases the flexural toughness were also reported by other researchers (Elsaid et al. 2011; Lam and Yatim 2015). Through Fig. 6.9(b), it can also be seen that the flexural toughness can be increased obviously with the increasing fiber dosage, and the improvement percent can be $10.66-28.86 \%, 64.54-81.80 \%$, and $70.25-92.80 \%$ for the fiber dosage of $0.25 \%$, $0.5 \%$, and $0.75 \%$, respectively. Besides, of all three types of fibers (RKF, AKF, and AHPKF), AKF seems to lead to the highest flexural toughness.



(a) 


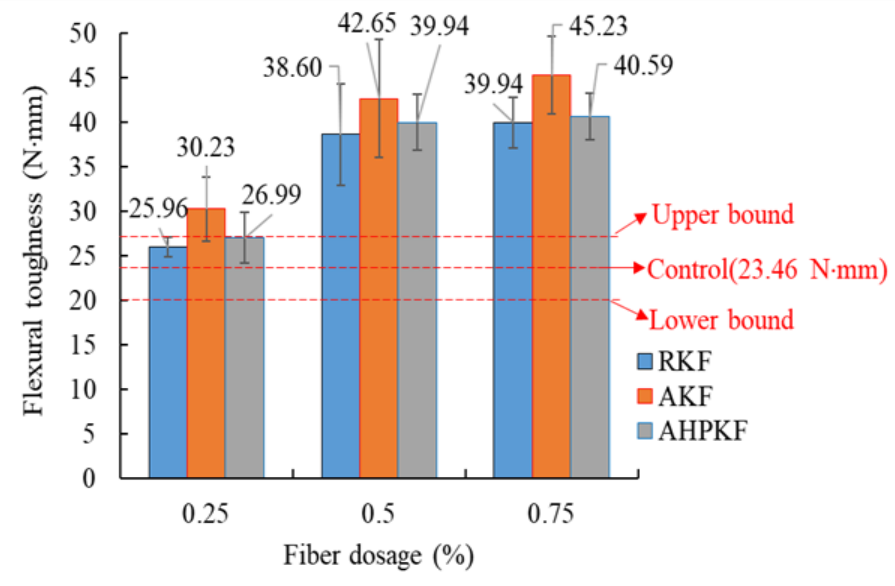

(b)

Fig. 6.9. Effect of fiber dosage and fiber type on (a) modulus of elasticity and (b) flexural toughness

\subsubsection{Effect of the Addition of Superplasticizer}

In this study, the superplasticizer is added into $0.75 \%$ kenaf fibers reinforced mortars to achieve a good flowability, and the effect of superplasticizer on compressive strength, flexural strength, modulus of elasticity, and flexural toughness is shown in Fig. 6.10. It can be seen that the compressive strength, flexural strength, modulus of elasticity, and flexural toughness of mortars all have been improved, which is mainly attributed to the increased density (see Table 6.2). Also, Fig. 6.10(a-b) shows that the addition of superplasticizer can lead the flexural strength to the same level as the control while the compressive strength is still slightly lower than that of the control. 




(a)

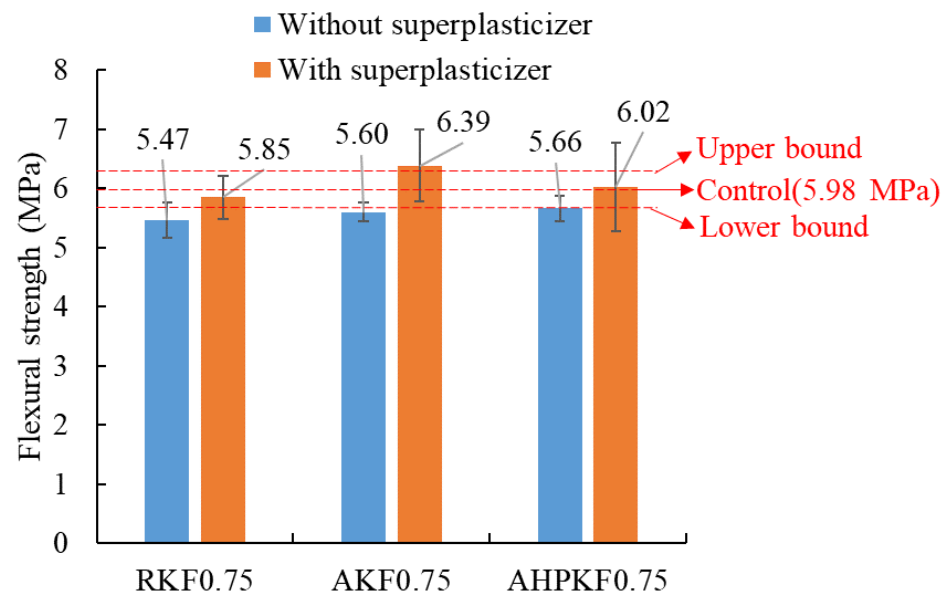

(b)




(c)

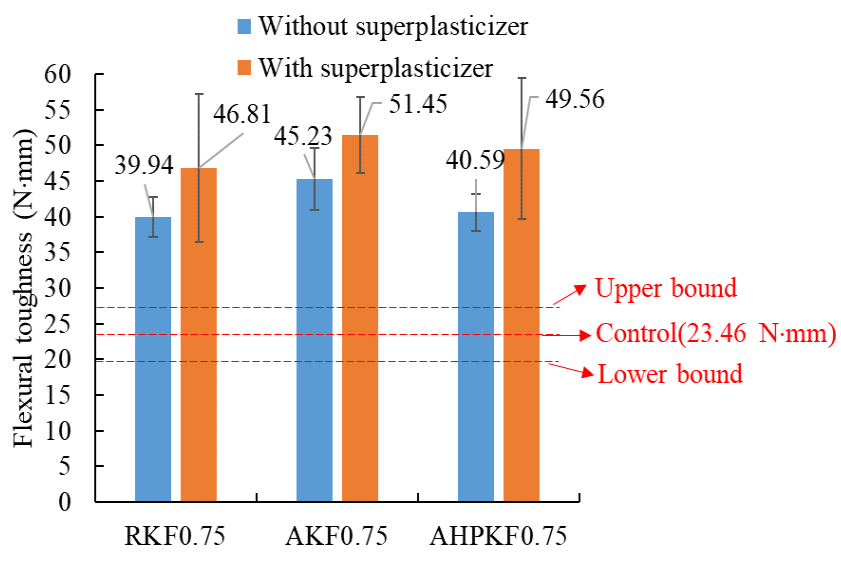

(d)

Fig. 6.10. Effect of superplasticizer on (a) compressive strength, (b) flexural strength, (c) modulus of elasticity, and (d) flexural toughness of $0.75 \%$ kenaf fibers reinforced mortars

\subsubsection{Microstructure}

The microstructure of the fracture surfaces of RKF0.5, AKF0.5, and AHPKF0.5 is shown in Fig. 6.11. On all of the left-panel figures, irrespective of fiber type, it can be clearly seen that some kenaf fibers are pulled out of the mortar matrix under the flexural test, which indicates the weak bonding between kenaf fibers and the mortar matrix. By carefully examining the right-panel figures, some slight differences can be observed. Fig. 6.11(a) shows that a thin layer of cementitious materials exists on the surface of RKF, and also a void exists surrounding RKF, which is not beneficial to the mechanical properties. Fig. 6.11(b) shows that some uneven imprints are left on the mortar matrix by AKF due to rough surface, which indicates that a bonding exists to a certain extent between AKF and the mortar matrix even if it is not strong enough. Fig. 6.11(c) shows that the fibrillation of AHPKF occurs and some individual fibrils can be clearly seen in one bundle of AHPKF, which is because some substances, mainly hemicellulose and lignin, have been removed 
(Williams et al. 2011). This can further increase the contact area of AHPKF with the mortar matrix and can be helpful to the mechanical properties. Generally, through microstructure analysis, it can be seen that the bonding between these three types of fibers (RKF, AKF, and AHPKF) and the cementitious matrix is not good enough due to the obvious fiber slippage, which is partly responsible for the worse mechanical properties of fiber reinforced mortars compared to the control. Meanwhile, it can also be seen that AKF and AHPKF can behave better than RKF in bonding due to the modified surface texture, which can lead to mortars with AKF or AHPKF have better mechanical properties than those with RKF.
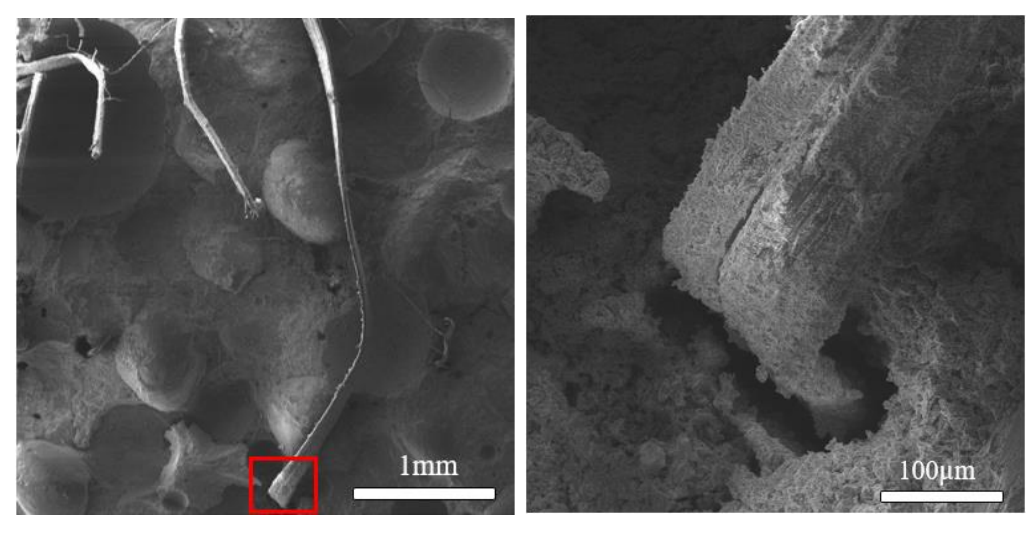

(a)
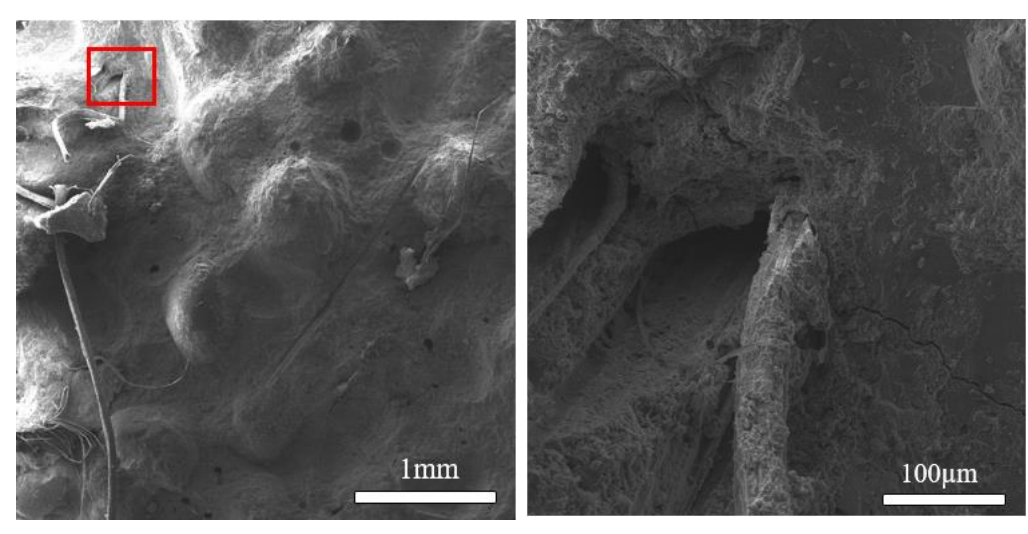

(b) 



(c)

Fig. 6.11. SEM images of the fracture surfaces of (a) RKF0.5, (b) AKF0.5, and (c)

AHPKF0.5 (Note: For each case, the right image is the enlarged rectangular section marked on the left image)

\subsubsection{Finite Element Analysis}

\subsubsection{Parameter Optimization for Mortar without Kenaf Fibers (The Control)}

For mortar without kenaf fibers (the control), the compressive strength (55.16 MPa) is directly obtained from the experiment. The modulus of elasticity and tensile strength can be initialized as 34.91 GPa and 3.33 MPa using Eq. (6.7) and Eq. (6.8), respectively. Together with other parameters introduced in section 6.3.1 of this paper, the load-deflection curve from finite element analysis can be obtained, which is denoted as "Control-FEA (original)" in Fig. 6.12. By comparing with the load-deflection curves directly from the experiment (also included in Fig. 6.12), it is clearly seen that there is a significant discrepancy between finite element analysis and experiment. Therefore, an optimization process is needed by adjusting the tensile strength and modulus of elasticity to make the curve from finite element analysis closely approach the experimental result as much as possible. Eventually, the modified tensile strength and modulus of elasticity are 4.95 $\mathrm{MPa}$ and $25 \mathrm{GPa}$, respectively, which are adopted as the fundamental parameters of mortar for 
the following analysis. The resulting modified load-deflection curve from finite element analysis is also plotted in Fig. 6.12, which is denoted as "Control-FEA (modified)". The corresponding peak load, deflection at peak, and flexural strain at peak from experiment and finite element analysis are compared in Table 6.3, which are in good agreement.

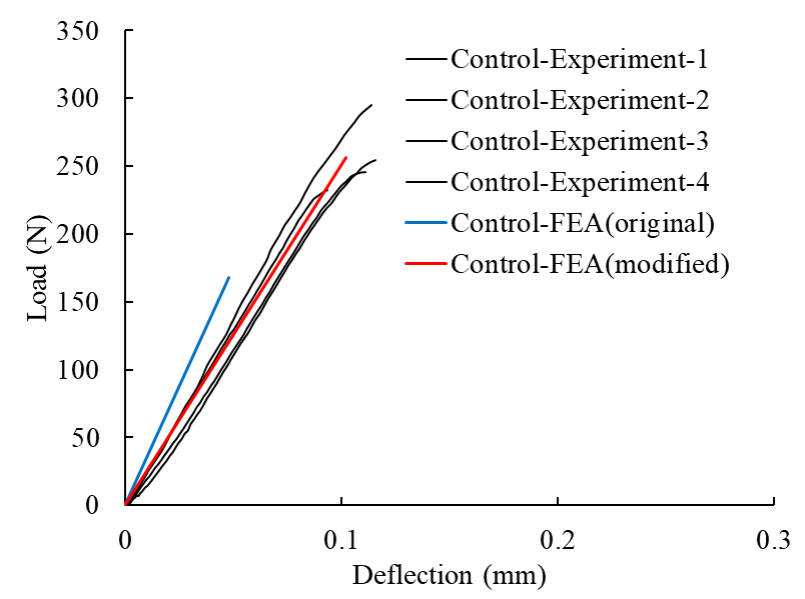

Fig. 6.12. Comparison of load-deflection curves of the control from FEA and experiment

Table 6.3 Comparison of experiment with finite element analysis for the control

\begin{tabular}{lccc}
\hline Specimens & Peak load (N) & $\begin{array}{c}\text { Deflection at peak } \\
(\delta, \mathrm{mm})\end{array}$ & $\begin{array}{c}\text { Flexural strain at peak } \\
(\varepsilon)^{*}\end{array}$ \\
\hline Control-Experiment & $257.20 \pm 26.24$ & $0.109 \pm 0.011$ & $0.000255 \pm 0.000026$ \\
Control-FEA & 256.11 & 0.102 & 0.000219 \\
\hline
\end{tabular}

Note: * The experimental value of $\varepsilon$ is calculated based on $\delta$ using $\varepsilon=6^{*} \delta^{*} h / l^{2}$, in which $h$ and $l$ are height and length of a beam.

\subsubsection{Stress and Cracking Strain of Mortar with Kenaf Fibers}

Before examining the stress and cracking strain within fiber reinforced mortars, it is necessary to compare the experimental and FEA results to assure the simulation is in agreement with the experiment. Take mortar with $0.75 \%$ AKF for example, by using the parameters of mortar matrix obtained from previous section $\left(f_{c}{ }^{\prime}=55.16 \mathrm{MPa}, E_{c}=25 \mathrm{GPa}\right.$, $f_{t}^{\prime}=4.95 \mathrm{MPa}$ ), the load-deflection curve (in red color) from the finite element analysis is compared to those (in black color) of four replicate specimens of AKF0.75P0.2 from the 
experiment, as shown in Fig. 6.13. Ican be seen that the load-deflection curve from finite element analysis is consistent with the experimental result. The peak loads from the experiment and finite element analysis are $274.54 \pm 27.19 \mathrm{~N}$ and $256.72 \mathrm{~N}$, respectively. Here, it has to be noted that since the pullout behavior of kenaf fibers is not modeled, the stress of kenaf fibers will continue increasing linearly with the strain after mortar cracks, and the load-deflection curve after the peak load will not be as accurate as the reality. This is one limitation of this model. However, since during the modelling of interest, the tensile stress of kenaf fibers is within their tensile capacity, and the load $(50.39 \pm 19.37 \mathrm{~N})$ that the specimen can bear immediately once cracking from the experiment is much close to 53.91 $\mathrm{N}$ obtained from finite element analysis, it is appropriate to approximately simulate the 0.75\% AKF specimen.



Fig. 6.13. Comparison of load-deflection curves of mortars with $0.75 \%$ AKF from finite element analysis and experiment

To visually identify the development of stress and cracking strain with deflection beyond cracking, three deflections are selected to assist in examining the stress and cracking strain contour bands. From the simulated curve in Fig. 6.13, it can be seen that 
the deflection of $0.102 \mathrm{~mm}$ that corresponds to the peak load where the cracking occurs is very critical, which is taken as the " 1 " deflection. Beyond the "1" deflection, there is an abrupt load decrease in the simulated curve, and the deflection of $0.108 \mathrm{~mm}$ closest to the "1" deflection is taken as the "2" deflection. The third deflection can be any deflection that is far from the " 2 " deflection to reveal the situation of specimens subject to a certain deflection from cracking, which is taken as $0.3 \mathrm{~mm}$ (denoted as " 3 " in Fig. 6.13). The stress and cracking strain contour bands of the control and AKF0.75 corresponding to these three deflections are shown in Fig. 6.14 and Fig. 6.15, respectively. Positive and negative values in the legend are indicative of tensile stress and compressive stress, respectively. Fig. 6.14 shows that before cracking ("1"), the stress contour band of AKF0.75 is almost the same as that of the control. However, after cracking (" 2 " and " 3 "), the compressive stress at the top of AKF0.75 is significantly higher than that at the top of the control. Moreover, when the deflection is $0.108 \mathrm{~mm}$ ("2"), a slight difference can be seen for the control and AKF0.75. Compared to the control, a clear tensional zone (shown in red color in the related figure) near the compressive zone exists for AKF0.75. This is because after cracking, the control completely fails, and no tensional zone exists; however, for AKF0.75, the failure is progressive, and the tensional zone shifts upward. Fig. $\mathbf{6 . 1 5}$ shows that the cracking strain of AKF0.75 is less than that of the control specimen in general. Moreover, once cracks appear (see "2" section in Fig. 6.15), the cracking strain of the control specimen can rapidly develop from the bottom to the top; however, the cracking strain of AKF0.75 does not develop to the whole depth of beams immediately, which indicates that the crack propagation is slowed down by fibers. This is mainly because, after the specimen cracks, kenaf fibers can bridge the cracked sections and delay crack propagation. 


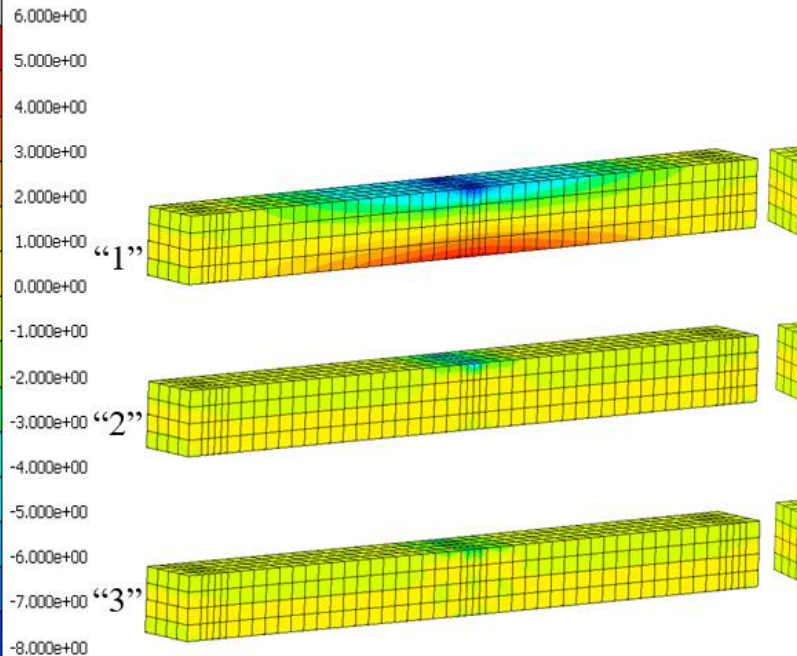

(a) Control
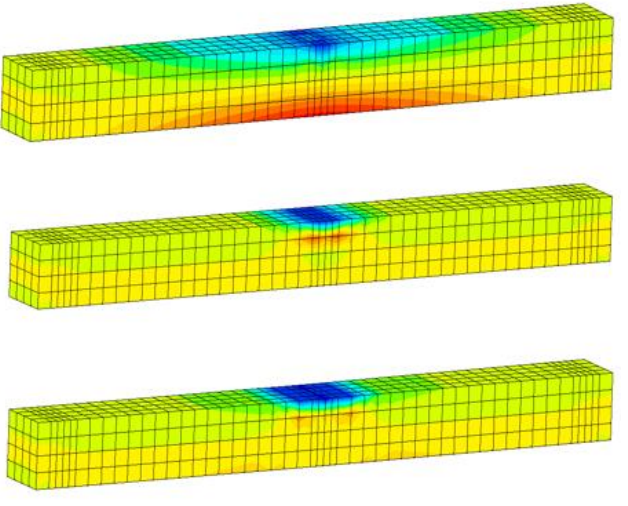

(b) AKF0.75

Fig. 6.14. Stress contour band of (a) the control and (b) AKF0.75

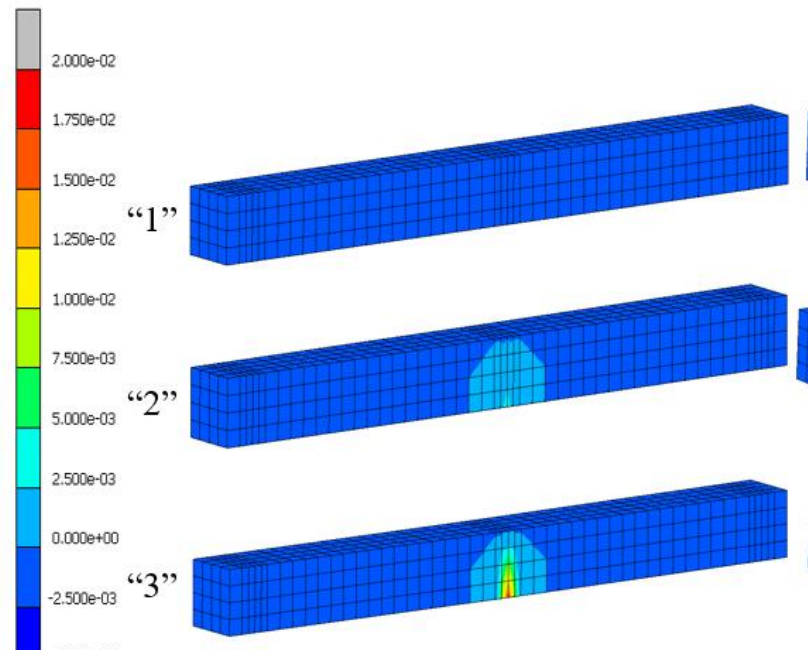

(a) Control
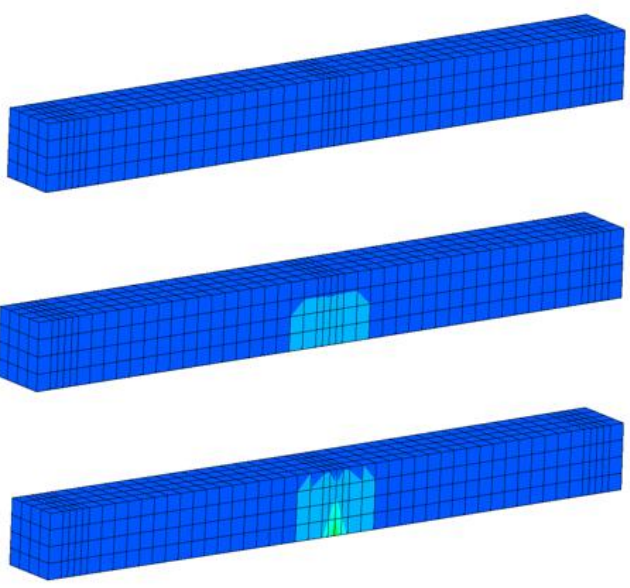

(b) AKF0.75

Fig. 6.15. Cracking strain contour band of (a) the control and (b) AKF0.75

\subsubsection{Effect of Fiber Dosage on Load-Bearing Capacity and Cracking Strain}

The load-deflection curves and cracking strain-deflection curves of mortar beams with $0.25 \%, 0.5 \%$, and $0.75 \%$ AKF are shown in Fig. 6.16(a) and Fig. 6.16(b), respectively. Fig. 6.16(a) shows that the peak load is not increased significantly with the fiber dosage increasing from $0.25 \%$ to $0.75 \%$; however, the residual load that is defined as the load that 
a specimen can bear after the peak load is reached is increased. A higher residual load can prevent a specimen from immediate full collapse after the peak load hyyis reached and enable the specimen to have a certain load bearing capacity at the post-cracking stage. The cracking strain appears (shown in Fig. 6.16(b)) after the cracking occurs, and it increases with the increase of deflection of the specimen. Fig. 6.16(b) shows that the cracking strain is reduced significantly with the increasing fiber dosage, especially when the fiber dosage increases from 0 to $0.5 \%$, which is consistent with the reduced length and width of cracks observed in the experiment (see Fig. 6.7). The reduced cracking strain represents the reduced extent of cracking, indicating a slow crack propagation after the mortar cracks. Therefore, with the increase of fiber dosage, the mortar is less prone to exhibit a sudden brittle failure. Generally, through the finite element analysis, it can be seen that a low content fiber cannot improve the peak load but can improve the residual load and reduce the cracking strain significantly.

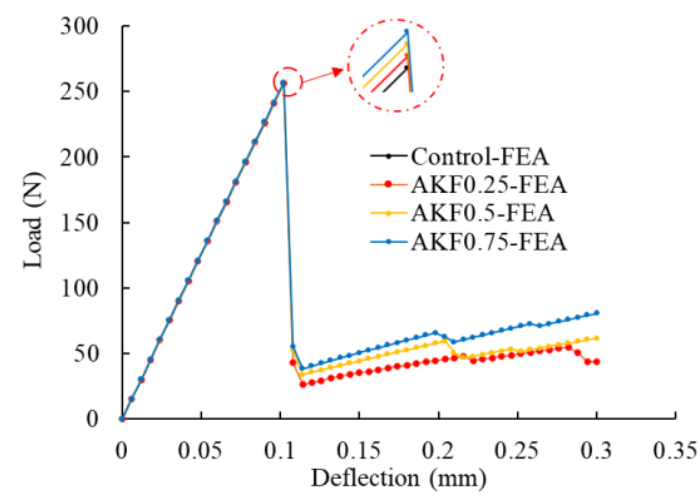

(a)

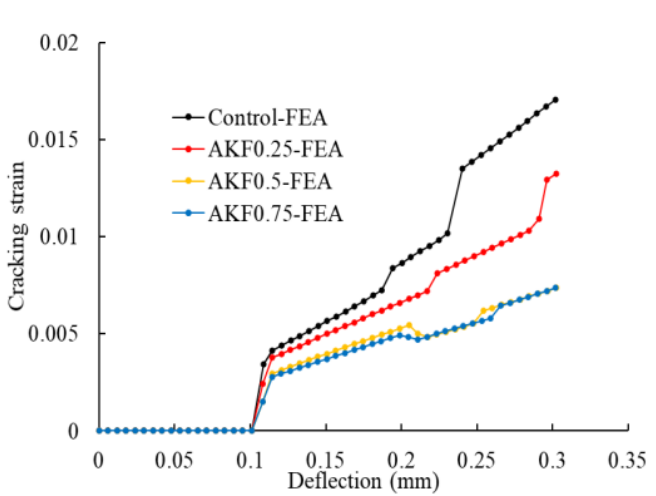

(b)

Fig. 6.16. (a) Load-deflection curves and (b) cracking strain-deflection curves of mortar beams with varying AKF dosages 


\subsection{Conclusions}

In this study, raw kenaf fibers (RKF), alkaline treated kenaf fibers (AKF), and alkaline-hydrogen peroxide treated kenaf fibers (AHPKF) with different dosages $(0.25 \%$, $0.5 \%$, and $0.75 \%$ by weight of cement) were incorporated in the mortar to evaluate their impact on the flexural behavior of mortar. Compressive test, flexural test, and SEM test were conducted. Moreover, the finite element analysis was adopted to assist in examining the stress and cracking strain of specimens. Several important conclusions can be drawn.

The presence of kenaf fibers in mortars can reduce compressive strength and flexural strength, which can be attributed to several factors, such as the reduced density of specimens, weak interfacial adhesion, and negatively affected cement hydration, etc. However, the flexural toughness can be increased significantly due to fiber bridging over cracks. Moreover, the addition of superplasticizer can improve the strength and toughness obviously through increasing the density of specimens.

With the increase of fiber dosage, the specimens tend to fail in a more ductile manner that the mortar cubes tend to be more intact while failing and the mortar beams tend to have smaller cracks at the mid-span after cracking. Moreover, the compressive strength and flexural strength are reduced, which is mainly due to the reduced density of specimens. The change of modulus of elasticity is not obvious. However, the flexural toughness is enhanced significantly, and the improvement can be $10.66-28.86 \%, 64.54-81.80 \%$, and $70.25-92.80 \%$ for the fiber dosage of $0.25 \%, 0.5 \%$, and $0.75 \%$, respectively.

By comparing specimens with RKF, AKF, and AHPKF, although no significant difference in density and modulus of elasticity can be seen, RKF seems to lead to the worst compressive strength, flexural strength, and flexural toughness. This is mainly because 
RKF has the largest amount of hemicellulose, lignin, and extractives and the relatively smooth surface. Moreover, by the comparison of AKF and AHPKF, the difference in mechanical properties is slight, but mostly AKF seems to be a little better than AHPKF.

The microstructure analysis shows that regardless of fiber type, the fiber pullout occurs due to a weak bonding, which is not beneficial to the mechanical properties of mortar. Meanwhile, AKF and AHPKF seem to behave better than RKF in the bonding in their ways, which lead mortars with AKF or AHPKF to have better mechanical properties than those with RKF.

The stress and cracking strain distribution of AKF0.75 and the control were examined in detail through finite element analysis. Before cracking 0.75\% AKF does not change the stress distribution within specimens obviously, but after cracking it can increase the stress level in the compressive zone, indicating a higher residual load. Also, $0.75 \%$ AKF can slow down crack propagation and reduce cracking strain significantly. Lastly, finite element analysis indicates that a low fiber dosage (up to $0.75 \%$ ) cannot improve the peak load significantly but can increase the residual load and reduce the cracking strain. More fibers are needed to be incorporated into mortar beams if the peak load needs to be improved obviously.

Given that with the increase of fiber dosage from $0.25 \%$ to $0.75 \%$, the strength is reduced yet the toughness is increased, and also the cracking strain is significantly reduced until $0.5 \%$ fiber dosage, $0.5 \%$ may be the best fiber dosage. If the volume fraction of aggregates in concrete is assumed as $60 \%-80 \%$ and the specific gravity of kenaf fibers is approximately assumed as 1, $0.5 \%$ fiber dosage by weight of cement will be converted into 
$0.12-0.24 \%$ fiber dosage by volume of concrete, which is the recommended value in improving the flexural properties of mortar. 


\section{CHAPTER 7 CONCLUSIONS AND FUTURE WORK}

\subsection{Conclusions}

In this dissertation, the hydration, shrinkage, cracking, and mechanical properties of cementitious materials with lignocellulosic biomass wastes were studied. Three types of lignocellulosic biomass wastes (hemp powders, wood chips, and kenaf fibers) at different scales were recycled and reutilized to partially replace cement, partially replace sand, or serve as reinforcements, respectively, in cementitious materials. In order to improve their effects on the performance of cementitious materials, these lignocellulosic biomass wastes were modified as required using physical or chemical treatment methods. The effect of untreated and treated lignocellulosic biomass wastes on cementitious materials was examined in detail. Some important conclusions can be drawn as follows.

\subsubsection{Effect of Hemp Powders on Cement Hydration}

Hemp powders were used to partially replace cement by $5 \%$ and $10 \%$ (by weight), respectively, which were found to delay cement hydration and affect the formation of hydration products. Even, for some cases, after 7-day hydration, they were still at the dormant phase, and the hydration was very slow.

Alkaline treatment (saturated $\mathrm{Ca}(\mathrm{OH})_{2}$ solution) on hemp powders could remove some hemicellulose and increase the relative cellulose content, which could mitigate their delaying effect on cement hydration. Moreover, the washing process following the alkaline 
treatment could further reduce the delaying effect by removing more hemicellulose and other unbeneficial substances.

Compared to coarse hemp powders, fine hemp powders had a higher specific surface area to contact with cement paste, which could lead them to result in a more delaying effect on cement hydration.

Compared to $5 \%$ replacement, $10 \%$ replacement could delay cement hydration more significantly, and the hydration could be almost completely inhibited during 7-day testing. The result indicated that the $10 \%$ replacement could be the limit replacement.

\subsubsection{Effect of Wood Chips on Mechanical Properties of Mortar}

Wood chips were used to partially replace silica sand by $5 \%$ and $10 \%$ (by weight), respectively, in mortars, which was found to reduce the compressive strength, flexural strength, and modulus of elasticity, but increase the toughness.

Compared to untorrefied wood chips, torrefied wood chips had a slightly rougher surface, which could increase the bonding with the cementitious matrix. Therefore, mortars with torrefied wood chips had higher strength and modulus of elasticity than those with untorrefied wood chips; however, the toughness was lower.

\subsubsection{Effect of Chemical Treatment on Kenaf Fibers}

Some inorganic chemicals (sodium hydroxide, potassium permanganate, potassium dichromate, hydrogen peroxide, and sodium chlorite) were used to modify kenaf fibers, which were found to remove some hemicellulose, lignin, and extractives of kenaf fibers. After chemical treatment, the moisture sorption was reduced, and the crystallinity index, surface roughness, and tensile strength were improved. 
Compared to raw kenaf fibers, solely alkaline treatment could lead to relatively good improvement. Moreover, of all chemical treatments, alkaline-hydrogen peroxide treatment exhibited the best generally.

\subsubsection{Effect of Kenaf Fibers on Shrinkage and Cracking of Cement Paste}

Raw kenaf fibers (RKF), alkaline treated kenaf fibers (AKF), and alkaline-hydrogen peroxide treated kenaf fibers (AHPKF) with the dosages of $0.25 \%$ and $0.5 \%$ by weight of cement were used as reinforcements in cement paste, which were found to reduce the autogenous shrinkage and drying shrinkage cracking significantly.

Compared to $0.25 \%$ fiber dosage, $0.5 \%$ fiber dosage could reduce the autogenous shrinkage and drying shrinkage cracking more. Of all three types of kenaf fibers, alkalinehydrogen peroxide treated fibers were the best.

\subsubsection{Effect of Kenaf Fibers on Flexural Behavior of Mortar}

Raw kenaf fibers (RKF), alkaline treated kenaf fibers (AKF), and alkaline-hydrogen peroxide treated kenaf fibers (AHPKF) with the dosages of $0.25 \%, 0.5 \%$, and $0.75 \%$ by weight of cement were used as reinforcements in mortars, which were found to reduce compressive strength and flexural strength due to the increased voids but increase flexural toughness significantly. Moreover, with the increase of fiber dosage from $0.25 \%$ to $0.75 \%$, the compressive strength and flexural strength were reduced; however, the flexural toughness was improved significantly. The addition of superplasticizer could improve the compressive strength, flexural strength, and flexural toughness compared to those without superplasticizer.

Of all three types of fibers (RKF, AKF, and AHPKF), RKF led to the worst compressive strength, flexural strength, and flexural toughness. Moreover, by the 
comparison of $\mathrm{AKF}$ and $\mathrm{AHPKF}$, the difference in mechanical properties was slight, but mostly AKF seemed to be a little better than AHPKF.

The microstructure analysis showed that the fiber pullout occurs due to weak bonding between the fibers and the mortar matrix. AKF and AHPKF seemed to behave better than RKF in the bonding.

The finite element analysis indicated that a low fiber dosage (up to $0.75 \%$ ) could not improve the peak load significantly but could increase the residual load, slow down crack propagation, and reduce the cracking strain significantly.

\subsubsection{Recommendations}

Based on this study, the concrete developed with lignocellulosic biomass wastes can be used for non-structural elements, such as pavement and roof, where the requirement for strength is relatively low. Moreover, since lignocellulosic biomass wastes have the ability of improving the toughness of concrete significantly, they can be suitable for the foundation floor for machinery in factories or other places where there is a high requirement for energy absorption when concrete is exposed to dynamic load.

The allowable dosages of hemp powders, wood chips, and kenaf fibers in concrete are different. When the volume fraction of aggregates in concrete is assumed as $60-80 \%$ and the specific gravity of hemp powder is approximately assumed as 1 , it is recommended that the limit dosage of hemp powders is $2.24-4.48 \%$ by volume of concrete ( $10 \%$ dosage limit by weight of cement), the dosages of wood chips by volume of concrete are roughly $5-10 \%$ for OW and HTW (10\% by weight of sand) and 2.5-5\% for LTW (5\% by weight of sand), respectively, and the dosage of kenaf fibers by volume of concrete is $0.12-0.24 \%$ ( $0.5 \%$ by weight of cement). 
Even if this research does not cover the long-term behavior of concrete with lignocellulosic biomass, based on the existing literature that lignocellulosic biomass can be degraded in the alkaline environment of concrete, the bonding between lignocellulosic biomass and the matrix may be compromised in the long run. This can hurt the mechanical properties of concrete. However, based on this research, some physical treatment (such as torrefaction treatment) and chemical treatment (such as alkaline treatment) can remove some easily degraded substances (such as hemicellulose and impurities) from lignocellulosic biomass, which is believed to improve the long-term behavior of concrete compared to those with raw lignocellulosic biomass. Therefore, it is recommended to modify lignocellulosic biomass physically or chemically prior to being used in concrete.

\subsection{Future Work}

This work suggests that the lignocellulosic biomass can affect the hydration, shrinkage, cracking, and mechanical properties of cementitious materials. Some future work on this topic can be further studied.

- Lignocellulosic biomass is found to delay cement hydration, which is mainly attributed to some saccharides generated from the degradation of lignocellulosic biomass. Since different saccharides may have differing effects on cement hydration and also the degradation of lignocellulosic biomass can produce some other substances aside from saccharides, the delaying mechanism of cement hydration can be further studied in detail.

- In this work, some physical and chemical treatments are applied to lignocellulosic biomass, which can increase cost and energy consumption. The treatment method can be optimized to improve its economy. 
- Lignocellulosic biomass can be degraded in the alkaline environment of cementitious materials, and their effects can vary with time in the long run. Therefore, the durability of cementitious materials with lignocellulosic biomass can be studied.

- To reduce the degradation of lignocellulosic biomass in cementitious materials, an alternative way is to lower the alkalinity of cementitious materials. The application of lignocellulosic biomass to low alkaline cement can be studied.

- Lignocellulosic biomass in cementitious materials can absorb much water, which can reduce the flowability and increase the porosity of cementitious materials. When a large amount of lignocellulosic biomass is used, superplasticizer should be added to improve the flowability. With the addition of superplasticizer, the effect of lignocellulosic biomass on cementitious materials can be studied.

- Lignocellulosic biomass is much lighter than the cementitious materials, and they can be possibly used to develop lightweight concrete in the future study.

- Due to the high water absorption capacity, the application of lignocellulosic biomass as an internal curing agent for concrete can be studied.

- In the finite element analysis in this research, there is one limitation with the model that the fiber orientation and fiber pullout behavior are not considered realistically. To realistically model the flexural behavior of cementitious materials with kenaf fibers using finite element method, the fiber orientation and fiber pullout behavior can be considered in the future work. 


\section{REFERENCES}

"ACI 318-14-Building Code Requirements for Structural Concrete." American Concrete Institute Farmington Hills, MI.

(2015). "ASTM E1705-15 Standard Terminology Relating to Biotechnology." ASTM International, West Conshohocken, PA.

A, I. (2016). "Biomass Concrete: Challenges and Future." MOJ Civil Engineering, 1(2). Abdel-Halim, E. (2014). "Chemical modification of cellulose extracted from sugarcane bagasse: Preparation of hydroxyethyl cellulose." Arabian Journal of Chemistry, $7(3), 362-371$.

Ahmad, H., and Fan, M. (2018). "Interfacial properties and structural performance of resin-coated natural fibre rebars within cementitious matrices." Cement and Concrete Composites, 87, 44-52.

Ahmad, R., Hamid, R., and Osman, S. A. (2019). "Physical and Chemical Modifications of Plant Fibres for Reinforcement in Cementitious Composites." Advances in Civil Engineering.

Al-Jelawy, H. (2013). "Experimental and numerical investigations on bond durability of CFRP strengthened concrete members subjected to environmental exposure." 
Ali, M., and Chouw, N. (2013). "Experimental investigations on coconut-fibre rope tensile strength and pullout from coconut fibre reinforced concrete." Construction and Building Materials, 41, 681-690.

Ali, M., Li, X., and Chouw, N. (2013). "Experimental investigations on bond strength between coconut fibre and concrete." Materials \& Design, 44, 596-605.

Alix, S., Philippe, E., Bessadok, A., Lebrun, L., Morvan, C., and Marais, S. (2009). "Effect of chemical treatments on water sorption and mechanical properties of flax fibres." Bioresource Technology, 100(20), 4742-4749.

Amel, B., Paridah, M., Rahim, S., Osman, Z., Zakiah, A., and Ahmed, S. (2014). "Effects of kenaf bast fibres on hydration behaviour of cement." Journal of Tropical Forest Science, 340-346.

Amel El, G., Imed Ben, M., Mohamed Hassen, V. B., and Mohamed Sadok, R. (2012). "SEPARATION AND CHARACTERIZATION OF NEW CELLULOSIC FIBRES FROM THE JUNCUS ACUTUS L PLANT." BioResources, 2002-2018.

Amiandamhen, S., Izekor, D., and Balogun, A. (2016). "Performance characteristics of treated kenaf bast fibre reinforced cement composite." Journal of the Indian Academy of Wood Science, 13(2), 156-160.

Andiç-Çakir, Ö., Sarikanat, M., Tüfekçi, H. B., Demirci, C., and Erdoğan, Ü. H. (2014). "Physical and mechanical properties of randomly oriented coir fiber-cementitious composites." Composites Part B: Engineering, 61, 49-54.

Arsyad, M., Wardana, I., and Irawan, Y. S. (2015). "The morphology of coconut fiber surface under chemical treatment." Matéria (Rio de Janeiro), 20(1), 169-177. 
Asasutjarit, C., Hirunlabh, J., Khedari, J., Charoenvai, S., Zeghmati, B., and Shin, U. C. (2007). "Development of coconut coir-based lightweight cement board." Construction and Building Materials, 21(2), 277-288.

ASTM (2008). "C191-08, Standard Test Methods for Time of Setting of Hydraulic Cement by Vicat Needle." ASTM International, West Conshohocken, PA. ASTM (2014). " C1698-09 Standard Test Method for Autogenous Strain of Cement Paste and Mortar." ASTM International, West Conshohocken, PA.

ASTM (2019). "C1609M-19 Standard Test Method for Flexural Performance of FiberReinforced Concrete (Using Beam With Third-Point Loading)." ASTM International, West Conshohocken, PA.

ASTM, C.-. (2008). "Standard test method for fundamental transverse, longitudinal, and torsional resonant frequencies of concrete specimens." Dynamic Young's Modulus, 5-6.

ASTM. (2009). "Standard test method for measurement of heat of hydration of hydraulic cementitious materials using isothermal conduction calorimetry." ASTM C170209a, West conshohocken, PA.

ASTMC1437-13 "Standard Test Method for Flow of Hydraulic Cement Mortar."

Awwad, E., Mabsout, M., Hamad, B., Farran, M. T., and Khatib, H. (2012). "Studies on fiber-reinforced concrete using industrial hemp fibers." Construction and Building Materials, 35, 710-717.

Ballesteros, J. E. M., Santos, S. F., Mármol, G., Savastano Jr, H., and Fiorelli, J. (2015). "Evaluation of cellulosic pulps treated by hornification as reinforcement of cementitious composites." Construction and Building Materials, 100, 83-90. 
Banthia, N., and Gupta, R. (2006). "Influence of polypropylene fiber geometry on plastic shrinkage cracking in concrete." Cement and concrete Research, 36(7), 12631267.

Barbosa, R., Lapa, N., Dias, D., and Mendes, B. (2013). "Concretes containing biomass ashes: Mechanical, chemical, and ecotoxic performances." Construction and Building Materials, 48, 457-463.

Baroghel-Bouny, V., and Kheirbek, A. "Effect of mix-parameters on autogenous deformations of cement pastes-Microstructural interpretations." Proc., International RILEM Workshop on Shrinkage of Concrete "Shrinkage, 115-141.

Baroghel-Bouny, V., Mounanga, P., Khelidj, A., Loukili, A., and Rafai, N. (2006).

"Autogenous deformations of cement pastes: part II. W/C effects, micro-macro correlations, and threshold values." Cement and Concrete Research, 36(1), 123 136.

Barth, K. E., and Wu, H. (2006). "Efficient nonlinear finite element modeling of slab on steel stringer bridges." Finite elements in analysis and design, 42(14-15), 13041313.

Bažant, Z. P., and Oh, B. H. (1983). "Crack band theory for fracture of concrete." Matériaux et construction, 16(3), 155-177.

Becchio, C., Corgnati, S. P., Kindinis, A., and Pagliolico, S. (2009). "Improving environmental sustainability of concrete products: Investigation on MWC thermal and mechanical properties." Energy and Buildings, 41(11), 1127-1134. 
Beckermann, G., and Pickering, K. L. (2008). "Engineering and evaluation of hemp fibre reinforced polypropylene composites: fibre treatment and matrix modification." Composites Part A: Applied Science and Manufacturing, 39(6), 979-988.

Bederina, M., Marmoret, L., Mezreb, K., Khenfer, M., Bali, A., and Quéneudec, M. (2007). "Effect of the addition of wood shavings on thermal conductivity of sand concretes: experimental study and modelling." Construction and Building Materials, 21(3), 662-668.

Benmansour, N., Agoudjil, B., Gherabli, A., Kareche, A., and Boudenne, A. (2014). "Thermal and mechanical performance of natural mortar reinforced with date palm fibers for use as insulating materials in building." Energy and Buildings, 81, 98-104.

Bentz, D. P. (2008). "A review of early-age properties of cement-based materials." Cement and Concrete Research, 38(2), 196-204.

Bentz, D. P., and Weiss, W. J. (2011). Internal curing: a 2010 state-of-the-art review, US Department of Commerce, National Institute of Standards and Technology ....

Berry, S. L., and Roderick, M. L. (2005). "Plant-water relations and the fibre saturation point." New Phytologist, 168(1), 25-37.

Bilba, K., Arsène, M.-A., and Ouensanga, A. (2003). "Sugar cane bagasse fibre reinforced cement composites. Part I. Influence of the botanical components of bagasse on the setting of bagasse/cement composite." Cement and concrete composites, 25(1), 91-96.

Boix, E., Gineau, E., Narciso, J. O., Höfte, H., Mouille, G., and Navard, P. (2020). "Influence of chemical treatments of miscanthus stem fragments on 
polysaccharide release in the presence of cement and on the mechanical properties of bio-based concrete materials." Cement and Concrete Composites, 105, 103429.

Bullard, J. W., Jennings, H. M., Livingston, R. A., Nonat, A., Scherer, G. W., Schweitzer, J. S., Scrivener, K. L., and Thomas, J. J. (2011). "Mechanisms of cement hydration." Cement and concrete research, 41(12), 1208-1223.

Bulut, Y., and Aksit, A. (2013). "A comparative study on chemical treatment of jute fiber: potassium dichromate, potassium permanganate and sodium perborate trihydrate." Cellulose, 20(6), 3155-3164.

Buyukozturk, O. (1977). "Nonlinear analysis of reinforced concrete structures." Computers \& Structures, 7(1), 149-156.

Cao, Y., Zavaterri, P., Youngblood, J., Moon, R., and Weiss, J. (2015). "The influence of cellulose nanocrystal additions on the performance of cement paste." Cement and Concrete Composites, 56, 73-83.

Carvalho, K. C. C., Mulinari, D. R., Voorwald, H. J. C., and Cioffi, M. O. H. (2010). "Chemical modification effect on the mechanical properties of hips/coconut fiber composites." BioResources, 5(2), 1143-1155.

Célino, A., Fréour, S., Jacquemin, F., and Casari, P. (2013). "Characterization and modeling of the moisture diffusion behavior of natural fibers." Journal of Applied Polymer Science, 130(1), 297-306.

Chakraborty, S., Kundu, S. P., Roy, A., Adhikari, B., and Majumder, S. B. (2013). "Effect of jute as fiber reinforcement controlling the hydration characteristics of cement matrix." Industrial \& Engineering Chemistry Research, 52(3), 1252-1260. 
Chakraborty, S., Kundu, S. P., Roy, A., Basak, R. K., Adhikari, B., and Majumder, S. (2013). "Improvement of the mechanical properties of jute fibre reinforced cement mortar: A statistical approach." Construction and Building Materials, 38, 776-784.

Chang, S., Zhao, Z., Zheng, A., He, F., Huang, Z., and Li, H. (2012). "Characterization of products from torrefaction of sprucewood and bagasse in an auger reactor." Energy \& Fuels, 26(11), 7009-7017.

Chen, D., Zheng, Z., Fu, K., Zeng, Z., Wang, J., and Lu, M. (2015). "Torrefaction of biomass stalk and its effect on the yield and quality of pyrolysis products." Fuel, $159,27-32$.

Chen, G., and Baker, G. (2004). "Analytical model for predication of crack spacing due to shrinkage in concrete pavements." Journal of Structural Engineering, 130(10), 1529-1533.

Chen, Y., Yang, H., Wang, X., Zhang, S., and Chen, H. (2012). "Biomass-based pyrolytic polygeneration system on cotton stalk pyrolysis: influence of temperature." Bioresource technology, 107, 411-418.

Chen, Y., Yu, Q., and Brouwers, H. (2017). "Acoustic performance and microstructural analysis of bio-based lightweight concrete containing miscanthus." Construction and Building Materials, 157, 839-851.

Choudhary, H., Anupama, A., Kumar, R., Panzi, M., Matteppanavar, S., Sherikar, B. N., and Sahoo, B. (2015). "Observation of phase transformations in cement during hydration." Construction and Building Materials, 101, 122-129. 
Cody, R. D., Cody, A. M., Spry, P. G., and Lee, H. (2001). "Reduction of concrete deterioration by ettringite using crystal growth inhibition techniques." Department of Geological and Atmospheric Sciences, Iowa State University.

Çomak, B., Bideci, A., and Bideci, Ö. S. (2018). "Effects of hemp fibers on characteristics of cement based mortar." Construction and Building Materials, $169,794-799$.

Correia, V., Santos, S., Tonoli, G., and Savastano Jr, H. (2016). "Characterization of vegetable fibers and their application in cementitious composites." Nonconventional and Vernacular Construction Materials, Elsevier, 83-110.

Correia, V. d. C., dos Santos, V., Rodier, L. B., Ghavami, K., and Savastano Jr, H. (2016). "Bamboo fiber at macro-, micro-and nanoscale for application as reinforcement." Green Materials, 4(1), 41-52.

Coutts, R. S., and Kightly, P. (1984). "Bonding in wood fibre-cement composites." Journal of Materials Science, 19(10), 3355-3359.

Cuthbertson, D., Berardi, U., Briens, C., and Berruti, F. (2019). "Biochar from residual biomass as a concrete filler for improved thermal and acoustic properties." Biomass and bioenergy, 120, 77-83.

Darquennes, A., Staquet, S., Delplancke-Ogletree, M.-P., and Espion, B. (2011). "Effect of autogenous deformation on the cracking risk of slag cement concretes." Cement and Concrete Composites, 33(3), 368-379.

Dawood, E. T., and Ramli, M. (2010). "Development of high strength flowable mortar with hybrid fiber." Construction and building materials, 24(6), 1043-1050. 
Dawood, E. T., and Ramli, M. (2012). "Properties of high-strength flowable mortar reinforced with palm fibers." ISRN Civil Engineering, 2012.

de Andrade Silva, F., Toledo Filho, R. D., de Almeida Melo Filho, J., and Fairbairn, E. d. M. R. (2010). "Physical and mechanical properties of durable sisal fiber-cement composites." Construction and building materials, 24(5), 777-785.

de Klerk, M. D., Kayondo, M., Moelich, G. M., de Villiers, W. I., Combrinck, R., and Boshoff, W. P. (2020). "Durability of chemically modified sisal fibre in cementbased composites." Construction and Building Materials, 241.

De Rosa, I. M., Kenny, J. M., Puglia, D., Santulli, C., and Sarasini, F. (2010). "Morphological, thermal and mechanical characterization of okra (Abelmoschus esculentus) fibres as potential reinforcement in polymer composites." Composites Science and Technology, 70(1), 116-122.

Demis, S., Tapali, J., and Papadakis, V. (2014). "An investigation of the effectiveness of the utilization of biomass ashes as pozzolanic materials." Construction and Building Materials, 68, 291-300.

Diógenes, H., Cossolino, L., Pereira, A., El Debs, M., and El Debs, A. (2011). "Determination of modulus of elasticity of concrete from the acoustic response." Revista IBRACON de Estruturas e Materiais, 4(5), 803-813.

Elmer, P. (2005). "FT-IR Spectroscopy Attenuated Total Reflectance (ATR)." Technical note, 27(11).

Elsaid, A., Dawood, M., Seracino, R., and Bobko, C. (2011). "Mechanical properties of kenaf fiber reinforced concrete." Construction and Building Materials, 25(4), 1991-2001. 
Feng, X., Garboczi, E. J., Bentz, D. P., Stutzman, P. E., and Mason, T. O. (2004).

"Estimation of the degree of hydration of blended cement pastes by a scanning electron microscope point-counting procedure." Cement and concrete research, 34(10), 1787-1793.

Ferreira, S. R., de Andrade Silva, F., Lima, P. R. L., and Toledo Filho, R. D. (2015). "Effect of fiber treatments on the sisal fiber properties and fiber-matrix bond in cement based systems." Construction and Building Materials, 101, 730-740.

Fidelis, M. E. A., Toledo Filho, R. D., de Andrade Silva, F., Mechtcherine, V., Butler, M., and Hempel, S. (2016). "The effect of accelerated aging on the interface of jute textile reinforced concrete." Cement and Concrete Composites, 74, 7-15.

Fonseca, D. A., Lupitskyy, R., Timmons, D., Gupta, M., and Satyavolu, J. (2014).

"Towards integrated biorefinery from dried distillers grains: selective extraction of pentoses using dilute acid hydrolysis." Biomass and Bioenergy, 71, 178-186.

Gao, P., Zhang, T., Luo, R., Wei, J., and Yu, Q. (2014). "Improvement of autogenous shrinkage measurement for cement paste at very early age: Corrugated tube method using non-contact sensors." Construction and Building Materials, 55, 57 62.

Gao, Y., Wang, X.-H., Yang, H.-P., and Chen, H.-P. (2012). "Characterization of products from hydrothermal treatments of cellulose." Energy, 42(1), 457-465.

Garzón-Roca, J., Adam, J. M., Calderón, P. A., and Valente, I. B. (2012). "Finite element modelling of steel-caged RC columns subjected to axial force and bending moment." Engineering Structures, 40, 168-186. 
Georgiadi-Stefanidi, K., Mistakidis, E., Perdikaris, P., and Papatheocharis, T. (2011). "Numerical simulation of the nonlinear bending response of fibre-reinforced cementitious matrix beams and comparison with experimental results." Engineering structures, 33(12), 3579-3589.

Gil, H., Ortega, A., and Pérez, J. (2017). "Mechanical behavior of mortar reinforced with sawdust waste." Procedia engineering, 200, 325-332.

Goriparthi, B. K., Suman, K., and Rao, N. M. (2012). "Effect of fiber surface treatments on mechanical and abrasive wear performance of polylactide/jute composites." Composites Part A: Applied Science and Manufacturing, 43(10), 1800-1808.

Govin, A., Peschard, A., and Guyonnet, R. (2006). "Modification of cement hydration at early ages by natural and heated wood." Cement and concrete composites, 28(1), $12-20$.

Guo, A., Sun, Z., and Satyavolu, J. (2019). "Impact of chemical treatment on the physiochemical and mechanical properties of kenaf fibers." Industrial Crops and Products, 141, 111726.

Gurunathan, T., Mohanty, S., and Nayak, S. K. (2015). "A review of the recent developments in biocomposites based on natural fibres and their application perspectives." Composites Part A: Applied Science and Manufacturing, 77, 1-25.

Horgnies, M., Chen, J., and Bouillon, C. (2013). "Overview about the use of Fourier transform infrared spectroscopy to study cementitious materials." WIT Trans. Eng. Sci, 77, 251-262. 
Hu, H.-T., Lin, F.-M., and Jan, Y.-Y. (2004). "Nonlinear finite element analysis of reinforced concrete beams strengthened by fiber-reinforced plastics." Composite Structures, 63(3-4), 271-281.

Hu, H.-T., and Schnobrich, W. C. (1990). "Nonlinear analysis of cracked reinforced concrete." Structural Journal, 87(2), 199-207.

Ismail, A. S., Jawaid, M., and Naveen, J. (2019). "Void Content, Tensile, Vibration and Acoustic Properties of Kenaf/Bamboo Fiber Reinforced Epoxy Hybrid Composites." Materials, 12(13), 2094.

Jo, B.-W., and Chakraborty, S. (2015). "A mild alkali treated jute fibre controlling the hydration behaviour of greener cement paste." Scientific reports, 5, 7837.

Jo, B. W., Chakraborty, S., and Kim, H. (2016). "Efficacy of alkali-treated jute as fibre reinforcement in enhancing the mechanical properties of cement mortar." Materials and Structures, 49(3), 1093-1104.

John, M. J., and Anandjiwala, R. D. (2008). "Recent developments in chemical modification and characterization of natural fiber-reinforced composites." Polymer composites, 29(2), 187-207.

John, M. J., and Thomas, S. (2008). "Biofibres and biocomposites." Carbohydrate polymers, 71(3), 343-364.

Jongvisuttisun, P. (2014). "Utilization of Eucalyptus Pulp Fibers in Cementitious Materials." Georgia Institute of Technology.

Jongvisuttisun, P., and Kurtis, K. E. (2015). "The role of hardwood pulp fibers in mitigation of early-age cracking." Cement and Concrete Composites, 57, 84-93. 
Jongvisuttisun, P., Negrello, C., and Kurtis, K. E. (2013). "Effect of processing variables on efficiency of eucalyptus pulps for internal curing." Cement and Concrete Composites, 37, 126-135.

Joseph, K., Thomas, S., and Pavithran, C. (1996). "Effect of chemical treatment on the tensile properties of short sisal fibre-reinforced polyethylene composites." Polymer, 37(23), 5139-5149.

Kabir, M., Wang, H., Lau, K., and Cardona, F. (2012). "Chemical treatments on plantbased natural fibre reinforced polymer composites: An overview." Composites Part B: Engineering, 43(7), 2883-2892.

Kabir, M., Wang, H., Lau, K., and Cardona, F. (2013). "Effects of chemical treatments on hemp fibre structure." Applied Surface Science, 276, 13-23.

Karim, M. R., Hossain, M. M., and Yusoff, S. B. "Engineering and sustainability aspect of palm oil shell powder in cement." Proc., AIP Conference Proceedings, AIP Publishing, 020038.

Kawashima, S., and Shah, S. P. (2011). "Early-age autogenous and drying shrinkage behavior of cellulose fiber-reinforced cementitious materials." Cement and Concrete Composites, 33(2), 201-208.

Khairallah, R. S. (2009). "Analysis of autogenous and drying shrinkage of concrete." Khan, M., and Ali, M. (2018). "Effect of super plasticizer on the properties of medium strength concrete prepared with coconut fiber." Construction and Building Materials, 182, 703-715. 
Kochova, K., Schollbach, K., Gauvin, F., and Brouwers, H. (2017). "Effect of saccharides on the hydration of ordinary Portland cement." Construction and Building Materials, 150, 268-275.

Lam, T. F., and Yatim, J. M. (2015). "Mechanical properties of kenaf fiber reinforced concrete with different fiber content and fiber length." Journal of Asian Concrete Federation, 1(1), 11-21.

Lazic, B. D., Janjic, S. D., Rijavec, T., and Kostić, M. (2017). "Effect of chemical treatments on the chemical composition and properties of flax fibers." Journal of the Serbian Chemical Society, 82(1), 83.

Le Troedec, M., Sedan, D., Peyratout, C., Bonnet, J. P., Smith, A., Guinebretiere, R., Gloaguen, V., and Krausz, P. (2008). "Influence of various chemical treatments on the composition and structure of hemp fibres." Composites Part A: Applied Science and Manufacturing, 39(3), 514-522.

Li, D.-C., and Jiang, H. (2017). "The thermochemical conversion of non-lignocellulosic biomass to form biochar: a review on characterizations and mechanism elucidation." Bioresource technology, 246, 57-68.

Li, X., Panigrahi, S., and Tabil, L. (2009). "A study on flax fiber-reinforced polyethylene biocomposites." Applied Engineering in Agriculture, 25(4), 525-531.

Li, X., Tabil, L. G., and Panigrahi, S. (2007). "Chemical treatments of natural fiber for use in natural fiber-reinforced composites: a review." Journal of Polymers and the Environment, 15(1), 25-33.

Li, Z., Wang, L., and Ai Wang, X. (2007). "Cement composites reinforced with surface modified coir fibers." Journal of composite materials, 41(12), 1445-1457. 
Li, Z., Wang, X., and Wang, L. (2006). "Properties of hemp fibre reinforced concrete composites." Composites Part A: Applied Science and Manufacturing, 37(3), 497505.

Lima, P. R., Santos, R. J., Ferreira, S. R., and Toledo Filho, R. D. (2014).

"Characterization and treatment of sisal fiber residues for cement-based composite application." Engenharia Agrícola, 34(5), 812-825.

Liu, D., Han, G., Huang, J., and Zhang, Y. (2009). "Composition and structure study of natural Nelumbo nucifera fiber." Carbohydrate polymers, 75(1), 39-43.

Liu, F. (2014). "Early-age hydration studies of Portland cement."

Liu, F., and Sun, Z. (2013). "Feasibility study of using Raman spectroscopy to detect hydration in wet pastes." ACI Materials Journal, 110(6), 611.

Liu, F., Wang, J., Qian, X., and Hollingsworth, J. (2017). "Internal curing of high performance concrete using cenospheres." Cement and Concrete Research, 95, $39-46$.

Lu, N., and Oza, S. "Effect of Physical and Chemical Surface Treatment on the Thermal Stability of Hemp Fibers as Reinforcement in Composite Structures." Proc., Applied Mechanics and Materials, Trans Tech Publ, 616-620.

Lu, X., Ye, L., Teng, J., and Jiang, J. (2005). "Meso-scale finite element model for FRP sheets/plates bonded to concrete." Engineering structures, 27(4), 564-575.

Lv, G.-j., Wu, S.-b., and Lou, R. (2010). "Kinetic study for the thermal decomposition of hemicellulose isolated from corn stalk." BioResources, 5(2), 1281-1291. 
Mahjoub, R., Yatim, J. M., Sam, A. R. M., and Hashemi, S. H. (2014). "Tensile properties of kenaf fiber due to various conditions of chemical fiber surface modifications." Construction and Building Materials, 55, 103-113.

Marc, M. (2010). "Volume B: Element Library." MSC. Software Corporation, 113-661. Mariselvam, V., and Logesh, M. "ANALYTICAL ANALYSIS ON MATERIAL PROPERTIES OF KENAF FIBER COMPOSITE." International Journal of Applied Engineering Research, 10(50), 2015.

Marušić, E., and Štirmer, N. (2016). "Autogenous shrinkage and expansion related to compressive strength and concrete composition." Journal of Advanced Concrete Technology, 14(9), 489-501.

Medina, J., Del Bosque, I. S., Frías, M., De Rojas, M. S., and Medina, C. (2017). "Characterisation and valorisation of biomass waste as a possible addition in ecocement design." Materials and Structures, 50(5), 207.

Mei, Y., Che, Q., Yang, Q., Draper, C., Yang, H., Zhang, S., and Chen, H. (2016). "Torrefaction of different parts from a corn stalk and its effect on the characterization of products." Industrial Crops and Products, 92, 26-33.

Mohammed, A., Bachtiar, D., Rejab, M., and Hasany, S. (2017). "Effect of Potassium Permanganate on Tensile Properties of Sugar Palm Fibre Reinforced Thermoplastic Polyurethane." Indian Journal of Science and Technology, 10(7).

Mohammed, B. S., Abdullahi, M., and Hoong, C. (2014). "Statistical models for concrete containing wood chipping as partial replacement to fine aggregate." Construction and building materials, 55, 13-19. 
Mohanty, A., Misra, M., and Drzal, L. (2002). "Sustainable bio-composites from renewable resources: opportunities and challenges in the green materials world." Journal of Polymers and the Environment, 10(1-2), 19-26.

Mohr, B., and Hood, K. (2010). "Influence of bleed water reabsorption on cement paste autogenous deformation." Cement and Concrete Research, 40(2), 220-225.

Mollah, M., Yu, W., Schennach, R., and Cocke, D. L. (2000). "A Fourier transform infrared spectroscopic investigation of the early hydration of Portland cement and the influence of sodium lignosulfonate." Cement and concrete research, 30(2), $267-273$.

Mussatto, S. I., Rocha, G. J., and Roberto, I. C. (2008). "Hydrogen peroxide bleaching of cellulose pulps obtained from brewer's spent grain." Cellulose, 15(4), 641-649.

Mwaikambo, L., and Ansell, M. (2003). "Hemp fibre reinforced cashew nut shell liquid composites." Composites science and technology, 63(9), 1297-1305.

Mwaikambo, L. Y., and Ansell, M. P. (2002). "Chemical modification of hemp, sisal, jute, and kapok fibers by alkalization." Journal of applied polymer science, 84(12), 2222-2234.

Nayak, S., and Mohanty, J. R. (2018). "Influence of chemical treatment on tensile strength, water absorption, surface morphology, and thermal analysis of areca sheath fibers." Journal of Natural Fibers, 1-11.

Onésippe, C., Passe-Coutrin, N., Toro, F., Delvasto, S., Bilba, K., and Arsène, M.-A. (2010). "Sugar cane bagasse fibres reinforced cement composites: thermal considerations." Composites Part A: Applied Science and Manufacturing, 41(4), $549-556$. 
Pane, I., and Hansen, W. (2005). "Investigation of blended cement hydration by isothermal calorimetry and thermal analysis." Cement and concrete research, $35(6), 1155-1164$.

Park, J., Meng, J., Lim, K. H., Rojas, O. J., and Park, S. (2013). "Transformation of lignocellulosic biomass during torrefaction." Journal of Analytical and Applied Pyrolysis, 100, 199-206.

Pejic, B. M., Kostic, M. M., Skundric, P. D., and Praskalo, J. Z. (2008). "The effects of hemicelluloses and lignin removal on water uptake behavior of hemp fibers." Bioresource Technology, 99(15), 7152-7159.

Peng, J., Bi, X., Sokhansanj, S., and Lim, C. (2013). "Torrefaction and densification of different species of softwood residues." Fuel, 111, 411-421.

Peschard, A., Govin, A., Grosseau, P., Guilhot, B., and Guyonnet, R. (2004). "Effect of polysaccharides on the hydration of cement paste at early ages." Cement and Concrete Research, 34(11), 2153-2158.

Petroudy, S. D. (2017). "Physical and mechanical properties of natural fibers." Advanced High Strength Natural Fibre Composites in Construction, Elsevier, 59-83.

Qi, C., Weiss, J., and Olek, J. (2003). "Characterization of plastic shrinkage cracking in fiber reinforced concrete using image analysis and a modified Weibull function." Materials and Structures, 36(6), 386-395.

Quiroga, A., Marzocchi, V., and Rintoul, I. (2016). "Influence of wood treatments on mechanical properties of wood-cement composites and of Populus Euroamericana wood fibers." Composites Part B: Engineering, 84, 25-32. 
Rahmani, T., Kiani, B., Bakhshi, M., and Shekarchizadeh, M. "Application of different fibers to reduce plastic shrinkage cracking of concrete." Proc., 7th RILEM International Conference on Cracking in Pavements, Springer, 635-642.

Rajamma, R., Ball, R. J., Tarelho, L. A., Allen, G. C., Labrincha, J. A., and Ferreira, V. M. (2009). "Characterisation and use of biomass fly ash in cement-based materials." Journal of hazardous materials, 172(2), 1049-1060.

Ramezani, M., Kim, Y. H., and Sun, Z. (2019). "Modeling the mechanical properties of cementitious materials containing CNTs." Cement and Concrete Composites, 104, 103347.

Ray, D., and Sarkar, B. (2001). "Characterization of alkali-treated jute fibers for physical and mechanical properties." Journal of Applied Polymer Science, 80(7), 10131020.

Razak, N. I. A., Ibrahim, N. A., Zainuddin, N., Rayung, M., and Saad, W. Z. (2014). "The influence of chemical surface modification of kenaf fiber using hydrogen peroxide on the mechanical properties of biodegradable kenaf fiber/poly (lactic acid) composites." Molecules, 19(3), 2957-2968.

Reddy, K. O., Maheswari, C. U., Shukla, M., Song, J., and Rajulu, A. V. (2013). "Tensile and structural characterization of alkali treated Borassus fruit fine fibers." Composites Part B: Engineering, 44(1), 433-438.

Rong, M. Z., Zhang, M. Q., Liu, Y., Yang, G. C., and Zeng, H. M. (2001). "The effect of fiber treatment on the mechanical properties of unidirectional sisal-reinforced epoxy composites." Composites Science and technology, 61(10), 1437-1447. 
Rots, J. G., Nauta, P., Kuster, G., and Blaauwendraad, J. (1985). "Smeared crack approach and fracture localization in concrete." HERON, 30 (1), 1985.

Safdar, M., Matsumoto, T., and Kakuma, K. (2016). "Flexural behavior of reinforced concrete beams repaired with ultra-high performance fiber reinforced concrete (UHPFRC)." Composite structures, 157, 448-460.

Saha, P., Manna, S., Chowdhury, S. R., Sen, R., Roy, D., and Adhikari, B. (2010). "Enhancement of tensile strength of lignocellulosic jute fibers by alkali-steam treatment." Bioresource technology, 101(9), 3182-3187.

Şahmaran, M., Lachemi, M., Hossain, K. M., and Li, V. C. (2009). "Internal curing of engineered cementitious composites for prevention of early age autogenous shrinkage cracking." Cement and concrete research, 39(10), 893-901.

Saje, D., Bandelj, B., Šušteršič, J., Lopatič, J., and Saje, F. (2010). "Shrinkage of polypropylene fiber-reinforced high-performance concrete." Journal of materials in civil engineering, 23(7), 941-952.

Sant, G., Lothenbach, B., Juilland, P., Le Saout, G., Weiss, J., and Scrivener, K. (2011). "The origin of early age expansions induced in cementitious materials containing shrinkage reducing admixtures." Cement and concrete research, 41(3), 218-229.

Sawpan, M. A., Pickering, K. L., and Fernyhough, A. (2011). "Effect of various chemical treatments on the fibre structure and tensile properties of industrial hemp fibres." Composites Part A: Applied Science and Manufacturing, 42(8), 888-895.

Sawsen, C., Fouzia, K., Mohamed, B., and Moussa, G. (2014). "Optimizing the formulation of flax fiber-reinforced cement composites." Construction and building Materials, 54, 659-664. 
Sellami, A., Merzoud, M., and Amziane, S. (2013). "Improvement of mechanical properties of green concrete by treatment of the vegetals fibers." Construction and Building Materials, 47, 1117-1124.

Senthamaraikannan, P., and Kathiresan, M. (2018). "Characterization of raw and alkali treated new natural cellulosic fiber from Coccinia grandis. L." Carbohydrate polymers, 186, 332-343.

Shang, H., and Sun, Z. (2019). "PAHs (naphthalene) removal from stormwater runoff by organoclay amended pervious concrete." Construction and Building Materials, 200, 170-180.

Shang, L., Ahrenfeldt, J., Holm, J. K., Sanadi, A. R., Barsberg, S., Thomsen, T., Stelte, W., and Henriksen, U. B. (2012). "Changes of chemical and mechanical behavior of torrefied wheat straw." Biomass and Bioenergy, 40, 63-70.

Shi, J., Lu, Y., Zhang, Y., Cai, L., and Shi, S. Q. (2018). "Effect of thermal treatment with water, $\mathrm{H} 2 \mathrm{SO} 4$ and $\mathrm{NaOH}$ aqueous solution on color, cell wall and chemical structure of poplar wood." Scientific reports, 8(1), 17735.

Sinha, E., and Rout, S. (2009). "Influence of fibre-surface treatment on structural, thermal and mechanical properties of jute fibre and its composite." Bulletin of materials science, 32(1), 65.

Siqueira, G., Várnai, A., Ferraz, A., and Milagres, A. M. (2013). "Enhancement of cellulose hydrolysis in sugarcane bagasse by the selective removal of lignin with sodium chlorite." Applied Energy, 102, 399-402. 
Sluiter, A., Hames, B., Ruiz, R., Scarlata, C., Sluiter, J., Templeton, D., and Crocker, D. (2008). "Determination of structural carbohydrates and lignin in biomass." Laboratory analytical procedure, 1617, 1-16.

Sluiter, A., Ruiz, R., Scarlata, C., Sluiter, J., and Templeton, D. (2005). "Determination of extractives in biomass." Laboratory Analytical Procedure (LAP), 1617.

Smith, B. J., Rawal, A., Funkhouser, G. P., Roberts, L. R., Gupta, V., Israelachvili, J. N., and Chmelka, B. F. (2011). "Origins of saccharide-dependent hydration at aluminate, silicate, and aluminosilicate surfaces." Proceedings of the National Academy of Sciences, 108(22), 8949-8954.

Snoeck, D., Smetryns, P.-A., and De Belie, N. (2015). "Improved multiple cracking and autogenous healing in cementitious materials by means of chemically-treated natural fibres." Biosystems Engineering, 139, 87-99.

Soleimani, T., Merati, A. A., Latifi, M., and Ramezanianpor, A. A. (2013). "Inhibition of cracks on the surface of cement mortar using estabragh fibers." Advances in Materials Science and Engineering, 2013.

Standard, A. (2012). "C778-12 standard specification for standard sand." ASTM International, West Conshohocken, PA.

Stevulova, N., Cigasova, J., Estokova, A., Terpakova, E., Geffert, A., Kacik, F., Singovszka, E., and Holub, M. (2014). "Properties characterization of chemically modified hemp hurds." Materials, 7(12), 8131-8150.

Sun, Z., Liu, F., Tong, T., Qi, C., and Yu, Q. (2017). "Hydration of Concrete Containing Hybrid Recycled Demolition Powders." Journal of Materials in Civil Engineering, 29(7), 04017037. 
Tao, Y., and Chen, J.-F. (2015). "Concrete damage plasticity model for modeling FRP-toconcrete bond behavior." Journal of Composites for Construction, 19(1), 04014026.

Teixeira, E. R., Mateus, R., Camoes, A. F., Bragança, L., and Branco, F. G. (2016). "Comparative environmental life-cycle analysis of concretes using biomass and coal fly ashes as partial cement replacement material." Journal of Cleaner Production, 112, 2221-2230.

Teng, J. G., Zhang, S. S., Dai, J., and Chen, J. (2013). "Three-dimensional meso-scale finite element modeling of bonded joints between a near-surface mounted FRP strip and concrete." Computers \& structures, 117, 105-117.

Toledo Filho, R. D., de Andrade Silva, F., Fairbairn, E., and de Almeida Melo Filho, J. (2009). "Durability of compression molded sisal fiber reinforced mortar laminates." Construction and building materials, 23(6), 2409-2420.

Toledo Filho, R. D., Scrivener, K., England, G. L., and Ghavami, K. (2000). "Durability of alkali-sensitive sisal and coconut fibres in cement mortar composites." Cement and concrete composites, 22(2), 127-143.

Tong, Y., Zhao, S., Ma, J., Wang, L., Zhang, Y., Gao, Y., and Xie, Y. M. (2014).

"Improving cracking and drying shrinkage properties of cement mortar by adding chemically treated luffa fibres." Construction and Building Materials, 71, $327-$ 333.

Vaickelionis, G., and Vaickelioniene, R. (2006). "Cement hydration in the presence of wood extractives and pozzolan mineral additives." Ceramics Silikaty, 50(2), 115. 
Van Bunderen, C., Snellings, R., Vandewalle, L., and Cizer, Ö. (2019). "Early-age hydration and autogenous deformation of cement paste containing flash calcined dredging sediments." Construction and Building Materials, 200, 104-115.

Vo, L. T., and Navard, P. (2016). "Treatments of plant biomass for cementitious building materials-A review." Construction and Building Materials, 121, 161-176.

Wang, S., Lin, H., Zhang, L., Dai, G., Zhao, Y., Wang, X., and Ru, B. (2016). "Structural characterization and pyrolysis behavior of cellulose and hemicellulose isolated from softwood Pinus armandii Franch." Energy \& Fuels, 30(7), 5721-5728.

Wei, J., and Meyer, C. (2014). "Improving degradation resistance of sisal fiber in concrete through fiber surface treatment." Applied Surface Science, 289, 511-523.

Williams, T., Hosur, M., Theodore, M., Netravali, A., Rangari, V., and Jeelani, S. (2011). "Time effects on morphology and bonding ability in mercerized natural fibers for composite reinforcement." International Journal of Polymer Science, 2011.

Xie, X., Gou, G., Wei, X., Zhou, Z., Jiang, M., Xu, X., Wang, Z., and Hui, D. (2016). "Influence of pretreatment of rice straw on hydration of straw fiber filled cement based composites." Construction and Building Materials, 113, 449-455.

Yan, L., Chouw, N., Huang, L., and Kasal, B. (2016). "Effect of alkali treatment on microstructure and mechanical properties of coir fibres, coir fibre reinforcedpolymer composites and reinforced-cementitious composites." Construction and Building Materials, 112, 168-182.

Yang, H., Yan, R., Chen, H., Lee, D. H., and Zheng, C. (2007). "Characteristics of hemicellulose, cellulose and lignin pyrolysis." Fuel, 86(12), 1781-1788. 
Yang, X., Sun, Z., Shui, L., and Ji, Y. (2017). "Characterization of the absolute volume change of cement pastes in early-age hydration process based on helium pycnometry." Construction and building materials, 142, 490-498.

Yao, L.-Z., and Wu, G. (2016). "Nonlinear 2D finite-element modeling of RC beams strengthened with prestressed NSM CFRP reinforcement." Journal of Composites for Construction, 20(4), 04016008.

Ylmén, R., Jäglid, U., Steenari, B.-M., and Panas, I. (2009). "Early hydration and setting of Portland cement monitored by IR, SEM and Vicat techniques." Cement and Concrete Research, 39(5), 433-439.

Zadeh, V. Z., and Bobko, C. P. (2014). "Nano-mechanical properties of internally cured kenaf fiber reinforced concrete using nanoindentation." Cement and Concrete Composites, 52, 9-17.

Zhang, J., Hou, D., and Han, Y. (2012). "Micromechanical modeling on autogenous and drying shrinkages of concrete." Construction and Building Materials, 29, 230240.

Zhang, W., and Koizumi, A. (2010). "Behavior of composite segment for shield tunnel." Tunnelling and Underground Space Technology, 25(4), 325-332.

Zhang, Y., Hosseinaei, O., Wang, S., and Zhou, Z. (2011). "Influence of hemicellulose extraction on water uptake behavior of wood strands." Wood and Fiber Science, 43(3), 244-250.

Zhou, X., Saini, H., and Kastiukas, G. (2017). "Engineering properties of treated natural hemp fiber-reinforced concrete." Frontiers in Built Environment, 3, 33. 


\section{APPENDIX}

\section{Correction for chemically bound water calculation}

TGA test was conducted on pure cement powder, each type of hemp powders, and paste mixtures according to the procedure introduced above. The weights of pure cement powder at $105^{\circ} \mathrm{C}$ and $1100^{\circ} \mathrm{C}$ are denoted as $C_{l}$ and $C_{2}$, respectively. The weights of hemp powders at $105{ }^{\circ} \mathrm{C}$ and $1100{ }^{\circ} \mathrm{C}$ are denoted as $H_{1}$ and $H_{2}$, respectively. The weights of cement paste mixtures at $105^{\circ} \mathrm{C}$ and $1100{ }^{\circ} \mathrm{C}$ are denoted as $W_{l}$ and $W_{2}$, respectively. The loss on ignition of pure cement powder between $105^{\circ} \mathrm{C}$ and $1100{ }^{\circ} \mathrm{C}$ is $\left(C_{1}-C_{2}\right) / C_{1}$, denoted as $L_{c}$. The weight loss percentage of hemp powders between $105^{\circ} \mathrm{C}$ and $1100{ }^{\circ} \mathrm{C}$ is $\left(H_{1}-H_{2}\right) / H_{1}$, denoted as $L_{h}$. The weight loss of the tested cement paste between 105 ${ }^{\circ} \mathrm{C}$ and $1100{ }^{\circ} \mathrm{C}$ is calculated as shown in eq. (1).

$$
W_{t}=W_{1}-W_{2}
$$

where $W_{1}$ is the weight of cement paste at $105^{\circ} \mathrm{C} ; W_{2}$ is the weight of cement paste at $1100^{\circ} \mathrm{C}$.

The weight loss of cement paste between $105^{\circ} \mathrm{C}$ and $1100^{\circ} \mathrm{C}\left(W_{t}\right)$ includes several main parts: (1) decomposition of chemically bound water; (2) loss on ignition of cement powder used; (3) decomposition of hemp powders if involved; and (4) calcium carbonate 
decomposition. Therefore, to calculate chemically bound water, $W_{t}$ needs to be modified. It should be noted that the calcium carbonate decomposition correction is not considered because it is hard to be exactly quantified in this study. Therefore, the calculated degree of hydration should be a little bit higher than its real value, but it does not affect the comparative analysis of all samples. Other steps for weight correction of $W_{t}$ are shown as follows:

(1) Hemp powder decomposition correction $\left(W_{h}\right)$

For cement paste with hemp powders, $W_{t}$ needs to be modified by considering the decomposition of hemp powders. Assuming the total weight of hemp powders used in cement paste is $H_{t}$. Based on the weight loss percentage of hemp powders between $105^{\circ} \mathrm{C}$ and $1100{ }^{\circ} \mathrm{C}, L_{h}$, the remaining weight of hemp powders incorporated into cement paste will be $\left(1-L_{h}\right) \times H_{t}$ when cement paste is heated to $1100{ }^{\circ} \mathrm{C}$. Because the weight of cement paste at $1100{ }^{\circ} \mathrm{C}$ is $W_{2}$, the weight of ignited cement will be $W_{2}-\left(1-L_{h}\right) \times H_{t}$ by excluding the remaining hemp powders. Based on the loss on ignition of pure cement powder, $L_{c}$, the total weight of cement powder used will be deduced as $\left[W_{2}-(1-\right.$ $\left.\left.L_{h}\right) \times H_{t}\right] /\left(1-L_{c}\right)$. If the replacement percentage of cement powder with hemp powders is denoted as $r$, then the total weight of hemp powders used will be $\left[W_{2}-(1-\right.$ $\left.\left.L_{h}\right) \times H_{t}\right] /\left[\left(1-L_{c}\right) \times(1-r)\right]$. Finally, an equilibrium can be achieved as shown in eq. (2), by which $H_{t}$ can be solved (shown in eq. (3)). The total weight of cement powder used can be calculated by substituting $H_{t}$ into $\left[W_{2}-\left(1-L_{h}\right) \times H_{t}\right] /\left(1-L_{c}\right)$, as shown in eq. (4), which is denoted as $C_{t}$. If no hemp powders are used in cement paste, the replacement content $r$ is 0 , then $C_{t}$ will be simplified into $W_{2} /\left(1-L_{c}\right)$.

$$
\frac{\left[W_{2}-\left(1-L_{h}\right) \times H_{t}\right] \times r}{\left(1-L_{c}\right) \times(1-r)}=H_{t}
$$




$$
\begin{aligned}
& H_{t}=\frac{W_{2} \times r}{\left(1-L_{h}\right) \times r+\left(1-L_{c}\right) \times(1-r)} \\
& C_{t}=\frac{W_{2} \times(1-r)}{\left(1-L_{h}\right) \times r+\left(1-L_{c}\right) \times(1-r)}
\end{aligned}
$$

where $H_{t}$ is the total weight of hemp powders used in cement paste; $C_{t}$ is the total weight of cement powder used in cement paste; $W_{2}$ is the weight of cement paste at $1100^{\circ} \mathrm{C} ; r$ is the replacement percentage of cement powder with hemp powders; $L_{h}$ is the weight loss percentage of hemp powders between $105^{\circ} \mathrm{C}$ and $1100{ }^{\circ} \mathrm{C} ; L_{c}$ is the loss on ignition of pure cement powder (between $105^{\circ} \mathrm{C}$ and $1100^{\circ} \mathrm{C}$ ).

Based on the total weight of hemp powders used in cement paste, $H_{t}$, and the weight loss percentage of hemp powders between $105^{\circ} \mathrm{C}$ and $1100^{\circ} \mathrm{C}, L_{h}$, the weight loss of hemp powders used in cement paste between $105^{\circ} \mathrm{C}$ and $1100{ }^{\circ} \mathrm{C}$ can be obtained as shown in eq. (5), denoted as $W_{h} . W_{h}$ is hemp powder decomposition correction content, which will be subtracted from $W_{t}$ for calculating chemically bound water if hemp powders involved.

$$
W_{h}=H_{t} \times L_{h}
$$

where $W_{h}$ is the weight loss of hemp powders used in cement paste between $105^{\circ} \mathrm{C}$ and $1100^{\circ} \mathrm{C} ; H_{t}$ is the total weight of hemp powders used in cement paste; $L_{h}$ is the weight loss percentage of hemp powders between $105^{\circ} \mathrm{C}$ and $1100{ }^{\circ} \mathrm{C}$.

(2) Loss on ignition correction $\left(W_{l}\right)$

Based on the loss on ignition of pure cement powder, $L_{c}$, the weight loss of cement powder used between $105^{\circ} \mathrm{C}$ and $1100^{\circ} \mathrm{C}$ will be $C_{t} \times L_{c}$ as shown in eq. (6), denoted as $W_{l} . W_{l}$ is the loss on ignition correction content, which will be subtracted from $W_{t}$ for calculating chemically bound water.

$$
W_{l}=C_{t} \times L_{c}
$$


where $W_{l}$ is the weight loss of cement powder used between $105^{\circ} \mathrm{C}$ and $1100{ }^{\circ} \mathrm{C} ; C_{t}$ is the total weight of cement powder used in cement paste; $L_{c}$ is the loss on ignition of pure cement powder.

With the abovementioned correction, the chemically bound water $\left(w_{b}\right)$ of cement paste with hemp powders can be calculated by using eq. (7). Fig. 10 also schematically plots the correction procedure of weight loss of cement paste.

$$
W_{b}=W_{t}-W_{l}-W_{h}
$$

where $W_{t}$ is the total weight loss of cement paste between $105^{\circ} \mathrm{C}$ and $1100{ }^{\circ} \mathrm{C} ; W_{l}$ is loss on ignition correction, namely the weight loss of cement powder used between $105^{\circ} \mathrm{C}$ and $1100{ }^{\circ} \mathrm{C} ; W_{h}$ is hemp powder decomposition correction, namely the weight loss of hemp powders used between $105^{\circ} \mathrm{C}$ and $1100{ }^{\circ} \mathrm{C}$.

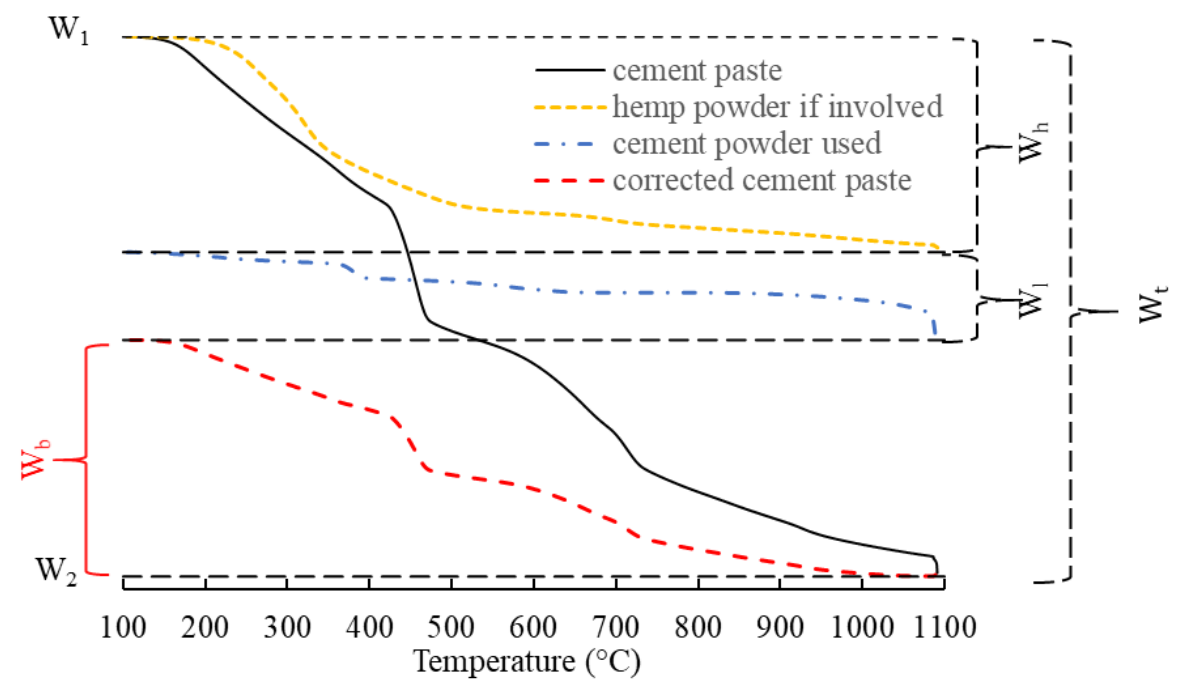

Fig. 10. Schematic of weight-loss correction of cement paste

\section{Degree of hydration calculation}

For cement paste with hemp powders, the weight of ignited cement is corrected to be $W_{2}-\left(1-L_{h}\right) \times H_{t}$ that has been introduced in "Hemp powder decomposition correction" section. The chemically bound water per unit gram of ignited cement then can 
be calculated by using $W_{b} /\left[W_{2}-\left(1-L_{h}\right) \times H_{t}\right]$, denoted as $W_{b g}$. By substituting $H_{t}$ obtained in eq. (3) into $W_{b} /\left[W_{2}-\left(1-L_{h}\right) \times H_{t}\right], W_{b g}$ can be obtained as shown in eq. (8). If no hemp powders are used in the paste mixtures, the replacement content $r$ is 0 , and then $W_{b g}$ will be simplified into $W_{b} / W_{2}$.

$$
W_{b g}=\frac{W_{b} \times\left[\left(1-L_{h}\right) \times r+\left(1-L_{c}\right) \times(1-r)\right]}{W_{2} \times(1-r) \times\left(1-L_{c}\right)}
$$

where $W_{b g}$ is the chemically bound water per unit gram of ignited cement; $W_{b}$ is the chemically bound water of cement paste; $W_{2}$ is the weight of cement paste at $1100{ }^{\circ} \mathrm{C} ; r$ is the replacement percentage of cement powder with hemp powders; $L_{h}$ is the weight loss percentage of hemp powders between $105^{\circ} \mathrm{C}$ and $1100{ }^{\circ} \mathrm{C} ; L_{c}$ is the loss on ignition of pure cement powder (between $105^{\circ} \mathrm{C}$ and $1100{ }^{\circ} \mathrm{C}$ ).

For completely hydrated Type I Portland cement, the chemically bound water per unit gram of ignited cement ranges from 0.23-0.25 (Pane and Hansen 2005). In this study, 0.25 is adopted. Therefore, the degree of hydration $(\mathrm{DoH})$ can be calculated by using $W_{b g}$ divided by 0.25 , as shown in eq. (9). If no hemp powders are used in paste mixtures, the replacement content $r$ is 0 , and then $D o H$ will be simplified into $W_{b} /\left(0.25 \times W_{2}\right)$.

$$
D o H=\frac{W_{b} \times\left(\left(1-L_{h}\right) \times r+\left(1-L_{c}\right) \times(1-r)\right)}{0.25 \times W_{2} \times(1-r) \times\left(1-L_{c}\right)}
$$

where $\mathrm{DoH}$ is degree of hydration of cement paste; $W_{b}$ is the chemically bound water of cement paste; $W_{2}$ is the weight of cement paste at $1100^{\circ} \mathrm{C} ; r$ is the replacement percentage of cement powder with hemp powders; $L_{h}$ is the weight loss percentage of hemp powders between $105^{\circ} \mathrm{C}$ and $1100^{\circ} \mathrm{C} ; L_{c}$ is the loss on ignition of pure cement powder (between 105 ${ }^{\circ} \mathrm{C}$ and $\left.1100^{\circ} \mathrm{C}\right)$. 


\section{CURRICULUM VITA}

\section{Aofei Guo}

\section{Personal Information}

- Email: a0guo003@ louisville.edu

- Tel: +1 (502) 9368055

- Address: Civil and Environmental Engineering Department, University of Louisville, Louisville, Kentucky, USA, 40292

\section{Research Interests}

- Hydration, shrinkage, microstructure, cracking, and mechanical properties of cementitious materials with lignocellulosic biomass wastes

- Cementitious materials with nanocellulose

- Internal curing of concrete

- Finite element and reliability analysis

\section{Education Experience}

- Aug. 2016-Present Civil Engineering, University of Louisville, Ph.D. (GPA: 3.88/4.00) Advisor: Zhihui Sun (z.sun@louisville.edu), Co-advisor: Dr. Jagannadh Satyavolu (jagannadh.satyavolu@louisville.edu)

- Sep. 2013-Jun. 2016 Structural Engineering, Hunan University, Master's degree (GPA: 87.24/100) Advisor: Fen Zhou (zhoufen@ @hnu.edu.cn)

- Sep. 2009-Jun. 2013 Architectural Environment \& Equipment Engineering, Henan University of Technology, Bachelor's degree (GPA: 83.66/100)

\section{Research Experience}

- Aug. 2016-Present Graduate Teaching and Research Assistant, Civil and Environmental Engineering Department and Conn Center for Renewable Energy Research, University of Louisville, Louisville, KY, USA

$>$ Chemical modification on lignocellulosic biomass wastes

> Hydration, shrinkage, microstructure, cracking, and mechanical properties of cementitious materials with physically or chemically treated lignocellulosic biomass wastes

Internal curing of concrete with Kentucky local lightweight aggregates

$>$ Mechanical properties and microstructure of cementitious materials with nanocellulose 
- Sep. 2013-Jun. 2016 Hunan University, Changsha, Hunan Province, China

$>$ Finite element and reliability analysis of slope stability

\section{Teaching Experience}

- Aug. 2016-Aug. 2017 Graduate Teaching Assistant, Civil and Environmental Engineering Department, University of Louisville, Louisville, KY, USA

\section{Academic Achievements}

- Published Paper

1. Guo, A., Sun, Z., \& Satyavolu, J. (2020). Impact of modified kenaf fibers on shrinkage and cracking of cement pastes. Construction and Building Materials, 264, 120230.

2. Guo, A., Sun, Z., Qi, C., \& Sathitsuksanoh, N. (2020). Hydration of Portland Cement Pastes Containing Untreated and Treated Hemp Powders. Journal of Materials in Civil Engineering, 32(6), 04020148.

3. Guo, A., Sun, Z., \& Satyavolu, J. (2019). Impact of chemical treatment on the physiochemical and mechanical properties of kenaf fibers. Industrial Crops and Products, 141, 111726.

4. Guo, A., Aamiri, O. B., Satyavolu, J., \& Sun, Z. (2019). Impact of thermally modified wood on mechanical properties of mortar. Construction and Building Materials, 208, 413420.

5. Fen, Zhou, Ao-fei, Guo, \& Yun-xing, Du. (2016). A New Method of Four Order Moments for Reliability Analysis on Slope Stability. Journal of Hunan University Natural Sciences, 43(5). (in Chinese)

- Paper under review

1. Aofei Guo, Zhihui Sun, Jagannadh Satyavolu, Experimental and Finite element analysis on flexural behavior of mortar beams with chemically modified kenaf fibers. Construction and Building Materials.

- Paper under Preparation

1. Aofei Guo, Zhihui Sun, Noppadon Sathitsuksanoh, Mechanical properties and microstructure of mortar with cellulose nanocrystals.

- Invention Patent

1. Zhou Fen, Aofei Guo, Yunxing Du. A type of unbonded prestressed geogrid with flexural resistance: China, ZL 20141 0282599.2[P]. 2015-12-02. (in Chinese)

\section{Honors and Awards}

- Dissertation Completion Award, University of Louisville, USA (2020)

- Graduate Research Assistantship, University of Louisville, USA (2017-2020)

- Graduate Student Council Research Award, University of Louisville, USA (2018)

- Graduate Teaching Assistantship, University of Louisville, USA (2016-2017)

- Outstanding Graduate of Henan Province, China (2013)

- National Encouragement Scholarship, China (2011)

- First Prize Scholarship, Henan University of Technology, China (2009-2013)

\section{Graduate Courses}

Advanced Mechanics of Solids, Structural Dynamics, Special Topics in CEE (Topic: Building Information Modeling), Construction Materials, Green Engineering \& Sustainable Design, Advanced Studies in English Writing. 